\title{
Narratives of Incorporation: An Anthropological Analysis of Same-Sex Civil Unions in New Zealand
}

\author{
By \\ Dionne Steven
}

A thesis

submitted to Victoria University of Wellington in fulfilment of the requirements for the degree of Doctor of Philosophy in Anthropology

Victoria University of Wellington

2013 


\section{Acknowledgements}

I would like to thank the participants in this study who generously welcomed me into their homes and shared with me their personal life experiences. I would also like to thank my supervisors, Professor Brigitte Bönisch-Brednich and Dr Catherine Trundle, for their encouragement and support and insightful engagement throughout this project. Thanks are also due to Dr James Urry, who supervised me in the early stages of this project, for his valuable advice and guidance. I am grateful to members of the School of Social \& Cultural Studies administration team, especially Monica Lichti and Carol Hogan, who always offered support and assistance. I am also grateful to my post-graduate fellows for their collegial support. In particular, I wish to thank Bronwyn McGovern and Mary Theberge who in addition provided friendship, personal support and counsel. My thanks go to my non-collegial friends who both supported and distracted me throughout the process. Thanks are also due to Victoria University of Wellington for providing me with a Doctoral Scholarship and to Howard Cattermole for his continued financial support. My deepest gratitude goes to my family for their unhesitating encouragement, support and interest in the project. A special thank you is due to my uncle, David McCrone, who not only provided me with personal support but also proofread the thesis. 


\begin{abstract}
In this thesis I examine civil unions from the perspective of New Zealand-based same-sex couples who have chosen to formalise their relationship. My approach is qualitative and in-depth and focuses on interpreting participants' own meanings and beliefs while also recognising the need for broader contextual knowledge. Through participants' narratives, I explore why it was important for couples to have a civil union, how they chose to mark or enact the occasion, and the meanings they attribute to their choices and actions. Rather than treating the civil union as an isolated event, my analysis situates the civil union within four longer processual trajectories: individual biographical narratives, partner interactions, close social relationships, and trajectories of a socio-political nature. I then explore the contours of participants' civil union ceremonies in terms of scale, style, and symbolic content. Throughout the thesis, I argue that civil unions facilitate incorporation for same-sex couples on a number of levels: incorporation in terms of inclusion in an important 'meaning-constitutive' practice; familial incorporation; and incorporation into mainstream society more generally. The incorporating effects of civil unions owe much to the symbolic capacities of law, the meaning inscribed in the socially dominant cultural model of marriage, and the characteristics of ritual. The importance of ritual to the anthropological enterprise is reaffirmed through this study; not only do rituals provide an important lens through which to examine the normative values of society but also the origins of social revitalization.
\end{abstract}




\section{Table of Contents}

Acknowledgements

Abstract 3

$\begin{array}{lr}\text { Table of Contents } & 4\end{array}$

$\begin{array}{lr}\text { 1 Introduction } & 6\end{array}$

$\begin{array}{ll}\text { Methodological Reflections } & 7\end{array}$

$\begin{array}{lc}\text { Empirical Reflections } & 18\end{array}$

$\begin{array}{ll}\text { Theoretical Reflections } & 27\end{array}$

$\begin{array}{ll}\text { Chapter Overviews } & 31\end{array}$

2 History of a Social Drama 36

$\begin{array}{ll}\text { Introduction } & 36\end{array}$

A History of Homosexuality in New Zealand 37

The 'Social Drama': Gay Liberation $\quad 49$

$\begin{array}{ll}\text { Concluding Comments } & 65\end{array}$

$\begin{array}{ll}3 \text { Trajectories of the Self } & 68\end{array}$

$\begin{array}{ll}\text { Introduction } & 68\end{array}$

Narratives of Separation $\quad 72$

Narratives of Liminality $\quad 84$

Narratives of Incorporation $\quad 91$

Civil Union and the Self 100

$\begin{array}{ll}\text { Concluding Comments } & 105\end{array}$

$\begin{array}{ll}4 \text { Trajectories of the Intimate } & 107\end{array}$

$\begin{array}{ll}\text { Introduction } & 107\end{array}$

Narratives of Meeting and Getting Together 109

$\begin{array}{ll}\text { Narratives of Relationship Progression } & 118\end{array}$

Civil Union and the Intimate Relationship 134

$\begin{array}{lr}\text { Concluding Comments } & 140\end{array}$ 
5 Trajectories of Close Social Relationships 142

Introduction $\quad 142$

Narratives of Familial Relations 143

Guest List Narratives 152

$\begin{array}{ll}\text { Narratives of Inclusion } & 161\end{array}$

Civil Union and Close Social Relationships $\quad 166$

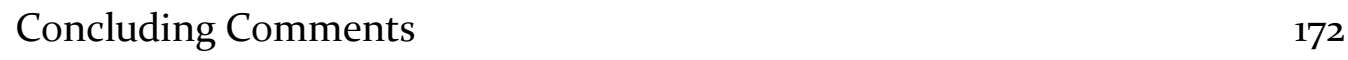

6 Trajectories of the Socio-Political $\quad 174$

$\begin{array}{ll}\text { Introduction } & 174\end{array}$

$\begin{array}{ll}\text { Narratives of the Political } & 175\end{array}$

$\begin{array}{ll}\text { Narratives of the Social } & 195\end{array}$

Concluding Comments 206

$\begin{array}{ll}7 \text { Rites of Civil Union } & 209\end{array}$

$\begin{array}{ll}\text { Introduction } & 209\end{array}$

Narratives of Resistance and Conformity 213

Narratives of Lifestyle Representations $\quad 224$

Narratives of the Experiential 243

$\begin{array}{lr}\text { Concluding Comments } & 247\end{array}$

8 Reflecting on Social Change $\quad 249$

$\begin{array}{ll}\text { Introduction } & 249\end{array}$

Shifting Boundaries and Social Revitalization $\quad 254$

$\begin{array}{lr}\text { Appendix 1: Participant Interview Guide } & 258\end{array}$

$\begin{array}{ll}\text { Bibliography } & 262\end{array}$ 


\section{1}

\section{Introduction}

The recent phenomenon of same-sex civil unions is of socio-historical significance for New Zealand and highlights a fundamental shift in societal attitudes. The enactment of the Civil Union legislation in 2005 made it possible for the first time in New Zealand's history for same-sex couples to enter into a relationship that, from a legal perspective at least, was equivalent to marriage. The significance of the Civil Union Act in the history of homosexual rights is perhaps only eclipsed by the New Zealand Homosexual Law Reform Act of 1986, which brought to an end 128 years of criminalising male homosexual activities. In less than twenty years, New Zealand society shifted from defining homosexuals as criminal and 'unnatural' to a position where the state legally sanctioned their relationships. As well as being of socio-historical significance, same-sex civil unions also present an opportunity to study a 'new' form of ritual or ceremony. Anthropologists have long considered the study of ritual as vital for understanding "the essential constitution of human societies" (Wilson 1954: 240). Rituals not only "reveal [normative] values at their deepest level" they may also, as Victor Turner notes, be “active agencies of change" (1986: 24).

In this thesis I explore civil unions from the perspective of gay male and lesbian couples who have chosen to formalise their relationships. More specifically, I examine why it is important for same-sex couples to have a civil union, how they are choosing to mark or enact the occasion, and the meanings they attribute to their choices and actions. Based on in-depth interviews, my research searches for 'native' meaning, but also seeks to locate such meanings in the context of a concrete social reality. Tacking back and forth between participants' narratives 
and the broader socio-historical processes that have influenced the ways in which their experiences are understood and shaped has led to an altogether deeper understanding of this new and significant phenomenon and, furthermore, reveals insights about New Zealand society more generally.

While my research is based upon the narratives of lesbians and gay men, it is not, however, about a particular sexuality. Rather it explores, as Kath Weston advocates, "sexuality through the lens of what amounts to standardised topics in the social sciences" (1998: 4). This thesis is, therefore, as much an exploration of identity, intimate relationships, kinship, inequality and social change as it is an exploration of same-sex civil unions. Throughout this thesis I argue that civil unions facilitate incorporation for same-sex couples on a number of levels: incorporation into an important 'meaning-constitutive' practice; familial incorporation; and incorporation into mainstream society more generally. The incorporating effects of civil unions, I suggest, owe much to the symbolic capacities of law, the meaning inscribed in the socially dominant cultural model of marriage, and the characteristics of ritual.

In this chapter I provide three contexts to situate the following ethnography. First, I reflect on my research methodology and introduce the participants of this study. Secondly, I review relevant literature on same-sex 'marriage'. Thirdly, I outline the work of three theorists who have been particularly helpful in making sense of the often complex and partial nature of participants' narratives as well as the broader socio-historical processes in which same-sex civil unions are embedded. Finally, in outlining the chapters to follow, I lay out the key arguments of the thesis.

\section{Methodological Reflections}

My research initially set out to understand contemporary motivations for getting married or for having a relationship formalised in a civil union. A need to limit the

\footnotetext{
${ }^{1}$ The word marriage when enclosed in single inverted commas ('marriage') refers generally to all forms of legal recognition for same-sex couples e.g. marriage, civil unions, registered partnerships, life partnerships, domestic partnerships.
} 
scope of my research, intellectual curiosity, and a gap in the academic literature, however, soon led me to focus my research exclusively on same-sex civil unions. Unlike many who have written on this subject, I am a heterosexual woman with no direct experience of being marginalised because of sexual orientation. In this sense I was an 'outsider', a non-native ethnographer. 'Outsiderhood' is of course part and parcel of the anthropological enterprise and, irrespective of their origins, the researcher needs to play the role of both outsider and insider throughout the course of their ethnographic inquiry. Despite this understanding, I admit to still having some early personal concerns over how informants would receive my 'coming out' as heterosexual. My concerns were centred on questions of authority and representation; did I, as a heterosexual, have the authority to write about the personal experiences of a minority culture of which I had only a superficial understanding?

In recent decades there has been a trend to define gender, sexuality and sometimes indigenous research as exclusively 'about, by and for' the group in question. Within the field of anthropology this trend has been no less apparent. As Ellen Lewin (1998) points out, scholars working in the area of homosexuality have generally been assumed by the rest of the profession to be gay. Gay and lesbian anthropologists have, in turn, unreflectively defined homosexual populations as their 'tribe', reinforcing this same expectation and implying that incursions by 'non-natives' into their territory smacks of colonialism and exploitation. Lewin, however, also notes that being gay does not always guarantee an "open door" or assure "unhesitating cooperation, particularly when race, nationality, generational, and class differences loom larger than sexual orientation in defining notions of identity" (1998: 39).

The 'ghettoization' of sexuality studies is, according to Kath Weston (1998: 24-25), a relatively recent development. Mentioning earlier researchers such as Westermarck (1906), Durkheim and Mauss (1963), Malinowski (1927), Benedict (1938, 1959), Landes (1937, 1940), Evans-Pritchard (1940, 1951, 1970, 1976), and Mead (1949) she notes the legacy of sexuality within the social sciences. Although largely 'flora-and-fauna' in their approach, these ethnographic findings have, as 
Weston observes, been influential in shaping debates about sexuality and intimacy to the present day. Weston, herself a lesbian, refuses to draw an artificial line around sexuality, making it a discrete object of study only to be undertaken by those on the 'inside'. Rather, she sees material on sexuality as an entry point for exploring broader topics. Like Lewin (1998), she also points out that "A person cannot 'just' study sexuality because sexuality is never separate from history, 'class', 'race', or a host of other social relations" (Weston 1998: 4).

Allison Kirkman (2001: 23) notes that within New Zealand universities "previous boundaries influencing what are seen as appropriate in terms of research methods are being questioned" and highlights instances where the gender or sexual orientation of the researcher differs from those of their participants or respondents. She does, however, warn that any research with gay and lesbian communities "involves an ethical and political intervention" and suggests, therefore, that researchers need to ensure "positive outcomes" and "prevent harmful effects to participants" (Kirkman 2001: 60). Extrapolating her point further, I suggest that in any research there is a responsibility on the part of the researcher - be they 'insider' or 'outsider' - to ensure that no harm befalls the community as a consequence of the research.

Concerns over my 'outsider' status generally proved unfounded, as most participants' responses were overwhelmingly positive and accommodating. Only two prospective participants raised my sexuality as an issue and only one declined to be interviewed. In many ways I was, of course, also an 'insider'. Shared characteristics such as language, nationality, culture, gender, generation and education provided common ground for empathetic connection, which often proved more meaningful than sexual identity. While my status as a heterosexual meant that I started my research as a gay cultural 'rookie', I believe this had its advantages. I approached the topic with 'fresh', unassuming eyes, taking nothing for granted, and with an impartiality that a native ethnographer might otherwise not have had. 
Semi-structured, in-depth interviews form the basis of my research and required participants to perform life narratives; to reflect upon their lives and the events surrounding their civil union experience in particular. Narrative as a research strategy and a method of analysis has become increasingly popular within the humanities and social sciences and is generally valued for what it can reveal about human experience. Catherine Reissman suggests that, "the push towards narrative comes from contemporary preoccupations with identity" (2008: 7). As Michel Foucault observes, modernity "does not liberate man from his own being; it compels him to face the task of producing himself" (1994: 50). In the discipline of anthropology, narrative analysis gained popularity as a method during the 1980s, in part as a result of the emergence of postmodern theory and the crisis associated with representation and ethnographic authorship. In this study, I view narrative as a metaphoric bridge between my epistemological framework and my research aim in that it provides me as a researcher with access to my participants' own voices and understandings of experience.

Thirty interviews with 57 people were conducted as part of this study. Twelve interviews took place in 2008 as part of a Master's thesis and a further 18 interviews were conducted in 2010 once the research had been upgraded to a $\mathrm{PhD}$. Whilst my sample size limits the generalisations I can make regarding the applicability of my findings to other same-sex civil unions, the depth of understanding that my research delivers would not have been possible using quantitative methods. The assertions I make throughout the thesis are restricted to the experiences narrated by participants in this study and are not intended to be representative of gay and lesbian people in New Zealand more generally.

Of the 30 interviews I conducted, 27 were with couples and three were with individuals whose partners were either unwilling or unavailable to take part in the study. I also interviewed three civil union celebrants, primarily for their experience as officiates at civil unions. All participants had entered into a samesex civil union or, in the case of one participant who had emigrated with his partner from the United Kingdom (UK), a registered civil partnership (the UK equivalent of a civil union). Twelve of the interviews were with male couples and 
18 were with female couples. I also interviewed a couple who were lesbian at the time of their civil union, but who had since become essentially an opposite-sex couple as one of them had transitioned to a male identity. The gender split in my participant sample reflects the gender split in civil unions nationally ( 56 per cent female couples versus 44 per cent male couples). I had a good range of participants in terms of age and relationship durations. Relationships ranged from three years to 45 years in duration. Participants' ages ranged from 27 years to 80 years. According to Bascand (2010), the median age of same-sex couples registering a civil union between April 2005 and December 2009 was, on average, seven years greater than that of opposite-sex couples: 41 years for male couples and 40 years for female couples. ${ }^{2}$ It is likely that the older profile of same-sex civil unions reflects the fact that same-sex couples have only recently been able to register their relationships. The median age of my participants was 47 years, making my sample slightly older than people in civil unions nationally.

Interviewees were recruited via a number of channels including mutual acquaintances, word of mouth, an email list for lesbians living in the greater Wellington region, progressive community Christian groups, and various other lesbian, gay, bisexual and transgender (LGBT) groups throughout New Zealand. The use of multiple entry points for locating participants had the advantage of providing me with a varied cross-section of couples with limited cross-over in terms of social networks. The majority of participants were located in the urban centres of Auckland, Wellington and Christchurch. I was also able to recruit and interview couples living in provincial parts of New Zealand including Gisborne, Hawke's Bay, Otaki, and Palmerston North. It should be noted, however, that many of those living in provincial places had at some stage also lived in urban city centres.

Most people I interviewed identified either as Pākehā or as of European descent. Four women identified as Māori, one as a New Zealand-born Samoan, and one male participant identified as an Indo-Zimbabwean. Participants' lifestyles could be described as falling within a 'middle-class' spectrum, an assertion based largely

\footnotetext{
${ }^{2}$ More recent data is not publicly available at present.
} 
on my participants' choice of career and my own impressions. They all owned a home, although one couple was renting the home they were living in and another couple's home was owned by a family trust. More than half of my participants had a tertiary education and several participants were engaged in post-graduate study at the time of their interview. My participants worked in a wide range of vocations that included teaching, politics, religious ministry, banking, clinical social work, counselling for organisations such as Victim Support, Rape Crisis and Women's Refuge, psychotherapy and psychology, biological science, environmental science, landscaping, acting, retail, and so on. One female participant was a full-time artist and another participant was at the time of her interview a full-time mother. An anomaly in my research sample was the statistical over-representation of 'psy'therapists: four of my male participants were engaged in the field of psychology and psychotherapy. As there is no evidence to suggest that male psychologists and psychotherapists are more likely to have a same-sex civil union than males in other professions, this anomaly can perhaps be attributed to the self-selected rather than random nature of my participant recruitment. Having so many 'psy'therapists in my sample did, however, have its benefits as they all tended to be highly reflective and articulate.

All but two interviews took place in the participants' own home; a setting that was convenient and comfortable for participants but also allowed me to observe the environment where my participants' relationships were largely lived out. Participants generally responded to questions in a remarkably open and frank manner and were more than willing to expand on issues of a deeply personal nature. I typically began each interview by asking each person to describe their background and their experience of 'coming out' as either a gay man or lesbian. In an attempt to understand the context and character of participants' civil unions, I then explored the 'genesis' and 'evolution' of the couple's relationship and how and why they came to the decision to have a civil union. After they had described their civil union ceremony in some detail, I then asked participants to reflect upon their civil union and to explore what changes, if any, had resulted, either for them 
as a couple or in their familial and social relationships. ${ }^{3}$ All interviews were digitally recorded and fully transcribed.

\section{Searching for 'meaning'}

My epistemological framework takes inspiration from the philosopher of understanding (verstehen) and one of the founding fathers of the interpretivist paradigm, Wilhelm Dilthey (1833-1911). I was introduced to Dilthey's oeuvre by Victor Turner who uses his work in his analysis of performance and experience. Like Turner, I was inspired by Dilthey's epistemology and found his 'structures of experience' useful both as a conceptual tool and as an analytical framework for understanding how people 'create' meaning. Although developed in the $19^{\text {th }}$ century, Dilthey's epistemology still holds relevance today and, indeed, seemingly anticipates contemporary understandings of the self as a 'reflexive project' (Giddens 1991). Dilthey's philosophy, put simply, seeks to explain how people "interpret the situations they are in, the events they encounter, and even their own nature, so as to create a more or less coherent and meaningful picture" (Rickman 1988: 25). ${ }^{4}$ Meaning, as Dilthey sees it, arises from the interplay between a person and their environment or, put another way, "in the lived experiences of action and reaction which signalize our dynamic involvement with the not-self" (Hodges 1974: 65). Thought is also involved "but only to clarify and integrate what is given in lived experience" (Hodges 1974: 65).

For Dilthey, 'lived experience' is the primary reality and, therefore, "is the foundation of the whole edifice of knowledge" (Hodges 1974: xiv). Experience, as Hodges explains, "is the only evidence we can have that anything exists; and further, it is only by reference to experience that we can define what we mean by saying that anything 'exists"' (1974: xiv). Dilthey contrasts 'lived experience' with 'life' seeing each experience as part of a whole. Each experience is, however, "distinguishable from another in that it has a specific function in relation to the life of an individual or a group as a whole" (Turner 1985: 211).

\footnotetext{
${ }^{3}$ See Appendix 1 for a copy of my interview guide.

${ }^{4}$ Direct translations of Dilthey into English are limited so I have therefore relied upon the interpretations, come translations, of other scholars, in particular Herbert Hodges (1974), H. P. Rickman (1988), and Rudolf Makkreel (1975).
} 
Three categories, according to Dilthey's epistemology, can be identified as structuring a person's experience and each category in turn is linked to a dimension of time. The category of 'value' arises predominantly from feeling and, from a temporal perspective, has a present orientation. The category of 'goal/end' arises from volition - the assertion of will - and therefore refers to the future. 'Meaning' is the third category that Dilthey distinguishes. 'Meaning', as Turner explains, "arises in memory, in cognition of the past, and is cognitive, self-reflexive, oriented to past experiences and concerned with what phenomenological sociologists might call 'negotiation' with the 'fit' between present and past" (1985: 214, original emphasis). Whilst Dilthey sees these three categories as irreducible, it is the category of meaning that he stresses. As Turner writes, it is "only the category of meaning that enables us to conceive an intrinsic affinity between the successive events in life, and all that the categories of value and end can tell us is caught up in this synthesis" (1986: 96, original emphasis). Makkreel understands Dilthey to be saying that "whereas life and experience move on into the future, our attempts to understand them lead back into the historical past" (1975: 328). In this understanding we can see, as Turner points out, how Dilthey rendered Kierkegaard's maxim: "we live forward and understand backwards" (1985: 214).

Because the process of 'creating' meaning involves reflexive processes, the past is granted primacy in Dilthey's philosophy. The past, as Makkreel explains, "is [also] the only mode of time that can be concretely apprehended as a whole made up of related parts" (1975:383). Even the present and future must be related to the past if they are to be understood as meaningful. Thus, the category of meaning can come to encompass all three modes of temporality if, as Makkreel (1975: 383) notes, the past is given primacy. Meaning, however, is not 'fixed'. The past is constantly expanding and may through the lens of the present be subject to reinterpretation as we review it reflexively. What we set as goals for the future may, furthermore, condition how we determine the meaning of the past (Makkreel 1975: 384). ${ }^{5}$ As my participants could only recall their civil union experience from their perspective in the present, I have therefore been cognisant

\footnotetext{
5 This aspect has particular relevance for gay men and lesbians in the 'coming out' process, something I explore in detail in chapter three.
} 
of the present-past relationship, recognising that decisions, explanations and meanings must inevitably be shaped to lead logically to the present and that information perceived as irrelevant or conflicting might necessarily be left out (Green 2004: 15).

Experience and reflexive thinking are of course also mediated by the culture and society of which we are a part. Language systems, in particular, play an important role in structuring our sense of self and how we experience and interpret the world beyond (Adams 2003: 231). 'Life narrative' is a further structure or framework involved in the process of converting experience into meaning. Simply put, life narratives are "storied autobiographical accounts told in the persons' own words" (McAdams 1988: 2). Narrative use is learned from an early age through the socialisation process and is culturally structured by language (Callero 2003: 124). Narratives, as psychologist Donald Polkinghorne defines them, have synergies with Dilthey's distinction between 'lived experience' and 'life'. He suggests that self-narratives require the narrator to link diverse events or experiences into "unified and understandable wholes" (Polkinghorne 1991: 136). Events perceived as important are selected, organised, connected and evaluated as meaningful. Selfnarratives are also an important framework for achieving personal identity and self-understanding, for providing answers to the question "Who am I" (Polkinghorne 1991: 136). A person's identity, as Anthony Giddens explains, "is not to be found in behaviour nor - important though this is - in the reactions of others, but in the capacity to keep a particular narrative going" (1991: 54, original emphasis). An individual's biography cannot, furthermore, be wholly fictive. Rather, "It must continually integrate events which occur in the external world, and sort them into the ongoing 'story' about the self' (Giddens 1991: 54). Life narratives thus involve two simultaneous processes. Not only does the narrator explain events and experiences to their audience, they also "engage in a process of explaining their own worlds to themselves" (Lewin 1998: 38).

The interviews, which form the basis of this study, required participants to perform life narratives; to reflect upon their lives and the events surrounding their civil union experience in particular. By paying close attention to participants' 
narratives I have sought to uncover the complex and sometimes contradictory nature of their accounts. Narratives, as Reissman points out, do not "speak for themselves" or offer a "window onto an 'essential self" (2008: 3). Whilst narratives generally strive to create order out of the chaos of experience, the final story as oral historian Anna Green notes "is rarely seamless" (2004: 17). 'Narrative coherence' may, as Catherine Hindmarsh points out, also be particularly difficult to achieve in the impromptu situation of an interview where "a person is asked unexpected questions and is asked to recount multiple and complex memories, to assess those memories, and provide opinions and explanations" (2005: 9). Rather than striving for coherence, narratives may, as Richard Bauman observes, "also be an instrument for obscuring, hedging, confusing, exploring, or questioning what went on, that is for keeping the coherence or comprehensibility of the event open to question" (1986: 5-6).

Bauman (1986) also points out that narratives have an essential double-ness. Not only do they recount events, they are also themselves events in which narratives are performed. As Deborah Shiffrin explains, when we verbalise experience we situate that "experience in and make [it] relevant to a particular 'here' and 'now,' a particular audience, and a particular set of interactional concerns and interpersonal issues” (1996: 168). The 'story teller', as Victor Turner notes, may seek to gain a particular effect or wish to present an ideal self according to specific strategic goals (1986: 97; Hindmarsh 2005: 10). In such instances, the narrator will compose their memories to fit with these goals or they will emphasise personally “significant moments” over others (Turner 1986: 97). Alistair Thomson also suggests that we "compose memories that help us to feel relatively comfortable with our lives and identities; that give us a sense of composure" or, that we "try to compose our memories to ensure that they will fit with what is publicly acceptable" (1994: 8, 11).

Recognising the situational and performative nature of narrative-based research is, as Hindmarsh observes, "important because it allows the researcher to remain aware of their own influence on the research subject, and the interaction of the researcher and informants in the construction of a narrative" (2005: 10). While 
participants were open and frank in their narratives, I would be naive to think that my status as a 'straight' (heterosexual) or, for that matter, as a middle-class Pākehā woman in her forties did not have some bearing on my participants' oral performances. By highlighting the performative nature of narratives, I am not suggesting that my participants' identities are in any way inauthentic; rather, as Reissman notes, "that they are situated and accomplished in social interaction" (2003: 337).

Like all research, narratives require interpretation: "the process of disentangling the meaning of something not obviously clear" (Rickman 1988: 56 ). Here, Dilthey again proves useful. As a philosopher, Dilthey recognised the "vexing problem" that things are mutually interdependent and, therefore, rejected any absolute starting points, resigning himself instead to "the ultimate circularity of philosophic expositions" (Rickman 1988: 43). This point also figures quite prominently in Dilthey's methodology and, in particular, in his notion of the 'hermeneutic circle'. The hermeneutic circle involves a recurring movement between the implicit and the explicit, the particular and the whole. It attempts to overcome the problem that "whatever one starts with [the particular or the whole] would have been clearer if one had started with [the other], which in turn is not self-explanatory” (Rickman 1988: 43). Rickman provides us with a useful analogy,

We cannot understand a sentence, let alone a larger piece of writing, if we have not understood the individual words of which it is made up. So clarification of a text takes the form of a kind of to-and-fro movement between attending to the parts and attending to the whole. This movement, which is an essential characteristic of all interpretation, is called the hermeneutic circle (1988: 64).

While I view the literal accuracy of my participants' accounts as less significant, I do, however, recognise like Dilthey that understanding beyond the simple, quick, and unproblematic presupposes some technical or broader contextual knowledge and inevitably involves interpretation. In this research I have, therefore, not only sought to discover how people construct meaning about their experiences and lives, but also to discover how their beliefs and stories relate to broader social processes. Tacking back and forth between participants' narratives (the particular) and the broader socio-historical processes (the whole) that have influenced the 
ways in which their experiences are understood and shaped has proved both enlightening and reassuring and has led to an altogether deeper articulation of meaning.

Meaning, though, as Norman Denzin (1994: 504) observes, is not literally in the 'text' but instead emerges through the deeply intertwined processes of research, interpretation and representation. To engage in representation is not an ethically neutral practice; any attempt to communicate such representation is a 'moral act' and therefore carries with it an ethic of responsibility. Representations are invariably also a view from 'somewhere' i.e. they are situated in particular historic, social and cultural settings. The entire research and writing process involved a great deal of self-reflexivity on my part; that inward-looking sometimes confessional and often self-critical examination of one's beliefs and assumptions. Throughout the thesis, I quote participants extensively. This practice reflects the articulate nature of my participants' narratives but is also an attempt on my part to deliver a representation as close to the meaning intended by participants as possible.

\section{Use of language and names}

Throughout the thesis, I have italicised participants' quotations. Words or terms appearing italicised and in double quotation marks also denote those used by participants. An ampersand between two names signals a participating couple in this study (e.g. Hailey \& Lara). Throughout the thesis, I primarily use the term 'lesbian' when referring to female participants generally and 'gay men' when referring to male participants generally. On occasion I also use the terms 'gay' or 'queer'. In these instances the term refers to both males and females. All participants' names have for ethical reasons been changed.

\section{EMPIRICAL REFLECTIONS}

Whilst my approach is largely inductive, other literature and concepts are used either for the purpose of informing my own research when understanding is problematic, for locating participants' narratives within a broader socio-historical context or, consistent with the anthropological tradition, for purposes of 
comparison. Most of the literature on same-sex 'marriage' has until fairly recently centred on normative arguments either 'for' or 'against' as activists and social critics contemplate the social consequences of same-sex 'marriage' from a wide spectrum of cultural and political standpoints (Green 2010). Empirical explorations into same-sex 'marriage' have, by comparison, been lacking. Given the recency of legally recognised same-sex 'marriage' in many contexts, though, the dearth of empirical studies is not surprising. This thesis seeks to add to a rich new vein of empirical explorations into the practices, meanings and effects of same-sex relationship recognition. Eight empirical studies are particularly worthy of note here as they have each in some way been influential in shaping my own research. The first four studies I wish to highlight are, in contrast to my own, based on the non-legal commitment ceremonies of same-sex couples in the United States and the United Kingdom.

Anthropologist Ellen Lewin (1998) and sociologists Gretchen Stiers (1999) and Kathleen Hull (2006) have each conducted ethnographically-oriented studies on same-sex 'marriage' in the United States. Their research is based on in-depth interviews with lesbian and gay male couples and, in Hull and Lewin's case, participant-observation of same-sex commitment ceremonies. All of Lewin's participants had taken part in a non-legally binding commitment ceremony with their same-sex partner. Stiers and Hull's participant groups included couples who had taken part in a non-legally binding commitment ceremony but also couples who had not. Stiers and Hull both consider the debates around same-sex 'marriage' from the perspective of lesbians and gay men. Lewin, by comparison, specifically states that she is not concerned with entering into these debates. Rather, she aims to "fashion an understanding of lesbian and gay weddings as powerful and complex ritual occasions" (Lewin 1998: 30). As in my own research, all three in their own way aim to provide an inside understanding of what 'marriage' means for gay male and lesbian couples.

Lewin's (1998) study draws from narrative analysis, ritual theory and the "invention of tradition" literature and focuses almost exclusively on her participants' ceremonies. Her analysis is organised around five key themes: 
tradition, family, community, authenticity, and resistance. Stiers' (1999) study is organised into three sections. First, she examines lesbians' and gay men's attitudes and practices towards love, commitment and the idea of "being married". Secondly, she focuses specifically on commitment ceremonies - motivations, what they did, and the language couples used. In her analysis of commitment ceremonies, Stiers applies van Gennep's (1960) three phase model of a rite of passage and Victor Turner's notion of 'communitas'. In part three, she discusses lesbian and gay men's attitudes toward the legalisation of same-sex marriages and domestic partnership legislation. Hull uses the concepts of culture, politics, law and legality to frame her discussion. She explores the relationship between legal and cultural dimensions in same-sex 'marriage' and elaborates a view of law as an influential cultural structure (2006: 2, 17). Law and culture, she claims, "interact to invest marriage with meaning both for heterosexuals and homosexuals" (Hull 2006: 25). Her analysis covers the following topics: gay and lesbian relationships, how some choose to enact their commitment in private or public rituals, the marriage debate among gays and lesbians, and attitudes regarding legal recognition.

Through their varying analyses, Lewin (1998), Stiers (1999), and Hull (2006), each argue that same-sex couples who create commitment ceremonies simultaneously participate in an act of accommodation whereby they conform to mainstream society, and in a strategy for resistance, in which they - lesbians and gay men "subvert traditional ideals about gender, sexuality, and marriage" (Stiers 1999: 107). Marriage, Hull explains, "is an extremely powerful cultural model of relationship, one that attracts couples even in the absence of legal rights and benefits" (2006: 2). The power of marriage as a cultural resource, she suggests, "lies in the fact that its dominant meanings are so widely shared in contemporary Western culture" (Hull 2006: 197). Marriage or commitment ceremonies may also be a strategy for inclusion or, as Stiers notes, "for claiming that being gay or lesbian is not all that different from being heterosexual" (1999: 108).

Like my own research findings, they suggest that same-sex commitment ceremonies reinforce the values associated with marriage, of love, commitment, 
family and, in many instances, monogamy. They also, as Stiers notes, "elicit social change" (1999: 122). Same-sex commitment ceremonies, consciously or not, reformulate cultural values by challenging the idea that marriage entails one man and one woman and has an underlying procreative function. Traditional conceptions of gender roles and common stereotypes of homosexuality are also challenged through their enactment (Stiers 1999: 109). Lewin describes commitment ceremonies as an opportunity for same-sex couples to "speak their discontent, and to demand recognition for the realities of their lives" (1998: 239). Hull, similarly, sees the "cultural enactment of marriage outside of official law" as a form of political action, even when the couples do not describe their actions in these terms. She claims that same-sex commitment ceremonies are "a form of politics that targets cultural values and beliefs rather than policies of the state" (Hull 2006: 3). Hull suggests that, "important symbolic resources are at stake in this kind of cultural politics: recognition, identity, inclusion and social support" (2006: 3).

Sociologists Jennifer Mason, Beccy Shipman and Carol Smart (2006; 2007) have conducted a study similar to those of Hull (2006), Lewin (1998) and Stiers (1999) but within a British context. Their research is based on 54 in-depth interviews with lesbian and gay males (37 couples and 17 individuals) and on two focus groups with parents of gay men and lesbians. The study was carried out shortly before the Civil Partnership legislation came into force in the UK in 2005. Apart from four couples who had married abroad, all participating couples were devising their own non-legal commitment ceremonies or registering their partnerships with local authorities (Mason, Shipman and Smart 2006: 2). According to Shipman and Smart, their research explores: "why lesbian and gay men might want to register their partnerships or have commitment ceremonies, what kinds of ceremonies are chosen and what meanings are attributed to particular rituals, whether wider families are supportive, and whether performing such rituals is a personal matter or part of a process of gaining greater legitimacy and recognition" (2007: 3.1). Three papers exploring different aspects of their research are worthy of note as they involve themes that I also build upon in my own study. 
In their paper "It's made a huge difference": recognition rights and the personal significance of civil partnership, Shipman and Smart (2007) highlight the incongruence between public discussions and reasons expressed by same-sex couples for wanting to 'marry'. Whilst in some instances they overlapped, generally personal reasons fell into five distinct categories: love, acknowledging mutual responsibilities, family recognition, legal rights and recognition, and a public statement of commitment (Shipman and Smart 2007: 4.1-4.16). Public debates in support of same-sex 'marriage', by comparison, tend to employ the rhetoric of equality and justice. This point is also taken up by Hull (2006) and Lewin (2001). Legal and political debates over same-sex marriage are, according to Lewin (2001: 46), largely irrelevant to the lived experiences of couples wishing to 'marry'. Hull (2006) sees supporters' tendencies to minimize the linkage between law and culture in favour of rights rhetoric as a key issue. Legal rights, she points out, have cultural resonance and significance beyond their tangible benefits and it is these cultural values that are of most significance for same-sex couples wanting to 'marry'. Shipman and Smart suggest that "outcomes at the personal level should be recognised as politically significant" (2007: 5.5). This shift in recognition, they suggest, "entails reading the political from the perspective of the personal, and not just reading [...] the personal from the level of the political" (Shipman and Smart 2007: 5.5).

Carol Smart's (2007) paper Same-sex couples and marriage: negotiating relational landscapes with families and friends, explores how a same-sex wedding impacts upon close personal relationships both at the time of the announcement and at the ceremony itself. The ceremony, she argues, is "a 'fateful moment' at which point lesbians and gay men must necessarily take stock of relationships which are meaningful to them" (Smart 2007: 671). Many of Smart's interviewees, like my own, went to considerable lengths to include kin as well as friends in their ceremony and to style a ceremony and party that would bring everyone together (Smart 2007: 683). Smart's empirical reflections also add to ongoing debates about the meaning and significance of both (given) family and (chosen) friends for same-sex couples. She suggests that it is important to recognise both the blurring of the boundaries between these categories as well as the meanings that individuals 
themselves ascribe to them (Smart 2007: 671). A wedding as a 'critical moment', also according to Smart, "takes everyday relationships out of their normal routine because people are forced to confront feelings which otherwise might be glossed over" (Smart 2007: 683). In this instance, family and friends are forced to confront their acceptance of same-sex relationships or their rejection of marriage because of its perceived heteronormative and patriarchal associations.

A further paper by Carol Smart (2008) 'Can I be bridesmaid?' Combining the personal and the political in same-sex weddings, explores the interplay between the personal and political in the decisions couples made over the type of ceremony they 'chose'. She argues that the kind of ceremonies that couples constructed were a reflection of their particular style of political engagement (Smart 2008: 765). In examining the shape of participants' ceremonies she elicits four forms, which she refers to as 'regular', 'demonstrative', 'minimalist', and 'religious' weddings. In doing so, she seeks to show how the mixture of the personal and the political can take different shapes while still conveying significant meanings (Smart 2008: 765). The four forms of 'wedding' ${ }^{6}$ identified by Smart have proved useful as a guide in analysing my own participants' styles of 'wedding'. However, while Smart links her forms specifically to a couple's style of political engagement, I use them more generally to frame the parameters of my participants' civil union ceremonies in terms of a private-public continuum.

The next four studies of significance for my research are based on legal same-sex 'marriage'. The economist Lee Badgett's (2009) study combines quantitative survey data with qualitative interviews with Dutch and American couples who have married or entered into a registered partnership. Through her interviews and analysis she explores: why same-sex couples choose to marry and how their reasons compare to those of opposite-sex couples'; whether allowing gay people to marry will change the institution of marriage; whether being able to marry will change gay people; and whether we need alternatives to marriage (Badgett 2009: 6). Badgett suggests that her data demonstrates that same-sex marriage is "more a

\footnotetext{
${ }^{6}$ The word wedding when enclosed in single inverted commas ('wedding') refers generally to a ceremonial act of joining rather than specifically to the act of marrying.
} 
cosmetic makeover of the old institution of marriage than a structural reconstruction" (2009: 212). As she points out, by the time legal recognition of same-sex relationships had become a serious political contender, the meaning of heterosexual marriage had also changed and in this current form marriage had become a salient fit for many gay men and lesbians. She sees no evidence to suggest that the social institution of marriage has been damaged in any way by extending the right to same-sex couples. Opening up marriage to same-sex couples, she claims, is "just the latest step toward renewing marriage's relevance for the twenty first century" (Badgett 2009: 213).

Adam Isaiah Green's (2010) study is based on in-depth interviews with 30 samesex married couples living in Toronto, Canada. In his paper Queer unions: samesex spouses marrying tradition and innovation, he explores how the lived experience of same-sex marriage compares to broader conceptual debates on the topic and suggests that the reality presents a far more complex picture of assimilation and innovation than the debates propose (Green 2010: 401). Like Lewin (1998), Stiers (1999) and Hull (2006), Green (2010:399) similarly argues that while same-sex couples embrace many of the traditional norms and values of marriage, they also adopt a range of non-traditional norms and practices that depart from and, even, destabilize the traditional marital form. In this way, samesex married spouses marry both tradition and innovation - a phenomenon which Green suggests arises out of a dual socialization process by competing 'meaningconstitutive' traditions: a “dominant 'meaning-constitutive' tradition (Gross 2005) that valorizes (heterosexual) marriage and kinship, on the one hand, but a queermeaning constitutive tradition that promotes sexual freedom and non-traditional gender relations, on the other" (2010: 399). While marriage consolidates and deepens commitment in the dyad relationship, it may also, according to Green, "serve as an important institutional bridge of legitimation to family" (2010: 412). In these instances, "marriage operates as a normalizing rite of passage that catalyzes support and recognition from family members otherwise opposed to or minimally tolerant of homosexuality" (Green 2010: 412). Several aspects of Green's analysis have been helpful in understanding and interpreting my own research data. Green's explication of the dual socialisation process that gay men and lesbians 
undergo by virtue of their sexuality casts illumination on a recurring tension between 'similarity' and 'difference' prevalent in the narratives that many of my participants constructed around self-identity, their intimate relationships, and their civil union ceremony. His notion of the 'wedding' as a 'normalizing rite of passage', moreover, helps to explain why the most profound outcome of many couples' civil union was the shifts that occurred in their relationships with family members. Extending Green's (2010) analysis further, though, I explore the role that law, the cultural model of marriage, and the characteristics of ritual play in this 'normalizing' process.

Shari Rochelle Lash's (2012) study explores Jewish same-sex weddings of couples also living in Toronto, Canada. Through her analysis she "demonstrates the ways [in which] ceremonies are adapted to meet the challenges that new ritual actors pose to an existing ritual structure" (Lash 2012: 162). She argues that, "the presence of legal entitlements in Canada diminishes the need for ritual innovation that might otherwise draw attention to sexual orientation or to larger issues of political injustice, as is the case with commitment ceremonies in the US” (Lash 2012: 162). The legal sanctioning of these unions, in effect, encourages rituals of conformity rather than rites of resistance. In this way Lash, like Hull (2006), highlights the powerful symbolic capacity of the law and its ability to render same-sex couples socially and morally equivalent to heterosexual couples (2012: 168). The presence of legal recognition, furthermore, had made it easier for these couples' families and communities to accept their same-sex relationships as authentic (Lash 2012: $170)$.

In New Zealand, the majority of academic literature on same-sex civil unions has tended to be based on the legal and/or political implications of the legislation. Empirical research on the phenomenon has, by comparison, been noticeably lacking. From the outset, my research has aimed to fill this empirical gap by providing an emic understanding of same-sex civil unions from the perspective of couples who have chosen to formalise their relationship. Another 'local' empirical study has, however, recently come to light. Maureen Baker and Vivienne Elizabeth's research was carried out in 2011 and explores how couples negotiate 
the transition from cohabitation to 'marriage'. Their study is based on 40 qualitative interviews with same-sex and opposite-sex cohabiting couples who were either planning to legalize their relationship or had already done so. They also interviewed ten celebrants who had officiated over both marriages and civil unions. Although the results of their study are still forthcoming, a preliminary draft of a paper I sighted indicates that their research explores "the social construction of cohabitation versus marriage, perceived differences between marriage and civil union, and the socio-political context surrounding civil unions" (Baker and Elizabeth, in press). Despite the legality of civil unions and the fact that a limited number of heterosexual couples have taken up this option, their study suggests that civil unions are still perceived by many as 'second-class marriage'.

All eight studies outlined above have been influential in shaping my own study. Importantly in the anthropological tradition, they also provide points of reference for the purposes of comparison. My approach, like theirs, is qualitative and indepth and focuses on interpreting people's own meanings, beliefs and views rather than on objective truth or hypothesis testing. While there are common patterns and underlying trends in our studies, there are, however, also some obvious disjunctions due to the 'differing jurisdictions' in which our participants' experiences are situated. Differences in jurisdiction are, as Jeffery Weeks observes, "the result of complexly divergent histories, cultures and political configurations" (2008: 790). In regard to the recognition of same-sex relationships, "Each country has taken its own path, reflecting its own cultural bias and political balance" (Weeks 2008: 790). Grounded specifically within a New Zealand context, my research therefore offers a unique socio-cultural perspective. By focusing exclusively on same-sex civil unions and the experiences of couples who have already formalised their relationship, my study also distinguishes itself from Baker and Elizabeth's New Zealand-based study.

In many respects, my research builds on these eight studies in that it both borrows from and/or extends their analyses. Following Shipman and Smart (2007), Hull (2006) and Lewin (2001), I pay close attention to the personal and the 
political. Debates and opposition have, by comparison, been relatively insignificant in New Zealand since civil unions were legislated. Rather than comparing public rhetoric with personal motivations, as they do, I therefore focus on the private and the public themes that emerge through couples' narratives. In analysing participants' ceremonies I also, like Lewin (1998), Stiers (1999) and Lash (2012), draw on ritual theory and, in particular, the work of Victor Turner. However, like Turner my analysis places more emphasis on the processual nature of rituals. Not only are rituals processual they are also embedded in ongoing social processes. 'Rituals', as such, should not be analysed in isolation as separate incidences, but instead as "points along a number of longer processual trajectories" (Rosaldo 1989: 20). Cognisant of this imperative, I therefore seek to locate participants' ceremonies and the meanings they attach to their choices and actions within broader historical processes of both a personal and socio-political nature. In outlining the incorporating effects of same-sex civil unions I also pay closer attention to the role that ritual plays in 'normalizing' same-sex relationships and in shifting the boundaries of wider society in terms of what is deemed socially and culturally acceptable.

\section{THEORETICAL REFLECTIONS}

The work of three theorists are particularly worthy of note in that they fulfil an important role in the thesis. Each, in some way, has helped to make sense of the experiences narrated by participants and to give shape to a host of complex and partial ideas. Of significance for my methodological approach, they have informed the 'whole'; the macro socio-historical processes and structures in which my participants' 'particular' narratives of experience are embedded. These theorists are the British sociologist Anthony Giddens (1991; 1992), the Canadian philosopher Charles Taylor (1994), and the British anthropologist Victor Turner (1986). While their respective works are individually distinct, they are not, however, discordant. In their own way, each gives attention to issues of identity, processes of reflexivity in the sense of self-objectification, and politics. Giddens' (1991; 1992) work astutely frames the historical transformations that have occurred in Western society, bringing us to what he refers to as an era of 'late modernity'. He argues that "Modern institutions differ from all preceding forms of social order in respect of 
their dynamism, the degree to which they undercut traditional habits and customs, and their global impact" (1991: 1). Giddens stresses "the emergence of new mechanisms of self-identity" which he sees as shaped by - yet also as shaping - the institutions of modernity (Giddens 1991: 2). His attention to the self as a reflexive project, the emergence of emancipatory politics, and the transformations that have occurred in contemporary intimate relationships have been particularly efficacious in understanding and interpreting the narratives of participants in this study.

Taylor (1994) also gives attention to issues of identity and how these relate to contemporary Western politics. He traces the moral and ethical changes that have occurred and how these changes have shaped present understandings of an individualised identity. Compared to Giddens, Taylor pays more attention to the dialogical nature of identity formation and places more emphasis on the ideal of 'authenticity' that has arisen around it. These aspects of Taylor's work have been especially helpful in understanding the process of identity formation as a gay man or lesbian. Taylor also illuminates the role of 'recognition' and how this notion informs our liberal democratic politics and the idea that misrecognition or nonrecognition may constitute a form of oppression. Taylor's distinction between a 'politics of equal recognition' for all citizens and a 'politics of difference' whereby everyone is recognised for their unique identity has, furthermore, been helpful in understanding a thematic tension between difference and similarity that recurred throughout many of my participants' narratives.

Victor Turner's work on performance differs from Giddens and Taylor's in that it establishes a model or framework for analysing and understanding the 'particular' and the 'whole' and, furthermore, creates an explicit link between social life and cultural representation. Turner's framework provides a natural structure for the thesis so is worthy of brief explication. Humans, as Turner sees them, are "selfperforming" animals (1986: 81). By this he means that, "Self is presented through the performance of roles, through performance that breaks roles, and through declaring to a given public that one has undergone a transformation of state and status, been saved or damned, elevated or released" (Turner 1986: 81). Through 
performance, people reveal themselves to themselves and in this way it is part of the process of self-reflexivity. People come to know themselves better "through acting or enactment [...] or by observing and/or participating in performances generated and presented by others" (Turner 1986: 81). Performance, "the presentation of self in everyday life" (as Erving Goffman (1971) entitled one of his books), is for Turner the "basic stuff of social life" and, therefore, a legitimate object of study for anthropology (1986: 81).

Turner distinguishes two classes of performance: 'social' performance and 'cultural' performance. 'Social' performances, according to Turner, are rooted in social life; in the various roles we perform in different social interactions and also include what Turner calls 'social dramas'. Turner first used the concept of a 'social drama' in his study of Ndembu village society but later went on to also apply it to social events he observed in Western societies (Turner 1957: 91; 1986: 37). A social drama is "an objectively isolable sequence of social interaction of a conflictive, competitive, or agonistic type" (Turner 1986: 33). Social dramas arise as a "consequence of shared understandings and experiences in the lives of members of the same changing sociocultural field" (Turner 1986: 36). A social drama typically exhibits a regular structure or sequence, which Turner groups into four successive phases: 1) breach of regular norm-governed social relations, 2) crisis, when people take sides in the dispute and the breach tends to widen, 3) the application of redressive or remedial procedures ranging from personal advice to the performance of public rituals, and 4) reintegration or recognition and legitimation of an irreparable schism between the contending parties (Turner 1986: 34-35). Social dramas are, therefore, essentially political in nature and have political outcomes. Through a social drama, social disputes may be settled and social relationships may be realigned (Myerhoff 1992: 48). Turner regards social drama as the "empirical unit of social process from which all cultural performances derive" (1986: 92). In this matter he emphasises the redressive phase which he sees as a particularly powerful "generative source of cultural performances" (Turner 1986: 92). 
Whereas 'social' performances are rooted in social 'reality', 'cultural' performances are concerned with representation and include aesthetic or stage dramas. The dominant genres of cultural performance include theatre, film, carnival, rites and ceremonies, festivals, religious readings, and so on. Whilst all performances to some extent involve reflexive processes, cultural performances do more so in that they are consciously constructed events. Turner turns to Milton Singer's observations when defining the features of a cultural performance. Each cultural performance, he suggests, has a "definitely limited time span, or at least a beginning and an end, has an organized program of activity, a set of performers, an audience, and a place and occasion of performance" (Turner 1986: 23 citing Singer 1972). Singer, furthermore, found that cultural performances are composed of "cultural media" - modes of communication including linguistic and nonlinguistic modes - and often involve more than one medium (Turner 1986: 23). Things, actions, and gestures, moreover, are assigned meanings with reference to emotions and ideas (Turner 1986: 23).

Turner, as mentioned above, stresses the 'processual' nature of cultural performances. Not only are they themselves processual, they are also embedded in ongoing social processes. The major genres of cultural performance and, for that matter narration (from myth to novel), he contends, "not only originate in the social drama but also continue to draw meaning and force [influence] from the social drama" (1986: 94). Genres of cultural performance and narrative, he suggests, "partly 'imitate' (by mimesis), the processual form of the social drama, and [...] partly, through reflection, assign 'meaning' to it” (Turner 1986: 95, original emphasis).

Turner's framework, in the present study, provides an explanatory link both between the 'particular' and the 'whole' and between social life and cultural representation. His notion of 'cultural performance' has applicability as a framing concept for my participants' civil union ceremonies and his emphasis on the processual nature of performances contextualises civil unions by locating them as a point "along a number of longer processual trajectories" (Rosaldo 1989: 20). Same-sex civil unions more generally, though, can in part be viewed as a phase 
within the larger context of a 'social drama'. The notion of social drama, moreover, provides a cohesive frame for the broader socio-historical processes that have influenced participants' experiences and the ways these experiences have been understood and shaped. The specific 'social drama' in question here is the gay rights movement or 'gay liberation' more generally. Within the context of New Zealand, the Homosexual Law Reform Act 1986, the Human Rights Act 1993, and the Civil Union Act 2004 can, I suggest, be considered juridical redressive procedures, Turner's third phase in a social drama. Same-sex civil unions can also be viewed as a redressive procedure or, the actualisation of a redressive procedure which, as I shall explore, go some way towards achieving reintegration.

\section{Chapter OVERView}

The three inter-related concepts that Turner's performative framework hinges on - 'social drama', cultural performance, and process - structure the thesis. Chapter two examines the broader socio-historical trajectory in which same-sex civil unions are situated, giving particular attention to the 'social drama' - gay liberation - and how it has unfolded. Beginning with the criminalisation of sodomy (anal sex) in New Zealand in 1858, I trace the emergence and mobilisation of New Zealand's gay rights movement and the legislative changes that were subsequently enacted. Through my analysis I explore the conditions that ultimately led to the legalisation of homosexuality and, later, to same-sex civil unions. I argue that the success of gay liberation depended on a number of important antecedents: the liberalisation of attitudes towards sex, the denaturalising tropes of second-wave feminism, the context of change generated by the social reform movements of the late 196os, and the development of a strong sense of community within homophile groups.

Chapters three to six locate the civil union event within longer processual trajectories. At the centre of a civil union are the couple and their relationship. Relationships are, as Kurdeck (2004) notes, complex systems and to achieve anything more than a superficial understanding, multiple factors must be considered. Huston (2000) proposes an interdisciplinary framework for the study of marital and other intimate relationships that proves useful as a guide. $\mathrm{He}$ 
argues that any marriage-like relationships need to be analysed on three levels: the individual partners, partner interactions, and societal forces - underscoring the fact that relationships exist within the context of other social relationships (Huston 2000: 298; Kurdeck 2004: 882). Adhering loosely to Huston's framework, chapter three situates the civil union within trajectories of an individual nature or what I refer to as trajectories of the self. Chapter four explores trajectories of the intimate and the meaning of the civil union specifically within the context of partner interactions. Chapters five and six correspond to what Huston refers to as 'societal forces'. Chapter five locates the civil union within the context of close social relationships while chapter six situates the civil union within trajectories of a socio-political nature.

Chapter three essentially explores the process of identity formation as a lesbian or gay man, or the process of 'coming out'. 'Coming out' stories featured strongly in participants' life narratives and were important for understanding the significance that participants attributed to their civil union. Using rites of passage (van Gennep 1960) as a metaphor, I examine how participants made sense of their own 'coming out' and how for some their civil union marked another stage within this on-going process. Troiden's (1989) work on homosexual identity formation illuminates participants' narrated experiences while a life course perspective captures the more dynamic variables associated with the formation of a nonheterosexual identity. I argue that a civil union when viewed within the process of 'coming out' can be seen as another level of social incorporation. For some participants, incorporation was experienced in terms of inclusion in an important 'meaning-constitutive' tradition ${ }^{7}$ (Gross 2005), while for others their civil union signalled another level of incorporation into mainstream (heterosexual) society.

Chapter four explores the dyad relationship at the level of partner interactions. I examine how couples met and got together and how their relationship has evolved over time. I then examine how and why participants came to the decision to have a civil union and what shifts if any have occurred in their relationship as a

\footnotetext{
${ }^{7}$ While I acknowledge that the term 'tradition' tends to oversimplify complexities, I use the term when specifically employed by theorists or when participants used the term in narrating their civil union experiences.
} 
consequence. Through my analysis I engage with theories of 'late' modernity as they relate to intimate relationships. I argue that many of the attributes characteristic of what Giddens (1992) refers to as the 'pure relationship' were implicit in participants' narratives of couple relationships. However, by not distinguishing between two analytically distinct forms of tradition - 'regulative' traditions and 'meaning-constitutive' traditions (Gross 2005) - Giddens fails to adequately account for the ways in which 'tradition' remains important. At the level of partner interactions, love and commitment were the most commonly narrated motivations for couples wanting a civil union. A growing commitment to the dyad relationship was also often an outcome of the civil union. I argue that the civil union strengthens the dyad relationship in a number of ways and in this respect acts as an external anchor.

Chapter five explores the social embeddedness of couples' relationships by situating the civil union within the context of close social relationships, namely those with family and friends. Having family and friends at their civil union was described by most couples as extremely important. For some this was simply about celebrating their civil union with those people most meaningful to them. Others used their civil union more consciously and purposefully as a vehicle for gaining recognition, acceptance and support. Often the most profound outcome of a couple's civil union was the shifts that occurred in their relationships with family of origin. Following Green (2010), I argue that for many participants their civil union acted as a 'normalizing rite of passage' that catalysed support and recognition from family members previously opposed to or nominally tolerant of homosexuality. Here, the legitimising effects of law intersect with the socially dominant cultural model of marriage to invest same-sex civil unions with meaning (Hull 2006). The effective and affective qualities of ritual, furthermore, worked to intensify the connection between ritual participants and the symbolic objects of communication and, in doing so, had the ability to transform the attitudes and behaviour of those present (Alexander 2006; Deflem 1991).

Chapter six explores the intersection between private troubles and public issues by situating the civil union within a more macro socio-political trajectory. I begin 
by outlining participants' early political involvements, highlighting the centrality of human emancipatory ideals and the role of 'recognition' in the sense that Charles Taylor (1994) uses the term. I then explore participants' varying attitudes towards the civil union legislation and the establishment of a separate institution from marriage. I argue that for some participants, their political principles were a motivating factor in their decision to have a civil union, while for others their political views were initially a barrier which had to be overcome through strategies of reframing or negotiation. In examining how a civil union has impacted on participants' relations at a more general societal level, I argue that legal recognition translated into a greater sense of social entitlement. Many participants also experienced a positive change in informal interactions, which in turn promoted feelings of greater incorporation into mainstream society. As in the previous chapter, I argue that the legitimacy conferred through legal recognition intersects with the social intelligibility of 'marriage' to make the gay individual a more socially recognised person. When viewed within a historical trajectory of homosexual rights, civil unions can, I suggest, be seen as an important institutional bridge of legitimation leading to greater acceptance and incorporation of gay people as citizens.

In chapter seven I depart from 'processual trajectories' to focus specifically on participants' civil union ceremonies in terms of scale, style and 'ritual' experience. A common concern for many participants in the planning stages of their civil union was how to negotiate proximity to and distance from a 'traditional' heterosexual wedding. Some wished to draw a parallel between what they were doing and a heterosexual marriage, while others wished to distance themselves. I argue that this distancing desire was informed both by a 'politics of difference' (Taylor 1994) as well as a desire to create a ceremony imbued with authenticity. A need for familiarity, however, typically meant that participants selected those wedding-related references that resonated but also felt free to 'invent' new ones of their own or to rearrange old symbols and give them a 'new' meaning. I argue that civil unions as 'cultural performances' can be defined as a reflexive and biographical representation of a couple's particular 'lifestyle' (Giddens 1991). The gravity of the occasion, the affective nature of ritual, and the socio-historical 
significance of same-sex civil unions combined to make the civil union a much more emotional and meaningful experience than many participants had anticipated.

Chapter eight summarises the thesis and offers a reflection on social change and the role that ritual plays in this process. Following Durkheim and Turner, I argue that ritual not only reaffirms the normative values of society but may also be a site for innovation and social revitalization. 


\section{2}

\section{History of a Social Drama}

\section{INTRODUCTION}

A study of homosexuality must, as Simon and Gagnon noted in 1967, necessarily begin with an analysis of the larger social order in which homosexuals are embedded. In this chapter, I explore the broader socio-historical processes that have influenced participants' experiences and the ways these experiences have been understood and shaped. Although gay men and lesbians have, in recent decades, made significant progress in gaining legal equality, this has not been achieved without considerable effort, often in the face of intolerant, hostile and even life-threatening opposition. Whilst it is now illegal in New Zealand to discriminate on grounds of sexual orientation, non-heterosexuals are still subjugated to dominant sex and gender ideologies, which normalise heterosexuality and encourage anti-gay prejudice. Participants' narratives and the discourses they constructed around their civil union experience and the civil union legislation more generally were, inevitably, informed by their collective history as an oppressed and stigmatised minority as well as their daily experience of what Herek refers to as "cultural and psychological heterosexism" (1990: 330).

Turner's notion of 'social drama', outlined above, provides a framework for exploring and understanding this broader historical trajectory. I begin by outlining the background to the 'social drama': the criminalisation of certain sex acts from the early years of British colonisation in New Zealand. I argue that five major social institutions have, throughout New Zealand's history, been responsible for the condemnation of homosexuality: religion, patriarchy, the law, psychiatry and psychology, and the mass media. I then examine the 'social drama' 
itself, the period from the gay liberation movement onwards. Through my analysis I explore the conditions that ultimately led to the legalisation of homosexuality. Following Guy (2002), I argue that gay liberation cannot be viewed satisfactorily as a single reform movement. Rather, its success depended on a number of important antecedents. These antecedents were the liberalisation of attitudes towards sex, the denaturalising tropes of second-wave feminism, the context of change generated by the social reform movements of the late 196os, and the development of a strong sense of community. I further argue that changes in heterosexual relationships and family forms, combined with the emergence of committed same-sex couples who wanted the same rights and recognition as heterosexual couples, both facilitated and provided a context of pressure for the ensuing civil union legislation. The progression in homosexual rights can, I contend, be situated more generally in the context of two broader social processes: a process of detraditionalisation and the separate but closely interconnected process of denaturalisation.

\section{A History of Homosexuality in New Zealand}

In the Western world, Judeo-Christian views of sex supplanted the ancient Greek view which recognised and accepted sexual relations between people of the same sex, but particularly those between adult men and adolescent boys through the practice of pederasty (Hornblower and Spawforth 1996: 720). ${ }^{8}$ Homosexuality and bisexuality came to be increasingly frowned upon and biblical references such as Sodom and Gomorrah were cited as evidence of their inherent sinfulness (Altman 1993 [1971]: 86). The Christian theology of 'natural law' also linked sexuality exclusively with procreation, which was in turn only legitimate within the context

\footnotetext{
${ }^{8}$ Historical records on same-sex relations between women for the same period are relatively sparse. The most well-known record is of Sappho, a poet from the island of Lesbos, who wrote many love poems addressed to women and girls. The $19^{\text {th }}$ century euphemism for female homosexuality, lesbianism, derives from Sappho and her home land (Hornblower and Spawforth 1996: 722).

Same-sex intimate relations were, according to Glamuzina and Laurie (1995: 151; see also Aspin 2005), also not uncommon in pre-European Māori societies, although the introduction of Christianity through missionaries and colonial settlers soon had an inhibiting impact on these practices.

Freud also believed in the essential bisexual nature of our original sex drive. He later, however, linked this to a linear concept of sexuality that located heterosexuality as more mature than homosexuality (Altman 1993 [1971]: 83).
} 
of religiously sanctioned marriage. Because homosexuality could not find its justification either in procreation or marriage it came to be viewed (along with masturbation and a number of other sexual acts) as unnatural and hence sinful. Homosexuality, as Dennis Altman notes, represented an "assertion of sexuality as an expression of hedonism and love, free of any utilitarian social ends" (1993 [1971]: 89). In the Western world today, utilitarian and repressive views of sex have largely receded, although they are still prevalent among some religious fundamentalist groups. These fundamentalist groups are also largely responsible for more recent opposition to gay-related legislation changes, a point to which I shall return.

As the importance of religion as a source of political legitimation declined, and Western societies became more secularised in their outlook, the state began to take a greater interest in its citizens' sexual lives (Brickell 2009: 81). As a British colony, New Zealand took its cue from English social and legal traditions. The enactment of the English Laws Act of 1858 made male homosexuality illegal in New Zealand and it would remain so for a further 128 years until the Homosexual Law Reform Act was passed in 1986 (Watkins 2006; Laurie 2004: 14, 21). In the Christian tradition, sex between men or more specifically 'sodomy' (which is not restricted to male coupling alone) was believed to be an unnatural offence and a breach of moral and Christian codes (Watkins 2006). Until 1867, the penalty for those found guilty of sodomy was death (Watkins 2006). After Britain replaced the death penalty for 'buggery' (sodomy and bestiality) with life imprisonment, New Zealand followed suit by enacting similar legislation through the Offences Against the Person Act 1867 (Watkins 2006; Laurie 2004: 14). In 1893, New Zealand's Criminal Code Act stipulated punishments of hard labour and flogging as well as life imprisonment, and made all sexual relations between men illegal. Consent, according to Alison Laurie (2004: 14), was at no point during this period considered a valid defence.

The fact that sexual relations between women have never been criminalised in New Zealand can be attributed to the emphasis placed on sodomy and to the great difficulty "nineteenth century decision-makers had in accepting that women 
might be sexual together" (Brickell 2009: 477). The patriarchal social system, dominant in the Western world for many centuries, not only endorsed JudeoChristian religions' repression of sex by defining circumscribed socially approved categories, it also subscribed to the notion that women are inherently inferior to men. For many centuries, women were thought not to have sexual feelings. Even when their ability to have sexual feelings was acknowledged, women were expected to suppress any urges they might have, heterosexual or otherwise. In his book Homosexuality and the Western Christian Tradition, Derrick Bailey (1955 cited in Altman 1993 [1971]: 92-93) argues that it is due to the perceived inferiority of women that male homosexual acts, particularly sodomy, came to be viewed as an intolerable perversion. This perversion, he suggests, lies not so much in human nature but in the fact that one male is compelled to "simulate the coital function of the female" (1955 cited in Altman 1993 [1971]: 93). The notion that women might be sexual together, moreover, disturbed "the myth that sex need be phalluscentred" (Altman 1993 [1971]: 88).

Prevailing attitudes towards female sexuality meant that little documentation on homoerotic engagement between women appeared until the mid-twentieth century. In 1905, though, the English sexologist Havelock Ellis claimed there was evidence to suggest that there were women in New Zealand practising lesbianism (Glamuzina 1993: 9). According to Julie Glamuzina (1993: 9), there were also a number of women who dressed and passed as men, bringing themselves to the attention of the law and the media. Amy Bock is cited as one of the earliest examples of a female passing as a male in New Zealand (Glamuzina 1993; Coleman 2001). In 1909, Amy Bock was imprisoned in Dunedin "for fraud after masquerading as a man and marrying another woman" who, reportedly, "thought that Bock was really a man" (Glamuzina 1993: 9). There were also groups of professional women, artists and writers who engaged in same-sex sexual liaisons, but these were generally not acknowledged publicly. ${ }^{9}$ The relative 'invisibility' of lesbianism meant the majority of women in New Zealand were largely ignorant of the phenomena. If they did become aware of lesbianism, by acknowledging their

\footnotetext{
${ }^{9}$ Katherine Mansfield (1988-1923), for example, had both male and female lovers and the poet, Ursula Bethell, was reputedly a lesbian (Glamuzina and Laurie 1995: 163; Glamuzina 1993: 10).
} 
own same-sex desires, then fear of social punishment typically restrained them from stepping outside socially prescribed gender norms (Glamuzina and Laurie 1995: 158). Because of the general ignorance of lesbianism, though, some women were able to live together without their families, colleagues or friends suspecting that they were anything other than platonic friends (Glamuzina and Laurie 1995: 160-161).

Chris Brickell's (2008) book Mates and Lovers, comprehensively documents the history of male, homoerotic engagement in New Zealand from the early years of British colonisation through to the Gay Liberation movement of the 1970s. Although sex between men was illegal, it was, according to Brickell, quite common in colonial New Zealand, particularly in situations where working men lived in close proximity to each other for extended periods of time. Colonial cities also provided opportunities for male homoerotic engagement through incidental meetings in 'certain' streets, gardens, pubs and hotels, and bathhouses (Brickell 2008: 42-47). The theatre was an additional 'home' for males with homoerotic desires and provided a safe environment for those who deviated from dominant and socially prescribed gender norms. Repeated visits by amateur dramatic clubs to distant settlements also meant that men who shared sexual interests could establish and "maintain their attachments as years went on" (ibid, 65). The physical and social restrictions imposed on women, by comparison, made it difficult for lesbians to make contact with others. There were, as Laurie notes, also "very few pubs where women could meet as, after 1911, women could be served only in special ladies' and escorts' bars" (2003: 14). The supply of alcohol to Māori women was also prohibited after 1910 and in some parts of the country this prohibition lasted until the later part of the 196os (ibid, 14). Coffee bars, social, occupational and sports networks would later become outlets for meeting 'like' others but, until then, lesbians largely had to rely on private contacts (ibid, 14).

By the end of the nineteenth century, a new body of thought was emerging in Europe - psychiatry - which began to describe intimate same-sex relationships in terms of a mental dysfunction rather than simply as sinful or unnatural (Brickell 2008: 88; Glamuzina and Laurie 1995: 153). In New Zealand, these 'new' medical 
ideas were slow to take root. According to Brickell, "very few late-nineteenthcentury men [or women] were committed into the care of the colony's psychiatrists on account of their homosexual feelings" (2008: 69). Few professionals and opinion-makers, he suggests, "embraced a medical approach before the 1920s - and its most intrusive innovations would have to wait for the late 1950s" (ibid 68-69). However, once the medical approach became prevalent in New Zealand, it was not uncommon for homosexual men and women to be placed in psychiatric institutions, often at their family's request, where they were subjected to aversion therapy and electronic shock treatment. Doctors, on the other hand, provided homosexual men with respite from flogging and hard labour. The physician came to be seen by many as the "compassionate replacement for the jailer" (ibid, 147). But to be viewed as ill rather than evil was not much of a consolation. As Altman (1993 [1971]: 66) comments, "it represents an attempt to destroy an individual's identity that is as brutal in a subtle way as is imprisonment”. Mental hospitals, somewhat ironically, were also a place that provided "erotic opportunities" and incidences of homosexual sex were, reportedly, quite common (Brickell 20o8: 71-72).

The turn towards psychiatry made homosexuality more visible, albeit within a discourse of pathology, but also began to cast doubt on comradely love as well (Brickell 2008: 68-69). The new questioning of close male friendships that emerged initiated "a slow redefinition of intimacy between men" (ibid, 72). 'Manly love' came to be viewed with suspicion and the open expression of emotion and affection as characteristics of the homosexual. In 1895, the high-profile trial of the English playwright Oscar Wilde "rocked polite society" and provided "ammunition for opponents of same-sex love" (ibid, 72). For those trying to make sense of their longings for other men it also, however, provided valuable information (ibid, 75). Brickell reports that local New Zealand newspaper coverage of the trial "combined three themes: wayward sexual practices, morally dubious forms of male intimacy, and the enervating influence of the arts" (2008: 73). After the 190os, the wider public began to link 'dandyism and foppishness' - attributes associated with Wilde - with homosexuality. However, many of those who were arrested in New Zealand for sodomy were in fact "burly labourers with tattoos and missing teeth, 
as much a contrast to Oscar Wilde as one could find" (ibid, 86). This is not to suggest that all males engaging in homoerotic practices in New Zealand deviated from the Oscar Wilde stereotype; rather that the homoerotic population was much more diverse than the stereotype portrayed.

Although well-known and understood today, the dichotomy between heterosexuality and homosexuality did not emerge until the late nineteenth century. The Hungarian writer Karoly Maria Benkert first coined the German term 'Homosexualität' in 1868. The poet Bill Addington Symonds then brought the term into English in 1891 as 'homosexuality' in his privately printed pamphlet $A$ Problem with Modern Ethics (Brickell 2008: 143). The German psychiatrist, Richard von Krafft-Ebing then adopted the term in his book Psychopathia Sexualis, which was translated into English a year after Symonds' pamphlet. In 1907, the New Zealand publication Truth used the term "homo-sexual sinner" to describe Oscar Wilde, but its use did not filter into popular discourse until much later (ibid, 143). Even during the 1920 and ' 30 , the term was a technical rather than populist one. The concept of the homosexual was, from the first, developed in opposition to 'normalcy' and was largely conceived of in behavioural terms: a homosexual was anyone who engaged in sexual acts with another of his or her sex (Altman 1993 [1971]: 21). Today, a purely behavioural definition of homosexuality is generally acknowledged as inadequate and social aspects are necessarily incorporated. As Altman observes, to understand the homosexual experience we need to recognise the extent to which social norms have shaped both their behaviour and their identity (1993 [1971]: 21). All members of society could, in theory, now be categorised according to their sexuality. However, as Herek (1990) observes, it was and usually still is only homosexuals who are reduced exclusively to their socioerotic identity.

In 1941, flogging was removed from the life imprisonment sentence for male homosexual acts in New Zealand and hard labour was subsequently removed in 1954. It was not until the New Zealand Crimes Act of 1961, however, that the sentence of life imprisonment was reduced to five to fourteen years, depending on the specific sexual act and the age of those involved. Lesbianism, somewhat 
conversely, was introduced through the Act: females over the age of 21 who 'indecently assaulted' girls under age 16 could now be prosecuted (Laurie 2004: 15). The renting of accommodation to male homosexuals was also criminalised through the 1961 Act and meant that landlords found guilty of such a crime were subject to ten years' imprisonment (ibid, 14-15). Although lesbian behaviour was less proscribed in the Act, lesbians were, like their male counterparts, still subject to loss of employment and housing if 'exposed'.

Throughout much of the $20^{\text {th }}$ century, the policing of male homosexual acts in New Zealand remained relatively circumscribed. Rather than actively pursuing men, the Police preferred "to deal with complaints as they came to hand" (Brickell 2008: 266). Those arrested for 'indecent assault' with a consenting adult were usually discharged, but complaints relating to "sex in public, persisting with unwilling partners, or involvement with children or youths" were likely to lead to court and result in imprisonment (ibid, 266). The higher public profile that these latter cases received helped perpetuate the negative stereotype that gay men are promiscuous, predatory and paedophiles. The accusation that gay people prey on children is, however, as Herek observes, also part of "a general cultural tendency to portray disliked minority groups (e.g. Jews, Blacks) as threats to the dominant society's most vulnerable members" (1991: 152).

Whilst it is well documented that there have always been homosexual acts between individuals, it is unclear whether these people defined their identities in terms of their sexual behaviour (Blumenfeld and Raymond 1993: 276). Those scholars defending an essentialist viewpoint, such as John Boswell (1980), "use the existence throughout the ages of anti-homosexual laws as evidence of a continuous homosexual culture" (Blumenfeld and Raymond 1993: 276). Others adopting a social constructionist viewpoint, by comparison, argue that "though there have always been homosexual acts, homosexual identity has emerged in the West only since the latter part of the 19th century" (ibid, 276). A conceptual shift, they suggest, developed whereby some people did not merely engage in same-sex activity, but saw themselves as homosexuals. I do not wish to enter into this 
debate. However, it is possible to conclude that gay 'communities' or a gay 'consciousness' emerged in part because of opposition to homoerotic engagement.

New Zealand's increasing urbanisation facilitated the expansion of homosexual networks and helped promote the emergence of gay subcultures. By the 1940s there was, according to Brickell, a well-established sense of community and a "group culture had coalesced" around "those who had decided to build an identity around their desires for other men" (2008: 195, 202). Many gay men and lesbians, however, continued to marry and maintain hidden relationships with same-sex partners. By the mid-1950s, homosexuality in New Zealand became more visible and entered public discourse, largely as a result of the media attention it had attracted through the 'weddings' of several male couples declaring their commitment to each other, the findings in the Kinsey Reports, and a high-profile murder case which drew the public's attention to lesbianism (Glamuzina and Laurie 1995). In 1954, Pauline Parker and Juliet Hulme were accused of murdering Pauline's mother Honora Parker, allegedly because she had threatened to break up their lesbian relationship (ibid). The case received a great deal of media coverage and, despite the absence of law prohibiting lesbian behaviour, negative attitudes were reinforced and lesbianism in the New Zealand public's mind came to be associated with 'evil', 'insanity', 'sexual perversion' and 'murder' (ibid, 18). ${ }^{10}$

The Kinsey Reports are considered to be two of the most influential scientific books of the $2 \mathrm{O}^{\text {th }}$ century. ${ }^{11}$ The reports brought "discourse about sexual behaviour into general public consciousness and discussion in a manner that previously would have been unthinkable" and, ultimately, served to alter lay views of sexual activity going forward (Guy 2002: 52; Giddens 1992: 29). Sexual Behavior in the Human Male (1949) was the first of the two Kinsey Reports to be published and was based primarily on personal interviews with American men. The second report titled Sexual Behavior in the Human Female was published in 1953 and was

\footnotetext{
${ }^{10}$ The Parker-Hulme case was later made into the movie Heavenly Creatures (1994) directed by Peter Jackson.

${ }^{11}$ Together the Kinsey Reports sold three-quarters of a million copies and were translated into thirteen languages.
} 
based on interviews with 6,00o American women. Kinsey found, as Giddens documents,

"[T]hat about 50 per cent of all American men were, in his terms, 'exclusively heterosexual' - that is, had neither participated in nor felt homosexual desires. Eighteen per cent were either exclusively homosexual or persistently bisexual. Among women, 2 per cent of women were wholly homosexual, 13 per cent of others had engaged in some form of homosexual activity, while a further 15 per cent reported having had homosexual urges without having acted on them (Giddens 1992: 13).

Kinsey argued that sexuality was a continuum and not a matter of fixed binary opposites, whereby a person is either exclusively homosexual or exclusively heterosexual. To illustrate this point, he introduced a seven-point scale showing the variations in sexuality that exist. Kinsey's findings, as Giddens notes, "shocked a disbelieving public at the time" (1992: 13). Homosexuality had until then been seen largely as a pathology, a form of psychosexual disturbance (Giddens 1992: 13). For homosexuals, though, the findings served to "break down the fear of total isolation" (Altman 1993 [1971]: 124). The Kinsey reports, aided by the introduction of the oral contraceptive pill, were, I suggest, influential in the 'sexual revolution' that ensued in the 196os. The liberalisation of attitudes towards sexual behaviour was, in turn, a necessary antecedent for the eventual liberalisation of attitudes towards homosexuality, a point to which I shall return.

Wellington's Dorian Society was founded in 1962 and was the first formally organised homosexual group in New Zealand. The Dorian's name alluded to the ancient Greek world and, as a society, it set out to promote a social life amongst its male members (Brickell 2008: 26). According to Brickell, the organisation "attracted a wide cross-section of homosexual society, in terms of both age and socio-economic backgrounds" (2008: 242). In 1963, the Dorian Society set up a subcommittee with the two-fold aim of educating the public on aspects of homosexuality and of challenging the illegality of sex between men (Brickell 20o8: 286). In 1966, the subcommittee adopted the title Wolfenden Association of New Zealand. The name was inspired by the 1957 'Wolfenden Report', which recommended legalising private, consenting sex between British men over the age 
of 21 (ibid, 287). The group, however, re-named itself the New Zealand Homosexual Law Reform Society (NZHLRS) soon after.

Early "homophile"12 organisations such as the NZHLRS were, according to Altman, "marked by caution, moderation and, often a sense of their own inferiority" (1993 [1971]: 124-125). Their aim, he suggests, was "to show that they too were respectable [and] that homosexuals could live restrained lives" (ibid, 125). Their liberal-minded heterosexual supporters, far from fully accepting or validating homosexuality, adopted a form of tolerance, a form of liberal pity that, according to Jeffrey Weeks (1993: 7), was as damaging to self-pride as more overt forms of homophobia. The NZHLRS was primarily concerned with the civil liberties and welfare of homosexual males within the existing social structure and did not necessarily accept the principle of full homosexual equality (Taylor 1977: 126). They lobbied to decriminalise sex between men in New Zealand and to encourage sympathetic public and professional opinion.

Contrary to previous trends, New Zealand did not follow Britain when in 1967 it decriminalised homosexual activities between consenting males under specific conditions (only two people present, both over 21, and not in the merchant navy). It was to take a further 21 years before homosexual activities between consenting males would be decriminalised in New Zealand - this victory being achieved after many years of campaigning both by homosexual and heterosexual individuals. As the first Western nation to give women the right to vote nationally, New Zealand was considered relatively progressive. Deferring the decriminalisation of homosexual acts, therefore, points to a high level of homophobia. The 'Hagley Park' trial of 1964 provides some illumination of New Zealanders' attitudes towards homosexuality at this time.

Charles Aberhart, a homosexual, was murdered in Christchurch's Hagley Park by six youths who had, according to Laurie Guy, "largely admitted that they had gone to Hagley Park to "bash a queer"' (2002: 9). Despite evidence to the contrary, the jury acquitted all six accused. The shape of the trial and its outcome suggested

\footnotetext{
${ }^{12}$ The word homophile is often used to refer to the gay rights movement of the 1950s and 1960s.
} 
that many New Zealanders viewed homosexuals as "fair game for bashing" and reflected a pervasive negativity towards homosexuals more generally (Guy 2002: 10). The case, however, was also a catalyst for more liberally-minded individuals to take action (ibid, 10). According to Guy, the tragic Hagley Park incident led Ian Breward, professor of church history at Knox College and subsequently moderator of the Presbyterian Church of New Zealand, to become vice-president of the New Zealand Homosexual Law Reform Society and also prompted the "Methodist minister Selwyn Dawson to preach his first-ever sermon on the plight of homosexuals" (ibid, 10).

\section{Winds of change}

Throughout the 196os, homophile groups grew in number and became more assertive. Their aim, however, was mostly integration into society and there was still an apologetic tone to their arguments (Altman 1993 [1971]: 125). The strong sense of gay community that had developed through the homophile groups, though, was a necessary pre-condition for the emergence of gay liberation. Community, as Weeks (1993: 10) notes, "is what makes possible a movement or movements". Community, however, does more than simply affirm a collective existence. It also, as Weeks points out, "makes possible a greater sense of individuality" (1993: 10). Following international developments, New Zealand's gay liberation movement flickered into life during the early 1970s, initially at Auckland University and later in Wellington and other main centres.

Whereas the 1940s and ' 50 s were an era marked by conformity for most New Zealanders, the late 1960s, as Michael King (1988: 91) observes, ended in a maelstrom of diversity on a scale the country had never seen before. All sorts of reform issues were materialising, issues such as anti-military involvement in Vietnam, pro-abortion, second-wave feminism, and anti-film censorship (Guy 2002: 50). Discourses on human rights were the foundation on which many of these social reform movements were based and these discourses were in turn informed by ideals of human emancipation. Ideas of human emancipation have since the early development of the 'modern era' come to the fore and now constitute a dominant force in the politics of modern liberal-democracies such as 
New Zealand (Giddens 1991: 210). Emancipation in the first instance was, according to Giddens, from the "dogmatic imperatives of tradition and religion" but then also came to be associated with the emancipation of individuals and groups from pre-existing social constraints and prejudices affecting their life chances. "[E]mancipatory politics is concerned above all with overcoming exploitative, unequal and oppressive social relations" so that individuals or groups can have the opportunity "to develop their potentialities" (Giddens 1991: 213). The social reform movements that erupted onto the scene during the late 196os were informed by these emancipatory ideals. Collectively they created a general climate of change and it is within this broader ferment that gay liberation must necessarily be considered. Second-wave feminism and sexual liberation were, however, movements of particular significance for gay rights activism.

Second-wave feminism, as Manuel Castells (1997) points out, was successful at deconstructing taken-for-granted assumptions on natural gender differences. In arguing for the acceptance of same-sex relationships, gay and lesbian rights activists relied on the same denaturalising tropes as feminists as well as appeals to universal human rights (Gross 2005: 289). Together, feminism and gay rights presented a growing challenge to patriarchy. Improvements in contraceptive technology, particularly the oral contraceptive pill, facilitated the separation of sex and reproduction, thereby reducing risks associated with "casual" or non-marital sex (Hull 2006: 5-6). The emancipatory effect of the oral contraceptive along with the findings in the Kinsey Reports were, as mentioned above, influential in the 'sexual revolution' that also emerged in the 1960s. Sexual liberation, in turn, gradually eroded the social stigma attached to premarital sex and cohabitation. The 'end of reproduction as fate' and the more general liberalisation of attitudes towards sex gave women, in particular, a greater degree of sexual autonomy but also made sex and sexuality generally more malleable - what Giddens (1992) refers to as "plastic sexuality". For gay men and lesbians, sexual liberation created a more generally accepting climate and homosexuality, as a consequence, began to "flourish" (Giddens 1992: 28). 


\section{The 'Social Drama': Gay Liberation}

The 1969 Stonewall Inn riots in New York City are considered by many historians to be the defining moment in the history of gay oppression in Western societies and the beginning of the modern gay liberation movement (Blumenfeld and Raymond 1993: 276). Viewed retrospectively, the riots also signalled the beginning of an episode of "tensional irruption" in the on-going social process, or what Victor Turner would refer to as a 'social drama' (1974: 33). 'Social dramas' arise in conflict situations when the interests and attitudes of groups and individuals within a given sociocultural field stand in obvious opposition (Turner 1974:33, 37). The Stonewall Inn riots represented the first of the four phases that Turner sees as typical of a 'social drama'. Rather than succumbing to police harassment, as was the norm, gay people in the Stonewall Inn on this particular occasion fought back. This act represented an overt breach in regular-norm governed social relations, a symbolic act of dissidence that triggered a confrontation and a subsequent phase of escalating antagonism between the contesting parties.

The Stonewall Inn riots convinced the gay community in the United States to come out, to be visible and to confront injustice on a larger, more organised and miliatnt scale. The riots gained a lot of media attention globally and also became a catalyst for activism in other parts of the world such as New Zealand (Brickell 2008: 290; Gearing 1997: 16). Sensing that change was in the air, gay men and lesbians in other countries were encouraged to mobilise, to enter into what Turner calls the crisis phase of a 'social drama'. During the crisis phase, the breach between the contesting parties tends to widen. Fundamental aspects of society are brought into frightening prominence: "factional intrigue, hitherto covert and privately conducted" is exposed as people take sides based on "deeply entrenched moral imperatives and constraints" (Turner 1974: 38, 35). Gay rights, set within the broader context of human rights, are the dominant issue in this particular 'social drama' and a yawning cleavage emerged between conservatives and religious fundamentalists on the one hand, and homosexuals and liberal-minded heterosexuals on the other. While the United States model of 'Stonewall' became, as Plummer notes, a "symbolic tale across the world", each "culture re-worked this in its own style" (2001: 249). One exception, though, was the cry "Out of the 
closets and into the streets" that had emerged in America. As Altman notes, the cry "spread through most of Western Europe, Canada, Australasia, and parts of Latin America" (1993 [1971]: 117).

Many New Zealanders, according to Brickell (2008: 290), sat up and paid attention to the events in New York which at the time seemed "fluid, exciting, [and] explosive". "Local men and women pored over the newspaper reports on the Stonewall Riots and the birth of Gay Liberation, and grabbed Time's issue on 'the homosexual in America' from the local booksellers' shelves" (Brickell 2008: 290). In 1972 at Auckland University, the New Zealand Gay Liberation Movement was ignited, "when Ngahuia Volkering (later Ngahuia Te Awekotuku) picked up a microphone at an open student forum and said, 'Who out there is crazy enough to come and do this with me?"' (Brickell 2008: 293-4). After the first Auckland Gay Liberation meeting, the future Labour MP Chris Carter reportedly wrote,

"we had the first gay demonstration in New Zealand, in Albert Park. There we were, this little group of interpid gays, standing around the statue of Queen Victoria, holding up signs that said 'Gay Pride' and 'Gay Rights'. People gawked at us and it was all a bit exciting and a bit scary" (Brickell 2008: 294).

Many demonstrations by activists were to follow. "In other main cities men and women had been quietly canvassing options since news of Stonewall had broken, and actvists in Wellington, Hamilton and Christchurch set up Gay Liberation groups in the second half of 1972" (Brickell 2008: 295).

Gay liberation, at a general level, "heralded the public presence and celebration of sexual diversity" (Weeks 1993: 11). Sex, as Weeks (1993: 11) points out, became a new frontline in politics and 'diversity' and 'difference' the new watchwords of sexual politics. Self-definition, according to Lindsay Taylor (1977: 127), was one of the first challenges faced by the movement. The word 'gay' was reflexively chosen over 'homosexual' because it did not refer to the hetero-homosexual dichotomy with its subtext of 'normal' and 'abnormal'. 'Gay' did not refer to heterosexual behaviour at all and thus reflected the belief that homosexuality had an independent existence. It also did not make the assumption that the two forms of sexual behaviour could not be found in the same person. The term 'gay', 
furthermore, collapsed the then common division of homosexuals into 'obligatory' and 'situational' (Taylor 1977: 128). The movement's definition of 'gay' was thus broad enough "to include all people who are to any degree homosexual and therefore liable to suffer discrimination" (ibid, 128). Because gay people had been historically defined as sinful and as pathological, the movement also set about defining a gay person in affirmative terms, as someone "who has the positive ability to relate physically, intellectually, and emotionally to people of the same sex" (ibid, 127). The term 'gay' of course also suggests "colourfulness, openness and legitimacy, a far cry from the image of homosexuality once held by many practising homosexuals as well as by the majority of heterosexual individuals" (Giddens 1992: 14). The gay cultural communities that emerged provided, as Giddens observes, "a new public face for homosexuality. On a more personal level, the term 'gay' also brought with it an increasingly widespread reference to sexuality as a quality or property of the self" (1992: 14).

The first women's liberation, gay liberation, and lesbian feminist groups were, according to Laurie (2004: 17), formed in New Zealand during the late 196os and early 1970s. Whilst gay men and lesbians were generally united in their desire to reform laws pertaining to homosexuality, their philosophy on how this should be achieved and broader issues of inequality did not always coincide. Lesbian feminists and radical gay men adopted the ideals of 'gay pride', visibility and public education and were generally more unapologetic and uncompromising in their political approach than the earlier homophile groups. ${ }^{13}$ They also advanced beyond the earlier groups' civil rights liberalism in that they were committed to an agenda beyond gay rights, becoming advocates for revolutionary social change, particularly around issues of sexism, racism, classism, and ableism (Laurie 2004: 17-18). Liberation, for the radical sector of the movement meant a society free not

\footnotetext{
${ }^{13}$ According to Laurie (2004) and Watkins (2006), radical gay and lesbian groups carried out nationwide protest marches and rallies and picketed in lines outside anti-homosexual law reform organisations such as the Salvation Army. They also infiltrated and disrupted anti-law-reform meetings by singing, whistleblowing, dancing in conga lines and making demands for equal speaking time (Laurie 2004: 22). During the infamous, Nuremburg-style ceremonial presentation of anti-Bill Petition boxes to Parliament, where protesters were held back by barricades, twenty-four Bill supporters were arrested and coverage of protesters being roughly dragged into Police vans was televised (Laurie 2004: 25). Information leaflets were handed out, advertisements ran in newspapers, and stickers and paste-up posters were produced to further leverage the Bill-supporters campaign and to educate the public.
} 
just from the distinction between homosexual and heterosexual but from that between 'abnormal' and 'normal' more generally.

Those adopting a more reformist approach (including many conservative gay men and members of the earlier NZHLRS) were opposed to this 'radical' philosophy and activism and feared that it would "alienate mainstream society" (Laurie 2004: 18). They tended instead to work within the confines of the parliamentary system and in "lobbying members of the established political parties - especially the Values and Labour Parties, which [were] more sympathetic towards the issue of homosexual rights" (Taylor 1977: 130). The radicalists' call to 'come out' also challenged the older expectation that "respectable citizens kept their erotic interests veiled" (Brickell 2008: 309). In response to their illegal status, many older gay men had, as Brickell observes, "adapted to the more secretive environment in which they had lived for many years, and some enjoyed the exclusive, invitationonly basis of the older queer circle" (ibid, 309). As one of Brickell's informants commented, "Half the intrigue of it was being secretive and discreet" (ibid, 309). To risk being 'outed' had also meant opening oneself up to shame and social castigation. Nigel Gearing (1997: 17) recounts how exposure through the courts and media had led several gay men to commit suicide after being busted in a police raid on a sauna in central Auckland during the 1970s. It is not surprising then that the calls being made by gay liberation radicals to "come out", "be visible", "be blatant", and to "be as gay and lesbian as you can all of the time" were, for many 'closeted' gay men, far too challenging (Watkins 2006; Gearing 1997: 17). Discretion, as Brickell notes, "provided a certain amount of shelter, and 'coming out' threatened to strip that away" (2008: 309).

The division between reformists and radical liberationists within the broader context of the gay community can be defined as a tension between philosophical imperatives. For the reformists, their goal was simply to gain acceptance and assimilate into mainstream (heterosexual) society. The goals of the radical liberationists were, by comparison, more ambitious. Rather than assimilating into the mainstream, they wished to assert their difference and be recognised as a distinct group or culture within society. This tension between assimilation and 
difference was also prevalent in my participants' narratives. Rather than adopting an either or stance, though, participants would often oscillate between the two: in some contexts the participant would emphasise their difference as a gay man or lesbian and in other contexts they would emphasise their similarity to mainstream heterosexual society. I return to this theme in subsequent chapters.

Many of those most active in the gay liberation movement were lesbian feminists (Brickell 2008: 300). As sex between women had never been illegal, this involvement is perhaps unsurprising. But lesbians, as Altman (1993 [971]: 93) observes, are "doubly oppressed". Not only have lesbians been oppressed for their same-sex desires, they have also been oppressed for their supposedly 'inferior' gender. Gay women, furthermore, were throughout much of history largely invisible. As noted above, patriarchal society had difficulty accepting that women could be sexual together. Many lesbians, as a consequence, saw men rather than the social system as the prime cause of their oppression. The lesbian separatist movement "with its aims of building an alternative society based on the replacement of 'male' values of aggression and dominance by 'female' values of cooperation and gentleness" was, as Taylor (1977) notes, for many women attractive. A core aim of the gay liberation movement, however, was to challenge institutionalised sexism and to more generally rid society of the gender-role system (Brickell 2008: 282). Their efforts targeted institutional structures that reinforced gender stereotypes: institutions such as education providers and the family. Gay liberationists argued that, "Until such structures [are] altered and marriage divested of its 'extra special privilege', [then] gay people don't really stand to gain much" (ibid, 282).

Brickell (2008: 306) suggests that three gay liberationist ideas became particularly popular and endured over time. These were: an analysis of oppression as the systematic marginalisation of a particular social group; a critique of 'homophobia' as extreme rage or fear reaction to homosexuals; and the concept of 'coming out' the public assertion and affirmation of one's homosexuality. The idea that homosexual people were oppressed was, according to Weeks (1993: 21), relatively new to mainstream society during the late 1960 s and early '7os. As a concept it 
brought with it a new awareness of the historical and social factors that had shaped attitudes toward, and inhibited the expression of, homosexuality. This new awareness of oppression also entered discourses of identity. As Dennis Altman famously wrote in the 1970s, "[t]o be a homosexual in our society is to be constantly aware that one bears a stigma" (1993 [1971]: 20). The notion of homophobia, somewhat ironically, reversed the direction of moral righteousness so that discomfort with homosexuality, rather than homosexuality itself, became the issue (Brickell 2008: 307-308). The solution to oppression and homophobia, according to liberationists, "lay in 'coming out of the closet', that metaphorical space of darkness, silence, repression and self-denial" (ibid, 308). 'Coming out' also, according to Brickell, "served a 'revolutionary' function”. It was believed that "if members of the community realised that perfectly ordinary friends and acquaintances were gay [...] then oppressive stereotypes about homosexuality would dissolve" (ibid, 308).

The homosexual law reform campaign began in earnest in March 1985 when the MP and campaign champion, Fran Wilde, presented a Bill to Parliament. The Bill was met with immediate opposition and bitter public and political debates ensued, fuelled by the expression of extreme viewpoints on both sides. The opposition's arguments often rested on moral and religious grounds: that homosexuality was 'unnatural' and that the Bible condemned it. Some argued that a change in law would lead to more homosexuality and that this would eventually result in the collapse of the family unit. The Coalition For Concerned Citizens, a group of fundamentalists who published The Social Effects of Homosexuality, also claimed that a law change would "allow for homosexual acts upon boys" and would "set the scene for the acceptance of paedophilia", therefore putting all children at risk (Gearing 1997: 19-20). Law reformists tried to counter their opponents through nationwide street marches and rallies, where information was handed out, and by disrupting anti-law-reform meetings. Law-reformists' arguments rested on issues of human rights, freedom of choice and on ending discrimination based on gender and sexuality (Watkins 2006). 
The HIV virus and AIDS were an important aspect of the campaign and were used as a defence by both sides of the debate. Some of those in opposition to the Bill claimed that AIDS was a gay disease, or even a divine punishment of homosexuals, and argued that decriminalising homosexuality would lead to massive increases in homosexual infections (Watkins 2006; Laurie 2004: 27). The news media inflamed this notion by distinguishing "between the 'guilty' patients - gay men - and 'innocent' victims - haemophiliacs who contacted HIV from contaminated blood" (Brickell 2008: 349). Law reformers, in contrast, claimed that the decriminalisation of homosexuality would help contain the spread of AIDS. They argued that decriminalisation would encourage people at risk of infection to come forward for testing, and that a public health campaign based on prevention strategies would encourage safer-sex practices more generally. On this matter, the law-reformers' arguments won through and the government decided to fund campaigns through the New Zealand AIDS Foundation (Watkins 2006; Laurie 2004: 27).

The final vote for the Homosexual Law Reform Bill was held on the $9^{\text {th }}$ July 1986 and was passed by 49 votes to 44 . The passage of the Bill, viewed within Turner's model, can be defined as a redressive mechanism, the third phase of a 'social drama'. In this phase, adjustive or redressive mechanisms are "brought into operation by leading or structurally representative members of the disturbed social system" in order to limit the spread or escalation of crisis (Turner 1974: 39). According to Turner, it is also in this phase "that both pragmatic techniques and symbolic action reach their fullest expression" (1974: 41). Indeed, the Homosexual Law Reform Act 1986 was as much symbolic as it was legal. Both sides of the debate, as Brickell notes, agreed that the passage of the Bill "would have an important impact on the standing of gay men and lesbians in the wider community" (2008: 352). Whilst the law would not change every person's opinion on homosexuality overnight it did have the power to shape and reinforce future public opinion.

As the Bill was passed into law, gay men, lesbians and their supporters partied whilst opponents predicted doom and gloom. For the first time in New Zealand's 
legal history, homosexual men could enter into sexual relationships without fear of prosecution. For the law reformers, though, it was still only a partial victory. The second part of the Bill, which would have removed discrimination on the basis of sexuality, was rejected. Opponents argued that homosexuality was not a human rights issue and that discrimination was fair and acceptable. It was not until the Human Rights Act was enacted in 1993 that it became illegal in New Zealand to discriminate on the grounds of sexual orientation (Watkins 2006).

The community at the centre of the 'social drama' is, according to Turner, at its most "self-conscious" during the redressive phase (1974: 41). Following law reform, the gay community adopted Auckland's Ponsonby Road as its 'capital' and, as the 1990 s began, "the carnivalesque began to overshadow the political" (Brickell 2008: 361; Gearing 1997: 27). Annual gay events such as Hero, Devotion, and Freedom were launched and publicly showcased and celebrated gay 'culture'. The festivals included colourful Mardi Gras-style street parades and regularly "featured scantily dressed marching boys, voluptuous drag queens, and female 'Elvis Presleys"' (Schrader 2010). As well as showcasing and celebrating gay culture, these public events also functioned as a form of reconciliation. Auckland's Hero Parade, for example, attracted hundreds of gay participants but, importantly, tens of thousands of spectators from mainstream (heterosexual) society as well (Schrader 2010).

The silence of the past had, as Kenneth Plummer (2001: 244) observes, been broken. A 'gay issues' culture had emerged to become a feature of public life, suggesting that reintegration - Turner's fourth phase in a 'social drama' - had been achieved on at least some levels. Studies of gay and lesbian cultures flourished and gender and queer studies became common features in academic institutions. Gay and lesbian people had their own media, professionals and spokespeople, and an enormous outpouring of books and writing all served to make gay debates very public (ibid, 245). These emergent gay and lesbian 'public spheres' have, according to Plummer, produced their own visible and positive cultures. These cultures have, in turn, leaked into more mainstream public spheres, but at the same time still provide an alternative, subaltern culture. The margins and boundaries of wider 
society had, as Plummer (2001: 245) notes, shifted and gay men and lesbians, as a consequence, experienced positive increases both in social recognition and legal equality. A public gay culture also created a new language in which 'gay rights' and 'gay citizenship' can be discussed. "Words such as homophobia, heterosexism, sex panics and hate crimes now capture very tangible phenomena that need addressing" (ibid, 245).

While emancipatory concerns are fundamental to its cause, feminism is also, as Giddens (1991: 216) notes, important for the role it has played in opening up the sphere of 'life politics'. Life politics, as Giddens defines it, flows from a freedom of choice generated through emancipation, either from the constraints of religion and tradition or from prejudice and oppression. Whereas emancipatory politics is a politics of life chances, life politics is a politics of life choices. Life politics is closely tied to the notion of the self as a reflexive project and gives priority to questions of self-identity. In liberating themselves from the home and domesticity, women were faced with a closed-off environment where the only available identities were those offered by male stereotypes (Giddens 1991: 216). Questions of self-identity thus came to the fore; questions such as who do I want to be and how do I want to act? The same too could be said for gay men and lesbians in a post law reform era. Whilst the shift from illegality to legality allowed for the rapid growth in visible gay and lesbian 'spheres', it also posed questions about the future of gay and lesbian identities: should their history of repression, secrecy, and political activism be abandoned in order to create new identities or should their history define their identities going forward? Should gay men and lesbians assimilate into mainstream society or should they remain a sub-culture on the fringe of society? At about the same time, popular beliefs about identity and selfhood were shifting. The 1970 s ethos of experimentation gave way to a belief that identity emanated from deep within. A burgeoning self-help industry encouraged introspection and sex-education brochures urged teenagers to 'discover' and 'acknowledge' their own true sexuality (Brickell 2008: 354).

These new understandings of identity emphasised the idea that each of us has an original or individual way of being human and, according to Charles Taylor, were 
accompanied by an ideal of "authenticity" - of being true to oneself and one's own particular way of being human (1994: 30). The 'psy' disciplines, as Nikolas Rose refers to them, were influential in shaping these beliefs and understandings (1998: 10). They produced what Rose (1998) refers to as a particular "regime of the self"; a certain way of thinking about and acting upon our selves. The self in this context is a psychological being "characterized by a profound inwardness" (Rose 1998: 4). Thus conceived, the self is "coherent, bounded, individualized, intentional, the locus of thought, action and belief, the origin of its own actions, the beneficiary of a unique biography" (Rose 1998: 3). The self is also the object of valorisation - a reflexive project (Rose 1998; Giddens 1991). Reflexivity, in this sense, involves, as Trundle observes, "both subjective and objective positionality, and engagement and detachment, as the self becomes an object for the self" (2009: 17, original emphasis). Through reflexive practices, an authentic inner self is uncovered and through 'lifestyle choices' and coherent self-narratives this authentic self is actualised (Giddens 1991). This "regime of the self", Rose suggests, has in turn "infused the shape and character of what we take to be liberty, autonomy, and choice in our politics and our ethics" (Rose 1998: 16). Freedom - so central to liberalism ${ }^{14}$ - has in the process "assumed an inescapably subjective form" representing the realisation of the potential of the psychological self. Freedom, thus, is the ethical and political standard but also becomes the benchmark by which we, as individuals, measure and 'regulate' ourselves (Rose 1998: 17).

As well as shaping contemporary understandings of self-identity, the intellectual and practical technologies of 'psy' have also, according to Rose, provided the rationale for technologies invented to govern the conduct of others (1998: 12, 16,

\footnotetext{
14 'Liberal', as applied to systems of government, classically implies, as Holden (1993: 16) notes, "a concern with individual freedoms that centres on the need to limit the power and authority of government". Liberty in a more general sense refers to individual freedom in a social context and the means to selfdetermination (Holden 1993: 23). 'Democracy', as Abraham Lincoln famously explained, is "government of the people, by the people, for the people" (Holden 1993: 7). The subsidiary meaning is that a democracy is a society in which there is equality (Holden 1993: 15). There is then, as Holden observes, "a tension as well as a harmony between liberty and democracy" (1993: 16). Liberty, on the one hand, involves an individualist perspective whilst democracy, on the other hand, involves a communitarian perspective. Citizenship theory helps to bring these two perspectives together by focussing "on the individual in their role as a citizen rather than simply on the individual" (Holden 1993: 97). A citizen, as such, has rights and privileges as an individual but conversely has duties and responsibilities as a member of a particular political community (Holden 1993: 95).
} 
100). The principles of rationality, privacy, and autonomy provide particularly important points of connection between psychological expertise and modern liberal forms of government (Rose 1998: 99). First, the authority of psychological expertise, grounded in the claim to truthful knowledge, appeals to liberal democracies' rational basis and provides justification for, and indeed 'ethicalizes', the exercise of power. The legal and penal systems provide obvious examples here (Rose 1998: 99). Secondly, the importance of liberalism as an ethos in modern liberal democracies means that 'private' spaces outside public powers need, necessarily, be demarcated. "Yet the events within these 'private' spaces - notably the market, organization, and the family - are", as Rose points out, "construed as having vital consequences for national wealth, health, and tranquillity" (1998: 99100). Psychological expertise and techniques provide indirect ways for liberal democratic governments to 'regulate'; "to shape and guide the choices and aspirations" of individuals in these 'private' spaces (Rose 1998: 100). ${ }^{15}$ Psychologically-oriented journals and books give advice on relationships, marriage, parenting, education and much more. Individuals, couples, and organisations engage a range of counselling services and the expertise of psytherapies more generally. These psychological techne involve self-reflexive practices and conspire to govern individuals "in terms of their freedom" and in the name of self-actualisation and fulfilment (Rose 1998: 100, 16).

Thirdly, modern liberal democratic governments seek to govern by "constructing a kind of regulated autonomy for social actors" (Rose 1998: 100). The modern liberal self, as Rose explains,

“... is 'obliged to be free', to construe all aspects of its life as the outcome of choices made among a number of oppositions. Each attribute of the person is to be realized through decisions, and justified in terms of motives, needs, and aspirations of the self" (Rose 1998: 100).

The technologies of 'psy' "gain their social power in liberal democracies because they share this ethic of competent autonomous selfhood, and because they promise to sustain, respect, and restore selfhood to citizens of such polities" (Rose

\footnotetext{
${ }^{15}$ In saying this, I do not suggest that 'psy' experts are in collusion with or a puppet for governments, but rather that there is a certain synergy in their goals.
} 
1998: 100). They constitute, as Rose observes, "technologies of individuality for the production and regulation of the individual who is "free to choose" (1998: 100). Rose concludes that, although those living in the Western world have been freed from the "arbitrary prescriptions of religious and political authorities, thus allowing a range of different answers to the question of how we should live", we have, however, "been bound into relationships with new authorities" (1998: 17). These new authorities, he suggests, are "more profoundly subjectifying because they appear to emanate from our individual desires to fulfil ourselves in our everyday lives, to craft our personalities, to discover who we really are" (Rose 1998: 17).

Rose's notion of a mutual dependence between liberal ideals and psychological discourses also informs our understanding of gay liberation and the broader ferment in which gay liberation is situated. ${ }^{16}$ Indeed, it could be said that gay liberation personified the "the contemporary regime of the free individual" that emerged from this confluence and that homosexual law reform represented the triumph of liberal political and ethical ideals more generally. The Stonewall Inn riots, mentioned above, symbolised a breach in regular norm-governed social relations and signalled the beginning of the modern gay liberation movement and a phase of mounting crisis not just in the United States but across the Western world more broadly. The emancipatory ideals of freedom, autonomy and choice provided the foundation for gay liberationists' political rhetoric but were also the basis on which the government moved to reform the law pertaining to homosexuality. The particular "regime of the self" produced by the 'psy' disciplines endorsed this ethic of a free, autonomous self and encouraged the notion of a reflexive identity. Reflexive practices are fundamental to the notion and process of 'coming out' which, as mentioned above, was one of the core tenets of the sexual politics of the 1970s and liberationist ideology more particularly.

\footnotetext{
${ }^{16}$ Somewhat paradoxically, though, the 'psy' disciplines were, as noted above, also complicit in gay and lesbian oppression. In gaining the authority to define 'normativity' they medicalised homosexuality.
} 


\section{The Civil Union Bill Campaign}

In a post law reform era, more same-sex couples formed openly committed, stable relationships and many also sought to establish viable families of their own. The meaning of heterosexual marriage had by this stage also changed and in its current form had become a salient fit for many lesbians and gay men. Intimate relationships between men and women had, as result of feminism and sexual emancipation, undergone profound transformations requiring "fundamental changes in their outlooks on, and behaviour towards, one another" (Giddens 1992: 7). 'Regulative traditions' (Gross 2005) around marriage had, furthermore, declined. Increases in divorce, cohabitation, single parenting and female labourforce participation, along with declines in the marriage rate, challenged assumptions and beliefs about 'normal' families and relationships in a way that is disturbing to some and liberating to others (Hull 2006: 4). Developments in reproductive technologies and practices weakened the previously exclusive link between heterosexual sex and biological reproduction and meant that gay couples were now equally able to create viable families of their own through surrogacy and donor insemination (Hull 2006: 5-6). The decline in regulative traditions around marriage and family formations combined with the emergence of committed same-sex couples who wanted the same rights and recognition as heterosexual couples both facilitated and provided a context of pressure for the ensuing civil union legislation - a further redressive mechanism in this on-going 'social drama'.

In June 2004, the Civil Union Bill was introduced by Labour Party MPs and Ministers David Benson-Pope and Lianne Dalziel. The aim of the Bill was to establish a new registration scheme for both same-sex and opposite-sex relationships that was equivalent in status to marriage (Benson-Pope 2004b). The Civil Union Bill was accompanied by the introduction of The Relationships (Statutory References) Bill which proposed legislative changes that meant that all couples in New Zealand, whether married, in a civil union, or in a de facto partnership could enjoy the same rights and assume the same responsibilities (Benson-Pope 2004a). These rights would extend to areas such as immigration, next-of-kin status, social welfare, and 'matrimonial' property but not as far as child adoption; only married couples could adopt, although people in non-marital 
relationships could adopt as individuals. The title of 'spouse' would also be reserved for married couples (Relationships (Statutory References) Act 2005).

International developments concerning the rights of same-sex couples also provided a context of pressure for the New Zealand government to legislate. The Civil Union and Relationships (Statutory References) Bills were positioned as progress towards New Zealand's compliance to its international human rights commitments in that it made the same legal rights and responsibilities available to all couples irrespective of their sexual orientation or marital status (BensonPope 2004a). In its recommendations, the Human Rights' Commission favoured extending New Zealand's Marriage Act to include same-sex couples, highlighting that the Netherlands, Belgium, four Canadian jurisdictions and Massachusetts in the United States already recognised same-sex marriages (Deery 2005: 68). The Commission did, however, acknowledge that the political reality in New Zealand meant that amending the Marriage Act was rather idealistic. It concluded that the Civil Union and Relationships (Statutory References) Bills provided a satisfactory alternative, at least for the present time (Deery 2005: 68). The Civil Union Bill was treated as a conscience issue by most political parties and passed its third and final reading by 65 votes to 55 in December 2004. The Relationships (Statutory References) Bill was passed shortly afterwards in March 2005.

Although debates over the civil union legislation were less acrimonious than those over the Homosexual Law Reform Bill of 1985-86, they still revealed the depth of opposition to homosexuality among some New Zealanders (Watkins 2006). Alison Laurie's (2004) report suggests that most of the submissions written in opposition to the Civil Union and Relationships (Statutory References) Bills came from a small sector of society holding a particular set of religious convictions, sometimes referred to as Biblical literalist or fundamentalist (Laurie 2004: 3). Their submissions reportedly often included explicit homophobic comments and generally opposed equal treatment for homosexuals on religious and moral grounds. ${ }^{17}$ These submissions were backed-up by anti-gay protests and rallies. The

\footnotetext{
${ }^{17}$ See Bruce Logan's (2000) booklet, Same Sex 'Marriage'?, which summarises a Christian fundamentalist's view and concludes that the "acceptance of same-sex 'marriage' as normative would mean the end of marriage and family as they have existed since history began" (2000: 29).
} 
most publicised rally was the 'Enough is Enough' march through central Wellington to Parliament, in August 2004. The march was organised by the Destiny Church ${ }^{18}$ and involved thousands of church members and supporters many wearing black shirts - marching down Lambton Quay punching the air with their fists and chanting "enough is enough" (Television New Zealand 2004a and 2004b; Beautiful Monsters 2004). Submissions put forward by supporters of the bills were, by comparison, based on arguments relating to human rights and equal recognition, were secular in nature, and often grounded in personal experience (Laurie 2004: 7).

Not all people within the gay community supported the civil union legislation. Some, such as the self-professed lesbian, Professor Marilyn Waring, argued that the establishment of a separate but equal institution for same-sex couples did not constitute a human right or social justice. While opposite-sex couples have the choice of marriage or a civil union, same-sex couples have only the option of a civil union. In an interview, Waring likened the proposed civil union legislation to other "separate but equal" approaches throughout history.

Apartheid is a separate but equal approach. Segregation in the American south was a separate but equal approach. The internment of Japanese people in World War II was a separate but equal approach and gay people wearing pink triangles being taken away before even the Jews were taken, was a separate but equal approach" (Waring cited in Scoop 2004).

There were also people within the gay community who thought the state should not play a role in people's relationships at all and that both marriage and civil unions were regressive. However, once the Destiny Church and other fundamentalist Christian groups became more vocal in their stand against the Civil Union Bill, many gay men and lesbians opposed to the Bill agreed to not speak out against those who wanted civil unions (Rolfe and Peel 2011; information from interviews with participants).

Viewed within a global context, New Zealand's civil union legislation can be described as taking a middle path between liberalism and conservatism. Although

\footnotetext{
${ }^{18}$ The Destiny Church is a Pentecostal Christian fundamentalist church based in New Zealand.
} 
a continuously moving target, at the present time, Argentina, Belgium, Canada, Denmark, Iceland, the Netherlands, Norway, Portugal, South Africa, Spain and Sweden can be said to be the most liberal and progressive in that they allow samesex couples to marry in exactly the same way as opposite-sex couples. New Zealand is joined by approximately twenty other countries in allowing same-sex civil unions, registered partnerships or life partnerships. As an institution, civil unions, registered partnerships and life partnerships are distinct from marriage and are not always accorded the same rights and responsibilities. In some countries, such as the United Kingdom and Germany, they are also only available to same-sex and not opposite-sex couples. In several countries, such as the United States, Australia and Mexico, same-sex 'marriages' are not recognised federally but some states or territories do grant same-sex couples legal recognition. In the United States, for example, marriages for same-sex couples are legal in nine states: Connecticut, Iowa, Maine, Maryland, Massachusetts, New Hampshire, New York, Vermont, and Washington, as well as in the District of Columbia and three Native American tribal jurisdictions. Several other states and districts in the United States have created legal alternatives such as civil unions for same-sex couples. In the state of California, same-sex marriages were performed between June and November 2008. However, a voter referendum (Proposition 8) approved by the Californian electorate meant that a ban on same-sex marriage was reinstated as part of California's constitution. Other countries are presently debating the issue of same-sex 'marriage' while others still, particularly Muslim nations, are emphatically opposed to them.

The passing into law of the Civil Union Act in 2005 made it possible for the first time in New Zealand's history for same-sex couples to enter into a relationship that, from a legal perspective at least, is equivalent to marriage. The first civil unions were celebrated on the $29^{\text {th }}$ of April 2005, just three days after the Act came into force (Bascand 2010). By December 2011, a total of 2,591 civil unions had been registered. Of these, 80 per cent were for same-sex couples, and of these ${ }^{6} 6$ per cent were for female couples and 44 per cent for male couples. 153,908 marriages were registered in New Zealand during the same period (June 2005 to 
December 2011). As at the $31^{\text {st }}$ of December 2011, 83 civil unions had been dissolved in New Zealand (Statistics New Zealand 2011; Bascand 2012).

\section{CONCLUding COMMENTS}

In tracing the background to the 'social drama', gay liberation, I have shown how religion, patriarchy, the law, psychiatry and psychology, and the mass media each played a role in the condemnation of homosexuality in New Zealand. I have argued that homosexual law reform cannot be viewed satisfactorily as a single reform movement. Rather, its success depended on a number of important antecedents: the liberalisation of attitudes towards sex, second-wave feminism's success in challenging presumed natural gender differences, and a more general climate of change generated by the social reform movements of the late $1960 \mathrm{~s}$ which, in turn, provided a context of pressure for homosexual law reform. The formation and growth of homophile groups, furthermore, provided the political mass and voice necessary for the eventual emergence of the gay liberation movement. The Stonewall Inn riots were the catalyst that mobilised the movement and the 'social drama' that subsequently unfolded. In a post law reform era, the decline in regulative traditions around marriage and family forms combined with the emergence of more openly committed same-sex couples wanting the same rights and recognition as heterosexual couples provided a further context of pressure for the subsequent civil union legislation. Viewed within Turner's model of a 'social drama', the Homosexual Law Reform Act 1986 and the Civil Union Act 2004 can be seen as juridical redressive mechanisms that, as I explore in subsequent chapters, have gone some way towards initiating reintegration.

The progression in homosexual rights can, I suggest, be situated more generally within the context of two broader social processes: a process of detraditionalisation and the separate but closely interconnected process of denaturalisation. Ideals of human emancipation initiated the process of detraditionalisation by freeing people first from the constraints of religion and tradition and secondly from pre-existing social constraints and prejudices. Emancipatory politics underpins discourses on human rights and is the basis on 
which many social reform movements - including gay liberation - have achieved profound social change. A 'life politics' flows from the liberating effects of emancipatory politics and gives priority to questions of self-identity and lifestyle choices. While emancipatory concerns are fundamental to second-wave feminism it is feminism's success in deconstructing taken-for-granted assumptions about natural gender differences that is of significance here. These denaturalising tropes were, as mentioned above, also taken up and used by gay rights activists and, together, gay rights activists and feminists challenged the presumed naturalness of patriarchy. The findings in the Kinsey Reports revealed the prevalence of homosexual activity amongst the wider population, thereby challenging the perception that homosexuality is both unnatural and abnormal. Contraception and more recent developments in reproductive technologies have extended the denaturalising process further. Contraception has meant that (heterosexual) sex and reproduction are not inevitably linked. Developments in reproductive technology have weakened the previously exclusive association between heterosexual sex and biological reproduction. The 'end of reproduction as fate' is, as Giddens observes, closely tied to the 'end of nature' in that reproduction is now no longer a natural process tied to the cosmic processes of life and death (1991: 206). The fact that sexuality need no longer have anything to do with reproduction - or vice versa - serves to reorder sexuality in relation to lifestyles but also significantly destabilises the homosexual/heterosexual binary which has previously characterised the sexual order (Giddens 1991: 206; Roseneil and Budgeon 2004: 140). The 'end of reproduction as fate' has also impacted on the detraditionalisation process. As a result of feminism and sexual emancipation, intimate relationships between men and women have been profoundly transformed and regulative traditions around marriage have, as a consequence, also declined (Giddens 1992: 7). Within the context of these changes, 'marriage' has become a more salient fit for lesbians and gay men who desire the same rights and recognitions available to heterosexual couples.

In this chapter I have explored the broader socio-historical trajectory that forms the backdrop to my participants' civil union experiences. In the chapters which follow my focus more generally is on the 'particular' experiences narrated by 
participants in this study. Chapter three is the first of four chapters which together seek to situate the civil union within longer processual trajectories. Starting at the level of the 'individual', it explores trajectories of the 'self. In essence, the chapter examines through participants' life narratives the process of identity formation primarily as a lesbian or gay man, and the meaning of the civil union specifically within this context. 


\section{3 \\ Trajectories of the Self}

\section{INTRODUCTION}

One of the most enduring legacies of the gay liberation movement was an assertion of identity and community embodied in the notion and process of 'coming out'. 'Coming out' and 'being out' are central issues for gay men and lesbians and generally a lifelong process (Hull 2006). 'Coming out' stories featured prominently in participants' life narratives and were critical for understanding the significance they attribute to their civil union at the level of the self. 'Coming out', like identity formation more generally, though, has both a personal and a social dimension which, to a greater or lesser extent, are linked dialogically. 'Coming out' therefore not only impacts on the individual but also has a bearing on relationships with family and friends and on intimate relationships, as well as on the broader social order. In this chapter I focus on 'coming out' at the level of the individual and experiences of self-disclosure to family and friends. However, as will become apparent, 'coming out' is a theme that regularly recurs throughout the thesis.

In this chapter, I explore through participants' narratives how they made sense of their own 'coming out'. I argue that gender, socio-historical context and life-stage identification as a non-heterosexual each worked to shape participants' particular experience of 'coming out'. I then examine the significance of the civil union at the level of the individual in terms of self-identity and biographical narrative. I argue that the civil union, when viewed within the process of 'coming out', can be seen as another level of social incorporation. For some participants, incorporation manifested as inclusion in an important 'meaning-constitutive' tradition (Gross 
2005), while for others, their civil union signalled greater incorporation into mainstream society and a positive recoding of the once negative gay life script. A same-sex civil union ceremony, furthermore, ultimately celebrates and affirms same-sex love. In this way, a civil union moves beyond simply assigning legal equality to same-sex couples to respecting them as a same-sex couple.

\section{Conceptual approach}

'Coming out' involves subjective identification and acceptance of the self as an "essential and timeless" lesbian or gay man or, as Kath Weston states, a "redocumenting" of identity "with respect to a new set of relevances" (1991: 68). The sequence inevitably varies but generally involves a process of self-discovery, selfacceptance and deliberate disclosure to 'straight' (heterosexual) others. 'Coming out' is structured in terms of a conceptual opposition between hiding (lying) and honesty (Weston 1991: 49).

In coming out, a person acts to create a sense of wholeness by establishing congruence between interior experience and external presentation, moving the inner into the outer, bringing the hidden to light, and transforming a private into a social reality. The closet [hiding] symbolizes isolation, the individual without society, a stranger even to self. Its imagery is consistent with the atomistic conceptions of a society in which individuated actors must struggle to communicate and gain legitimacy for private truths. In the process of coming out, a person hopes to leave behind the extreme self-consciousness alluded to by the man who joked that he came out to his parents because he was tired of remembering to edit pictures of his lover out of his slide shows (Weston 1991: 50).

Paula Rust suggests that, through the process of 'coming out', "a person sheds a false heterosexual identity and comes to correctly identify and label" himself or herself as a homosexual (1993: 53). In this sense, 'coming out' optimises the notion of a rite of passage in that it involves a process of individual and social transformation. ${ }^{19}$ Rites of passage are typically associated with 'life-crisis' or 'lifecycle' events such as birth, death, marriage, and provide a model for initiations into various special groups (Bell 1997: 95). Through a rite of passage a ritual

\footnotetext{
${ }^{19}$ Gilbert Herdt (1989) also described the process of 'coming out' as a rite of passage.
} 
subject leaves behind one social identity, and passes through a stage of no identity or affiliation before being reincorporated back into society having assumed a new identity (Bell 1997: 95). Aspects of separation, liminality, and incorporation - the three phases of a rite of passage - were implicit in the way participants described their experiences of 'coming out' and, therefore, provide a useful framework and set of ideas for interpretation. While literature on rites of passage tends to focus on ritualised acts, I instead use the ideas of a passage and stages metaphorically. In structuring this chapter I distinguish between 'narratives of separation', 'narratives of liminality', and 'narratives of incorporation'. ${ }^{20}$

Richard Troiden's (1989) work on homosexual identity formation and the fourstage model he developed is also helpful in understanding participants' narratives of 'coming out'. The four stages that Troiden (1989) identifies include, first, a prepuberty sensitization stage characterized by generalized feelings of marginality; secondly, a stage of identity confusion experienced during adolescence; thirdly, a stage of identity assumption whereby self-definition as non-heterosexual and presentation to other non-heterosexuals occurs; and fourthly, a stage of commitment to this identity evidenced externally through disclosure to 'straight' others. The first two stages loosely correlate with the separation phase of a rite of passage in that it is during this time that the subject experiences feelings of dislocation and confusion over their presumed identity. The third stage optimises the notion of liminality in that the subject is essentially 'betwixt and between'; neither heterosexual nor homosexual. It is, however, from this phase that the subject emerges internally transformed as gay, lesbian or bisexual. It is also during this phase that the subject generally seeks out 'like' others. The fourth stage of Troiden's model clearly articulates the incorporation phase of a rite of passage. It is during this phase that the internally transformed subject makes their status socially salient by deliberately disclosing their 'new' sexual identity to significant 'straight' (heterosexual) others. This last stage, as I will discuss, is not, however, by any means discrete or necessarily assured. Due to the presumed heteronormativity of

\footnotetext{
${ }^{20}$ Hindmarsh (2005) similarly used the three stages of a rite of passage to structure and interpret participants' narratives of migration.
} 
mainstream society, 'coming out' to 'straight' others is generally an on-going process and disclosure does not automatically presuppose acceptance.

\section{Overlaying a life course perspective}

Whilst I draw understanding from Troiden's model, I do, however, acknowledge that the formation of a non-heterosexual identity and an associated personal narrative occurs within distinct socio-historical contexts and is subject to gender and life-stage identification variables. While the shared experience of institutional hostility towards homosexuality unifies gay men and lesbians, their experiences are also "shaped by their gendered histories and by the linked but significantly different histories of lesbianism and male homosexuality" (Weeks, Heaphy and Donovan 2001: 28-29). Dominant socio-political views, available role models, and the vernacular of the time also work to shape both the experience of 'coming out' and the subsequent narrative-construction process (Cohler and Hammack 2006: 151). Those participants, for example, born in the 1930 and 1940 sere coming of age in a post World War Two era marked by "social conservatism and stigmatisation" which, for gay men in particular, "fostered a hidden, subversive sexual identity" (Cohler et al. 2006: 153).

Those born in the 1950s, by comparison, came of age during the 1970s; a highly charged era marked by political and social liberalism and converging social movements (Cohler et al. 2006: 155). Although it was still illegal to be homosexual, attitudes towards and acceptance of homosexuality improved markedly during this period and paved the way for future legislative changes. The dual sense of claiming a gay identity for oneself and communicating that identity to others, which 'coming out' has come to assume, also emerged during this period (Weston 1991: 44). 'Coming out' in the 1950s, by comparison, would by today's standards be considered "strictly closetry" as it then referred only to a person's entrance into the gay world. Disclosure to anyone else at this time, particularly if you were male, was, as one of Weston's (1991: 44) interviewees put it, equivalent to declaring oneself "fit for the insane asylum" as it would inevitably lead to prosecution, institutionalisation and loss of employment. 
Participants born in the 1970 and 1980 s make up a third cohort. They were coming of age during the 1990 s in a post homosexual law reform era. With the legalisation of homosexuality many families and communities became increasingly more accepting and being gay became, as Cohler and Hammack observe, "one of several (relatively) permissible sexual 'lifeways"' (2006: 154). Most models of homosexual identity formation such as Troiden's (1989) tend to be based on the assumption that coming out occurs in a climate of alienation and shame, with few supports to assist youths in exploring this aspect of their identity (Floyd and Bakeman 2006: 295). 'Coming out' in a climate of greater openness may, however, be a comparatively less daunting experience and, as Floyd and Bakeman note, individuals may in fact not even pass through the same stagesequence of questioning and self-discovery (2006: 295). To better capture the dynamic variables associated with the formation of a non-heterosexual identity I have, therefore, overlaid a life course development perspective to Troiden's (1989) stage-sequential framework. In doing so I pay close attention to the historical circumstances, maturational and gender factors which also shaped participants' particular 'coming out' experiences.

\section{NARRATIVES OF SEPARATION}

Separation was generally narrated by participants in terms of feelings of "difference" beginning in early childhood. These feelings were often accompanied by an innate sense of not meeting familial expectations and/or of "not fitting in" but were rarely linked to homosexuality until adolescence or even later. As Martin explained,

I think I knew in sort of an intuitive way from an early age. I had a feeling of being different even as a pre-schooler. So as far back as that I had a feeling of never quite fitting in. And then it wasn't until in my late teenage years that I suddenly realised, 'oh my goodness it's really about who I am attracted to and it's about being gay'.

Contemporary understandings of individual identity tend to emphasise the idea that each of us has an original way of being human. A person's identity is not, however, as Charles Taylor (1994: 34) observes, worked out in isolation, but crucially depends on dialogical relations with others both at a personal level and a 
social level. During childhood, relationships at the kin and peer level tend to dominate and are, therefore, the key loci for early identity formation; for selfdiscovery and self-affirmation. An identity can, as such, be formed or malformed through the course of contact with significant others such as family and peers and is vulnerable to 'recognition' being given or withheld.

A person's identity is also, as Appiah (1994: 154) notes, constituted through the concepts and practices made available by their culture and society and in this respect has both a collective dimension as well as a personal. By collective, Appiah refers to the social categories that intersect and make up our collective identities. By personal, he means particular attributes such as wit, intelligence, and charm. Whilst both dimensions involve properties important for social life, the collective dimension relates specifically to broader social categories such as gender, ethnicity, nationality, and sexuality. These large collective identities provide loose norms or models, which inform wider society's understandings of how a person in this social category properly behaves. They also, importantly, "play a role in shaping the life plans of those who make these collective identities central to their individual identities" (Appiah 1994: 159). In short, these collective identities provide what we might call scripts: "narratives that people can use in shaping their life plans and in telling their life stories" (Appiah 1994: 160). These scripts do not simply bear relevance for modern Westerners but for people cross-culturally;

[I]t matters to people that their lives have a certain narrative unity; they want to be able to tell a story of their lives that makes sense. The story - my story should cohere in the way appropriate by the standards made available in my culture to a person of my identity. In telling that story, how I fit into the wider story of various collectivities is, for most of us, important (Appiah 1994: 160).

In this sense, we make up ourselves from a 'tool kit' of options made available by our culture and society. Whilst we do make choices, rarely do we determine the options among which we may choose (Appiah 1994: 155).

Although shifts occur over time, the social and cultural context of 'coming out' as either gay, lesbian or bisexual generally exists within a predominantly heterosexual society reflecting particular understandings of gender, ideas of human nature, and 
'normality' (Markowe 1996: 1). Negative cultural scripts on and stereotypes of homosexuality have tended to be cast in opposition to dominant heterosexual gender ideals, with gay men regarded as 'effeminate' and lesbians as 'butch' or masculine. Although the gay population is, of course, far more diverse than these stereotypes suggest, a few participants did employ gender metaphors to interpret and explain childhood feelings of marginality. Given that mastery of gender roles is emphasised during childhood, rather than sexual scripts, this use of gender metaphors is not, however, unduly surprising (Troiden 1989: 52).

Evan (aged 70), for example, grew up in New Zealand during the 1940 s and ' 50 s with two "macho elder brothers" who, according to Evan, were highly sports motivated. He described feeling a continuous pressure to conform to the kiwi male ideal as his brothers had. He said he tried playing soccer, cricket and rugby but was not keen on sport. He recalls that on several occasions he was "strapped" at high school for refusing to participate. Evan's interests lay in more creativelyoriented directions but he said he felt ashamed of that side of himself and did not allow it to develop until much later. Evan was and still is very much interested in gardening. In the world that he grew up in, though, it was inappropriate for a male to be enthusiastic about flowers; men of this time were, according to dominant gender scripts, allowed only to grow vegetables.

According to Jock Phillips (1996: 284), the traditional male script that developed in New Zealand was particularly narrow and ostracised homosexuals, artists and intellectuals alike. "At the heart of the stereotype was a belief in the primacy of physical abilities and the all-round skills of the pioneer" (Phillips 1996: 282). Rugby to a large extent personified these qualities and was adopted as the perfect counter to increasing urbanisation and the perceived associated decline in virility (Phillips 1996: 99-100). After the turn of the century, rugby became compulsory for all boys in New Zealand high schools and hardness and conformity the desired characteristics of the archetypal New Zealand male (Phillips 1996: 105). Displays of emotional intensity, sensitivity or creativity, such as those exhibited by Evan, raised questions over an individual's masculinity (Phillips 1996: 107; 283). Unluckily for Evan, it was also during the post war decade of the 1950s that the 
New Zealand male stereotype was at its most "triumphant", defined as it was by sporting prowess, military heroism, beer drinking and racing (Phillips 1996: 263265).

Scripts or stereotypes around the kiwi female are far less pronounced than those relating to their male counterparts. New Zealand women have, however, sometimes been perceived as being more independent than women elsewhere and are often portrayed as relatively unfeminine; as not being held back by ideas about being 'lady like' and, therefore, as willing to take on more traditionally 'masculine' tasks. Several female participants did, however, express their childhood sense of difference in gendered terms. Jenny (aged 44), for example, described herself as the opposite of her identical twin sister. As she explained,

My sister wore pink and I refused point blank. My sister was into dolls and girly stuff and I refused point blank. [...] My sister used to play with all the little girls and I used to play Cowboys and Indians with all the boys and was always getting stuck up trees and stuff.

Jenny recalled an incident when she actually wanted to play with the other little six year old girls. Rather than accepting her into their circle, though, "they rounded on me and said, 'you can't play with us. You're weird. You don't know how to play our games"'. Being excluded because she did not fit the appropriate script was not only hurtful for Jenny, it also reinforced her sense of difference - of not fitting in. Loana (aged 38) similarly described herself as "your typical sort of tomboy - butch you know". She said she always knew she did not want to be a boy, just that she enjoyed the "stuff that boys did like playing with guns and getting dirty and being strong and stuff like that".

Although childhood experiences of isolation and difference were rarely linked to homosexuality at the time, they did, however, provide the basis for subsequent self-definition as homosexual. 'Coming out' as gay, lesbian or bisexual can have a de-stabilising or 'disembedding' effect on an individual's biography. In order for a stable self-identity to be re-asserted, the person must necessarily embark on a self-conscious re-ordering of self-narratives and, in the process, the past becomes reconstructed in "anticipation of the likely life trajectory of the future" (Giddens 
1991: 72). Incidences of gender inappropriate behaviour and interests experienced in the pre-pubescent sensitization phase are, for example, later recast as having sexual meaning pointing to a non-heterosexual essence (Troiden 1989: 50). The reinterpretation of past events is, according to Troiden (1989: 52), indeed a necessary (but not sufficient) condition for the eventual adoption of a homosexual identity.

\section{Awakening desires and identity confusion}

Most participants reported that they first became aware of their feelings towards the same sex during their adolescence years, when childhood perceptions of the self as different gradually began to crystallize into views of the self as sexually different (Troiden 1989: 70). Having "crushes" on friends or teachers at school was a relatively common experience narrated by female participants. Loana (aged 38), for example, said her first recollection of an attraction to another female was to her fifth form economics teacher. Coming from a strong Christian and highly heterosexual background, though, she said she dismissed these feelings thinking "no, you're not meant to think like that". Relationships with peers tend to take on greater salience during adolescence. Many participants, however, recalled feeling “out of step” with their peers' experiences. Grace (aged 42), for example, recalled that as her school friends became increasingly interested in boys, her feelings of difference also became more pronounced as she, by comparison, was "never remotely interested in boys". Jason (aged 33) also recalls feeling different from his peers because of his lack of heterosexual interest: "boys would look at pictures of girls when they were growing up and I'd just think, well that just does nothing for me".

Several male participants reported having had sexual experiences with school friends of the same sex. Will (aged 65), for example, recalled that he started having sexual experiences with school friends when he was aged about 13 or 14. According to Will, though, these sexual liaisons had a subversive quality: "it was something that went on but nobody ever talked about it". Ross's early sexual experience was initiated by someone much older than himself who also happened to be his Scoutmaster. He recalls when he was aged about eleven years old listening in on a 
"clandestine conversation" that boys at his school were having about sex. He said he remembers thinking that these boys "were talking total rubbish; it's nothing like that". Ross's parents did not become aware of his relationship with the Scoutmaster until some years after it began. Once they did know, though, Ross recalls there being a lot of "confusion" over a sexually abusive relationship and about his being gay and one thing causing the other. In his later years at school, Ross ended up in a highly depressed state. He was taken to see a psychiatrist and was, reportedly, subjected to "all sorts of treatment including ECT [electric current treatment]". "So those years were really confusing for me" (Ross, 62).

Becky (aged 54) had "dated" boys but said that falling in love with a female school friend helped clarify where her sexuality lay. Her significant peers at the time were a group of politically minded girls from her school: "these were radical feminist, anti-war advocate types, you know. We were the modern politicos at school". Given her peers' radical attitudes, Becky decided to disclose her sexuality to them, but found, somewhat to her surprise, that being gay "was just one step too far [for them]".

It didn't work out all that well somehow because they didn't really have a context, and I had the feeling that they found me threatening, that they might be tainted with the same brush or something or other. But I'm not sure how much of that was in my head. [...] Maybe I overreacted, but I actually got depressed myself. That's the only time in my life when I have done that, and I became anorexic for a while. [...] Yeah. So that was a bit of a traumatic time for me.

For those brought up in a society with strong hetero-normative expectations, the sexual confusion they may experience on initially becoming aware of their samesex desires serves to accentuate the general problems faced by all teenagers (Stewart 1993: 45). As they come to recognise that they are different from mainstream society, previously taken-for-granted cultural scripts are rendered largely irrelevant in terms of self-identity and relationship choices. "Ontological security" - knowledge of and an acceptance of the reality of things and of others may be undermined and a feeling of biographical discontinuity may be experienced (Giddens 1991: 53-54). In becoming aware that they cannot trust previously accepted answers to questions such as, "Who am I? "Where do I 
belong?" the emerging non-heterosexual will undoubtedly experience anxiety. The stigma surrounding homosexuality more generally fuels this sense of anxiety and discourages lesbians or gay males from discussing their emerging sexual desires, further adding to their general sense of alienation (Troiden 1989: 55). Calvin (aged 63), for example, said he realised he was gay during his mid-teens but did not feel confident or comfortable enough to talk about his sexuality until he was attending university. One of the biggest barriers for Calvin was his mother and the disparaging way in which she spoke about gay men.

Mum worked in the Warrant Office in the Police Station and she used to come home and say, 'I've been typing out reports on these dirty old men that were in toilets and things and 'they ought to be put away' and all this. And I heard this at a time when I was thinking, 'Who can I tell? Who can I talk to about it?'

Ignorance and inaccurate knowledge and/or bisexual feelings and behaviour are also sources of identity confusion for the young non-heterosexual. As Troiden notes, "people are unlikely to identify themselves in terms of a social category, as long as they are unaware that the category exists" (1989: 55). Several participants in this study reported having been sexually active with both boys and girls during their teenage years. According to Troiden (1989: 54), homosexuals generally exhibit greater variability in their adolescent sexual feelings and behaviour than heterosexuals. Western societies such as New Zealand have, however, tended to portray people in binary terms as either homosexual or heterosexual. In the absence of any clear or affirmative cultural scripts, bisexual arousal and behaviour only adds to the adolescent's general uncertainty and confusion regarding their sexual orientation (Troiden 1989: 54).

\section{Multiple trajectories}

Although many participants shared an early awareness of difference, from here their pathways frequently diverged. Some consolidated an erotic interest in the same sex and a social identity as a non-heterosexual relatively early on in life. Others pursued a heterosexual life, sometimes marrying and having children, and only later in life, following a divorce or upon meeting and falling in love with someone of the same sex, did they then 'cross over' and establish an identity as a non-heterosexual. The context and challenges associated with 'coming out' during 
adolescence or earlier differ greatly from those experienced by people who selfidentify as gay or lesbian during adulthood (Floyd and Bakeman 2006: 290-291). Young self-identifiers are at high school and usually still subject to parental authority whereas adult self-identifiers have usually achieved a degree of financial independence and have access to a wider range of social options (Floyd et al. 2006: 294). Adult self-identifiers may, however, as Porche and Purvin (2008: 150) point out, fear the loss of social relationships previously established when identifying as a heterosexual, a factor which can in turn be associated with destructive behaviours.

Among lesbian and gay scholars, there has been an ongoing debate over whether homosexuality is innate (thus an 'orientation') or chosen (thus an 'identity') (Stiers 1999: xix). Sexuality experts of the Kinsey tradition, however, generally view heterosexuality and homosexuality as matters of degree rather than kind. As Troiden explains; "People are described as occupying various points along a continuum in their sexual behaviours and responsiveness from heterosexuality through bisexuality to exclusive homosexuality" (1989: 45). My own participants' narratives, to some extent, endorse both these positions. There were some participants who situated themselves at the exclusively homosexual end of the continuum. These participants tended to perceive their homosexuality in essentialist terms, as part of their being, something they were 'born' with. As Jason, for example, explained, "When I was at school, I knew all the way through that I was gay. I just never had any doubt; for as long as I can remember, I've been attracted to other males".

There were also those participants who were "technically" bisexual. They tended to perceive their gay or lesbian identity more in terms of an active choice made during adulthood (Markowe 1996: 196-197). Joss for example, entered a same-sex relationship only after divorcing her husband of 34 years. She said she had always been aware that she was attracted to other women and even reported that she had a "very affectionate relationship with a girl at school". For Joss, though, her sexuality was more fluid or, as she described it, "a choice". 
I don't feel like I was doing the wrong thing when I was married or that I was born to be only a lesbian, but I don't think I'll go back. [...] My theory is that it's not the same for everybody, but that there's a spectrum and there's some people who are exclusively attracted to the same sex and other people who are somewhere in the middle and others who can't even imagine it. So, I'm somewhere in the middle. Yes, so I don't regret having been married really.

The identity confusion reduction strategies posited by Troiden (1989) also help account for variances in life-stage identification as a non-heterosexual. Lesbians and gay males, he suggests, generally respond to the experience of identity confusion by adopting one or more of the following strategies: denial, repair, avoidance, redefinition, and acceptance. Those who use denial as a strategy for reducing identity confusion, deny the homosexual component to their feelings, fantasies, or activities. Repair, according to Troiden, involves "wholesale attempts to eradicate homosexual feelings and behaviours" and often involves the help of professionals (1989: 56). Those adopting a strategy of avoidance generally recognise that their behaviour, thoughts or fantasies are homosexual but see them as unacceptable and, therefore, to be avoided. Redefinition is "reflected through the use of special case, ambisexual, temporary identity or situational strategies" (Troiden 1989: 57). For a non-heterosexual to assume an identity as a lesbian or gay man they must, at least partially, reconcile their identity confusion and adopt a strategy of acceptance. A strategy of acceptance involves an individual acknowledging that their behaviour, feelings and fantasies may be homosexual and seeking out additional sources of information to learn more about their sexual feelings (Troiden 1989: 58). Depending on which strategies an individual adopts and for how long determines when self-definition and self-acceptance as a nonheterosexual occurs. Someone with a self-perception anchored in denial, repair, avoidance or redefinition may, according to Troiden (1989: 58), sustain it for months, years or even permanently.

Most of my participants, in narrating their 'coming out', described experiences consistent with the identity confusion reduction strategies posited by Troiden (1989). Even those who consolidated an identity as a non-heterosexual, relatively early on in life, were not exempt. Trisha, for example, was quite clear from an early 
age where her sexual desires lay. In an attempt to reconcile her sexuality with her Christian faith, she adopted what Troiden (1989) refers to as a repair strategy. While attending Bible College, Trisha discussed her concerns over her sexuality with her college "elders", who recommended that she do a course called "Living Waters":

It's an exodus programme for women. [...] Oh yes, I did it twice [laughs]. Each [course] was four months intensive, including the group therapy as well as individual therapy twice a week. Anyway, long story short, you can see it obviously worked [laughing] ... but it really, - I have to say, it's one of the most evil programmes I've ever encountered. [...] It has really messed people's lives up. I spent another two years in therapy afterwards, just trying to cope with the residual effects (Trisha, 48 ).

Trisha eventually realised that she was never going to be other than a lesbian. After reconciling this insight at a personal level she was then able to go on and became a minister in the church.

For several other participants, religion also played an important underlying role in their early attitude formation. Barbara, for example, described her teenage self as "quite strongly bisexual". At the time, she was also a member of an evangelical Christian church and recalls thinking that "being gay was just not okay". Instead of pursuing her non-heterosexual feelings and fantasies, Barbara adopted an avoidance strategy, immersing herself in a heterosexual marriage. Only decades later, after falling in love with a woman whilst on holiday, would her same-sex desires be "re-awoken". Although nothing of a sexual nature actually happened with this particular woman, the intensity of the feeling was strong enough to compel Barbara to seek counselling and to work out what it was she really wanted. Despite the upheaval it caused her family, she ultimately adopted a strategy of acceptance. As she recalled it, "I was really clear that I could not follow this path but it would be like shutting the door on my true self. And I would be living a compromise and my soul would die. That's what it felt like" (Barbara, 51). Up to this point, Barbara had not had an intimate relationship with a woman. She said that 
this aspect did not really bother her. What was important for her was "the selfidentity thing".

Falling in love with someone of the same sex was a commonly narrated catalyst for adopting a strategy of acceptance, particularly for female participants who 'crossed over' later in life. Lesbians, as Troiden (1989: 59-60) notes, are more likely to define themselves in emotional contexts than gay males who typically arrive at homosexual self-definitions in socio-sexual contexts. These gender variations, he suggests, can be attributed to patterns laid down during sex-role socialization (Troiden 1989: 6o). Women also, according to Floyd and Bakeman (2006: 289), tend to experience the milestones related to awareness and self-identification at older ages than men and are more likely to have had heterosexual experiences early on and to have identified as bisexual at some stage. Several male participants, who 'crossed over' later in life did, however, also define themselves in more romantically orientated contexts. Greg (aged 55), for example, did not 'come out' as a gay man until he was aged 44. He had a series of quite long-term relationships with women including one that lasted for twelve years. Greg said he suspected that had it not been for the AIDs epidemic during the 1980s he might have 'come out' sooner. It was the intensity of the feeling he experienced upon meeting and falling in love with another man, though, that finally meant that he could not, as he put it, "pretend anymore".

Consistent with the rite of passage metaphor, the later-in-life experience of 'crossing over' often precipitated at junctures that could be described as a 'crisis'. Cheryl, for example, was married for 17 years. When aged about 31 she had a "major breakdown and got into some major therapy". Soon after this episode she began to study acting and it is here that she met and fell in love with a woman who would become her partner for the next ten years. As a consequence, Cheryl decided to leave her husband, a decision which she described as, "the hardest [...] I've ever made in my life. It was extremely difficult ... he really loved me and I broke his heart". Cheryl, however, said she could not deny her feelings. "Being with a

\footnotetext{
${ }^{21}$ Floyd and Bakeman's (2006: 288-289) research suggests that Barbara followed what is termed an identity-centred sequence of development whereby self-identification as a non-heterosexual occurs before any specific same-sex sexual activity.
} 
woman sexually, I just felt released ... I just thought, 'Oh my god!' ... I know it's well used, about stepping into your own skin, but I just felt completely liberated" (Cheryl, 54). Other participants who 'crossed over' similarly described the affinity they felt with their first same-sex sexual experience: "the feeling of coming home was very strong"; "Oh, this is what it is about for goodness sake"; "the first time I slept with him it felt like I had come home. It felt completely natural. There was nothing forced about it at all. It was wonderful"; "Everything made sense, everything clicked, it all fell into place. I realised, you know, what had been going on”.

Positive changes in social attitudes towards homosexuality also no doubt helped make some participants' 'crossing over' more comfortable. Bill (aged 8o), for example, emigrated from England to New Zealand in 1956. He said he had always been aware that he was sexually attracted to males but said New Zealand seemed a very narrow, conservative country back then. He married a few years after arriving and went on to have two daughters. After he had been widowed for six years, Bill became involved as a volunteer for the AIDS Foundation. He said he knew someone who was HIV positive and wanted to do something to help, but also did not see any reason why he should spend the rest of his life alone. As he put it, "volunteering for the Foundation I was sure to meet other gay men". Indeed, it was at a party associated with the Foundation that he met and fell in love with his future civil union partner, Evan.

Although the particular trajectories that participants followed varied greatly, an ideal of "authenticity" was a common underlying factor in their decision to ultimately assume an identity as a non-heterosexual (Taylor 1994). According to Charles Taylor, the notion of "authenticity" - of being true to oneself and one's own particular way of being human - arose along with the idea of an individualised identity at the end of the eighteenth century and, since then, has "burrowed very deep into modern consciousness" (1994: 30). "Authenticity", he suggests, "is a powerful moral ideal that accords importance to a kind of contract with the self, with one's own inner nature, which it sees as in danger of being lost, partly through pressures toward outward conformity" (Taylor 1994: 30). In this sense, adopting a strategy of acceptance as a non-heterosexual ultimately meant 
for participants honouring their essential self, their own originality, but also meant taking a corresponding stance against the heteronormativity of wider society.

\section{NARRATIVES OF LIMINALITY}

Having at least partially detached from an identity that no longer appears viable, the non-heterosexual enters the liminal or 'betwixt and between' phase. The liminary is essentially between established social categories: "They can no longer take their heterosexual identity as given, but have yet to develop a perception of themselves as homosexual" (Troiden 1989: 53). Whilst the liminal phase is marked by a sense of disorientation and ambiguity there is, however, also the possibility of new perspectives. In this sense liminality is both destructive and constructive and it is from this phase that the subject emerges personally transformed, having assumed an identity as either a gay man or lesbian. The liminal phase is, therefore, potentially a chaotic time as the liminary is no longer governed by clear cultural scripts. It is also a period of reflexive scrutiny where normal limits to thought, self-understanding and behaviour are unravelled. The liminal phase in 'coming out' is in many ways consistent with what Anthony Giddens (1991: 143) refers to as "fateful moments". Fateful moments are "transition points which have major implications not just for the circumstances of an individual's future conduct, but for self-identity" (Giddens 1991: 143). The decision to 'come out', once taken, will as, Giddens explains, "reshape the reflexive project of identity through the lifestyle consequences which ensue" (1991: 143).

\section{Self-discovery and the quest for like others}

The liminal experiences that were most elaborated upon in participants' narratives were those to do with self-discovery and a quest to find 'like' others. Social contact with other gay, lesbian or bisexual people plays an important role in this phase and positive contact facilitates homosexual identity formation (Troiden 1989: 61). When a lesbian or gay male gains access to a non-stigmatizing, supportive gay person or community they have the opportunity to obtain information about homosexuality at first hand. "Direct positive exposure provides a basis for reexamining and re-evaluating their own ideas about homosexuality, and for seeing 
similarities between themselves and those labelled 'homosexual"' (Troiden 1989: 61). Once the emerging lesbian or gay male sees that 'like' others lead good, useful, positive lives, the meanings attributed to the homosexual script begin to change in a more favourable direction and the problems of isolation and identity confusion begin to recede (Plummer 1981: 100; Troiden 1989: 61).

Although Jason, for example, was always clear on his sexual orientation, he did not assume a gay identity until after he had finished his university studies and was working. He said he probably could have 'come out' a lot earlier but that "it just didn't seem terribly convenient" [laughing as he said this]. A gay friend from university, whom Jason held in high regard, became his 'like' other, and was who he confided in about his sexuality and the challenges that being gay presented. Upon the recommendation of his friend, Jason joined a gay support group and through his attendance gained the confidence he needed to commit to a gay identity and to eventually disclose this identity to his parents.

Many other participants also found that university provided them with opportunities to make social contact with 'like' others as well as a more generally non-stigmatizing and supportive environment conducive for exploring their sexuality. Nick (aged 47), for example, described his first few years at university as an exciting time of self-discovery in which he "flowered, as it were". Marcus (aged 40) also recalls that it was during his time at university that things began to "click into place" in terms of his sexuality. The resources and information available to him while studying helped him to realise that his sexual attraction for other males was in fact relatively 'normal' and that these feelings were unlikely to ever dissipate. It was also while at university that Marcus first 'came out' publicly.

I'm probably the only person who came out by power point [laughing.] When I was asked at university - I was lecturing identities to the senior psych students and we had a lecture on gay identity so I thought that would be a good place to do it. And so it was quite spectacular! Yeah, it went down very well. And I did the same lecture for the next five years [...] so that was kind of quite cool.

For several participants, moving to a big city was integral in their quest to find 'like' others. Discovering what Kath Weston (1998: 36-37) refers to as "the gay 
imaginary" depends upon access to print, television, and other media and facilities that disseminate gay-related material. Prior to the communication revolution initiated by the Internet, these resources were generally most accessible in urbanbased areas (Weston 1998: 36). Geoffrey (aged 67), for example, grew up in provincial Hawke's Bay during the 1950s. He said that at the time there was limited information and opportunities to connect with 'like' others and he "escaped" to Wellington at the first opportunity. Geoffrey described the somewhat clandestine nature of the gay scene he encountered on arriving in Wellington:

There was the Dorian Society which I didn't join, partly because the people I got to know were very anti the Dorian because it basically meant acknowledging publicly that you were gay if you belonged to that club. And in those days, the police were hot on the trail as well. In fact, the very first [gay] party I went to in Wellington was raided by the police. I thought, 'oh god, here we go; one week out of Hawke's Bay and I'm going to end up in the clink!' [laughing]. So, that's how it was. And of course in those days, it was the good old six o'clock closing in the pubs. So I went to the pub after work, found out where the party was, go to the bottle store and buy something, and off you went in a taxi. That's how it was all done in those days.

For some participants, the anonymity of city life, or another country, also provided freedom for personal exploration. Dominic (aged 48), who had grown up in New Zealand, said he waited until he got to London before he really explored his sexuality. Released from the normal constraints of home and without the fear of bumping into people who knew his family, Dominic found himself with an unusual amount of license to perform in ways normally socially tabooed (Turner 1985: 160; La Fontaine 1985: 165). As he described it, "that was my time"; I was "almost a little bit promiscuous really". For Michael (aged 45), who had grown up in the United Kingdom, moving to the United States was the 'prerequisite' he needed to explore his sexuality. It was, however, back in the United Kingdom that he ultimately found his community of 'like' others.

It was wonderful! I had run away from the UK to go to the States; I had a job there. I thought maybe if I go over to the States it will be different, i.e. I won't be gay. And I went over there and that was the first time I had bought a gay porn magazine. And I was looking at it and thinking, 'Christ this is me, this is what 
fires me up!' And so I stayed there for about 18 months, on and off. But I thought, 'I don't want to be here, I want to be in the UK'. And so I came back to the UK. I think I must have got back on a Thursday and on Friday evening I went and saw a film up in London called 'Maurice' [...]. And I watched it, I was transfixed and I just sat in the cinema and watched it a second time. And on the Saturday morning I said, 'I am a gay man'. And that was it. I just made that shift. [...]. And then in fact on the Saturday night I went down to Croydon, just South of London. There used to be a gay and lesbian theatre company called Lesbian and Gay Sweat Shop and I went out to see a performance of a play called 'This Island's Mine'. That was a contemporary play and there were lots of same-sex couples in the audience who were just doing normal things. And there were images in the play of couples kissing, snogging, having sex and everything and I thought, 'yeah, this is me, this is my life'. And that kind of cemented the decision that I had made on the Saturday morning and that was it.

A link between second wave feminism and lesbianism is well known and for most female participants was described as an important part of their identity. Becoming involved in feminism during the late 1970s was for Colleen (aged 62) the catalyst for her 'crossing over'. At the time, Colleen was married with two young sons. She began attending women's conventions and reading feminist literature which broadened her thinking and introduced her to new possibilities for selfunderstanding. Soon after, she met and fell in love with a woman. Colleen described being with a woman for the first time as making "a lot of sense".

I thought: 'oh, no wonder I have not been able to do it right and do everything right'. And the feeling of coming home was very strong. 'Oh, this is what it is for goodness sake. Why didn't someone tell me? No wonder I felt so awkward and so out of it.' But even looking back from that point, when it clicked into place, is what it felt like even in my teenage years where I was in love with my best friend. So was everybody, but for me the emotional depth had always been with women. And I just thought everyone felt that way, but of course I don't think they did looking back.

Colleen's involvement with feminism continued. She was part of a small group in Napier which she described as the "vanguard of the woman's movement". They organised women's gatherings and were, reportedly, viewed "as quite out there". 
Whilst there was extensive support for being feminist, Colleen recalls there being little support for being lesbian: "It wasn't hard but it wasn't that supported either". Other participants, like Becky mentioned above, also commented on a perceived lack of support from heterosexual feminists, which no doubt contributed to the eventual formation of lesbian-specific feminist groups.

Discovering a certain salience in social categorization - both in terms of accessibility and fit - is also necessary in assuming an identity as a gay man or lesbian. As Troiden points out, even with an innate orientation to homosexuality "people [must still] construct their sexual feelings to the extent that they actively interpret, define, and make sense of their erotic yearnings using systems of sexual meanings articulated by the wider culture" (1989: 45). For several participants, finding a salient fit in terms of 'like' others was described as something of a challenge. Becky (aged 54), for example, somewhat in reverse to the urban migration mentioned above, left the big city of Auckland to attend university in provincial Palmerston North. Compared to Auckland, Becky said Palmerston North was a "desert politically". She also had little in common with the few other gay people she encountered there.

There was one sort of butch-femme lesbian couple, and some terrible old poofs. So really extreme gay men [laughing] who were using kind of old models of how relationships should be. And so that wasn't feeding my soul, if you like.

Back in Auckland however, Becky met some "quite outspoken and articulate ... very clever lesbian women who were involved in the gay liberation movement". These women not only helped broaden Becky's thinking around gay issues, they also presented possibilities for being lesbian that held greater personal salience. After moving back to Auckland more permanently, Becky then flatted in a lesbian household that as she recalls had "some ... prominent advocates and so on living in it”. These women also provided Becky with affirmative role models.

These were people who stood with straight spines and spoke to the world about who they really were, and didn't cringe away and follow some stereotype of what was still probably expected of gay and lesbian people. A lot of those older women back then had been diagnosed with mental disorders because it was actually still 
at that time a psychological disorder. [...] So I mean people still thought we were nuts and lots of those women had actually had ECT and all sorts of things to try and change their minds. But I suppose also they were living lifestyles outside of [mainstream] society, and so had been... well, had had difficult lives and so probably quite a lot of them had been through depression ... and lots of women were drinking, that sort of stuff. So I probably drank quite a lot, but never mind [laughing].

For several other female participants, their biggest barrier to assuming a lesbian identity was a perception that you had to be 'butch'. As Jenny (aged 44) explained, What was happening in the late '7os and early '8os was a lot of young women, when they came out, did several things: they shaved their hair off, they got a tattoo, they got a motorbike and they 'outed' themselves to everybody they could think of as aggressively as they could [...] It was a statement of fact. And it's like, that is so not me.

Jodie, similarly, said she had an issue with identifying with her local lesbian community. At the time, Jodie wore dresses and heels and did not feel that she fitted the 'butch' 'dykie' image prevalent amongst the lesbians she was meeting. Jodie (aged 46) also found the 'closeted' nature of the lesbian scene in Christchurch during the 1980s very off-putting: "Back then it was seedy, awful little places. Awful pubs, awful sort of locked up nightclubs and stufflike that".

Although organised religion has never been openly supportive of homosexuality, it was for Martin where he found his salient fit in terms of 'like' others. As he recalled,

I did meet a number of gay men within the church, other clergymen. In fact my first contacts with the gay community were within the church. And there's a whole network of gay clergy throughout the country and there still are and I'm still in touch with that network, even years later. And so that's really how I made that connection. And then before I was ordained, I'd been away to England and done a bit of a trip and stuff and felt more confident about myself and so I decided I didn't want to be ordained without being up front with the Bishop. So I went and the Bishop was Sir Paul Reeves. So I went and talked to him and said, 'Look, I'm gay, and if you're going to ordain me you need to know that's who I 
am.' And he said, 'Oh well that's alright then.' And we chatted about various things and so that was quite a good start for me. Not everybody subsequently has been as accommodating but he was very positive (Martin, 57).

\section{Changing significance of 'community'}

While the idea of a sexual community may be a fiction, for most participants it was a necessary fiction that ultimately enabled and empowered them. As 'members' of an imagined community, people feel an attachment to a necessarily fictional group be it nation, race, gender, class, or sexuality. As Weeks observes,

[I]t provides the context for the articulation of identity, the vocabulary of values through which ways of life can be developed, the accumulated skills by which new possibilities can be explored and hazards negotiated, and the context for the emergence of new social movements and political campaigns (Weeks 1996 cited in Weeks, Heaphy and Donovan 2001: 88).

Not all participants, however, viewed the idea of a sexual community as equally significant. Younger participants generally did not consider a gay community to be as necessary as older participants did. Jason (aged 33), for example, commented that he had never really felt at home in a specifically gay scene and nor did he see it as particularly necessary: "I think it's all a bit desperate really. It's not necessary. I think we're reasonably well advanced or progressive in this day and age". Will (aged 65) and Geoffrey (aged 67), for their part, recalled somewhat nostalgically the clubs of the "olden days" where gay people across a range of generations congregated and intermingled. Commenting on how things had changed, Geoffrey remarked,

There's not the same necessity to have a gay club or gay bar - it's not illegal. Once that law change went through, it's gradually watered down, hasn't it? Most of the young ones don't see any point in going to a [gay bar]. They say, 'no, we just go to a bar'.

Growing up in an era where it was illegal to be gay fostered a subversive culture and lifestyle and generally encouraged a stronger, albeit clandestine, bond within the gay community. For a gay man, being potentially the subject of discrimination and ill-treatment also meant that sexuality became the most defining aspect of his identity. For those who grew up in a post homosexual law reform era the stigma of 
sexuality was, by comparison, largely removed. No longer was it necessary to live a subversive lifestyle and being gay became just one among many aspects making up a person's social identity. As Will (aged 65) commented,

They [younger gay people] don't have the restrictions about where they go as we did. They choose their friends. The sexuality aspect is not quite so important to them as it was - or still is - to us. They're not quite so community oriented. Yeah, because they've grown up basically in a really free society where they can't be stigmatised so much ... and they can be more open about themselves from a young age.

Where narratives of separation were marked by innate feelings of difference and isolation, narratives of liminality were marked by a sense of belonging or connectedness. Although initially disorienting, liminality was generally narrated as a positive experience whereby initial strangeness and disorientation gave way to familiarity and a sense of internal congruency.

\section{NARRATIVES OF INCORPORATION}

It is during the last phase of a rite of passage that the internally transformed subject makes their status socially salient. The incorporation phase corresponds to what Troiden (1989) refers to in his model of homosexual identity formation as the commitment stage. The main characteristics of the commitment stage, he suggests, are self-acceptance and comfort with the non-heterosexual identity and role (Troiden 1989: 63). Commitment in this sense has both internal and external dimensions. Commitment is indicated internally by positive increases in the perception of non-heterosexual identities and its salience for the self. Commitment is indicated externally by the formation of same-sex love relationships, deliberate disclosure of the 'new' non-heterosexual identity to non-homosexual audiences, and a shift in the type of stigma-management strategies employed (Troiden 1989: 63). The incorporation experiences narrated by participants reflected both the internal and external dimensions of commitment referred to by Troiden (1989). Incorporation at an internal level was narrated in terms of feeling at home with their new sexual identity and integrating this feeling into other aspects of their identity. These narratives were characteristically marked by a sense of relief at 
realising their true authentic self, and an associated feeling of relative fulfilment. Narratives of incorporation at an external level most commonly referred to 'coming out' to family and, in particular, to parents and were generally associated with sometimes powerful feelings of anxiety, usually stemming from a fear of familial rejection, discrimination and even violence - all experiences that can, as Herek (1991: 146-147) comments, "have enduring psychological consequences" on the individual.

\section{Internal incorporation}

Whilst I did not wish to 'label' my participants I did ask each of them how they defined or referred to their sexual identity. Social identities, as already discussed, are largely social creations that we make up from a 'tool kit' of options made available by our culture. The particular labels we adopt reference particular cultural scripts (Weeks, Heaphy and Donovan 2001: 43). Given the range of terms used in reference to homosexuality, I was interested in understanding which terms had greatest resonance and what meaning participants attached to particular labels. Sexuality labels also often hinted at intersections with other aspects of identity such as culture, gender, and politics and, furthermore, highlighted how self-descriptions change over time.

Most men in this study generally identified with the term 'gay' although two males said they also used the term 'queer' on occasion. The terms used by female participants were more varied and included 'lesbian', 'dyke', 'queer', and 'takatāpui'. Those participants who employed the term 'queer' tended to be younger, to have had opposite-sex relationships as well same-sex relationships in their lifetime, had a history of activism, and/or generally avoided essentialising labels. They said they preferred the term 'queer' because it did not "fix" people too rigidly along lines of sexuality or gender. 'Queer' was also described as more "inclusive” and "encompassing" - as denoting a community that included lesbian, gay, bisexual, transgender, and inter-sex people rather than one or the other. The term 'queer' was also perceived as having political connotations. The "re-claiming" of a word that has traditionally meant odd or unusual was seen as a means of selfempowerment for those oppressed by the heteronormativity of wider society. 
Older participants, by comparison, considered the term 'queer' derogatory. Geoffrey (aged 67), for example, stated that he "hated" the word 'queer'. "You know that in our age bracket it was a putdown”. Will, Geoffrey's partner, added, in a somewhat vehement tone, that people used to shout out to them, "You fucking queer! So we don't like that term at all. We were conditioned by our childhood. Young people today grow up always being legal so they haven't got the same connotations associated with different words that we have”.

Although several participants had previously been involved in heterosexual relationships and marriages, very few participants employed the term bisexual when describing their sexual identity and even then only to refer to their sexuality in a "technical" sense. Becky, for example, explained that from a political perspective it was not prudent to identify yourself as bisexual, "because you're neither one thing nor the other". Another participant who referred to the term in her narrative did so only to comment on how "badly colonised" she thought the term had become.

For Māori participants, the term 'takatāpui' provided an intersection between culture and sexual identity. According to Clive Aspin (2005), the term 'takatāpui' was first recorded in 1834 in the Williams Dictionary of the Māori Language and was used to refer to "an intimate companion of the same-sex". Evidence that "precolonial Māori society embraced and celebrated sexuality in all its diversity", including same-sex relationships, has, according to Aspin (2005), been found in artworks (mostly carvings), written documents and oral accounts. Other Māori, however, refute this claim, asserting that takatāpui relationships were merely tolerated. In a contemporary context, the word takatāpui has been reclaimed and is used to refer to a person who is Māori and either gay, lesbian, bisexual, transgender, or transsexual. Takatāpui, like the term 'queer', is therefore gender neutral but also provides an intersection between sexual orientation and culture that other 'labels' do not and this was the reason given by Māori participants for using the term. 
One Māori participant, Yvonne, reported having been involved in setting up a group for takatāpui some years back. She said the group provided an opportunity for takatāpui people to reconnect with and express their culture either through language, kapa haka or te kanga. Many takatāpui, according to Yvonne, felt they had to choose between their Māori community and their 'queer' community. In the pākehā-dominated 'queer' community they had to "down play" their Māori culture and politics and on the marae they had to suppress their 'queer' identity. In recent years, takatāpui has grown in profile aided no doubt by Māori Television hosting a magazine-style programme called Takatāpui. The programme is a vehicle both for showcasing takatāpui people and for exploring takatāpui-related issues. Māori, however, are still divided over the place of takatāpui in Māori culture. Marama said her Māori mother's family were quite accepting of 'queer' sexualities whereas her partner Deb reported that her Christian Māori mother thought it "unnatural" and a "sin".

Sexuality also intersected with gender and politics in the way participants positioned themselves. Marama \& Deb were both keen to point out that whilst they defined themselves as takatāpui they were also feminists. Māori politics was also described by Yvonne as an important aspect of her identity and, indeed, had been a focus in her career. Most participants in this study self-identified as having a left-leaning political orientation and even those who identified as politically conservative reported being passionate about human rights issues and gay rights issues in particular. Some participants reported having been actively involved in campaigning against issues of oppression (e.g. women's rights, gay rights, apartheid, legalising abortion, the Vietnam War) and several participants had actively participated in the Civil Union Bill campaign. I return specifically to trajectories of a socio-political nature in chapter six.

\section{External incorporation}

'Coming out' to 'straight' others brings the issue of sexuality to the forefront; it involves taking a stand against, what Weeks, Heaphy and Donovan refer to as the "heterosexual assumption" - the "all-embracing institutional invalidation of homosexuality, and presumption in favour of heterosexuality" (2001: 41). It also 
potentially involves taking a stand against significant others' understandings of who you are. Within the overall 'coming out' narrative, accounts of disclosure to family were in ascendance and generally assumed the form of a 'ready-made' story one that has been told over and over because the occasion represents a key experience (Bönisch-Brednich 2002: 11). ${ }^{22}$ Taylor provides an insight into why the experience of 'coming out' to family might evoke such a powerful emotional response. Because we define our early identity in dialogue with, and sometimes in struggle against, what our family want to see in us, they always hold a significant role in our lives. Even after we have outgrown our parents, or they have disappeared from our lives, the conversation with them continues within us as long as we live (Taylor 1994: 33).

Experiences of 'coming out' to parents were variously described as "traumatic", "disastrous", "really difficult" and often as initiating a period of "fall out". Many participants reported that they had delayed telling their parents about their sexual identity as long as possible. In some instances disclosure to parents was precipitated by another family member threatening exposure if they themselves did not "confess". In other instances, disclosure was hastened by a parent confronting them with their suspicions. Michael's mother, for example, rang him at 6am one morning demanding to be told what his "preferences" were. When he replied that he preferred men his mother reacted by exclaiming, "Oh dear, I am never going to be able to speak to the neighbours again" and then slammed down the phone. Michael did not hear from his mother for about three months so decided to go and see her. His mother described his sexual 'preference' as "dreadful", "a waste", and "a shame" and, although not a practising Christian, claimed that "it was against God's will".

For a few participants, self-disclosure to parents was motivated partly out of respect for their committed intimate relationship. Dominic (aged 48), for example, said he made a special trip back to New Zealand when he was 31 years old to inform his parents that he was gay and that Max was not simply a man that he boarded with in London but his partner. Dominic's mother, upon hearing the

\footnotetext{
${ }^{22}$ Weston also observes in her study that 'coming out' to 'blood relatives' often generates a powerful emotional response second to none (1991: 43).
} 
news, apparently collapsed and was untypically emotional. His father, standing on the periphery, responded by exclaiming, "how could you do this to your mother?!"

Many participants described their parents' reaction to their non-heterosexual disclosure as a "process" often involving initial shock, fear, rejection and/or denial, but also eventual acceptance. Heather (aged 39) said that her "religious" family had found her admission of lesbianism "really difficult to cope with". As she recalled,

Mum said, 'don't come home till you change back to the way you were'. [...] It caused a bit of a rift between my sister and me [too] because she didn't back me up to them. She [Heather's sister] said, 'you've ruined Christmas'. It all happened around Christmas. [...] And then it probably took about another three or four or five years before Mum and Dad could really talk about it or sort of acknowledge it.

Emile (aged 41) also reported that his family had initially taken the news "very badly" when he announced at age eighteen that he was gay, but had since come to terms with his sexuality.

Yeah, I [...] had major arguments [with my parents]. My father kicked me out of the house but then regretted it. So one week later [he] called me back. But it left a big impression in my mind. I took a long time to forgive them for that. But now it's over. It's all fine. I had years to prepare myself for that and suddenly they had to adjust in a few weeks. So I can understand their side.

According to Stewart (1993: 74), many of the fears that parents have for their lesbian, gay or bisexual children originate from stereotypes that have been unconsciously absorbed and come to be believed as factual. 'Coming out' forces parents to relocate their child within the wider social narrative. Where the characteristics central to a gay collective identity have been viewed negatively this mindset may have a destabilising effect on how they view their now gay-identified child. In order for them to see their child once again with dignity, they must - just as the non-heterosexual initiand had to do - recode the larger gay collective identity according to more positive life scripts. Parental grief over a child's disclosure is, according to Stewart (1993), more often for themselves than their child and, in many cases, is to do with the thought that there will be no grandchildren. Several of my participants did indeed report that expressions of 
parental grief had been one of the first reactions they had encountered, particularly from their mothers. Only one participant in this study, however, specifically reported experiencing lasting rejection. As he explained, "I don't have a relationship with my mother; she's homophobic. So that ended about eleven years ago or so" (Marcus, 40).

Narratives of disclosure varied across generational cohorts, reflecting dominant socio-political views and cultural scripts of their time. For those participants born during the 1940s, making a non-heterosexual identity socially salient generally did not refer to 'coming out' to 'straight' others. Rather, disclosure at this time referred primarily to a person's entrance into the gay world. As Will (aged 65) pointed out,

You had to be really cautious. We were actually criminals and could be arrested and thrown into prison. And it happened. Although, we were open to our friends, but you were still cautious. It depended on who you were talking to, whether you were prepared to divulge ... to make it obvious what your sexuality was or your relationship was.

Will recalled that he had never 'come out' to his family. Even when he brought his partner Geoffrey home to meet his family he simply referred to him as a "friend" leaving them to draw their own conclusions. Derek (aged 67) said he had tried on several occasions to tell his mother that he was gay but she had refused to listen. As he explained, "She knew, but she didn't want it confirmed". Geoffrey (aged 67) managed to 'come out' to his parents but said that "neither of them could get their heads around it; Dad sort of because he'd been in the war and had seen something of that sort of activity while he was away in the air force, but my mother didn't have a clue!"

Becky (aged 54) came out to her parents in the 1970s while in her first year at university. She described the experience as "pretty disastrous" overall. According to Becky, her parents had very conservative views. Her mother, in particular, had grown up in a very religious family and had lived a very sheltered life.

Mum certainly engaged at a very [laughs] intense level to try and convince me that I was completely ruining my life, and that I'd been seduced by these awful 
older women and - they didn't actually exist at all, just in her head [laughing]. Yeah, she probably had grown up with this sort of horror of this terrible sexuality, this homosexuality thing, and had no idea what it was actually like. I mean, she had never known anybody who was 'out' as a gay person or whatever. [...] So I think her concept was this is something that happens. You get molested in a toilet or something or other, and that's what homosexuality's about. [...] So that was pretty scary.

Becky said she felt very isolated and cut adrift from her mother who had, until her 'coming out', been very close and supportive of her: "She was really proud of me and so on, doing well at school and university, and in sports teams and so on. This just wrecked everything. It took a long time to get over that."

For Brandon (aged 27) who grew up in a post homosexual law reform era, disclosing his sexual identity to his parents at age 15 was a comparatively painless experience. His very liberally-minded parents were more than accepting when he announced to them that he was gay and, although he was initially a bit fearful about 'coming out' to his school friends, they were in fact quite accepting and supportive when he did eventually tell them. Brandon still recalled the incident of 'coming out' to his parents with some vividness:

My father was driving me home from work or something. I was working at Pak ' $n$ ' Save [...] and there must've been some kind of argument and I sort of just blurted it out: there! I don't know... I wanted to cause some drama and stir it up, you know. It wasn't sort of a heart-rending moment of pouring out my emotions. It was more like, I'm going to slug this against you and see what happens. And their response was typically liberal. It was, 'Oh no that's fine, I completely understand. If you ever need a chance to talk...' And I'm thinking, 'damn it!' I would rather have had some hysterics or some sort of big explosion. And that was that really.

For Max and Colleen, who were both married with children at the time of their 'coming out', the process was somewhat different from other participants. Their most significant disclosures were to their spouses and, when they were old enough to understand, their children. Colleen's sons were aged eight and nine years when she left her husband for a woman. According to Colleen (aged 62), her 
sons were not particularly disturbed by the change in circumstances or by their mother's change in sexual orientation. As she explained,

At that age, kids are worried about practicalities rather than anything else. They didn't think it was at all funny [strange] that it was me and Barb [her new partner at the time] who were together rather than me and a man.

At the time that Max separated from their mother, his eldest son was aged three years and his youngest son was aged just six months. Max said that part of his agreement with his ex-wife had been that his sons should not be informed of his sexual orientation until they were "old enough to ask questions". In hindsight, Max (aged 52) believes that not 'coming out' to his children until they were in their teens was a mistake as they had by that stage already been exposed to homophobic attitudes both in the playground and through the media.

They had already internalised this demonised view of gay men as perverts and child chasers and brown nosers and faggots and things [...]. And suddenly they wake up one day and realise their dad's gay.

Max recalled that his sons had each rejected him for about a year after finding out: "They were angry. Why did all the other boys in the playground have ordinary normal dads and why did they have a gay dad?" Max said that when his ex-wife became a born-again Christian, his sons' attitudes towards his gay identity once again turned "topsy turvy". "Suddenly I became the pervert, this quite demonised person. And that was probably much harder for me to deal with. I was very judged; very distrusted". At the time of his interview, Max reportedly had a very close relationship with his eldest son, but did not have any contact with his younger son.

In addition to the often negative responses they received from family members, some participants recalled encountering negative or homophobic responses from friends and work colleagues. Many of these responses derived from a negative perception of gay men and lesbians as deviant and/or as paedophiles. Jody (aged 35), for example, said she was "banned" from seeing her neighbour's Down syndrome daughter once they found out she was "romantically" involved with another woman. As Jody recalls, her neighbour believed she was no longer "safe" 
to be around their daughter. Jill (aged 45), similarly recalled feeling worried about disclosing her 'new' sexual identity to her best friend; "That's because she has kids and people have stereotypical reactions to gay people and kids. It's the bizarrest thing". As a strong swimmer, Garth (aged 52) said he had once thought he might like to be a swim instructor but had immediately abandoned the idea because of the common perception that gay men are child molesters. His partner Derek added,

The thing that would [...] concern me about the swimming [...] is that you are actually touching the child [...]. And you only have to have one child who does the 'Peter Ellis' thing on [you] and you are in deep trouble. ${ }^{23}$

Due to the heteronormativity of mainstream society, 'coming out' to straight others is not by any means a discrete process but rather involves continuous disclosure to an expanding series of audiences (Troiden 1989: 65). Unlike a typical rite of passage, then, the metaphorical incorporation phase in 'coming out' is an on-going process.

\section{Civil Union And the SElF}

Gay men and lesbians, as Adam Isaiah Green (2010) astutely observes, undergo a "dual socialization". Initially, as a young person, they are socialised within the "dominant, heteronormative meaning-constitutive tradition" and later, by virtue of their sexuality, into a more subversive "queer meaning-constitutive tradition" that includes norms and practices that depart from and innovate upon dominant heteronormative practices (Green 2010: 428). Green (2010) borrows the term 'meaning-constitutive tradition' from Gross (2005) which is worthy of brief explication. In analysing the traditions that shape behaviour, Gross (2005) makes an analytic distinction between 'regulative' traditions and 'meaning-constitutive' traditions. Regulative traditions, he suggests, are marked by the threat of exclusion from the moral community in which one exists (Gross 2005: 296).

\footnotetext{
${ }^{23}$ In June 1993 Peter Ellis was found guilty on 16 counts of sexual offences involving children in his care at the Christchurch Civic Creche and was sentenced to ten years' imprisonment. This outcome has been strongly criticised with concerns centering on how the children's testimonies were obtained and presented to the jury. Ellis has always maintained his innocence and many New Zealanders have supported calls to overturn his convictions.
} 
Meaning-constitutive traditions by comparison arise internally as a person comes into being through interaction with the cultural and linguistic components of their society (Gross 2005: 296). While both traditions shape social action, meaning-constitutive traditions do so by establishing limits on what may be expressed to oneself and others in a given situation. Meaning-constitutive traditions therefore influence the "thinkability" of particular acts and projects. As Gross explains, "[t]hey provide agents with the semiotic resources out of which their meaningful action, including instances of meaningful novelty, must be painstakingly built up" (2005: 296). Meaning-constitutive traditions are, therefore, part of the cultural 'tool kit' of options out of which we make up our identities (Appiah 1994).

Although gay men and lesbians are dually socialised, they do, however, live with and alongside heterosexuals and heteronormativity and are, therefore, in significant measure, subject to the latter's socialising properties (Green 2010: 427). Evidence of both heteronormative meaning-constitutive practices and queer meaning-constitutive practices were apparent in the narratives that participants constructed around self-identity, their intimate relationships and their civil union ceremony. Following Green (2010), I argue that participants arrive at civil unions with a foot anchored in each of these traditions. Some participants, however, had more weight on the foot in 'heteronormativity' while others had more weight on the foot in 'homosexuality'.

For many participants, 'marriage' was a powerful meaning-constitutive practice and a major motivating factor in their desire to a have a civil union. As Emile articulately expressed it,

Maybe we define relationships in terms of marriage less and less, but traditionally a relationship had to be somehow recognised officially through marriage. And somehow civil union is a little bit like that. [...] A wedding or marriage is a little bit more than signing a bit of paper, as we know. It's simply more than that. And I think a civil union could be a little bit like that as well. [...] It's being part of a club, fitting in a little bit as well. I don't know ... We grow up with this kind of idea that people get married and a wedding day is such a big day, you know, it's 
your day. In tradition, I'm talking about; I don't think that everybody kind of believes that now, but there is a subconscious kind of mapping.

When a person comes to accept an identity as a gay man or lesbian they may also, as Herdt and Boxer note, have had "to give up previously internalised heterosocial life goals" (1992: 19). This relinquishing process, they suggest, may "involve some 'grief work' and mourning as previously held expectations of marriage, heterosexual parenthood etc. are replaced with new expectations, ideals and ambitions" (Herdt and Boxer 1992: 19). Several participants, such as Marcus (aged 40), did indeed recall that when they had 'come out' they had also had to come to terms with the fact that they would be unlikely to ever marry.

When you come out [marriage is] one of the things [...] you realise that you are not going to have. You are not allowed to have marriage so you kind of grieve for that and you lose all that. [...] You kind of put it away from yourself and it's quite hard; you can't have the white picket fence and the two and a half kids and the big party wedding thing or the engagement and rings and things. So, I don't know, it's a cost. And then to start talking about it again, it was quite weird.

For many participants, the establishment of civil unions - the only comparable template presently available to non-heterosexuals - provided an opportunity to fulfil aspirations established through early socialisation. For Lara (aged 32), entering into a civil union with Hailey was described as a "natural progression":

It just felt like the right thing to do. Probably just that stupid 'straight' thing where you just get engaged and get married. [...] Yeah, I would admit, I'm quite kind of straight-laced and a little bit conservative like that. And it's just [...] like anybody else, you just get married.

As a cultural model, marriage is both a meaning system and a practice. It is guided by laws that establish who may marry and when, it communicates something about the nature of those relationships, and provides a framework for how these relationships should be celebrated and lived out. As a meaning-constitutive tradition 'marriage' brings psychosocial benefits and protections "that bears in significant ways upon the self, the dyad and one's relationship to the larger social order" (Green 2010: 416). For many participants, entering into a civil union created 
the same sense of order and meaning that a marriage would and provided a structure for future life plans.

Marriage in most Western societies is generally no longer viewed as part of the maturation process as it once was. It was interesting, therefore, that a number of participants situated their civil union in the context of developmental or life-cycle processes. Participants, particularly those in longer-duration relationships or whose motivations for having a civil union were pragmatically based, were often surprised by the transformative effect of their civil union. Brad (aged 44), for example, articulated it as follows:

There are certain rites of passage that mark different changes in one's social status with age or your social role and you know there are some traditional ceremonies around initiations... And I feel like my social standing has changed in the process [of entering into a civil union]. I feel older somehow. I don't know, it's funny. I felt that I went from being some bachelor boy kind of thing with the boyfriend to someone middle aged and married. [...]. It's so uncanny. And that's where I think there's this deeper layer that neither of us was conscious of until [we] got deep into it really.

For participants who had lived much of their adult life either closeted or on the margins of society, a civil union represented a dramatic increase in social incorporation and a corresponding demarking of difference. Ross (aged 62), for example, described feeling as if he was "entering into a much bigger framework that includes the whole world";

I'm part of that now. I'm not marginalised as a poof or whatever. I'm in a civil union. Now I'm part of that framework that the government established. The Labour Government established that possibility that people like us could be in the frame along with everyone else.

Incorporation into mainstream society also signalled a positive recoding of the once negative life script of the gay individual which in turn contributed to a positive sense of identity and self-worth. As Martin (aged 57), put it:

It's that social recognition I think. When I went and filled in the form [at the Births, Deaths and Marriages office] I was surprised how it affected me. And I 
think that's what it was, suddenly I thought, 'gosh I'm in the mainstream here, this is what people do'. And I never thought I would do that. I didn't never want to do it, but I just didn't think I ever would. And so I found myself doing it and I thought, this seems quite nice to feel acknowledged.

For some, their civil union precipitated a whole new level of 'outness' and a corresponding increase in social incorporation. Deb (aged 48), for example, narrated the following story:

So the badminton lot, I've been playing with them for 3 years [...] and we are quite chummy, quite close. We go away on trips and things like that but I've never 'come out' to them. I've never told them. They all know Marama. Marama's been playing badminton but I've never ever said Marama's my partner. She's just [my foster son's] other aunty. And so, anyway, one of the woman at badminton, I told her we were getting a civil union on such and such a day. And, anyway, when we got back from our civil union, we came home and there was a bunch of flowers sitting on the doorstep. And it was like from the badminton club. [...] And I thought, 'far out', because they didn't run screaming from the room which [...] can be part of your experience. [...] And then when I got back to badminton [...], you could see some of them were a little bit squeamish but in general people were coming up and saying, 'congratulations'. [...]. And it's been quite nice. [...] I can be more inclusive with Marama in things and stuff. [...] So, I'm more 'out' and I think it happened by accident really. I hadn't even anticipated those consequences.

Rather than being a passive act of conformity or assimilation on the part of the gay individual, incorporation instead signals that the boundaries of wider society have shifted to accommodate gay and lesbian relationships. Same-sex love thus becomes socially and culturally acceptable and, indeed, something worthy of celebration. A same-sex civil union ceremony ultimately embodies the sexuality of the couple, making it something to honour and share rather than hide. In this way a civil union ceremony moves beyond simply treating same-sex couples with equal dignity, despite their being gay ("for this requires a concession that being gay counts naturally or to some degree against one's dignity"), and respects them as a same-sex couple (Appiah 1994: 162). 


\section{CONCLUDing COMMENTS}

In this chapter, I have explored the process of identity formation as a gay man or lesbian or, what is more commonly referred to as 'coming out'. Using rites of passage as a metaphor, I examined how participants made sense of their own 'coming out' and how for some their civil union marked another stage in this ongoing process. Troiden's work on homosexual identity formation illuminated participants' narrated experiences while a life course perspective captured the more dynamic variables associated with the formation of a non-heterosexual identity. I have shown how gender, socio-historical context and life-stage identification as a non-heterosexual each worked to shape participants' particular experiences of 'coming out'.

In exploring the significance of the civil union at the level of the individual, I have argued that for many participants 'marriage' was a powerful meaning-constitutive tradition and a major motivating factor in their desire to a have a civil union. A civil union - the only comparable template presently available to nonheterosexuals in New Zealand - provided an opportunity to fulfil aspirations established through early socialisation. The civil union in turn created a sense of order and meaning for the individual and a structure for future life plans. Others experienced their civil union as greater incorporation into mainstream society and a corresponding positive recoding of the once negative gay life script. In celebrating and affirming same-sex love, I have argued that the civil union ceremony moves beyond simply assigning legal equality to same-sex relationships to respecting them as a same-sex couple.

Commitment to a homosexual identity is, as discussed above, externally indicated by deliberate disclosure of the non-heterosexual identity to significant 'straight' others. It is also, according to Troiden (1989), indicated by the formation of samesex love relationships. A same-sex love relationship, he suggests, is not only an external sign of commitment to homosexuality as a way of life, it is also "a concrete manifestation of a synthesis of same-sex emotionality and sexuality into a meaningful whole" (1989: 65). 'Love' relationships more generally, though, are also important crucibles for the on-going formation of identity and self and, as 
late modernity theorists claim, are often also the locus of a 'meaningful life' (Taylor 1994: 36; Giddens 1991, 1992; Beck and Beck-Gernsheim 1995). It is these intimate 'love' relationships that I examine in the next chapter. 


\section{4}

Trajectories of the Intimate

\section{INTRODUCTION}

In this chapter I explore the dyad relationship at the level of partner interactions and the significance of the civil union within this particular trajectory. Before having a civil union was even potentially on the table, the couple had to reach a stage in their relationship that was characterised by love, some degree of commitment, and some expectation of a continuing relationship. Through participants' narratives, I examine how couples met and got together, how their relationship has evolved over time and what aspects of their relationship they have considered to be of particular importance for securing relationship durability. I then examine how and why participants came to the decision to have a civil union and what shifts if any have occurred in their relationship as a consequence.

Through my analysis I engage with theories of 'late' modernity, particularly as they relate to intimate relationships. According to key social theorists on the topic (see for example, Bauman (200o), Beck and Beck-Gernsheim (1995), Castells (1997), and Giddens (1991, 1992)), intimate relationships between heterosexual romantic/sexual partners have, in recent decades, been undergoing profound changes. Although differing in emphasis and orientation, these theorists largely attribute these transformations to processes of "detraditionalisation" (Gross 2005). Central to these detraditionalising processes is, as mentioned in chapter two, the relative decline in power inequality between the sexes, specifically in terms of assumptions over natural gender differences, marriage as the locus for procreation, and the tradition of male dominance within households tied to a gendered division of labour (Gross 2005: 287). As Giddens observes, "In a world of increasing sexual equality - even if 
such equality is far from complete - both sexes are called upon to make fundamental changes in their outlooks on, and behaviour towards, one another" (1992: 7).

Gay men and lesbians have not, by comparison, been subject to the same detraditionalising processes as heterosexuals, "for they have had to 'get along' without traditionally established frameworks of marriage, in conditions of relative equality between partners" anyway (Giddens 1992: 15). As a result, gay couples have, according to Giddens (1992: 15), preceded most heterosexuals in developing intimate relationships, in the sense the term has come to assume today. In this way Giddens sees gay and lesbian couples as the "pioneers", the "prime everyday experimenters" who have forged new paths for heterosexuals as well as for themselves (1992: 135). Emerging from this general restructuring of intimacy is what Giddens (1992: 58) refers to as the 'pure relationship'. The pure relationship is characterised by emotional and sexual equality. It is a partnership entered into for its own sake and lasts only as long as both partners are satisfied with the rewards they get from it (Giddens 1991: 90). The pure relationship is not tied to an institution such as marriage or necessarily to the desire to raise children. Rather it is "free-floating", independent of social institutions or economic life (ibid, 89). The pure relationship exists primarily in the realms of emotion and self-identity. Here, love is experienced as contingent and confluent and the relationship is negotiated in terms of a friendship ethic. In the absence of more 'traditional' external anchors, intimacy and commitment have become the new basis for securing relationship durability as well as the extent to which couples are able to create and maintain "shared histories" and integrate their "life plan calendars" (ibid, 97).

Many of the attributes characteristic of the pure relationship were indeed implicit in participants' narratives of couple relationships, and as a concept it is useful for interpreting and understanding the bases of partner interactions. However, the choice of participants to enter into a civil union to some extent conflicts with Giddens' notion of a pure relationship in which he sees 'marriage' becoming "just one lifestyle among others" (Giddens 1992: 154). Following Gross (2005), I argue that by not distinguishing between two analytically distinct forms of tradition - 
'regulative traditions' and 'meaning-constitutive traditions' (discussed in the previous chapter) - Giddens fails to adequately account for the ways in which 'tradition' remains of central importance for some people. While the regulative practices around marriage have declined, for many people - including many of my own participants - the image of the form of couple-hood inscribed in this practice continues to function as a hegemonic ideal in many intimate relationships (Gross 2005). In this way, people are free to choose from a 'tool kit' of options that incorporates both 'traditional' and 'modern' components. For gay men and lesbians there is also the added choice between heteronormative meaningconstititve practices and queer meaning-constitutive practices.

At the level of partner interactions, love and commitment were the most commonly narrated motivations for couples to want a civil union. A growing commitment to the dyad relationship was also often an outcome of the civil union. I argue that the civil union strengthens the dyad relationship in a number of ways. Premised on lifelong partnerships, the civil union reduces commitment ambiguity, creating for some participants a more stable relationship environment. For other couples, the reality of their commitment was enhanced through its public witnessing. As a 'key experience' the civil union also creates an important 'memory' in the couples' 'shared history' and further entwines the partners' 'life-plan calendars'. In this respect the civil union acts as an external anchor and forms a barrier to relationship dissolution.

\section{Narratives of Meeting and Getting Together}

Ideals of 'romantic love' and intimacy permeate contemporary Western society and, according to some late modernity theorists (see Beck and Beck-Gernsheim 1995; Bulcroft, Bulcroft, Bradley and Simpson 2000; Lindholm 2001), have become the central focus of personal life. In an increasingly rationalised and depersonalised world without direct institutional regulation, the need for a 'significant other' with whom hopes and fears, gains and losses can be shared, becomes increasingly important as the antidote to anomic modern living. A pervasive ethos of expressive individualism, furthermore, makes intimate relationships a salient part of individual identity. While 'detraditionalisation' has on the one hand freed modern 
individuals from previous constraints and obligations, it has, however, also brought with it a "profound loss of inner stability" (Beck and Beck-Gernsheim 1995: 46). Questions such as 'Who am I? Where did I come from? And where am I going?' have become central to self-identity and finding answers to these questions an increasing source of stress (ibid, 47-48). 'Leading a meaningless life' has, as Beck and Beck-Gernsheim observe, become "the predominant malady of the present day" and 'love' relationships increasingly a panacea - a crucial source of meaning and security and the basis for person-related stability (1995: 50). In this way, love and identity have become closely intertwined. As Alberoni writes, being in love has become "the search for one's own destiny ... a search for one's own self to the very bottom" (1983 cited in Beck and Beck-Gernsheim 1995: 51). For non-heterosexuals, an intimate relationship is, as already mentioned, of further significance in that it is also an external sign of commitment to a homosexual identity and way of life (Troiden 1989: 65).

Today, a high proportion of mass culture and media centres thematically on "nonrationalised love relationships and an elaboration of the romantic ideals of spontaneity, emotional intensity, and relationship permanence" (Bulcroft, Bulcroft, Bradley and Simpson 2000: 65). Alfred Gell (2011) indeed suggests that modern love would be "unthinkable without fiction, and romantic fiction in particular". Popular fiction, he explains, is what has replaced the traditional ties that once structured relationships. Rather than representing real life after the fact, fiction, he suggests, precedes and guides the actions of real-life lovers; it provides the 'scripts' for forming and conducting love relationships in a late modern setting (Gell 2011). Research indicates that people are also unlikely to settle for anything "less than a relationship where they feel a considerable amount of romantic love for their partner" (Whitehead and Popenoe cited in Gross 2005:302).

Gay men and lesbians are exposed to the same dominant culture as everyone else, so it is unsurprising that they too draw heavily on ideals of intimacy and romantic love when narrating the significance of their relationships. Stories about how couples in this study met and got together were recalled vividly and frequently assumed the form of a 'ready-made' story: one that has been recounted over and 
over because it represents certain key experiences and, through the process, has assumed a structure that conforms to "popular forms of storytelling" (BönischBrednich 2002: 11; Green 2004: 11). These stories were symbolically significant in that they represented the 'genesis' of the intimate relationship and were the basis on which the couple began to build a "shared history" (Giddens 1991: 97). In recounting these stories it was also apparent that participants were, to some extent, 'reliving' the emotional intensity they had experienced in the early stages of their union.

Couples variously met either by chance, through mutual friends, affinity groups or work, or at gay-specific events. Meeting at gay-specific events was significant in that it dispelled uncertainty - at least in terms of others' sexual orientation - but also provided a non-judgmental environment for same-sex 'romancing'. Some couples had developed friendships first whilst for others attraction was much more immediate and often accompanied by an intuitive feeling that this relationship was "special" or "the one". Derek, for example, recalled feeling "love at first sight" when he met Garth at a mutual friend's party. Garth in turn said that within an hour or two of meeting Derek he was already thinking, as he described it, "Oh, this is what I'm looking for". At the time, Garth was in New Zealand on vacation. From their first meeting, it took just ten months for Garth to move to New Zealand from the United Kingdom so he could share his life with Derek. On the fourth anniversary of their first meeting, Derek \& Garth celebrated their civil union at their home in the presence of friends and family.

Evan \& Bill similarly described how their first meeting was accompanied by a strong attraction and an intuitive feeling that this relationship was "special". They narrated a story of how they had met at a garden party for volunteers of the AIDS Foundation.

Bill: Everybody all took a bit of food and there was this guy in the kitchen doing things with rye bread and asparagus ... And anyway, it was a social, pleasant occasion. And I was busy chatting to someone, and I was aware after a while of this man next to me and this sort of electric vibration. And it was Evan. And, to cut a long story short, he [Evan] said to me, 'Well would you go home via Ngaio?' 
Go home via Ngaio? The man's mad! [laughing as he said this as he lived some distance away in the opposite direction]. And he [Evan] got into his car, and I thought, 'well I better get his address anyway'. I got his address, and came back via Ngaio.

Evan: And he didn't leave [laughing].

Bill: I did eventually go home. I had to go home, you know, and put the cat out [laughing.] So that was it, basically. It was wonderful. Yeah.

At the time of their interview in 2010, Evan and Bill had been together 24 years. They celebrated their civil union on the $1^{\text {st }}$ May 2005 just five days after the civil union legislation was enacted.

Marcy \& Barbara's attraction to each other, which they subsequently attributed to a deep spiritual connection, preceded any formal introduction. Marcy recalled that she had observed Barbara at a few lesbian events and had felt "incredibly drawn" to her. Barbara also recalled feeling "uncomfortably attracted" to Marcy. They met at a lesbian dance they both happened to be attending. They recalled that, during the dance, they had gone for a walk along a nearby beach, which Marcy described as "like a speed dating situation”. During their walk they shared life histories and discovered that they both had children, as well as various other "extraordinary connections". Three weeks after their 'walk on the beach', Barbara "popped the question":

We were in my kitchen and I was holding you [Marcy]. And I just looked into your eyes, and it's like I'd known you forever and ever in a million lifetimes, in different guises, and it wouldn't have mattered what gender you were, what shape you were, what colour you were, whether you were disabled or not. It was like the soul was eternal. And I just remember feeling overwhelmed by that. [...] We both felt that something much bigger than either of us was drawing us together and that it was a gift [...] and we could take the gift or not [...] I think I said something about how I could live with you for the rest of my life and you said, 'Well, you haven't asked me' [laughing] (Barbara).

Barbara moved in with Marcy the week before Christmas 2007 and on the 29th February 2008 - a leap year - they celebrated their civil union with close family and friends. 
Yvonne \& Loana's attraction was ignited over a game of Chinese checkers at a lesbian event. They met up several times subsequently before deciding to have what they referred to as a "one night stand". This "one night stand" was, however, sufficient for Yvonne to decide that Loana was "the one" for her, compelling her to finish the relationship she was then involved in.

That night after Loana fell asleep and I lay awake, I knew that was it. I knew she was the one. I knew it was forever. And so the next day, I rang up my partner [at the time] and said, 'nah, it's all over. It's finished.' I packed up all her [expartner's] stuff and I said to her, 'you move it all out' [...]. It was done, it was clear (Yvonne).

Loana moved in with Yvonne a couple of weeks later and in February 2006 on the $14^{\text {th }}$ anniversary of the day they met they celebrated their relationship in a civil union.

'Love at first sight' is, as Gell (2011) observes, an extreme instance of the 'scripted' characteristic of modern romantic love. In many ways it is also an 'ideal type' for modern love in the sense that it is both arbitrary - not anchored in external referents - and, as some of my participants' narratives indicate, seemingly predestined. Brad \& Marcus, for example, narrated the following story:

Marcus: We were on holiday in the Manawatu Gorge. And it was a semi-dry creek, river bed and there were thousands of these rock things around so we were both scuffling around looking at rocks. [...] So, Brad got a rock and I got a rock and we brought bits and pieces back that we found and we were just talking about stuff. And then we realised that we had two halves of the same rock! Hundreds of metres apart and we had found two halves of the same rock!

Brad: It has always been a sort of reminder when things get rough and we feel like killing each other as you do in relationships. So, whenever I'm thinking, 'I'm out of here, this is no good' then I kind of think about the rock and I think, 'hang on, maybe...'

Marcus: So that's kind of a metaphor for us.

In an era marked by an ethos of 'choice', the notion of predestination helps diminish anxiety or doubt over whether one has made the 'right' choice of love partner and is not missing out on some potentially greater opportunity. As Brad \& 
Marcus's narrative indicates, it also inhibits reflexivity and the interrogation either of present or future destinations, thus providing a barrier to relationship dissolution.

For some study participants, 'love' was experienced in less emotionally emphatic or instantaneous terms and more as something into which they grew. Will \& Geoffrey, for example, met through mutual friends in London in 1965. Although they "hit it off" immediately and soon after made the decision to move in together, Will said that 'being in love' developed more gradually.

Will: As far as I was concerned, there was never any moment of, you know, celestial angels singing and I'm deeply in love with somebody, and all the rest of it. It didn't happen like that with me.

Geoffrey: I didn't hear any angels either [laughing].

Will: The longer we stayed together, the more emotionally involved I got, without actually consciously thinking about it. So falling in love is something, I don't know what that's like, because I... I grew into it, rather than fell into it. ... I mean you watch the romantic comedies or movies and so on and people meet and light bulbs explode and all the rest of it. And none of that. So, I don't know how Geoffrey felt but no...

Geoffrey: Just sort of happened in a way.

Will \& Geoffrey marked their $40^{\text {th }}$ anniversary together in October 2005 by formalising their relationship in a civil union ceremony attended by close friends and family.

For several participants, their sexual identity was inextricably linked to their samesex love relationship. Neither Paige nor Cathy, for example, had a same-sex relationship prior to their getting together and, indeed, had never even considered that they might possibly be gay. They met through their work and became flat mates for a year before "anything happened". They said they had immediately "clicked" as good friends and found that they had quite a lot in common. While attending a music concert together, Cathy \& Paige crossed the line from a platonic to a physically intimate friendship. Paige departed for her sister's wedding in Australia the very next morning leaving them little time to talk over what had 
occurred the night before. After an anxious and somewhat confusing week for both of them, Cathy joined Paige in Australia for a holiday. Seeing each other again at the airport was described as a "critical moment" punctuated by nerves and anxiety about in what if any direction their relationship would proceed.

Cathy: I remember coming down the escalator and seeing you [Paige] and you were smiling and I was smiling and that was that, yeah. That was okay. We were both happy.

Paige: Big hug right in the middle of the airport [laughing].

For Cathy \& Paige their 'falling in love' marked a turning point in terms of their sexual identity and ultimately became the catalyst for 'coming out', both to themselves and later to family and friends. Within six years of becoming an intimate couple, they then formalised their relationship in a civil union attended by family members and friends.

For Bridget, meeting and falling in love with Becky precipitated her 'crossing over'. At the time they met, Bridget was in a relatively long-term heterosexual relationship. Becky, by comparison, had been 'out' as a lesbian for several years and at the time had "open" relationships with two other women. Bridget recalls that around this time she had started thinking that she would like to "try a girl sometime. And this boyfriend, being quite sort of hippie-ish, liberal, you know, said, 'oh yeah, that'd be cool'. So that was fine, 'Off you go. Get yourself an interest' ... So I did."

Bridget perceived Becky to be non-threatening to her existing relationship and someone with whom she could have "a bit of fun", so initiated a casual affair between them. Bridget, however, soon found that her "bit of fun" and experimentation had become much more than that.

We had just an amazingly physical startling affair really. Yeah, which started out as just being all about sex, which was really lovely and way superior to anything I'd experienced before. And then just became such a kind of physical attraction, you couldn't avoid thinking about. I just wanted this proximity for my lifetime.

Becky, for her part, found that she had "fallen completely in lust and love with Bridget". She said she had always thought of herself as a liberal person who was 
capable of open relationships but found with Bridget that she suddenly felt incredibly jealous.

So it wasn't good for me. And I was thinking, how long? How many months am I going to be tortured with this before she just leaves me and goes back to him [the boyfriend] permanently?' ... I thought, this is really gonna hurt.

Despite the risk, Becky resolved to continue their affair for as long as Bridget was happy to do so. Six months later, after a weekend away together, though, Bridget decided that she wanted to spend time with Becky on a more permanent basis. After breaking the news to her boyfriend and selling the house they owned jointly, Bridget moved in with Becky. In June 2005, they celebrated 19 years together in a civil union at their home in the presence of family and friends.

Giddens (1992) argues that in a culture where individual self-fulfilment and growth become the primary standards by which intimate relationships are judged, older, more traditional narratives of romantic love, which stress obligations of lifetime commitment, are giving way to a new ideal - that of 'confluent love' which he also sees as characteristic of the pure relationship. Romantic love, as Giddens (1992: 61) defines it, involves projective identification of 'amour passion', as the means whereby prospective partners become attached and then bound to one another. Confluent love, by comparison, depends upon intimacy for its continuance (ibid, 61). Here, intimacy presumes the mutual disclosure of emotions which the individual is unlikely to hold up to a wider public gaze (ibid, 139). Unlike romantic love, confluent love cannot be taken for granted; it is both active and contingent and, as such, jars with the 'forever' and 'one-and-only' ideals of the romantic love complex (ibid, 61). Giddens indeed links the prevalence of separation and divorce in late modern society to the emergence of confluent love as "it is a feature of the pure relationship that it can be terminated, more or less at will" (ibid, 137). Confluent love presumes equality in emotional give and take and, here, love only develops to the degree to which intimacy does, to the degree to which each partner is prepared to be vulnerable to the other (ibid, 62). Unlike romantic love, confluent love has no specific connection to heterosexuality (ibid, 63). 
On the latter point alone, one might expect confluent love to be in ascendance in participants' narratives. However, as already demonstrated, romantic love was an important meaning-constitutive 'script' for many, playing an important role in structuring at least the early stages of their relationship (Gross 2005: 286). This can in part be attributed to the dual socialisation process discussed in the previous chapter, but as Gross notes, the romantic scripts of today have also become more androgynous; less about "the coming together of fundamentally dissimilar [gendered] partners and more the notion of a fusion of souls in which partners who share certain lifestyle tastes and aspirations can become one" (2005: 304). In this respect, romantic love scripts have become more salient for gay men and lesbians rather than less so. The dominance and salience of romantic love as a cultural script was clearly illustrated by Becky. As a "staunch feminist", she was surprised that romance formed such an important tenet in her relationship with Bridget and had required a significant shift in thinking on her part: "I grew up on feminist text, Germaine Greer, where romance is complete bullshit and absolute rubbish and so on. And so, I'm afraid I had to get over that, cos I actually really fell in love and felt very romantic towards Bridget".

While many participants drew on the qualities and ideals associated with romantic love, aspects characteristic of the pure relationship were, however, also evident in these same participants' narratives, particularly when describing the basis of their relationship and accounting for its durability. Giddens (1992) himself notes that the projected identification associated with romantic love may sometimes set up the longer-term pathway to confluent love. Bulcroft, Bulcroft, Bradley and Simpson (200o), however, provide a more comprehensive answer. Rather than fragmenting under the pressures of late modernity, romantic love has, they suggest, become more dominant than ever. Society, they argue, has "blurred and melded traditional components of romance with contemporary standards of rationality" (Bulcroft, et al. 2000: 87). The romantic script is, they suggest, indeed one of the few surviving incentives for the institution of marriage (Bulcroft, et al. 2000: 87). 


\section{Narratives of Relationship Progression}

In the absence of predefined gender roles and without the traditional framework of marriage, gay male and lesbian relationships have had few external references governing how they should be structured. These relationships, therefore, generally tend to involve a greater degree of self-invention and personal fashioning than heterosexual relationships. Whilst this freedom may be framed as liberating it can, however, also make the task of achieving homeostasis within the relationship all the more challenging. In this section, I explore how couples' relationships have evolved over time and what aspects of their relationship they considered important as a basis for securing relationship durability. I argue that a friendship ethic, commitment, reciprocity and expressive individualism were an important basis for many participants' relationships and in this way were consistent with many features characteristic of the pure relationship (Giddens 1991; 1992).

\section{'Scripts', role models and stereotypes}

Frank \& Bryan met in Auckland during the 1970s when they were aged 17 and 21 respectively. They recalled that they had been fortunate enough to have met quite a number of same-sex couples in long-term relationships. These couples provided them with affirmative same-sex relationship models and created an expectation that it was possible for them as gay men to also have a long-lasting partnership just as their parents had.

So it never seemed to us, even though publicly it was difficult and in terms of legally it was impossible, but in terms of just living your life it was not strange for us to think that we would not live a life together. I mean, early on we thought that we would live together forever like you do when you are young. And suddenly like 35 years have gone by (Frank).

Frank \& Bryan's experience described above was, particularly for the time, somewhat untypical. Although much has improved since homosexual law reform, the range of scripts or models specifically available for same-sex couples has been vastly more limited than those available for different-sex couples (Blasius 1994: 191). Those that were popularly portrayed were mostly negative. Indeed, the stereotypes perpetuated throughout much of the $20^{\text {th }}$ century, that gay men are 
promiscuous, predatory and paedophiles, meant that relationships between homosexual men had largely been played down or ignored by mainstream society altogether. The classification of homosexuality as illegal, furthermore, generally discouraged gay couples from being open about their relationships so negative stereotypes went largely unchallenged. Lesbians, by contrast, were seen as more likely to form couple relationships given their different sexual and emotional needs, but the prevailing climate of homophobia meant that these relationships too remained largely invisible (Weeks, Heaphy and Donovan 2001: 104).

The liberalisation of New Zealand laws on homosexuality in 1986 led to the formation of more open same-sex relationships which, in turn, provided more visible models for others. Since the 1990s, there have also, according to Weeks, et al. (2001), been a growing number of texts published on same-sex relationships. These texts "seek to affirm the reality of and validity of same sex partnerships and to explore the subtleties and complexities of non-heterosexual relationships" (Weeks, et al. 2001: 104). Gay male and lesbian couples are also increasingly a feature in popular fiction and are frequently being depicted as committed, stable, family units. ${ }^{24}$

One stereotype that has to some extent prevailed is the butch-femme model: the assumption that lesbian and gay male relationships imitate the gendering that occurs in heterosexual relationships whereby one same-sex partner assumes a pseudo-masculine role while the other partner assumes a pseudo-feminine role. Marcus, for example, mentioned that he frequently encountered societal pressure to categorise his partner and himself according to gender stereotypes and recalled the surprise he had often witnessed when people met Brad for the first time:

There is a lot of pressure out there, people wanting to stick you in a box. And people will meet Brad, [...] they'll meet him for the first time, and they'll say, 'oh, he wasn't what I expected'. And I'll say, 'what did you expect some...' What they are trying not to say to be rude but is what they actually mean is some little blonde, feminine, cutesy, girly thing. They can't figure out that we both are big

\footnotetext{
${ }^{24}$ Recent examples include the gay male couple in the American sitcom Modern Family who adopt a child and the lesbian couple in the movie The Kids are Alright who had two children by donor insemination.
} 
hairy blokes you know. It doesn't kind of fit the stereotype. So, one of us has to be flapping Nellie to make it work (Marcus).

Most lesbians and gay men do not, according to Herek (1991: 163), play rigid "husband/wife" roles such as in decision-making, sexual behaviour, and in the division of household tasks. A few female participants did, however, use butchfemme metaphors to describe how gender definitions shaped their identities and relationships. Loana, as mentioned in the previous chapter, had from a young age thought of herself as "your typical sort of tomboy; butch you know". Yvonne \& Loana had the most noticeably 'gendered' relationship in my study and indeed used explicit butch-femme metaphors throughout their interview. Loana not only appeared more 'butch' or ‘tomboyish' than her partner Yvonne, she also assumed the more stereotypically male roles such as proposing 'marriage'. Her friends were also referred to as "butch mates" and her pre-civil union celebration with friends was described as her "stag night", the term normally associated with the groom's pre-wedding ritual. At their civil union, the butch-femme metaphor manifested itself most visibly by Loana wearing a trouser suit and Yvonne wearing a soft, flowing dress.

The use of butch-femme as a template in lesbian relationships is, however, far more complex than a simple imitation of heterosexual gender roles and, according to Laird (2000), can constantly change in meaning. Many lesbians, she suggests, "use the butch-femme metaphor [...] consciously, creatively, and playfully performing gender and sexuality in ways that are not rigid or constraining but that may be freeing in terms of mastering new learnings [...] or to add spice and innovation to sexual expression" (Laird 2000: 461). Jenny \& Beth, for example, recounted an incident which clearly illustrates a conscious performance of 'butchfemme'. The setting for their story was a theatre where Jenny was involved in building a stage and putting up a lighting rig for a show.

Jenny: We've mellowed over the years but at that stage I was doing butch with a capital 'B'. I mean, really short hair and I was very, very fit and very masculine and stuff.

Beth: Yeah, you probably had a tool belt on that day too. 
Jenny: And [Beth] said she'd bring me lunch. All of the other girls that were on the crew were having fish and chips.

Beth: And then my wicked streak cut in.

Jenny: Beth walked in with a little red riding hood basket with a red check tablecloth on it with egg sandwiches with the crusts cut off.

Beth: I did it deliberately.

Jenny: And I'm hanging from this piece of scaffolding by my belt hanging lights from it. Anyway, [when Beth goes to leave], she says 'Love you' [makes three kissing sounds]. Oh dear!

Beth: I knew you had a sense of humour [laughing].

Laird also points out that what is “one woman's butch is another woman's femme, as gender performance is relational, exists in the eye of the beholder as well as the performer, and is always mediated by race, social class, local context, historical time, and other factors" (2000: 461). Amongst male participants, there were suggestions of 'gendering' but this tended to be less performance-based and more to do with variations in personality and propensity to emotional expressiveness.

Without culturally defined and often rigid gender norms, same-sex relationships tend to have a greater commitment to equality than 'traditional' heterosexual relationships (Herek 2006: 610; Weeks, Heaphy and Donovan 2001: 111). Cohabiting same-sex couples are also, according to Herek, "less likely than heterosexual couples to divide household labour according to culturally defined gender roles. Instead, each partner often takes on both traditionally masculine and feminine tasks" (2006: 610). In his study of gay Christian relationships, Andrew Yip (1997: 36-37), identifies two patterns in the division of household labour. The first is an 'equality pattern' whereby tasks are shared and the second is a 'specialization pattern' whereby partners take on specific tasks that suit their individual aptitudes. Yip's (1997) patterns resonate with my own participants' accounts. Male participants, in particular, appeared to adopt the second pattern mentioned by Yip (1997). Brad \& Marcus, for example, said they had what they referred to as their "islands of expertise". "I mean, I do the housework and ironing but at the same time I do the plumbing and painting. Brad does the accounts but at 
the same time he does the cooking. So I think it's divided up the way it fits. It's not such a gendered thing" (Marcus).

Without a history of gender inequality to put right, gay male and lesbian relationships also have, as Giddens (1992) observes, more latitude for exploring attitudes and traits that would normally be 'prohibited' within the pure relationship. Incidences of instrumental control and dominance, when confined within the sphere of sexuality and turned into fantasy, become permissible and may even, as Giddens points out, help to neutralise aggression, which might otherwise make itself felt elsewhere (1992: 144).

\section{Commonalities and a friendship ethic}

Whilst attraction and/or 'love' were frequently described as the basis for couples getting together, they generally did not attribute their relationship's on-going success to these dimensions alone. Some attributed the success of their relationship to having similar interests and enjoying each other's company, others to their shared values and goals in life. Will \& Geoffrey articulated this aspect succinctly:

Will: We obviously got on very well. We knew that from number one. Apart from being sexually compatible we enjoyed each other's company. We had similar views and that, and we had similar backgrounds. And we were both, in a way, colonials in London.

Geoffrey: Yeah, but it was also the fact that when we both said what we wanted in the future, was to meet someone and grow old with them, sort of thing, and we both had the same [goals]. So, having been bought up in different parts of the world, the values we were brought up with were basically all the same. So that made a difference too.

For Marama \& Deb, being feminist Māori women from similar backgrounds was described as a significant aspect in their relationship durability: "you don't have to explain yourself you just connect all the time ... so it's just easier" (Deb). Before meeting Marama, Deb had several relationships with women all of who were "white". She recalled the feelings of conflict and resentment she experienced in one particular relationship. 
The girlfriend that I was with, she grew up on a farm; her father got a ballot farm. That land was taken off Mãori people to give to those soldiers who came back from the war. ... Māori came back from the war and had no land and got nothing, sort of thing. So you can't help but experience that resentment, feel resentment every time you go up and visit on their farm. You see the privilege that she got: she got sent to St. Cuthbert's [a private school] up in Auckland and the privilege that she was able to have because of that. So there would always be that sort of conflict if you like. And then there was the lack of understanding by her [the girlfriend] as to why I felt that way, sort of stuff.

Deb also added that, being politically Māori "it's really not a good look" when "you go drag your blond, blue eyed girlfriend along". "So really, that's why the relationship finished after two years because you couldn't keep going. So, you don't have to worry about that with a Māori woman".

Marama \& Deb also attributed their relationship's success to the fact that they had been able to "evolve" both as individuals and as a couple over the 21 years that they had been together. They met and became "really good mates" through a Māori craft design course they were both enrolled in. During the first two years of the course, Deb had been in a relationship with another woman while Marama had been in a relationship with a male. After Deb's relationship broke up she mentioned to Marama that she was going to a hui for Māori women where she hoped to find herself a new girlfriend. Marama recalls thinking, "that [girlfriend] could be me! ... And that was kind of like when I thought, I kind of realised, that I like her [Deb] a whole lot and I could 'come out' with her, sort of thing". At the course end of year party Marama \& Deb became intimate friends. Twenty-one years later, in June 2008 they formalised their relationship in a private civil union.

For some couples, having a sense of progress or momentum was described as important. Bryan \& Frank, for example, said they had projects that they worked on together or goals that they set and then jointly worked towards: "we have always had projects to do whether it was travel, whether it was buying our farm, whether it was politics. We've always had projects which we've worked on together" (Bryan). Frank also attributed the longevity of their relationship to their strong friendship: "I think we are still like best friends as well. Like, I'd rather spend my day with Bryan 
than anybody else. And he still rings me several times a day, every day and I ring him several times a day".

Friendship was a common theme across a number of participants' relationship narratives. Whilst a friendship model is not universal, lesbians and gay men do tend to combine the need for friendship and romantic love in one person (Blumstein and Schwartz 1983 cited in Weeks, et al. 2001: 120). Similar interests, resources and skills tend to be the basis for a friendship and, as a script, also typically fosters equality and assumes that partners are relatively equal in status and power (Peplau, Venigas and Miller Campbell 1996 cited in Weeks, et al. 2001: 120). Within the context of the pure relationship, though, friendship as an ethic has been elevated more generally and plays an important metaphor in structuring these relationships. Like a modern friendship, the pure relationship is sought only for what the relationship can bring to the partners involved and the connection with the other person is valued for its own sake.

\section{Commitment}

In the context of a pure relationship, trust can no longer be anchored in criteria outside the relationship itself and must, therefore, be mobilised through a process of mutual disclosure (Giddens 1991: 6). Mutual trust between partners is in turn closely related to the achievement of intimacy, which as already mentioned, is a key component of the pure relationship and "a major condition for any long-term stability the partners might achieve" (ibid, 94-96). For a relationship to stand a chance of lasting, commitment is also necessary. Commitment, another species of trust, replaces the external anchors typical of pre-modern heterosexual relationships. Commitment, in this context, is to the relationship as well as the other person (ibid, 6). While commitment can to some extent be regularised by the forces of love, "sentiments of love", Giddens claims, "do not in and of themselves generate commitment, and nor do they in any sense authorise it"; the pure relationship, he suggests, instead relies substantially on elements of reciprocity (ibid, 93). "To generate commitment and develop a shared history, an individual must give of [themselves] to the other. That is, [they] must provide in word and 
deed, some guarantees to the other that the relationship can be sustained for an indefinite period" (Giddens 1992: 137).

Commitment was a common and sometimes recurring theme in all couples' narratives of relationship progression. At a personal and emotional level, commitment usually involved each individual in the relationship acknowledging their desire for relationship-permanence and, usually, a corresponding commitment to working through issues as they arose with a focus on resolution. At a physical or material level, commitment was variously demonstrated either by living together, establishing financial interdependence, buying property jointly, having commitment ceremonies or celebrating anniversaries, and/or by having children.

Many couples reported that commitment had been a feature of their relationship early on and marriage metaphors were frequently used to describe the form that this commitment had taken.

Bryan: We always felt that we were sort of like married really and we behaved like we were. We always had the same bank account and we just shared everything.

Frank: We often also shared clothes, toiletries too.

In describing their lifestyle, Bryan, also remarked: "we have a very conventional life really ... the only thing that is different about us from a very conventional married couple is that we are both men". Bill, similarly, used quite quotidian terms to describe his and Evan's lifestyle: "I think we're just a suburban couple, basically". Lara \& Hailey described themselves as "like two old ladies" and Brandon said he and Jason were "an old married couple pretty much a month after [they] moved in together".

Living together as a couple was usually the first 'physical' demonstration of commitment to the relationship and, as already mentioned, was for some couples something that happened quite swiftly after first meeting. Other couples took a little longer to reach this point. Martin \& Ross's relationship was initially conducted trans-city. After several months of to-ing and fro-ing they decided to 
meet at a location somewhere in the middle. They jokingly referred to this meeting as "the summit" as it was here that they decided the fate of their relationship; that they would make a commitment to go on and be together. Having made this decision, Martin said that his personal and emotional commitment to Ross was clear and absolute.

That meeting we had [...] that's when I decided: am I gonna do this or not? Yes I am. So this is it, and till death us do part really. I didn't say that to myself, but that's what I meant. And so I had that commitment right from the beginning and yes it was a very exciting time at the beginning and then everyday life comes upon you and you think, 'oh my goodness!' ... And over the years, there have been difficult times, but I've never thought that I wanted to change that [commitment]. That's always just been a given for me really'.

Exactly a year after the night when they first met, Martin with all his worldly possessions moved to a new city to begin his life with Ross. To mark their $25^{\text {th }}$ anniversary, they formalised the commitment they had made to each other at their "summit" in a private civil union followed by a celebratory party with friends and family.

Brad \& Marcus had known each other for 18 months before they moved in together. Prior to meeting Marcus, Brad had been involved in a long-term relationship and had been wary of jumping too quickly into another. During the first two years that they lived together, though, they cemented their relationship and commitment to each other. As Brad explained,

We rented that place together for about two years and then in that time we sort of came together a bit more. ... We did it step by step really. It just evolved and clicked into place. ... And then we bought our first house together ... and then everything was just together.

In contrast to Martin's experience, commitment at an emotional level was for Brad \& Marcus described in less conscious or emphatic terms: "It wasn't like a decision you were making; it's something you wake up with one morning and you can't imagine not being together. And, you know, you kind of make future plans that always include the other and suddenly you realise one day that this is it" (Marcus). 
For most participants, sharing was synonymous with commitment and the most significant aspect of sharing was establishing financial interdependence. For Max the correlation between commitment and finances was explicit: "The thing is we're committed; we own this house together, everything we have is in joint names, the cars are in joint names, the savings are in joint names". The decision to merge finances or to make a substantial joint-purchase was described by several participants as representing a significant 'step-up' in their commitment to the relationship. Marcus, for example, compared their decision to merge finances to an engagement.

\section{Because you are gay, you don't have engagements or things like that. ... I can still remember the moment we decided to merge our finances, it was like the bowling club at Mt Eden and we were sitting there and that was the significant moment; that was like the ring or the proposal or whatever.}

Max recalled that his decision to support Dominic whilst he was studying had marked a turning point in his commitment, and had generated a greater sense of stability and permanence in their relationship as a whole.

Jenny \& Beth recalled that they merged their finances quite early on in their relationship. Beth said they would have done so eventually anyway but that disparities in their incomes forced the issue. Although Jenny \& Beth described merging their finances as "the perfectly natural thing to do", they also said it represented "a massive gesture of trust" and the "letting go of independence". Becky said that financial sharing was part of their commitment and the model they used reflected the fact that they considered their relationship to be akin to a marriage; "For me it was like my parents did. [...] For me, it [our relationship] was like a marriage, yeah". Bridget added that she also thought there was something "quite romantic" about it, noting that she had not had this system with her ex-boyfriend; "We just halved and kept track which made it good when we were splitting up".

In her study of income sharing in New Zealand families, Robin Fleming argues that a couple's ideology - "their beliefs about how a couple should live" - has greater influence over their patterns of money allocation than "practical, psychological, socio-economic and ethnic factors" (1997: 38-39). She identifies three basic forms of money-management systems: systems based on the gendered division of 
responsibilities; systems based on common ownership and togetherness; and systems based on financial autonomy. Most of my participants' moneymanagement patterns fell within the second system under the categories which Fleming (1997) labels as "true" and "partial poolers". "Poolers" have joint bank accounts and, according to Fleming (1997), also believe that their income is jointly owned. More importantly, though, they tend to describe their "relationship in terms that emphasise togetherness, mutual support and sharing" and place high value on communication and trust (Fleming 1997: 40-41).

A few participants' money-management systems fell within the third system labelled by Fleming (1997) as "independent with a kitty”. Derek \& Garth were one such couple. They have separate bank accounts as well as a joint account to cover agreed common expenses. For Derek \& Garth their separate bank accounts did not, however, correlate with a 'what is yours is yours' and 'what is mine is mine' attitude. They were clear to point out that their money-management system was much more flexible than the structure implied and in reality they shared everything. Couples adopting an independent money-management system are, according to Fleming, more likely to view their relationship as a partnership between "two independent and autonomous individuals" who have "chosen to live together out of mutual regard" (1997: 43). Whilst all my participants' narratives, to a greater or lesser extent, indicated that they maintained an ethos of individuality within their relationships, Derek \& Garth were most explicit on the matter and, indeed, seemed to celebrate each other's individuality and complementary talents.

Garth: The whole thing works really well. I mean, when we have dinner parties I usually end up doing all the cleaning and getting it all set up. Derek is busy in the kitchen serving food. I mean it all just works. [...] It's just extraordinary.

Derek: I rattle pots and pans and he gets out the bottles. It's great.

Garth: [...] I think it's amazing how it's all sort of come together where we both bring different qualities to the whole relationship. It's so important.

Without the option of legal marriage, joint home ownership was, for many participants, experienced as the most serious level of legal commitment. It also often indicated being open and 'out' as a same-sex couple to a broader circle of 
friends and family. In many instances a joint home purchase also prompted the couple to take additional steps in estate planning. While estate planning formalised their commitment further it was also largely an attempt to gain the same legal protections and rights that a married couple would have. Brad \& Marcus, for example, described the steps they took after purchasing their first home.

Brad: There wasn't any civil union then. The Relationship Property Act wasn't around yet. So, Marcus's family being, well his mother particularly being psychotic and stuff, we were quite careful about setting everything up legally.

Marcus: It took ages layering things so the wills couldn't be challenged.

As well as ensuring protection from outsiders, binding agreements such as wills, powers of attorney, and joint home ownership serve to entwine the couple's lifeplan calendars further and provide at least some disincentive to relationship dissolution.

Before civil unions became an option, many couples had found alternative ways to mark their commitment symbolically. These symbolic markings usually coincided with an agreement on the couples' behalf that their relationship was akin to a 'marriage'. Male couples were more likely to simply exchange rings as a mark of their commitment whereas female couples were more likely to embellish the exchange in a ritualised ceremony. Without a legal requirement for witnesses, these ceremonies were sometimes a private affair with only the committing couple present although, in some instances, couples later "threw" a party to announce their commitment more publicly. For others, their ceremony was attended by a select group of friends and family members. Ceremonies were sometimes timed to coincide with the anniversary of the couple's meeting and, in other instances, became the anniversary itself. The decision to wear rings on the 'wedding' finger not only marked a transition in the couple's relationship but also became a public symbol of their commitment.

Several male participants specifically mentioned in their narratives that sexual exclusivity was a criterion of their commitment. Michael, for example, said that he and his partner had always been clear on this matter, describing it as a "prerequisite": 
[...] not just because of safer sex and lurgies but ... I think I would be jealous as hell if I knew that a partner of mine was seeing someone else. [...] For me, and for Damian as well, it's one of the lovely ways that you can say this is a commitment between two people to the exclusion of everything else. And that was part of our vows. It seems to be very significant. Because there are so many things [...] in this life now, which are free and easy to get. But if you are able to hold on to something that is only for you two that's got to be good.

A subscription to the 'ideal' of sexual "monogamy" stands in contrast to the common cultural stereotype that gay men - even ones in long-term relationships are sexually 'promiscuous'. Worth (2003), however, suggests that "monogamy" amongst gay male couples in New Zealand is not so unusual: of "[t]hree hundred and forty-one men in the Male Call study - just under half the men in relationships of six months or more - were monogamous"25. Like Michael and his partner, many of these men also wanted to "prove" that their long-term relationships are special and different from "the lives of other single gay men by reverting to expectations and ideals of fidelity similar to those of their parents' generation" (Worth 2003: 96).

For other male participants, sexual exclusivity was not or had not always been a feature of their commitment. Martin \& Ross's relationship, for example, had not always been a sexually monogamous one. They described their "being together" as the basis of their commitment rather than fidelity. Calvin \& Ehsan's relationship had for the first eleven years been a sexually exclusive one. With a 20 year age gap, though, and increasing differences in their sexual desires, they said they decided to introduce what they referred to as some "different situations". Ehsan was very clear to point out, though, that they always discussed what they were planning to do and made sure that the sexual liaison was with someone whom the other partner had first met. ${ }^{26}$

\footnotetext{
${ }^{25}$ The Male Call/Waea Mai, Tane Ma study is based on a nationwide survey of New Zealand gay and bisexual men who have sex with other men. The telephone-based survey was conducted between May and June 1996 and was funded by the Health Research Council. According to Worth, the "Male Call study examined the ways in which HIV/AIDS knowledge and safe sexual practice are related to a number of important demographic and contextual variables" (Worth 2003: 33 ).

${ }^{26}$ Herek (1991) also notes that same-gender couples may be more likely to discuss and negotiate the issue of sexual monogamy directly. Many gay male partners, he suggests, "distinguish between sexual exclusivity and emotional fidelity, allowing each other the option of having sexual liaisons with other
} 
We are quite proud that we're not - I'm sorry to say this here but it's true - we're not the normal gay open relationship; do what you like type thing. It's a very discussed situation and we don't ever do anything anonymous. [...] We were getting into routine and we were getting a bit tired of that side of it. Having said that, everything works very well but there's a huge difference sex-wise between Calvin and I. So, we've got that sorted (Ehsan).

Becky \& Bridget were the only female participants in this study to specifically raise the subject of sexual exclusivity. Sexual "monogamy" had not been an explicit feature of the commitment they made to each other in their 1987 ceremony, although it did subsequently come to be an important feature. Because Becky was the only woman Bridget had slept with when they got together, there was a sense that she needed to "play the field" a bit to make sure that her relationship with Becky was really what she wanted. Although they did have a "little experiment" in the early stages with a previous girlfriend of Becky's, their relationship had, however, been sexually exclusive ever since.

In a world of 'plastic sexuality' (freed from the inevitability of reproduction and moulded by the individual) and 'pure relationships', sexual monogamy more generally is not, according to Giddens (1992), a pre-requisite. Rather it is something that has "to be 'reworked' in the context of commitment and trust" (Giddens 1992: 146). Here, fidelity "has no meaning except as an aspect of that integrity which trust in the other presumes" (ibid, 146). Sexual exclusivity may, however, as some of my participants' narratives indicate, still play a role in the relationship to the degree to which the partners mutually deem it desirable or essential (ibid, 63).

\section{Children}

In recent decades, changes in marriage and family forms have been dramatic and have challenged assumptions and beliefs about what constitutes 'normal' families. Single parenting is commonplace and divorce and remarriage have produced a variety of "blended" families (Hull 2006: 4-5). In settings of late modernity, having

males", usually on the proviso that certain rules are followed (Herek 1991: 163). Lesbian couples, by comparison are, according to Herek, more likely to be sexually exclusive (1991: 163). 
children has to a greater or lesser extent become a matter of choice. Like the intimate relationship, children have for some people become a potential source of meaning and small children, in particular, the antithesis to an increasingly rational, efficient, fast, and disciplined world (Beck and Beck-Gernsheim 1995: 106). Deterrents against having children may, however, include "wanting 'a life of one's own', an aspect of an individualized society which used to affect only men and is now spreading to women as well" (ibid, 108). The demands being made on parents have also risen sharply, making having children a potentially expensive and responsible undertaking (ibid, 109).

Amidst this tide of change, lesbian and gay male couples have increasingly sought to establish "viable family units of their own either by acting as co-parents to children from previous marriages or by becoming parents together through artificial insemination, surrogacy, adoption or foster parenting" (Hull 2006: 5). Frank \& Bryan and Cathy \& Paige were the only two couples in this study for whom children were specifically a planned part of their relationship. Having children was in fact, for Cathy \& Paige, one of the first things they had discussed and agreed upon when they formed their intimate relationship. At the time of their interview, Cathy had given birth to a son conceived through artificial donor insemination. Paige, however, was also about to undergo the fertility process using the same donor inseminator. In this way, their children would be biologically related albeit through an absent and largely anonymous father. Frank \& Bryan had three children between them. Their children were also conceived in non-traditional ways, although in their case with a lesbian couple with whom they shared the parenting. Frank had one child with one woman and Bryan had two children with the other. Frank, however, was clear to point out that they considered all three to be "their" children.

Ten participants had children from previous (heterosexual) relationships/marriages. Apart from Max, whom I mentioned in the previous chapter, most participants reported that their children had accepted the news of their 'coming out' reasonably well. For two participants, though, a change in same-sex partner was a source of distress for their children. Jessie's son, for example, was only 18 months old when 
she got together with her previous partner and, through the duration of their relationship, she had become a second Mum to him. When their relationship broke up and Jessie later formed a committed relationship with Gail, her son's "fantasy" that she and her ex-partner might get back together was shattered: "He went through a stage of where it was really difficult for him, and he was very paranoid about Gail and it was hard" (Jessie). Although by that stage an adult, Jessie said their civil union had still had a significant effect on her son.

Jessie: I think it [the civil union] gave him a way to talk about it [their relationship], and it also coincided with him getting older, and then also with meeting the woman that he loves, and we're actually a great combo now as a family.

Gail: We're all good mates, aren't we? It's great.

Several other participants also mentioned that their civil union had made a difference for their children and is a theme I return to in chapter five.

Some participants had made a conscious decision not to have children. Becky, for example, said she would have liked Bridget to have had a child but that Bridget had not been interested. Bridget said she had initially not wanted a child "getting in the way" of their relationship but then later thought she was "a bit too old". She also half-jokingly commented on how "expensive" babies are and that she had not relished the thought of living on one income. Other participants had found alternative ways to incorporate children into their lives. Deb is the legal foster parent of a nephew and Yvonne \& Loana had several nieces and nephews living with them over the years. ${ }^{27}$ Brad \& Marcus said they had two godsons that they spent a lot of time with and also knew two lesbian "mums" who wanted them to spend "boy" time with their sons when they were a bit older. Several participants, however, expressed sadness over not having children. Michael said he would have loved to have had children but that his partner was adamantly against the idea. Emile said he and Robbie had looked into the possibility of adopting a few years back but had found that you could only adopt as a couple if you were spouses, a

\footnotetext{
${ }^{27}$ The fostering and adoption of children within the extended family/ whanau is a common pattern in both Māori and Polynesian societies. Tamaiti whangai is the Māori term for a child who is nurtured or raised within their whanau but by someone other than his or her biological parents.
} 
married heterosexual couple. Although you can adopt as a single person, Emile believed that their status as a "recognised" de facto couple would prohibit either Robbie or himself from applying. ${ }^{28}$ For both personal and political reasons, Emile had felt upset about not being able to adopt and it had taken him some time to reconcile his feelings. When I asked if they had considered surrogacy or shared parenting, Emile said they had not been interested in having a child "as part of an experiment".

Although currently under review, the New Zealand Adoption Law as it stands is not in keeping with other recent legislative changes such as those captured within the umbrella Relationship (Statutory References) Act 2005 whereby married, civil union, or de facto relationships are in most instances recognised equally in terms of obligations, rights and entitlements. Despite growing tolerance of sexual differences, non-heterosexual parenting, as Weeks, et al. (2001: 158) note, still continues to incite acute anxiety. The idea of gay fathers is particularly controversial owing to the deeply embedded myth that gay men prey upon and corrupt the young (ibid, 160). Parenting as such, along with same-sex marriage, "has become the touchstone issue for attitudes towards non-heterosexual relationships, the yardstick by which social acceptance may be judged" (ibid, 158).

\section{Civil Union and The Intimate Relationship}

Reaching a stage of love, intimacy and commitment were necessary antecedents for couples to consider entering a civil union. However, a romantic, practical, or social spark was often also required to push at least one member of the couple into a decision-making mode (Badgett 2009 also notes this point in her study). For most participants, the idea of a civil union arose through mutual discussion while for others some prompting from friends or family motivated their thinking. Bryan \& Frank, for example, said they had not felt any real need to have a civil union for themselves. Having been together for 33 years (at the time of their civil union), they said they "already felt married". The pressure to have a civil union came from family and friends who wanted an opportunity to celebrate and affirm

\footnotetext{
${ }^{28}$ In actual fact, an individual from a de facto relationship can adopt a child and their partner can then apply for guardianship.
} 
their relationship. For a few couples, the decision to have a civil union was initiated by one individual in the relationship making a romantic proposal. Yvonne \& Loana, for example, narrated their proposal story:

Loana: As soon as we got together I had been asking Yvonne to marry me within the first minute. And first thing it was sort of like jokingly, but I come from a fairly traditional background and we come from a family of long-termers. So, yeah, right from the early days I was sort of asking Yvonne and it was always sort of like: 'oh no, why would we do it? It's not even legal, you know. Let's wait until it's legal'. And then, you know, I was over in Sydney when Yvonne texted me to say that she was at Parliament [...] when the [Civil Union] Bill was passed. [...] And she said, 'It's legal now'. And I was going, 'Oh cool, excellent'. And then she was hanging around [waiting] for me to ask her.

Yvonne: For more than 10 years I'd been going, 'no, not until it's legal - it's a basic human right'. And then it was legal and she didn't ask me and she said nothing. I was going: 'um... hey, are you going to say something?' She goes: 'oh yeah'. Nothing, nothing, nothing. And then one day, we happened to be at the place - and it's the first time we'd been back there since we met there [...]

Loana: I knew we were going to [the place where they first met] so I knew that that was where I was going to ask her or write down what I was going to ask her. And so, yeah, I picked something up and just basically gave it to Yvonne because we were there with mates who had their kids with them as well. And so, I just sort of like shoved this card in Yvonne's hand.

Yvonne: Little card in this little gauze bag.

Loana: Gave it to her to read.

Yvonne: And it said: 'will you be my partner in love for life'. And that was your proposal.

Loana: Yeah, that was it. Of course all the kids got excited and we went to McDonalds for our celebration [laughing] and it was pretty much all going.

Romantic proposals largely followed the extended rituals of marriage and further illustrated the on-going dominance of the romantic love script in some participants' relationships. Proposals were generally made by the individual who was initially more interested in having a civil union or for whom the meaningconstitutive practice of marriage was strongest. Michael recalled that for his 
proposal he had left a card and a pair of custom-made cufflinks incorporating precious stones from his late mother's rings on the breakfast table for his partner to find when he came downstairs in the morning. Michael said he was extremely nervous about what his partner's response would be as he had indicated a year before that a civil partnership (the UK equivalent of a civil union) was not for him. For his proposal, Dominic presented Max with a red rose, card and invitation. He even got down on bended knee when Max, somewhat tongue-in-cheek, requested that he do so.

Motivations for wanting a civil union typically centred on romantic, practical or social reasons, and for some participants their political principles were also an important factor. I return in detail to the practical, social and political motivations in the following two chapters but here I will focus on those motivations central to the intimate relationship. At the level of partner interactions, the most commonly narrated motivation for having a civil union was a desire to express a commitment to the relationship and an intention to stay together. For those participants in longer-duration relationships, commitment was typically narrated in terms of a "reaffirmation" or "honouring" of an already established and committed relationship whereas for those whose relationships were comparatively more recent, the commitment was narrated in more future-oriented terms and as indicating a desire to build an enduring life together.

For those in longer-duration relationships, a significant anniversary was also sometimes a motivating factor in their decision to have a civil union. Although Martin \& Ross, for example, had initially thought there was little advantage for them in having a civil union, their $25^{\text {th }}$ anniversary prompted a change of mind.

I still don't know why I suggested it, but it'd just been on my mind for a while that it was a way to acknowledge the 25 years really and to say, 'well we've done 25 years, here's looking ahead to another 25'. And this would be quite a nice thing to do just for us (Martin).

Will \& Geoffrey, similarly, decided to mark their $40^{\text {th }}$ anniversary by formalising their relationship in a civil union. Will, rather humorously commented, 
I suspect if we'd been talking about a civil union in the first two or three years of our meeting, I would have been very reticent because I'm not one who does things without being absolutely sure that's the way to go. Whereas, by the time we hit 40 years ... I think I've made my mind up now [laughing].

Jody \& Grace said they decided to have a civil union primarily because they wanted to do something special to mark their relationship's tenth anniversary. For Jody, the legal aspect of a civil union represented "the final commitment" she could make to Grace.

For some participants, a further motivating factor in their decision to have a civil union was a desire to create a context of stability for current or future children. Where children were the product of a previous relationship, commitment was not just to the partner but to their children as well. Sharon, for example, said that for her their civil union was not just about her commitment to Helen but also to Helen's daughters as well.

Like I'm not just a partner, I'm not just somebody in their life for five seconds, tear their hearts out because they loved me... I think I was not just marrying her [Helen], I was marrying the extended family as well and so to me it was about bringing all those things in line.

Some partners or couples were initially reticent about a civil union and processes of negotiation and/or reframing were necessary to shift them into a positive decision-making mode. While I explore the source of these concerns in detail in chapter six, I briefly mention here those relating specifically to 'commitment'. Max, for example, was not particularly keen on a civil union or on making a formal commitment and took six months to agree to Dominic's proposal. Max said the feelings of guilt and betrayal he had experienced when he left his wife and children resurfaced with Dominic's proposal: "I had been through this marriage before. I had made promises before and I had betrayed them by leaving her. And I didn't know if I wanted to put myself through that test again". Max described these feelings as a "really huge hurdle" that he had to overcome before he could accept Dominic's proposal. 
As a feminist, Marama said she had "issues around marriage and ownership and stuff'. Seeing a civil union as comparable to a marriage, she had not responded affirmatively when Deb suggested they formalise their relationship. She eventually agreed to a civil union, though, for reasons of commitment both to Deb and their relationship.

So Deb had to talk me through it because I saw it as being a marriage and [...] I wasn't interested in being seen as being in a marriage together and I didn't want any of the notions of man, woman, and whatever. [...] I think too for me it was about commitment. If I brush all of that aside, it was actually about commitment to my partner. So I came into the civil union because it was something that Deb really wanted and that I could just do it (Marama).

Having already been together for many years, Brad \& Marcus said they were conscious of not wanting to undermine the commitment they had made to each other years before:

Like we had already made our commitment to one another long ago and in some ways it felt like ... it didn't only feel facile but it felt like an insult to what we'd had to do before for one another. Like we couldn't get married before, it wasn't available. And so we had kind of done our own committing to one another. And so I didn't want to undo that and pretend yes suddenly we'd decided to get married because it wasn't like that (Brad).

Brad \& Marcus procrastinated before finally deciding to go ahead with a civil union. The final catalyst when it came, though, was a practical rather than a romantic one and is something I return to in chapter six.

Whilst love was a significant feature in many participants' relationship narratives it was rarely mentioned as the reason for having a civil union. Only a very few couples in shorter-duration relationships in fact mentioned love as a motivating factor and, even then, love was rarely sufficient in and of itself. Hailey described her motivation for entering a civil union with her partner of three years as follows:

I think for me it was just about, really loving you [Lara]. That was the primary reason [for wanting to have a civil union]. And [...] I guess it [a civil union] sets it 
apart from other relationships. And that our intention is to try and stay together forever. That's the goal - we want our lives to be together.

Those couples in shorter durations relationships were more likely to still be in the emotionally intense 'falling in love' stage of their relationship, perhaps hinting at why they were the only ones who specifically mentioned love as a motivating factor for their civil union. Those in longer-duration relationships, by comparison, were more likely to have moved into the "calmer more rational state of being in love" whereby love was taken for granted as a given (Lindholm 2001: 337).

Many participants reported, as a consequence of their civil union, a growing commitment to the dyad relationship which often translated into a greater sense of relationship stability. For those couples who had already been in a committed relationship for many years prior to the legislation, the consolidating impact of their civil union on their relationship was all the more surprising. Some couples had trouble putting words to the emotional effects of their civil union. Many reported feeling "different" about their relationship after their civil union but were unable to pinpoint exactly why. I argue that the civil union strengthens the dyad relationship in a number of ways. Premised on life-long partnerships, the civil union helps to reduce commitment ambiguity, creating what some participants described as a more "secure", "stable" and "permanent" relationship environment. For other participants, the reality of their commitment was enhanced through its public witnessing. As Hull (2006) points out, making a public statement has a doubly binding effect: witnesses are asked to support the couple and hold them accountable to their commitment, and the couple's commitment is enhanced through its public witnessing. Although divorce statistics might suggest otherwise, "[t]he cost of defaulting on their commitment will be to face the embarrassment of backtracking on their public declaration" (Hull 2006: 51). For a few participants the act of expressing their already private commitment to the wider world was described as profoundly significant and as subsequently adding extra depth to their relationship. For Trisha, the shift she experienced in her relationship with Pam after their civil union was attributed not so much to the legality that it gave but to the fact that she had made, as she referred to it, a "public confession". Confession in this context refers to the disclosure of intimate emotions to the 
wider world; emotions that until that point had been largely confined to the realms of the dyad relationship. The fact that they had "chosen" to make this "confession" was also significant in that it reflected the "solidness" of their relationship and the absolute certainty they felt in it being a life-long partnership. The civil union as a 'key experience' also creates an important 'memory' in the couples' 'shared history' and further entwines the partners' 'life-plan calendars'. I argue that in this way, the civil union acts as an external anchor and forms an additional barrier to relationship dissolution.

\section{CONCLUding COMMENTS}

In this chapter I have explored the civil union within the context of partner interactions. Through participants' narratives I have shown how in varying degrees they drew on 'traditional', 'modern', 'queer' and 'heteronormative' ways of relating. Many of the attributes characteristic of what Giddens (1991: 1992) refers to as the 'pure relationship' - equality, reciprocity, commitment and a friendship ethic - were implicit in how participants narrated the bases of their relationships and accounted for their durability. However, against Giddens, I have argued that the 'meaningconstitutive' traditions of romantic love and the image of couple-hood inscribed in marriage were also important in structuring many of my participants' relationships (Gross 2005). At the level of partner interactions, love and commitment - past and future - were the most commonly narrated motivations for couples to want a civil union. A growing commitment to the dyad relationship was also often reported as consequence of the civil union. Premised on life-long partnerships, the civil union had a strengthening effect on some couples' relationships. For other couples, the reality of their commitment was enhanced through its public witnessing. As a 'key experience' the civil union also creates an important 'memory' in the couples' 'shared history' and further entwines the partners' 'life-plan calendars'.

The decline in regulative traditions around marriage and family forms have, as mentioned in chapter two, helped to pave the way for greater acceptance and recognition of same-sex relationships. The decentering of heterorelations together with the progressive equalisation of legal and social conditions for lesbians and gay men has also, as Sasha Roseneil observes, resulted in "a significant destabilization 
of the homosexual/heterosexual binary which has characterized the modern sexual order" (2000 cited in Roseneil and Budgeon 2004: 140). Weeks, Heaphy and Donovan similarly suggest that "one of the most remarkable features of domestic change over recent years is [...] the emergence of common patterns in both homosexual and heterosexual ways of life as a result of these long-term shifts in relationship patterns" (1999: 85). Following Giddens, they see both homosexuals and heterosexuals increasingly yearning for a 'pure relationship', experiencing love as contingent, confluent, and seeking to live their sexual relationships in terms of a friendship ethic (Weeks, Heaphy and Donovan 2001). While I do not disagree with these assertions, I do, however, suggest that the trajectory is not simply a unidirectional one towards modernity. The decline in regulative practices around marriage, romantic love and family forms have, as I have shown, enabled 'moderns' to choose between 'traditional' and 'modern' forms of relating or to choose both at the same time. This tension between 'traditional' and 'modern', and indeed between 'queer' and 'heteronormative' practices, was also clearly articulated in participants' narratives of civil union ceremonies, and is a theme I explore in chapter seven.

The following two chapters recognise the fact that intimate relationships are embedded in other social relations. Chapter five explores the civil union within the context of close social relationships, namely those with family and friends, while chapter six situates the civil union within a more macro socio-political context. In different ways both these chapters explore the intersection between law and culture and how civil unions serve as an important institutional bridge of legitimation (Green 2010). 


\section{Trajectories of Close Social Relationships}

\section{INTRODUCTION}

Whilst the couple whose relationship is the theme of the 'wedding' are making a commitment to each other, they are also, as Lewin notes, "representing themselves to a selected group of witnesses, an audience in essence" (1998: 54). The process of planning and constructing a civil union ceremony is, therefore, likely to be associated with periods of reflection not only on how they as a couple want to present their relationship but also on those relationships - past, present and future - which are most meaningful to them (Smart 2007: 671). At a more mundane level, decisions need to be made "about who to tell, who to invite (either to the ceremony or the party afterwards) and how to prepare oneself emotionally for possible derision, rejection and distress" especially from family of origin (Smart 2007: 677).

This chapter seeks to situate participants' civil unions within the context of close social relationships, namely those with family and friends. To provide context, I begin by outlining the couples' familial relationships pre-civil union. I then turn specifically to the events surrounding the civil union itself. I explore how couples decided whom it was important for them to have at their civil union, how they chose to involve their guests, and what impact if any their civil union has had on these relationships going forward. I argue that for some participants an important motivating factor in having a civil union was a desire to gain recognition, acceptance and support from family members while for others their civil union was simply a chance to celebrate and affirm their relationship with those people most meaningful to them. 
Often the most profound outcome of a couple's civil union was the shifts that occurred in their relationships with family members. Following Green, I argue that the civil union "operates as a normalizing rite of passage that catalyzes support and recognition from family members otherwise opposed to or miniminally tolerant of homosexuality" (2010: 412). For many participants' families, the legitimacy conferred through legal recognition played a significant role in rendering same-sex relationships socially 'normal'. The legitimising effects of law also intersected with the socially dominant cultural model of marriage to invest same-sex civil unions with meaning and, in many instances, initiated or accelerated processes of familial acceptance and incorporation. The effective and affective qualities of ritual, furthermore, worked to intensify the connection between ritual participants and the symbolic objects of communication and, in doing so, had the ability to transform the attitudes and behaviour of those present (Alexander 2006: 30; Deflem 1991: 5).

\section{NARRATiVEs OF FAMilial RELATions}

When a gay-identified child 'comes out', parents' understandings of who they are are challenged and they are forced to relocate them according to a new set of narratives. When parents have viewed the characteristics central to a gay collective identity negatively then the relationship with their now gay-identified child may be significantly undermined. In order for them to see their child once again with dignity, they must recode the larger gay collective identity according to more positive life scripts. For many participants, 'coming out' as a gay man or lesbian had a destabilising effect on their relationships with family, and parents in particular. Some described their parents' initial reactions to their nonheterosexual disclosure as one of shock, fear, rejection and/or denial but, in most cases, reported that some degree of acceptance had eventuated. Parents' reactions typically varied according to generation, socio-political context and religious beliefs, with younger participants' parents generally responding more positively to their non-heterosexual disclosure than older participants' parents.

Not all participants in this study had in fact 'come out' to their parents. As discussed in chapter three, for those born in the 1940s, making a non-heterosexual 
identity socially salient generally did not refer to 'coming out' to 'straight' others but instead referred mostly to a person's entrance into the gay world. For these participants, growing up in an era where it was illegal to be homosexual, having a gay community was essential; a gay community provided the context for the articulation of identity but, importantly, was also the prime focus for emotional support that the family of origin was unable to provide. For participants who 'crossed over' later in life, 'coming out' sometimes had a destabilising effect on a range of social relationships that had been established as a 'heterosexual'. Jill, for example, recalled that her 'coming out' had a destabilising effect on her relationship with her best friend. Max likewise reported that his sons had rejected him for about a year when he finally disclosed his sexuality to them. When Cheryl informed her parents that she had left her husband and children to be with a woman, they refused to see her for five years. It was only by her continually writing to them and calling that they eventually agreed to resume contact.

Gay men and lesbians who have experienced detachment or exclusion from their families of origin because of their sexuality often forge new 'families' that include lovers, ex-lovers, and close friendships, as well as supportive 'blood' relatives. Brad for example, said that he and Marcus had what he referred to as,

Quite a big queer family that includes heterosexual couples - our friends who are the parents of our oldest god son - and then my ex-partner who I'm very close to and Marcus has become close to as well, and his current partner. We are godfathers to his son. He's got two lesbian mums. So we often have big Sunday dinners all together with the children.

Brad said he considered these people to be his family in more ways than his actual family of origin. "Although we are close to my grandma we are not so close to my parents" (Brad). Marcus added, "Yeah, we talk about our family of choice versus our family of origin".

'Families of choice' are "united by choice and love not by biological ties" (Hayden 1995: 44). They provide what Weeks, Heaphy and Donovan (2001: 11) describe as the "life-line" that the family of origin has failed to provide, often because of their offspring's sexual orientation. Rather than substitutes for the 'real' thing, though, 
these chosen families have many features typical of biological families, such as the sharing of resources, caring, responsibilities and obligations. Because they are 'chosen', though, the relationship tends to be based on a subjective appreciation which, for a non-heterosexual in particular, cannot necessarily be assumed in 'given' families. Even where ties to family of origin remain highly significant, the friends as family model may still have salience as it provides a context of approval and an environment where the non-heterosexual can feel free to truly be themself - something they may not feel in the presence of 'straight' family of origin who are only nominally tolerant of homosexuality. For a few participants in this study, detachment from family of origin was not a result of their 'coming out' but instead was attributed to a history of familial dysfunction. For these participants, close friends and a few 'blood' relatives had also become the prime focus for ongoing emotional and social support rather than their natal family.

The identification of friends as family is not, however, limited to nonheterosexuals. As Silva and Smart observe, the 'friends as family' model is "a reflection of how the subjective meaning of family is changing" more generally "and how individuals may be shifting their locus of intimacy and support away from kin towards other people" (1999: 9). In an era that prioritises individual choice and the acceptance of diversity, 'family' becomes a matter of personal choice or invention; part of what Giddens (1992) sees as the 'everyday experiments in living'. Here, 'family' becomes increasingly a matter of negotiation rather than ascription, drawing into question the old saying, 'you can pick your friends but not your family'. 'Families of choice', as Marilyn Strathern observes, thus challenge the privilege enjoyed by straight, blood-based kinship in that they "make explicit the fact that there was always a choice as to whether or not biology is made the foundation of relationships" and their existence highlights the inherently "symbolic status" of biology (1993: 196). Rather than undermining family links, Silva and Smart suggest that, "families remain a crucial relational entity playing a fundamental part in the intimate life of and connections between individuals" (1999: 5). It is just that the notion of family has come to encompass much more than a 'traditional' institutional definition. 
In researching families, Silva and Smart (1999: 11) advocate for a focus on family practices, arguing that families in a contemporary Western context 'are' what families 'do'. Ties to family of origin dominated most participants' relational narratives and for some were also an important motivating factor in having a civil union. It is to these familial relationships that I, therefore, pay closest attention in this chapter.

Those participants whose family had responded relatively positively to their 'coming out' tended to also more readily embrace their intimate same-sex relationship. For Brandon (aged 27), 'coming out' to his liberally-minded parents was, as mentioned in chapter three, a relatively painless experience. His parents had been more than accepting of his sexuality and, later, also of his relationship with Jason. When the Civil Union Bill was passed, Brandon's parents had presented them with a bottle of champagne "congratulating" them on the fact that they could now have their relationship legally recognised. Although Bryan \& Frank got together during the 1970s at a time when it was still illegal to be homosexual in New Zealand, their parents and siblings were always very supportive of their relationship. Bryan commented that they had even lived with his parents for two years while they were saving money to buy a farm. Pressure for them to have a civil union initially came from family and friends who wanted an opportunity to celebrate and affirm their relationship. Having been together for 33 years at the time, Bryan said, they hadn't really seen the need to have a civil union: "Well, we already felt married." Frank added, "So [our civil union] was a very public affirmation of our relationship by our families. Even though for years our families have of course accepted our relationship and been part of our lives jointly, the public affirmation of it with our families was very important".

Several participants mentioned how various supportive family members had over the years commented disparagingly on the inequality of the law in that it did not recognise same-sex couples. Cathy's father, for example, had quite early on in their relationship said that he was "disappointed" that there was no way for Cathy \& Paige to have their relationship recognised. "And then the civil union thing came along and he was pleased that we had a way of kind of announcing [our relationship] 
to the world" (Paige). Trisha's sister apparently rang her and Pam on the day the Civil Union Bill went through, demanding to know when they were getting "married" and to ask if she could be a "bridesmaid". "I said, we hadn't decided yet. And she said, 'But you can!' And I said, 'I know, isn't it fantastic, we can!'” (Trisha).

For other participants, familial acceptance of either their sexuality or their intimate same-sex relationship was not nearly so immediate or unequivocal. Many described their relationship with family as a "progression" often from complete denial in the beginning to acceptance and incorporation over time. Loana's Samoan Christian parents, for example, were for the first two years in complete denial about the nature of her relationship with Yvonne and, every time they visited, asked when Loana was going to get a boyfriend. It wasn't until Yvonne \& Loana jointly purchased a car and merged their finances that Loana's parents started to accept that Yvonne was not "going anywhere". Being Samoan, Loana had obligatorily contributed money to family-based events or projects and her mother had often instructed her on exactly how much. Yvonne said that once they bought the car together and merged their finances, this practice was no longer acceptable. "It was like, actually we live together, we pay bills together. Your mother can't actually tell you anymore how much she needs of your pay. You know, it's got to be a negotiated thing. That money can't just disappear from our joint life anymore". Loana's mother soon realised that if she wanted money from Loana she also needed Yvonne's approval and, furthermore, if Yvonne was excluded from any of their family events then Loana would, in an act of solidarity, also refuse to attend.

With time, Loana's parents did, however, accept their relationship and Yvonne was eventually incorporated into the family. As Yvonne recalled, "I went from being Loana's friend to being her girlfriend to being her partner to them then calling me their daughter-in-law to calling me their daughter". While sick in hospital, Loana's mother commented to Yvonne that of all her seven children she believed that Loana and she had the "happiest relationship". Before passing away she also made Yvonne "promise to look after her baby [Loana] for her". For Loana's father it took approximately ten years for him to finally "understand and accept" their relationship. Yvonne recalled a time when Loana was sick and had to stay with her 
father because she herself was away. When Yvonne returned, Loana's father exclaimed to her, "How do you sleep with her? Her snoring, how do you get to sleep?" At this point Yvonne said she realised that he "totally understands. He's got no blinkers about this. He understands that we sleep together, we have a sexual relationship".

Dominic was already in a committed relationship with Max when he came out as a gay man to his parents. After the initial shock, Dominic said his mother in particular was quite accepting of his sexuality and their relationship. Once aware of the true nature of their relationship, Max said his telephone conversations with Dominic's mother shifted to a new level of "intimacy". "She could say, 'how's that boy of yours?' or, 'how's that man of yours?' and I'd say, 'oh, he's doing really well'. And there was a sort of different intimacy to the familiarity" (Max). Dominic's father was accepting of their relationship but, as Dominic pointed out, acceptance and understanding are not necessarily the same thing.

Dominic: He accepts it but he doesn't understand it.

Max: He's always very nice to me. He's always genuinely nice to me and always asks how I am, how's my work? But he doesn't tend to ask me about Dominic, so he can't quite address that we're a couple yet. But when we stay there we go down to breakfast together.

Max \& Dominic had not, however, always stayed with Dominic's parents when they visited. When they first moved to New Zealand from the UK, they stayed in a motel so, as they put it, "it wasn't in their faces". However, Max said they finally got to a point where they felt they had to take "a bit of stand" on the matter.

Max: You know when [Dominic's] sisters come home with their husbands ... they were allowed to stay in the guest room with a double bed and they talked about us staying in the twin bedroom, you know. I said, I'm not prepared to compromise on that, we'll stay in the motel. So, in the end, Dominic spoke to his mum and dad and said, 'look ... we are a committed couple, you know, we're as good as married - as much as the law allows it'.

Dominic: And my mother gave the nod so, therefore, my father followed suit.

Max: So now we stay in the double bedded room in their house. 
Reflecting on how "old school" his father is in his thinking, Dominic said that since one of his sisters had left her husband and taken up with an old boyfriend, she was not allowed to sleep in the same bedroom as her boyfriend when they were staying at her parents' house. "So gay, straight or whatever, he would still have his set ideas that marriage is for life and until you're married well then you can't share the bed" (Dominic). Max added that since their civil union and Dominic's sister's marriage break-up it was almost like they were "the good ones" in the family now. "Because in [Dominic's father's] eyes we are married - as much as he ever talks about it - but he finds us much less the sinners. So it's quite a good life now. It's got a humorous irony [laughing]".

For some participants, their long-term intimate same-sex relationship had helped their parents to accept their sexuality. Heather, for example, said that it wasn't until she got together with Jill that her parents were able to come to terms with her being a lesbian. An intimate same-sex relationship represents a concrete manifestation of a non-heterosexual identity and in this way dispels any residual speculation on a parent's part that it is simply a passing phase. Many of the fears that parents have for their lesbian, gay or bisexual child revolve around stereotypes that have been unconsciously absorbed and believed as factual (Stewart 1993: 74). While house sitting for her parents one time, Heather said she discovered that many of her parents' concerns were based on their fears of her being in some "deviant underground world". While flicking through a book she had given them, she discovered a number of newspaper clippings: "All the clippings indicated to me that they were just trying to see pictures of gay people as being normal and not being deviant and strange and walking down the street or riding bikes naked kind of thing (Heather). Heather recounted an incident, which she believed had also helped her parents to consolidate a view that gay couples are "normal" and in a relationship not dissimilar to a heterosexual relationship.

Dad got really ill and they [Mum and Dad] had to live with us for a while. And that shifted things quite a lot because they saw us living normal lives like normal people, you know. Arguing over the toilet paper and who didn't replace the toilet roll or whatever - the little things. And making dinner and having friends around. So that kind of shifted things. 
Heather added that it was not until their civil union, though, that they "actually became a family". Many other participants also alluded to the consolidating effects of their civil union when narrating their familial relations. For these participants, their civil union facilitated another level of incorporation and represented the end point in a long "progression" towards familial acceptance. I return in detail to this aspect of participants' civil unions in the latter part of this chapter.

Some couples had more involvement with one partner's family than they did with the other's because of differences in geographic proximity or because one partner's parents had passed away. Martin \& Ross, for example, were involved in each other's family but more so with Ross's family who lived in the same city as them. Reflecting on his relationship with Ross's family, Martin commented,

I've really loved being part of Ross's family because his parents were very similar to mine. And one of his sisters in particular I'm very fond of and her big extended Irish family. She married into a big Irish family and they're loud and gregarious and great fun. And I've really enjoyed being part of that and still do. So I've felt that I got incorporated into that. And I was fond of his parents. [...] We looked after [Ross's] mother a lot when she was sick and she stayed here quite a bit.

In other instances one partner was not as close to their family as the other partner was to theirs. Occasionally one partner's family was less supportive of the samesex nature of the relationship, but for other participants the estrangement was attributed to a history of familial dysfunction. Marcus described his mother as "completely homophobic" and, consequently, as rarely a feature in his and Brad's life. His father (divorced from his mother), although not necessarily homophobic, was described by partner Brad as "indifferent about Marcus" although, he apparently "loves" Brad.

Marcus: He thinks Brad is the bee's knees. He doesn't talk to me on the phone he talks to Brad.

Brad: We both love music a lot so he could sit with me for hours listening to music.

Other participants also noted that their parents often "adored" or got on better with their partner than they did with them. This tendency was generally perceived 
somewhat backhandedly as a positive though, as it helped facilitate familial acceptance of their relationship.

Brad's parents, in comparison to Marcus's, had always been quite happy to include Marcus and to "treat him as part of the family". According to Brad, his parents were not, however, entirely "comfortable" with the nature of their relationship. As he and Marcus explained,

Brad: They don't celebrate [our relationship], they don't tell their friends easily who Marcus is, so he becomes a friend.

Marcus: They do flip and then they get me to call them Mum and Dad as well.

Brad: So it's this weird thing, on the one hand we are sort of within the family they are quite kind of loving - but it's like they haven't 'come out' themselves about who we are [...] It's like they haven't quite 'come out' of the closet.

Some participants had found acceptance and support from others within their familial network. Geoffrey, for example, had two aunts who had been very supportive of Will and himself. One of these aunts, whom he was particularly close to, was, in fact, his witness at their civil union. Brad's grandmother, somewhat surprisingly, had been "a whole lot more accepting" than his parents. As Brad explained,

It's strange because you tend to think that homophobic people are older rather than younger whereas my gran has been a whole lot more accepting. I mean she was quite keen for us to move in together. She got Marcus aside and said to him, 'now when are you going to move in together?' And she gives him advice on how to deal with me and what to cook and what not to cook. [...] So she is the rare one probably in the whole family and Marcus's family. She is the one who has been most accepting. And she comes and stays with us. Well, she hasn't recently because she has got older, but she spent a lot of time with us and we had a lot of fun. Marcus takes her shopping.

Trisha similarly mentioned how surprised she was by her own grandmother's understanding and acceptance of her relationship with Pam.

You know, when I introduced [Pam] to my then 98-year-old grandmother, I said, 'Nana, this is my companion', thinking that would be the language she would 
understand. And then my brother who Pam hadn't met at that stage also came to the rest home just at that moment and she [her grandmother] turned around and went, 'Oh Trev, have you met Trisha's girlfriend?' [Laughing] Oh, no flies on you are there Nana!

\section{GUEST LiST NARRATIVES}

Having family and friends attend their civil union was described by most participants as extremely important. For those participants who had experienced familial acceptance and incorporation relatively early on in their relationship, this wish was typically expressed as a desire to celebrate their relationship and commitment with those people most meaningful to them. For other participants, an important motivating factor in having a civil union was a desire to gain recognition, acceptance and support, primarily from family of origin. These participants often used their civil union as an opportunity to express to others what their relationship meant and how it should be treated. By having a civil union they hoped to demonstrate the strength and depth of their commitment to each other and to assert the relative equality of their relationship to a heterosexual marriage.

For Cheryl, whose parents had rejected her for five years after she 'crossed over', a desire for "recognition" was an important aspect of their civil union. She said she "hated" the feeling of being "second best or undervalued" and wanted her family, employers, colleagues and friends to "recognise" the significance of their relationship. Lara said she used their civil union consciously and purposefully as a vehicle for gaining familial acceptance. Although her family had never rejected her for being "queer", she still felt there were residual elements of denial of her 'orientation' and the significance of her relationship with Hailey. Having a ceremony that was comparable to her brother's heterosexual wedding the year before was for her an important means for establishing her relationship both as 'real' and as equally legitimate as a heterosexual relationship. As she expressed it,

By bringing it out there and doing what my brother had done [...] was a normalisation. And they [her family] are probably just happy that it's just the 
same, that it's not some kind of weird girl thing or whatever they think. I really don't know entirely what they think (Lara).

Part of Trisha \& Pam's motivation for having a church-based 'wedding' was that their family would see their relationship as comparable to a heterosexual marriage and not, as Pam described it, as "some phase or new, fangled thing". Although many weddings in New Zealand today are no longer performed in a church, they are to some extent still viewed as the 'traditional' standard. By performing their ceremony in a church Trisha \& Pam hoped to draw a direct correlation between a heterosexual wedding and what they themselves were doing.

Marriages today are generally no longer looked upon as an alliance between two kinship groups as they once were. Indeed, in Western sociology of the family, there is a pervasive idea "that marriage is about 'finding oneself, about selfactualization, and about a rather private journey" (Smart and Shipman 2004: 495). Some of my participants did, however, describe their civil union in terms of a kinship alliance. Reflecting on their civil union, Helen, for example, commented, "It was a marriage of two families. ... It's about more people than just you. And for us, we're really strong family people". Helen also added that she thought a civil union would give "people the opportunity to have some kind of context to put their relationship in, some kind of framework to hang it on, to understand it. I mean, everybody can understand what marriage means". The social intelligibility of 'marriage' is an important point I discuss later in this chapter.

Cultural performances such as 'weddings' tend to make social relations visible by publicly displaying closeness and distance. They are also, as Evans-Pritchard (1951: 166) observes, important occasions of social life when relationships are often formally defined. Decisions over who to invite can, as such, become a political exercise as exclusion sends a message, to those excluded, that their relationship is relatively distant. Yvonne, for example, recalled the difficulty she and Loana had in finalising their civil union guest list.

Loana goes, 'Ok well, where are we going to have it [their civil union]?' [And I say] 'I'm thinking the Town Hall'. And she like choked. And I was going, 'Well think about it?' She said, 'Isn't that a bit big?' And I go, 'Well, how many people?' And 
we start writing out our first invitation list, which was 450 people. We both come from huge families, we are really active in the community, we travel overseas lots and ... yeah, 450. And then we were like, ok, and we got the list down. We got it down to 250. It was really hard. It's the most political and difficult thing I've done in my life and we still get people occasionally making little comments because they weren't invited.

Michael said they could have had at least double the number of guests at their civil partnership (the UK equivalent of a civil union) but wanted there only those people who played a central role in their lives. Cathy \& Paige said the biggest decision they faced was over whether or not to invite their extended family of origin. "It was either all or none and it ended up being none ... You can't invite one aunty and not another" (Cathy). While cost played a role in their decision, they also said they did not want anyone there who was in any way uncomfortable with the same-sex nature of their relationship. As Paige explained,

We didn't want to feel like we would have to change how we behaved to each other on the day because someone else might be feeling a bit uncomfortable about it ... So we just thought, nah. There's people who are one hundred per cent into this who are coming, and if there's anyone who's a bit iffy then we just decided we didn't want them there, because that would mean that we would feel like we couldn't be open and how we wanted to be.

For most participants, their civil union was the first time they had disclosed intimate emotions to the wider world; emotions that until that point had been largely confined to the dyad relationship. Commenting on their guest list, Max said he wanted only those people who were most meaningful to them at their civil union, but also only those whom he felt comfortable sharing something "so private" with.

I invited a few colleagues from the office but I was very selective. [...] So Dominic invited just one of [his] work colleagues, didn't you? But the rest were family and friends. We were very careful about who we invited because we didn't just want to have a congregation we wanted to have people who in some way were meaningful to us so that's why we were very selective about who we invited. 
Those couples who had, prior to the civil union legislation, had commitment ceremonies or ceremonies to mark milestones in their relationship, such as an anniversary, said they felt entitled or, in some instances, even duty-bound to have a bigger ceremony for their civil union and to include previously excluded 'straight' relatives. In comparing their commitment ceremony with their civil union, Heather, for example, commented that their commitment ceremony was just about them and their relationship with each other whereas their civil union was "a commitment between everybody that was there". For Heather, what distinguished their civil union from their commitment ceremony was the legal dimension. Now that their relationship was deemed socially legitimate, they felt a greater sense of entitlement to share their relationship and commitment with their broader social and familial networks. She also felt that the legal aspect had "changed the commitment to a community of commitment. It was like everyone was there saying, we support you as a couple and, if things are going wrong, we'll help you work it out". Beth similarly commented that their tenth anniversary celebration had been a relatively private and "safe" affair. Their civil union, by comparison, was far more public: "I felt absolutely entitled to invite [Jenny's] family and the next generation of my family and a wider range of people to this. Yeah, it was very much about standing up in front of the broad mix of our community".

When it came to inviting parents, a few participants recalled experiencing high levels of anxiety as if they were 'coming out' all over again. Despite their years together as a couple and suggestions of acceptance and understanding on her father's behalf, Loana said she still felt extremely anxious informing him of their pending civil union and asking if he would please honour them by being there.

It was a huge thing for me to ask him to do this, but yeah. He pretty much took it in his stride and said, 'Of course'. Even in the week leading up I was still sort of hesitant thinking he is just saying yes and is not going to turn up on the day or make some sort of stink excuse. So yeah, it wasn't until I actually saw him there [at the civil union] that I thought, 'Okay, we are all good now'. And during the reception, [...] he just sort of whispered to me, 'Mum would have been really proud'. And I was sad that Mum wasn't there but in a way was quite relieved because it probably would have been four times the size. I don't think she would have allowed me just to invite my cousins [laughing] (Loana). 
Becky also experienced a degree of anxiety in telling her mother that she and Bridget were having a civil union and in asking her to be there. Becky attributed her apprehension to the fact that her mother was "a bit frail" but also because she thought her mother might be a bit unsure about "this sort of public recognition of marriage thing”. Bridget, however, interjected saying:

Oh, that was in your head I think. Yeah, you were surprised at the time that you suddenly had to tell your mother you were going to have a civil union. This is the mother who I'd been going round and having dinner with every week and, you know, doing crosswords with for about 20 years. And suddenly Becky was a bit sort of like, 'Oh God, I've got to tell my mother. What if she blows up like she did when I was sixteen!'

'Coming out' to her mother at age sixteen had been a traumatic experience for both Becky and her mother and was something that Becky felt had never been resolved or even subsequently discussed. Whilst her mother had accepted her sexuality and welcomed her partner Bridget into the family, Becky was concerned that a civil union might be one step too far for her mother and that she would once again be faced with rejection. Her mother did, however, attend their civil union although, according to Becky, she did so as a result of her brother's rather forceful prompting: "So she felt she had to go. And she always did things if she felt she had to do them. She'd be thinking, 'is it the right thing to do? Yes, yes, it is. Well okay, I'll do it then' [laughter]".

Although generally celebratory occasions, 'weddings' can in the planning stages be stressful and new or existing tensions between partners may be exacerbated. For several couples, their civil union guest list was a source of consternation, ultimately requiring careful negotiation and compromise. Heather \& Jill, for example, reported that they had their "first big row ever" over whom they should invite to their civil union. To some extent this argument was tied to expectations of scale but the main source of conflict was over who they defined as most important in their lives.

Jill: We were arguing about who we were going to invite.

Heather: [And] how big it was going to be. [...] I wanted small and Jill wanted big. 
Jill: Well, not so much wanting big, but I had a whole lot of people that I wanted to invite, like friends. [...] And, I mean, surprisingly or not, my dysfunctional upbringing meant that I've never been particularly close to my family. So, friends for me have always been way more important than family - apart from a couple of cousins. And I had all these friends that were really important to me. And they were the ones that I wanted there. And I'd been to their weddings.

Heather, on the other hand, was much closer to her family of origin and had imagined mainly family and a couple of joint friends being at their civil union: "Just a small core group really". Heather said she had not wanted friends of Jill whom she had never met at their civil union and Jill in return said she had not wanted Heather's relatives whom she had never met at their civil union. They eventually resolved the issue by agreeing on a "selection criteria": "If one of us was in hospital, you know, on life support who would we call? And so that's how we came up with the list in the end" (Heather).

Disagreements between couples over whom they should invite to their civil union often highlighted an ethic of personal choice and increasing diversity in terms of how people define significant relationships. For some participants, interactions with family of origin remained more important than friendships and for other participants vice versa. Out of 62 study participants, though, only nine reported that they had no 'blood' or family of origin members at their civil union. In contrast to assertions in the 'family of choice' literature ${ }^{29}$, Sharon mentioned how they had prioritised family of origin and neighbours over their "gay community".

There wasn't a lot of the gay community there. It was mainly all family and a few neighbours. People that are dear to us [...] We didn't want to make it like we're coming out and we're having a civil union blah, blah, blah ... it wasn't about that. It was just about embracing the people that we hold dear in our lives really.

The absence of family of origin members at a civil union was sometimes a matter of choice, either on the part of the participant or the invitee, or due to geographical or mobility constraints. Neither Calvin nor Ehsan, for example, invited family of origin members to their civil union. To some extent, this decision

\footnotetext{
${ }^{29}$ Developed substantially by Weston (1997) and Weeks, Heaphy and Donovan (2001).
} 
was made because their families lived in the UK and Zimbabwe, but also because they were planning what they referred to as only a "low key" affair. Ehsan also mentioned that, as a Muslim, he sometimes struggled with reconciling his religious beliefs with his sexuality, so had not wanted to make a "big thing" of their civil union, particularly with his family. Only one brother was informed that he and Calvin were having a civil union; "I didn't tell the rest of the family only because they have been so supportive towards us. I didn't want to rock the boat ... it's just to do with respect really".

Geoffrey \& Will's guest list was made up of close friends ("not necessarily gay"), a few of Will's work colleagues, and a few members of Geoffrey's family. Will's family lived in the UK and for health or financial reasons were unable to make the trip to New Zealand for the occasion. Geoffrey said that he had decided not to invite his parents who had never really come to terms either with his sexuality or his 40 year relationship with Will. As he explained, "No, no, it would have been a waste of time. I wanted them just to muddle on with their own thoughts without rubbing their noses in it really. I didn't see the necessity for it".

For Brad \& Marcus being attentive to the different needs of people proved too challenging. Instead of inviting family and friends they chose a very small affair with only the requisite two witnesses present. As Marcus explained,

The problem was that we couldn't actually please everybody else. There was my family who was - one side is completely ambivalent while the other side is completely hostile so they were not coming. And then Brad's family who wouldn't be that thrilled to go but at the same time would be offended if they were left out.

Cost was also a consideration. They could not afford to host a large 'wedding' for all their friends but also did not want any of them to feel excluded because they had not been invited. "So we just thought we would do something really small and then tell people afterwards" (Brad).

Several participants invited to their civil union family of origin members who, for various reasons, chose not to attend. Michael, for example, invited his birth mother and half-brother to his civil partnership ceremony. Despite living locally, 
they had failed to attend. Whilst the implied rejection of their absence was acknowledged it was not, however, framed especially as a major source of disappointment. In the speech Michael gave at their reception, he acknowledged the importance of his and his partner's 'family of choice': "All of you here today are proof of the fact that we don't need parents. The presence of our 'real' and significant family and friends is testament to that". Whilst Michael's statement downplays the importance of family of origin for them, it does, however, highlight the ongoing importance of 'family' as an organising concept for close relationships more generally.

Both Cheryl and Jodie's mothers used health issues as a last minute reason for not attending their daughter's civil union. While their mothers genuinely liked their partners, they were not, however, entirely comfortable with the "lesbian thing". Jodie said her mother had chosen to remain in hospital until the day after their civil union. Cheryl's mother's reason for not attending was that "she was not feeling well and didn't want to bring down the kind of feeling of the day". Her mother was not, however, entirely unsupportive of them wanting to get "married". As Cheryl and Nicky recalled,

Nicky: She gave us a dollop of money.

Cheryl: And a nice wedding present.

Nicky: She made some fruit chutney that we had with the salmon that we had.

Cheryl: We just thought, okay, whatever. That's your decision. She regretted it hugely afterward [though].

Trisha's "anti-gay" brother texted her on the morning of their civil union to say that he would not be coming. "He texted me about an hour before the rehearsal [saying] 'I forgot, sorry'. That was the last straw for me" (Trisha). Her brother's last minute absence at their civil union had apparently caused some "angst" amongst Trisha's other siblings who, reportedly "sorted him out after the fact". According to Trisha her relationship with her brother had, however, improved since their civil union: "At least he talks to me now [laughs]. And he thinks Pam's lovely. So yeah, but that was a real slap in the face". 
For Jill, whose friends were more important to her than 'family of origin', it was a huge disappointment that her "best friend" chose not to attend their civil union, giving the excuse that it was too close to Christmas. Jill said that if there was anything she might have done differently for their civil union it would have been to push harder for her friend to be there.

I was really angry about it actually - that she was so dismissive of it - that it wasn't important enough. Because it was all about what she had to do for Christmas and, it's like, did you hear me do this shit about your wedding ... when I turned up, yeah, for your third wedding?

Jill's narrative about her best friend's absence at their civil union indicates that some people do not view a civil union as comparable to a heterosexual wedding or as having the same significance. Jill did, however, note that her friend had "realised afterwards how important it was and what it really stood for".

Jody recalled that her mother and brother had attended their civil union but in her opinion were only there for the "sake of appearances". As she described it, "Everybody else was as excited as anything and Mum and [my brother] were just sitting there as normal really. But they came. And that didn't worry me because we knew that that's what they were going to be like".

Guests' attendance was, however, generally interpreted as indicating commitment to the couple and their union and, therefore, as enhancing the perceived legitimacy of the occasion. Participation by guests who had travelled from distant locations, or who had undergone some level of hardship to be at the ceremony, was particularly valued (Lewin 1998 also notes this point in her study). The generosity and commitment demonstrated by guests travelling from afar often generated a greater sense of obligation to reciprocate. Emile, for example, said they had sent invitations to people "just for polite reasons" and were surprised when people living in the United States and Australia accepted. Emile said they were initially planning quite an informal occasion but felt duty-bound to organise things "properly" when they found out how many people were making the effort to attend. The biggest surprise of all for Emile, though, occurred when his parents who live in France said they also wanted to attend. Despite the short notice, prior 
travel commitments, and the fact that they had only just visited New Zealand the year before, they insisted on being at their son's civil union.

I called my parents and I said to them, 'Listen guys, I am inviting you for polite reasons because if I went ahead without telling you, you would be upset, but Robbie and I are going to have a civil union'. And to be honest, my parents had been great, I mean with our relationship, but I never thought that actually they would understand that we would have this kind of formalisation of our relationship. I really thought, well actually, they would say, 'Oh well, have a good time, but no thanks'. But my parents got really into it. [...] And that really surprised me. I was really amazed that they would show an interest. [...] And then I thought, well if they are coming what about asking my sisters to come as well, why not?! (Emile)

One of Emile's two sisters was also able to attend their civil union, although he helped out by paying for her airfare. For Emile, his family's attendance at their civil union was significant. As he expressed it, "they decided to come, the three of them. It was so special. Wow!"

\section{NARRATIVES OF INCLUSION}

Whilst the couple and the relationship are the focus of the civil union, many participants went to extraordinary lengths to include family and friends and to style a ceremony and party which would bring everyone together. The bringing together of family and friends - if only for a day - was also often described by participants as one of the most significant aspects of their civil union and considerable satisfaction was voiced by those whose family had attended and provided visible support - perhaps most significant, as Smart notes, "because it could not necessarily or automatically be relied upon" (2007: 683).

Some participants accommodated special or "favourite" family members and friends living abroad by timing their civil union to coincide with Christmas holidays or an already planned trip to New Zealand. Others said they were conscious of giving their overseas guests sufficient time to save money for the trip. As part of their civil union budget, Yvonne \& Loana also set aside a travel fund to assist those guests who were struggling to raise the necessary money. The location 
for a number of participants' civil union was also selected on the basis that it would be more convenient for family members. Trisha \& Pam, for example, live in the South Island but chose to have their civil union in the Waikato because it would make it easier for their respective families to attend.

For many participants, it was important that their guests feel comfortable at their civil union. A relaxed and informal-styled 'wedding', often at their own home or at a friend or parent's, was chosen by several participants as it was viewed as more likely to facilitate an atmosphere of ease and encourage intermingling between their different social groups. Emile \& Robbie did not have a 'home-based' civil union but said they found an "amazing place" that met all their criteria. Not only was it conveniently located for Robbie's parents, it also reflected Emile and Robbie's shared passion for art. Importantly, they also thought the mosaic sculptures and abstract art would provide a "conversation starter" for their guests, many of whom had never previously met.

Derek \& Garth said they wanted their ceremony to be about everybody there and not just about them: "[our guests] were not spectators they were actually part of it and I think that's what we really wanted" (Derek). In many instances, involving guests meant getting them to give a reading, recite a poem, or make a speech. Marcy said that,

To honour Barbara's father and my mother we asked them to be witnesses for our civil union. So that was really special, because they're not going to be with us forever. And so, to acknowledge them, we also pinned a buttonhole [corsage] on them. [...] And Barbara's dad spoke from his heart. He can be quite emotional.

Barbara added that, "having our parents as close signatories on our civil union certificate was really like a blessing, an affirmation”. Both Marcy and Barbara's children also came forward and said a few words during their ceremony and after the signing of the register came up and gave both Marcy \& Barbara a hug: "So that was lovely, yeah".

Other participants also found ways to involve their children. Frank \& Bryan had their three children walk up and present "the rings" during their ceremony. Jessie 
had her son as her "best man" and said he had signed the register as her witness. As part of their wedding present to them, Cheryl's three children had offered their services as waiters and waitresses for the reception: "They are all trained so did a fabulous job" (Cheryl). Seeing her children take over running the reception was for Cheryl one of the standout moments of the day. One of Bill's daughters gave a reading during his and Evan's ceremony and his son-in-law acted as Master of Ceremonies during their reception. Not feeling constrained by 'tradition', Paige said she decided to have her only brother as her witness. "Because he's the only boy, he was never going to be a bridesmaid for anyone [...] so I thought, well, here's his opportunity to do what his sisters have done for each other. Yeah, so it was quite fun".

Some of the most innovative aspects of participants' civil unions were in fact the ways in which they involved their guests. Lara \& Hailey described their treeplanting 'ritual':

Lara: Before the ceremony one of our friends went around everybody and they wrote down a wish for us on a piece of paper. And I guess they thought that they were going to give us the wish but what we did was, because we were trying to work out a way to include everybody in the actual ceremony as well and we wanted to plant a tree, we put their wishes in the hole first. So it's kind of like [...] mulchie stuff. And so hopefully the tree won't die. It's looking ok at the moment. We planted it in a place where we are going to have a little outdoor seating area. Because it gets all the afternoon and evening sun so it will be there all the time.

Hailey: And it's flourishing. We also, during the ceremony, got everyone to say like, "Do you?" "We do agree." So it was quite participatory.

At the beginning of their ceremony, Heather \& Jill introduced each of their guests by presenting them with an item of personal significance.

Heather: So to introduce people we had a prop of something that connected us with them. So for my sister, you know, I had [a photo] of my first day of school, with the two of us together with our umbrellas and little bags. And I had my little soft toy that I'd bought in America for Mum and Dad so they didn't feel like they'd lost, you know, [that I'd] grown up and left home. [...] And another friend, whose lavender she gave us when she went overseas, which was still alive - which 
died and I'd thrown it in the garden and it just exploded [into life]. So I cut some lavender for her and gave her the lavender. And Jill had a tea towel for her cousin because they always used to do the dishes together and swat each other.

Jill: Wet tea towel fights.

Heather: So we had a little thing for everybody that we gave to them - that connected us. [...] So, introducing everybody meant that I connected with them and they connected with me before we had to do the sort of mushy stuff that was quite hard to do in front of a whole lot people.

In many instances, friends and family were also described as essential to the planning and execution of the civil union. A few participants reported that parents had contributed to the cost of their civil union ${ }^{30}$ and several participants said that friends and family had helped them with the catering. Yvonne \& Loana spent approximately $\$ 30,000$ on their civil union but said this figure would have been substantially higher without the help of friends and family. Their invitations were designed and printed by a friend as part of their 'wedding' present to them; their brother in-law provided a "wicked" sound system for their reception and another friend offered to be their photographer. A friend of Loana's, who is head of home economics at her old college, made their wedding cake and a friend of Yvonne's did her make-up which also involved painting on a Māori moko. Lara \& Hailey recounted a "story" about how both their mothers, who had never before met, jointly made their civil union cake:

My mother made the cake. It's a Christmas cake, an old Christmas cake recipe. And my mother made it and then shipped it up to Auckland and then your [Hailey's] mother decorated it, because Hailey's mum decorates cakes really nicely. So that was a nice little thing for the mums to do (Lara).

Some couples had talented guests perform items such as songs or dances at their civil union. Music, for instance, featured strongly in Laura and Colleen's civil union. The choir to which they both belonged sang at their civil union and Laura performed with her band.

\footnotetext{
${ }^{30}$ In a Western marriage it has been customary for the bride's parents to pay for the wedding. This practice, however, has changed in recent years. Both sets of parents may contribute to the wedding costs or the marrying couple may pay for their wedding themselves.
} 
Several participants commented on how surprised they had been by people's enthusiasm. Barbara, for example, said that she was "amazed at the number of people who got so excited and enthusiastic" about their civil union. "Like, one of my colleagues at work got really involved in all the flowers and did huge amounts of flower arranging, blowing up balloons, and decorating the place". Reflecting on the big party they held in honour of their civil union, Joss commented: "It was totally moving how many people just pitched in to make it happen. It was incredible”.

Whilst it is not unusual for people to have different 'clusters' of social relationships, gay men and lesbians are more inclined to keep different groups of people "compartmentalised" - often along lines of sexual orientation - particularly if they have been 'closeted' about their sexuality, experienced episodes of homophobia, or had issues with family accepting their 'orientation'. As Lara expressed it,

It was [...] a bit trippy seeing everybody from different parts of your life all together. It was really nice but I [...] would probably tend towards keeping people quite compartmentalised. [...] [It was also] a little bit stressful because I was worried about how my family would be [...] with the 'queer' stuff.

On the actual day of their civil union, though, Lara's family were, as Hailey expressed it, "sweet"; "They were so fine, so relaxed and easy and took themselves off when they needed to and talked to people really easily".

For some participants, the diversity of their guests was in fact one of the most memorable aspects of their civil union. For example, when I asked Bill what stood out for him, he replied: "the generosity of spirit of people and the mix of people. There were straight people, gay people, transgender people, politicians ... a whole mix of people. And it was great - good fun!" One of Yvonne \& Loana's friends had apparently commented on the diverse nature of the guests at their civil union: "Oh, so you've got this whole Māori, Pākehā, lesbian, gay, trans, people with disabilities things going on". Yvonne recalled with some pride,

You couldn't give someone that criteria and you couldn't pay people to put something like that together but that's just how our life is ... We have lots and lots of photos of our day and what we saw was the mixture of people. So in any 
one shot you've got... ok, there's our lesbian softball players, there's our really born-again-Christian brother-in-law [...] and, yeah, our enormous nephews dancing with these little pakeha lesbians. And I think, even though we had been 'out' all our relationship - our kids have known that - they don't see any other part of our lesbian-gay world.

For many participants, their civil union represented a de-compartmentalisation of their 'queer' world and their 'straight' world and in this way signalled another level of incorporation in the ongoing 'coming out' process. The diversity of their guests also reflects the expanding notion of 'family' and how, for many people, the locus of intimacy and support extends beyond the traditional boundaries of kinship.

\section{Civil Union and Close Social Relationships}

Often the most profound outcomes of a couple's civil union were the shifts that occurred in their close social relationships. Heather, for example, described their civil union as a "turning point" in terms of how her parents perceived and related to her partner Jill. After Heather \& Jill had been together for eight years, Jill had finally been accepted as "the daughter in-law". As Heather explained, "We're the girls and Jill is the daughter-in-law. And Jill gets Dad's season pass at the rugby when he's away". Heather's parents had reportedly, also started taking an interest in Jill's career. Whilst this level of ownership and incorporation might have happened eventually, Heather believed that their civil union had "made it happen or brought it forward". Heather attributed the shift in her parent's attitude to the fact that their relationship was now 'legal': "The legal sanctioning [...] made us, in their eyes, different [...] It's kind of like you're grownups". She also added somewhat humorously, "Now that my sister's got a boyfriend, [...] we're saying, 'Jill has traditional first rights on the season pass for the rugby' [laughing]" (Heather).

Some participants said they had often had the sense that people generally did not consider their relationship to be as "serious" as a heterosexual relationship and that this view was something that had changed since their civil union. Cathy, for example, recalled that many of her colleagues had seemed quite surprised when she had announced at work that she and Paige were having a civil union. 
It was like they suddenly took our relationship seriously, that we were actually getting hooked up [laughs]. And they just kind of pictured us as being, I don't know, flatmates or something. I don't know what they... I don't know what was going on in their heads, but I did kind of sense that it did make them [...] take us more seriously as a couple.

Thinking back to before their civil union, Brad similarly commented on how people had talked about him and Marcus as "the boys":

Brad: A lot of people do think of us like that and they call us the boys. And it's got a slightly diminutive kind of effect. It makes you feel younger - the use of the word 'boys'.

Marcus: Like lads kicking around together.

Brad: I think that's how some people see us, like a couple of brothers or hanging out together. And I think that's somehow how people try to get their head around us being a couple. So that was something that has shifted for us since our civil union.

Becky \& Bridget were surprised how people started to treat them differently as soon as they announced they were having a civil union. As Becky explained, "So we had this marriage about to happen and suddenly people were saying nice things to us". Reflecting on this change, Bridget commented, "They could relate [...] and they could kind of make the link, you know? 'Oh, that's like I had, you know? And your relationship is like my marriage', yeah". Becky described this acknowledgement of their relationship as "a completely new experience". Bridget added that it "was one of the neat surprises about doing [the civil union]".

Emile said he was surprised by how much difference their civil union had made for his parents. Pondering this, Emile commented,

I'm wondering if for our parents - parents with gay children - whether somehow it's fitting in to that kind of understanding of relationships. For my parents it was very much the case and my sister as well once they found out actually what a civil union in New Zealand was.

Many participants felt their civil union had helped to "normalise" their relationship, and that this normalisation had, in turn, helped accelerate processes 
of familial acceptance and incorporation. At the time that the Civil Union Bill was being debated, the government select committee went to great lengths to position civil unions as something quite distinct from a marriage. Many participants' families and friends, however, referred to their civil union as a wedding and regarded them as being married. Yvonne, for example, said that their civil union had helped them "repair" some of their relationships with their born-again Christian family because, as she explained, "they respected that we were married". Marriage, as mentioned in preceding chapters, is an important meaningconstitutive tradition and "an extremely powerful cultural model of relationships" (Hull 2006: 2). As Hull points out, its power as a cultural resource "lies in the fact that its dominant meanings are so widely shared in contemporary Western culture" (2006: 197). As a relatively new institution, civil unions have not as yet developed their own language or customs. As the comparable and socially dominant cultural model, marriage thus becomes the default script from which guests and participants alike draw various resources, meanings and schema about family, love and maturity (Hull 2006: 14). Within the widely understood framework of marriage the previously ambiguous relationship is translated or clarified, dispelling any uncertainties over its true nature. The familiarity of the occasion, furthermore, helps to facilitate acceptance and stress the equivalency of same-sex love to heterosexual love (Lash 2012: 169). Importantly for family, it also provides a code for locating the partner in kinship terms; this person is like a wife or a husband and, therefore, a son/daughter, sister/brother-in-law.

Many participants reported that their civil union had also made a difference for their children. Marama, for instance, mentioned how important their civil union had been for Deb's nephew, of whom she is the legal guardian. "It was about legally normalising us and our family really. So that's kind of nice actually. It's interesting that that's [what] the impact [was] on him. He was all for it. He was quite excited about the idea (Marama). The civil union both clarified and "normalised" the relationship - not just for the children themselves but for their peers as well - by locating the relationship within a readily understandable 
framework..$^{31}$ The status of 'married' also had a perceived legitimacy attached to it and, importantly for some participants' children, signalled permanency; code for 'this person is going to be around in the future therefore I can allow myself to get close to them'.

Some female participants reported that their partners' children had since their civil union started to refer to them as their step-mum and that they had also received Mother's Day cards. Although Gail had been involved in Jessie's son's life for many years, he apparently decided when they were having their civil union that Gail was now his "stepmother". Gail said that their civil union had made sense for Jessie's son: "It gave him a bit of a framework". Jessie thought that choosing to call Gail his stepmother meant that her son had accepted her "at a really deep level”. It also, as Gail noted, gave him a way of explaining their relationship to other people by situating it in kinship terms. Reflecting on her son's "deeper" acceptance of Gail, Jessie commented, "it was one of the most significant results of getting civil unioned". Gail added, "Yeah, and not one we even anticipated really".

For some friends and family, attending a same-sex civil union constituted a form of 'coming out'. Attendance suggested at least a degree of acceptance and, at best, an affirmation of the couple's relationship. As Hull notes, "the act of deciding to have a public ritual [...] forces others to make what amounts to a political decision, because merely showing up constitutes active participation in the ritual" (2006: 72). For some guests, the civil union may also have been the first time they had witnessed same-sex intimacy up-close. Most participants, however, reported that their guests had seemed genuinely pleased to be there and were often "really quite profoundly moved" during the formal part of the ceremony. Frank, for instance, described their ceremony as "very emotional" and recalls that lots of people cried: "I think everybody cried!" Garth said that during the formal part of their ceremony "it was amazing to hear the sort of little sniffles going off all around".

\footnotetext{
${ }^{31}$ In a Canadian television documentary titled: Why thee wed? (2006), some couples also reported that it had made a difference for their children to be able to say to others that their same-sex parents were married because of its perceived legitimacy.
} 
For a few family members, attending the civil union assumed the significance of a personal rite de passage involving what Gilbert Herdt (1987) might refer to as a process of 'radical resocialization'. According to some participants' accounts, previously homophobic relatives underwent a transformation, if not in status then in attitudes, becoming firm advocates for gay equality. Reflecting on the transformation that occurred in Jodie's father, Kate remarked,

For her dad [the civil union] put our relationship in the family category, because he was always very much blood is thicker than water. And the only way you get through that is by marriage, which of course we can't do, but now he includes [civil unions] in it. And he is also Catholic and he was very, very anti-gay, very homophobic. But now he gets really cross if people are homophobic.

Parents did not, however, always react in the same way. Trisha said she immediately experienced a sense of acceptance and "ownership" as a daughter-inlaw from Pam's father but not from Pam's mother. For Pam's mother, there was too much conflict between her religious beliefs and the "gay thing". According to Pam, "She just never got her head around it. [...] She always thought she'd done something wrong - especially with two gay kids; how did that happen?!" (Pam). Pam's mother did, however, attend their civil union and, according to Trisha had, in fact, been "gracious enough".

Not all people in the gay and lesbian community were approving of civil unions either. Will, for example, recalled that a "very dear friend", who had been both his "attendant" and their Master of Ceremonies, had not been supportive of civil unions. Because the civil union was for Will \& Geoffrey, though, he had agreed to be a part. Will \& Geoffrey described how the experience of their civil union had prompted a change of heart.

Will: When he actually got here, and suddenly he realised what we were doing what was involved in all this - I think it suddenly hit him. He had [the] experience of saying, 'hello, this is not just something frivolous'.

Geoffrey: He made a comment about something we had in [the celebrant's] thing, and he whispered in your ear, 'That's totally thrown me'. So, suddenly it all fell into place for him. 
A: In the absent friends toast, [...] we were able to mention our departed parents.

We also mentioned my [attendant's] departed partner. And he just cracked.

Law, in a democratic society, has powerful symbolic capacities and the ability to shift the boundaries of wider society in terms of what is deemed socially and culturally acceptable. I argue that for many participants' families, the legitimacy conferred through legal recognition played a significant role in re-framing their loved one's same-sex relationship as socially normal. The legitimising effects of law also intersected with the socially dominant cultural model of marriage to invest same-sex civil unions with meaning and, in many instances, initiated or accelerated processes of familial acceptance and incorporation. As Heather noted, whilst this level of incorporation may have happened "eventually", the civil union "made it happen or brought it forward". The characteristics of ritual also, I suggest, have a role to play in shifting the boundaries of social acceptability. Importantly, they also help explain the sometimes 'radical' transformations that occurred in some guests' attitudes as well as the heightened emotions more generally experienced during the ceremonies.

The very act of congregating is, as Durkheim (1995: 217) observes, an "extremely powerful stimulant". Once gathered together, a sort of "electricity" may be generated by the ritual participants' closeness, producing what Durkheim refers to as 'collective effervescence'. Durkheim distinguishes two forms of collective effervescence: creative and re-creative. Both forms are characterised by intense emotions, but whereas re-creative collective effervescence strengthens existing moral ideals, creative collective effervescence is "a phenomenon during which new ideas and morality can emerge as well as ideal conceptions of society" (Olaveson 2001: 101). Civil unions as 'effervescent assemblies' can within Durkheim's framework be seen simultaneously as creative and re-creative in that they reinforce the ideals associated with marriage - love, commitment, family, and maturity - while also challenging the presumed heteronormativity of marriage. Within effervescent assemblies, there is also "a compulsion to dissolve limits, differentiation and particularity", especially during moments of heightened emotional intensity (Ramp 1998: 144, 146). This de-differentiating tendency of 
collective effervescence has similarities with Turner's notion of 'communitas'. Communitas, according to Turner, is an "expression of sociability that stresses equality and comradeship" (1974: 232). Like collective effervescence, communitas is also usually experienced as a "deep" or intense emotion which can be transformative in nature (Olaveson 2001: 104).

Turner's notion of communitas and Durkheim's notion of collective effervescence help account for the often intense emotions experienced by guests during the ceremony. The formal characteristics of ritual, furthermore, mean that messages are conveyed in an "authenticating and arresting manner" - as unquestionable (Moore and Myerhoff 1977: 8). Ritual, as such, discourages inquiry making it an effective form for communicating "those very things which are most in doubt" (Moore and Myerhoff 1977: 18; 24). Familiar symbols provide the content and potency of rituals and imbue the action with greater meaning. The power of symbols lies in their ability to transcend words and make the complex simple, to be multi-vocal, and to also arouse emotions. These effective and affective qualities of ritual, I suggest, work to intensify the connection between ritual participants and the symbolic objects of communication and, in doing so, have the ability to transform the attitudes and behaviour of those present (Alexander 2006: 30; Deflem 1991: 5). In this way, rituals may be active agencies of change representing, as Turners suggests, "the eye by which culture [or persons] sees itself and the drawing board on which creative actors sketch out what they believe to be more apt or interesting 'designs for living” (1986: 24).

\section{CONCLUding COMMENTS}

For many participants, 'coming out' as a gay man or lesbian had a destabilising effect on their familial relationships, particularly those with parents. For some this period of disjunction was relatively short-lived while for others it was ongoing or even permanent. Some described their relationship with their family in terms of a "progression", ultimately leading to familial acceptance and incorporation. For most participants in this study, interactions with family of origin remained as important as, if not more important than, those with friends. For a few participants who had experienced detachment or exclusion, either because of 
their sexuality or a more general history of familial dysfunction, friends took on greater salience as their 'family of choice'.

Having family and friends at their civil union was described by most participants as extremely important. Some simply wished to celebrate their civil union with those people most meaningful to them while others used their civil union more consciously and purposefully; as a vehicle for gaining recognition, acceptance and support from family and friends. Guests' attendance at the civil union was, in turn, highly valued by couples and many went to considerable lengths to include them in the ceremony.

Often the most profound outcome of a couple's civil union was the shifts that occurred in their relationships with family of origin. In accounting for these transformations, I have argued that the civil union operates as a 'normalizing rite of passage' that catalyses support and recognition from family members otherwise opposed to or nominally tolerant of homosexuality (Green 2010). For many participants' families, the legitimacy conferred through legal recognition played a significant role in rendering same-sex relationships socially 'normal'. The legitimising effects of law also intersected with the socially dominant cultural model of marriage to invest same-sex civil unions with meaning and, in many instances, initiated or accelerated processes of familial acceptance and incorporation. The effective and affective qualities of ritual, furthermore, worked to intensify the connection between ritual participants and the symbolic objects of communication and, in doing so, had the ability to transform the attitudes and behaviour of those present (Alexander 2006: 30; Deflem 1991: 5).

In this chapter, I have explored the social embeddedness of couples' relationships by situating the civil union within the context of close social relationships. In the next chapter I continue with the theme of social embeddedness by exploring the meaning of the civil union within a macro socio-political context. 


\section{6}

\section{Trajectories of the Socio-Political}

\section{INTRODUCTION}

Participants' narratives and the discourses they constructed around their civil union experience were informed both by their history as an oppressed and stigmatised minority and by a rhetoric of rights and recognition. One of the key ideas to emerge and endure from the gay liberation movement was the idea that homosexual people were oppressed. The concept of oppression illuminated the historical and social factors that had shaped attitudes toward, and inhibited the expression of, homosexuality or, what C. Wright Mills might refer to as the intersection between private troubles and public issues. This chapter explores this intersection by situating the civil union specifically within a socio-political context. For heuristic purposes I distinguish between narratives of the political and narratives of the social although, in reality, the boundaries are far less discrete than the division implies. There is, however, a temporal aspect to the distinction. Narratives of the political largely refer to events prior to the civil union while narratives of the social refer largely to events subsequent to the civil union.

To provide context, I begin by outlining participants' early political involvement. I then examine participants' narrated views towards the civil union legislation. Whilst all my participants had chosen to formalise their relationship in a civil union, their attitudes towards the Civil Union Bill itself varied considerably. At the heart of the matter was the establishment of a separate institution. I argue that, for some participants, their political principles were a motivating factor in their decision to have a civil union, while for others their political views were initially a barrier which had to be overcome through strategies of reframing or 
negotiation. In narratives of the social I then examine how legal recognition of same-sex relationships has impacted on relations at a more general societal level. I argue that for many participants, legal recognition translated into a greater sense of entitlement, which for some also produced a corresponding feeling of confidence to be more 'out' as a couple. Participants often reported a positive change in informal interactions as a consequence of their civil union which in turn promoted feelings of greater incorporation into mainstream society. As in the previous chapter, I argue that the legitimacy conferred through legal recognition intersects with the social intelligibility of 'marriage' to assign same-sex civil union couples with a social status to which heteronormative society can relate. When viewed within a historical trajectory of homosexual rights, civil unions can, I suggest, be seen as an important institutional bridge of legitimation leading to greater incorporation of gay people as citizens.

\section{Narratives of the Political}

Many participants in this study reported that they had been politically active at some point in their life. Those who had not been active politically often recalled that they had, however, been supportive of issues from the side lines. Political involvement typically centred on issues of human emancipation. The particular issue(s) participants were involved in generally reflected strands of their identity that were subject to discrimination and/or oppression or were issues they felt particularly passionate about. An ideal of human emancipation is closely linked to contemporary understandings of identity and its underlying ethos of authenticity and self-growth. As an ideal, emancipation has come to the fore in the realm of politics. The idea that we have a "personal identity to discover, a personal identity to fulfil" has, as Roszak argues, "become a subversive political force of major proportions" (cited in Giddens 1991: 209). Giddens defines emancipatory politics as "a generic outlook concerned above all with liberating individuals and groups from constraints which adversely affect their life chances" (1991: 210). Emancipatory politics starts from the premise that some social groups are, owing to their identity as say women, indigenous persons, or homosexuals, vulnerable to cultural imperialism and are concerned with reducing or eliminating "exploitation, inequality and oppression" (Heyes 2007; Giddens 1991: 211; original emphasis). 
Justice, equality and participation are the ethical imperatives that underpin emancipatory politics (Giddens 1991: 215). However, 'recognition', in the sense that Charles Taylor (1994:36) uses the term, also plays an essential role. The absence of recognition, either at a personal or social level, can, as Taylor observes, "inflict damage on those who are denied" (1994:36-27). As discussed in chapter three, an identity can be formed or malformed through the course of contact with significant others such as family and peers and is vulnerable to 'recognition' being given or withheld. At a social level, non-recognition or indeed misrecognition (the projection of an inferior or demeaning image on another) can inflict harm and can be a form of oppression, imprisoning someone in a false, distorted, and reduced mode of being (Taylor 1994: 25). The role and importance of recognition is now widely acknowledged in one form or another and is central to discourses on human rights and principles of equal citizenship (Taylor 1994: 36, 38).

Citizenship, as a concept, is constitutively built on a set of binary constructs that are concerned with the exercise of rights and entitlements in the public realm of a given nation state (Stychin 2001: 285-286, 289). Members of dominant groups, whose identities are privileged as conforming to the national 'norm' are, as Seuffert (2006) notes, 'unmarked' by race, gender, or sexual orientation and are, as a consequence, granted full recognition and access in terms of citizenship rights. Those viewed by the majority as deviating from the 'norm' are, by comparison, 'marked' by their 'otherness'. They are in Taylor's (1994) terms, misrecognised and, as such, experience diminished citizen rights relative to the dominant social group. Until the enactment of the New Zealand Homosexual Law Reform Act in 1986, it was illegal to be a gay man in a gay relationship and discrimination on the basis of sexual orientation was not explicitly prohibited until 1993 under the Human Rights Act. While gay men have been historically misrecognised, lesbians, by comparison, have gone largely unrecognised by society in any formal legal sense. It has never been illegal to be a lesbian in New Zealand and, for some time, it was even believed impossible for two women to be sexual together. Although misrecognition and non-recognition present different issues, they have the potential to be equally insidious; both can inflict harm and constitute a form of oppression. 
The institutionalised oppression of homosexuals that existed in New Zealand, prior to the legislative changes detailed above, produced inequities based on membership in a certain social identity group. As well as being denied full citizenship rights, such as the right to marry, gay men and lesbians were also subjected to denigration, dehumanization and demonization, which were then sometimes also used to justify aggression and violence towards gay people. To identify as a gay person essentially meant accepting a marginalised life and a status as a second class citizen.

Since the adoption of the Universal Declaration of Rights by the United National General Assembly in 1948, human rights as a doctrine has become a cornerstone of national and international policy. It is also the basis on which many groups and social movements - including gay liberationists - have achieved profound social change. The invocation of equal rights claims has, as Hunter observes, become "one of the most powerful weapons available to a movement seeking justice for the excluded and disempowered. The very framing of one's assertions in terms of rights highlights one's membership in, and thus the justifiable reciprocity of one's claim on, the larger polis" (1991: 27). Those who have been denied full recognition and rights have, as Seuffert notes, also often argued against second class citizenship (2006: 289). Gay identity movements, for example, have primarily pursued a politics of 'sexual citizenship' aimed at national recognition, both in terms of equal rights and what Steven Seidman (2001: 323) refers to as, "gay purification" - as possessing the "psychological, moral, and social traits that render them good and warrant their integration" into the wider polity. In seeking full admission to the polity, the gay movement has, as Seidman (2001: 323) observes, sought to make being gay irrelevant to national citizenship.

Given the long-time social classification of gay men as criminal and unnatural, it is not surprising that gay equality issues were a core focus for many male participants' political activism and later, due to its relevance for the gay community, also HIV/AIDS. Bryan \& Frank, for example, have throughout their lives together been extremely active in gay rights and in bringing about political and legal reform. Although they met during the 1970s when it was still illegal to be 
a gay man and in a gay relationship they had, apparently, always been open about their relationship. Reflecting on this candid approach, Bryan commented,

We have always lived an openly gay life, which people might find astonishing because we were teachers in the '7os and '8os at a time when New Zealand was a very conservative society. It was illegal to be male and gay and in a gay relationship. But we were never any different. We never pretended to be straight.

Despite living an openly gay life, Frank \& Bryan said they were always very aware that their sexuality was against the law: "As gay men, we were not equal in this society". They counted themselves fortunate to have never experienced any overt discrimination for being gay but when the Homosexual Law Reform Bill came along, an issue that strongly affected their lives, they said it was natural for them to get involved. Bryan attended the first ever gay liberation meeting to be held in New Zealand in 1972 and by the 1980s, when the Homosexual Law Reform Bill was being debated, he had entered politics. Throughout his career in politics, Bryan, with the support of Frank, has been active in the fight for political and legal reform on matters concerning the equality of gay men and lesbians and they were both key proponents in the Civil Union Bill campaign.

Over the years, Evan \& Bill have also been involved in many politically-oriented gay organisations. Before meeting Bill, Evan was actively involved in the Homosexual Law Reform campaign which also, reportedly, provided the catalyst he needed to come out as a gay man. He entered the gay law reform debate initially through talkback radio but ended up working full time on the campaign. Through his involvement in the campaign, Evan said he came to realise the importance of being visible and of labelling himself as gay - even though he risked a 14 year prison sentence if he was caught. Fran Wilde, who led the campaign for homosexual law reform, was, according to Evan, very concerned for people like himself who had through the campaign 'come out' publicly and been noted in the media. "She just thought, 'well, if the Bill doesn't go through we are in deep trouble'. Anyway, the Bill did go through - with a struggle and a fight." Because of the very real threat of incarceration, many gay men, as discussed in chapter two, chose not to become involved in the Homosexual Law Reform campaign. For some who had been 'closeted' about their sexuality, active involvement in the campaign also 
risked revealing their sexuality to otherwise unsuspecting straight family and friends.

After the Bill was passed in 1985, Evan continued to pursue his quest for gay equality by becoming actively involved with the AIDS Foundation which is where he met his life partner Bill. Although Bill had not previously been involved in politics, he very quickly joined Evan in his mission and together they have been involved with many lesbian and gay issues since, including the Civil Union Bill campaign and the fight to gain legal recognition for same-sex relationships.

Having grown up in South Africa, Brad said that reforming apartheid had taken priority over gay rights in terms of his political activism. More recently, though, Brad said he had, through his work in medicine and psychotherapy, also written articles and given talks that "challenge and deconstruct some of the homophobic theories in psychoanalysis". In contrast to most participants' self-proclaimed leftleaning political orientations, Jason had been a member of the Young Nationals while at university. ${ }^{32}$ Through his involvement he had, however, tried to influence the National Party's policies around gay and lesbian issues. In his present employment Jason has also been involved in many lesbian, gay, bisexual and transsexual (LGBT) initiatives including setting up a networking group for the LGBT employees. A few other participants in this study had, through their work in government organisations, also been in a position to influence policy decisions that impacted on gay people in New Zealand.

Female participants' political activism was typically more diverse than male participants' and reflected the intersection of multiple forms of discrimination. Gender-based discrimination, however, generally took precedence with most female participants reporting that they had first become politically active through feminism and only later did they become actively involved in other political movements. Jessie, for example, described herself first and foremost as a feminist. During the 1970s she had, however, also become actively involved in a number of other human rights-based issues such as the anti-war movement and protests

\footnotetext{
${ }^{32}$ The New Zealand Labour Party has typically been more supportive of gay rights issues than the more conservatively oriented National Party.
} 
against apartheid in South Africa. In the 1980s, she then became involved in the campaign for homosexual law reform in her capacity as an actor. Her present political interests were less human rights-based and more to do with issues around the environment. Becky, as discussed in chapter three, was politically active first in feminism and later in gay rights issues. After being diagnosed and treated for breast cancer, she had also become involved in "breast cancer politics" and in trying to influence decisions in healthcare regarding funding for treatment. For female participants who were Māori or Samoan, culture was a further axis of oppression and another competing factor in terms of their identity politics. For Yvonne, Māori politics and issues of tino rangatiratanga (Māori sovereignty) had been an important focus in her career. She had also, as mentioned in chapter three, been involved in setting up an organisation for takatāpui, which provided an explicit intersection for a politics based on both culture and sexuality.

Although Bridget did not consider herself to be as politically motivated as partner Becky, she had, prior to the civil union legislation, made several submissions to Statistics New Zealand about having a question on sexual orientation included in the national census. When the Civil Union Bill was finally passed, Bridget recalled thinking, “Oh, thank God for that. That'll do. They'll have to put a box in for it now, won't they? So we've won that one". Bridget's comment highlights the importance of bureaucratic recognition within the state structure and the power of statistics to make some groups visible or, conversely, invisible. The denial of recognition can, as mentioned above, be a form of oppression, thereby reinforcing the notion of second-class citizenship. 'Visibility' as a theme was regularly mentioned by participants and was analytically important on two levels. Being visible was seen as the necessary corollary to oppression and essential for gaining full access to citizenship rights. Visibility was also seen as a key tool for breaking down social prejudices and phobias. By being "out there", society would come to see gay people as 'normal' and ordinary, providing a counter challenge to negative stereotypes that foster social fear. 


\section{The Civil Union Bill: attitudes and campaign involvement}

Civil unions, like marriage, are essentially a social construct, a creation of law: a state-sanctioned contract affirming bonds of love to which one consents (Austin 2006: 192). As institutions, marriage and civil unions provide recognition in the public sphere for a typically private sphere activity: our private sexual lives. Law, as a social practice, is, according to Robert Post (n.d.), "built around the need for fostering cooperative and coordinated action". In a democratic society such as New Zealand, the law - in theory - is an implicit contract expressing the collective will of citizens, decided and adjusted through democratic processes and institutions. Although ultimately shaped by its internal logic, law is as such structurally affected by politics. It operates in the selection and transformation of political decisions into legally significant elements (Paulus 2000: 471). Once committed to the professional expertise of the legal system, though, political decisions generally cease being political in an agonistic sense and may even, in turn, constrain future political action (Post, n.d.). The law therefore plays not only an important role in conferring rights and entitlements it also, as discussed in the previous chapter, plays a powerful role in constructing the symbolic order - what Drucilla Cornella describes as the "imaginary domain” (cited in Austin 2001: 196).

For subordinated social actors, official law has particularly powerful symbolic capacities (Hull 2006: 147, 198). It can demark inclusion, acceptance and approval on the one hand or exclusion, inequality and oppression on the other. For all study participants, legal recognition of same-sex relationships by the state held symbolic significance in its own right. For the first time in New Zealand's history, same-sex couples were being formally recognised and offered the opportunity to enter into a legal relationship comparable in status, rights and responsibilities to a heterosexual marriage. Most participants also anticipated positive ripple effects on mainstream society's beliefs and attitudes: legal recognition not only conferred legitimacy it also had the capacity to 'normalise' gay and lesbian relationships and was, therefore, seen as the key to greater social acceptance.

Law, as Bourdieu (1987) explains, is a constitutive force in modern liberal societies and a quintessential form of symbolic power. In naming, law creates the thing that 
it names and "confers upon the reality which arises from its classificatory operations the maximum permanence that any social entity has the power to confer upon another" (Bourdieu 1987: 838). The law's power stems from its recognition as the legitimate form of ethical representation and practice which, in turn, presupposes a commitment to common values and the existence of explicit rules and sanctions (Bourdieu 1987: 844). "The universalizing claims of legal doctrine and procedure, which are manifested in the work of juridical formalization, contribute", furthermore, "to the establishment of their practical 'universality"' (Bourdieu 1987: 844). In this way, law extends beyond the circle of those who are already 'believers' to society more generally (Bourdieu 1987: 843). The civil union legislation thus gives credence and validity to same-sex relationships but also has the capacity to produce deeper, transformative effects in society as a whole - "eventually naturalising the presence of same-sex couples in ways that efforts to educate and persuade through argument and information never would" do (Hull 2006: 127).

Whilst all my participants had chosen to formalise their relationship in a civil union, their attitudes towards the civil union legislation itself varied considerably. At the heart of the matter was the establishment of a separate institution and questions over equality. Although the Civil Union Act 2004 does much to extend the conventional rights of marriage to gay couples, it still does not permit them to marry. Rather, it sets up a two-tier system whereby heterosexual couples have the choice of either a civil union or a marriage while same-sex couples have only the option of a civil union. Although Evan \& Bill became vigorous proponents in the Civil Union Bill campaign they did not, however, initially support the establishment of a separate institution. In the beginning, they believed it had to be "marriage or nothing". Evan compared his early view on civil unions to the uncompromising attitude he had taken during the Homosexual Law Reform campaign. Back then, he had belonged to a group that advocated for the legal age of consenting sex between men to be 16: "Either the legal age [was] 16 or we did not want the Bill to go through. If it wasn't 16 it wasn't equal with heterosexuals. It was still saying that being gay's bad". 
However, as the Civil Union Bill progressed through the government select committee, Bill said they started to realise that a civil union would confer the same rights and responsibilities as a marriage. This aspect was important in initiating a change in their thinking.

The name was different, sure. But it was also available to heterosexual couples and, therefore, put us on a par [...] with heterosexual couples who wanted civil unions. [...]. But underlying that was the sort of pragmatic approach; what the hell did it matter what they called it as long as it gave me the legal recognition and the same rights and responsibilities [as married heterosexual couples]. Because if I went to Australia, it wouldn't be recognised, if I went to the States, it wouldn't be recognised. So, what was crucially important, particularly at our time of life, was to have something that recognised and gave us some sort of status, here and now, in New Zealand. And that's what it's done. Yeah. And there's still a debate going on about marriage [...] But, you know, I don't see that we would have achieved anything by going for marriage, and we might in fact not have got it through.

Further rationalising their change in thinking, Bill added, "from my point of view, [marriage] also seemed to imply some sort of religious element to it, you know. And yet, you know, it's a state institution - marriage. The wedding is the church thing, but the signing of the papers is the state institution, which is what we've got". The final "clincher" for Evan \& Bill came when a member of Parliament, Peter Dunne, proposed that gay and lesbian couples be paid the lower pension rate of a married couple rather than that of two singles, but without the same legal recognition. “That really swayed both of us. Right, we've got to support civil unions!" (Evan). Having reconciled their ambivalence to the establishment of a separate institution, Evan \& Bill became firm advocates, setting up the Civil Union Support Society in 2004. Their home became the headquarters for the operation and a hive of political activity.

Evan \& Bill's narrative detailed above encapsulates many of the themes raised by other participants. For some, the establishment of a separate institution was yet another example of gay men and lesbians being denied the same rights as heterosexuals. Others were more pragmatic in their approach and viewed civil unions as "progress" towards equality. Some participants said they "preferred" the 
idea of a civil union to marriage because the legislation was genuinely "equality driven" and/or did not have the historically religious and patriarchal connotations of marriage. 'Rights' rhetoric was often employed to frame what participants viewed as positive about the civil union legislation but also what they viewed as negative about it. Most believed that same-sex couples should be entitled to the same legal rights and protections as opposite-sex couples; that their relationships were equal to and, therefore, as valid as opposite-sex relationships. Although some participants voiced a preference for civil unions over marriage, most still felt that same-sex couples should have the right to choose either to marry or to enter into a civil union, in the same way that opposite-sex couples are able to.

For some participants, the distinction between marriage and civil unions, and differential access based on the gender of the couple, was another example of gay oppression and further evidence that society still viewed same-sex relationships as inferior to heterosexual relationships. Brad, for example, drew a comparison between marriage and civil unions and the apartheid system:

It's like saying, yeah, you can have your civil unions and we'll have our marriage and they are the same but just don't come and mess with our marriage. It's a weird thing, like it still feels like [we] are not able to join the country club. It still feels like a distinction is being made.

For Marcus, "the big difference is, politically, equity and equality are not the same thing”. Although he viewed civil unions as equitable to marriage in terms of the legal rights they conferred, they were still separate from and, therefore, not equal to marriage. For Marcus and many other participants, the symbolic and cultural aspects of marriage were equally as important as formal legal recognition. As a relatively new institution, civil unions were seen as lacking the history, traditions, and socio-cultural meanings that are associated with marriage. As Marcus expressed it, "I think marriage is spiritual and soul and religion and ritual and life and kids. [...] That's the whole nine yards". Speaking from his own experience, Marcus believed that many same-sex couples entered a civil union purely because of the legal benefits and not because they believed they were entering a meaningful symbolic institution. Michael, similarly, acknowledged the near legal 
equality that civil unions provided but said that "in terms of social, moral and emotional equality" he viewed marriage as "higher up the ladder". Although pleased that she and Jill were now able to have their relationship legally recognised through a civil union, Heather said she also felt "quite incensed" that the Marriage Act still discriminated against same-sex couples.

We don't have equality in an ideological sense and possibly in a legal sense. But the ideology of it, you know, [...] I've still got a little bit of that in me that says, yes, I understand and agree with the Jenny and Jools ${ }^{33}$ when they say that we have got second best and that there's an Act there that discriminates against us and it shouldn't. And that we should have the choice. [...] So, you know, that still eats at me.

For participants such as Heather, Marcus, Brad and Michael, same-sex couples are still being denied access to a symbolic resource and an important meaningconstitutive practice - one that brings psycho-social benefits and protections which may, as discussed in chapter three, have a significant bearing on the self, the dyad and one's relationship to the larger social order (Green 2010: 416). In denying homosexuals the same access to the state-controlled symbolic order that heterosexuals currently enjoy, homosexuals' rights of citizenship are undermined (Austin 2006: 186). Full admission to a polity not only entails a grant of formal public rights, it also assumes an expressive ethos. To be fully admitted, one must be allowed to express and affirm in a public manner those aspects of one's identity that matter most while also being universally accepted in a social way.

Those who viewed civil unions as "progress" generally would have preferred the option of marriage, but adopted a pragmatic approach in terms of what was presently achievable. Loana, for example, said she was "rapt" that as lesbians they now had the choice to become a legally declared couple.

For me, [...] it's just more steps. You know, we've been taking small steps all our life, being minorities and stuff. And things don't just happen, as you want them, straight away. So [...] it would be great to have an equal thing but if civil union is

\footnotetext{
${ }^{33}$ Jenny Rowan and Jools Joslin were one of three same-sex couples in long-term relationships who went to court for the right to marry. They argued that civil unions were not equality and eventually travelled to Canada to have a legal marriage.
} 
the step that we have to take to get to the end and get equal status [...] then so be it. And if people didn't want civil unions well they could say no. And for those of us who actually wanted something legal it was great to have that option [...]. So for me I see civil unions as the step to having equality. We've all got to start somewhere.

Colleen likewise viewed civil unions as a positive step for gay rights: "because it was making people talk about it and raising the issues in houses that had never discussed such things before". Several participants, such as Bill mentioned above, also believed that mainstream New Zealand society was not quite ready for samesex marriage and that by insisting on the right to marry the gay community may have missed out completely.

Some participants who "preferred" the idea of a civil union to a marriage did so because they viewed the legislation as non-discriminatory. Unlike other countries, such as Britain, whose comparable legislation pertains only to same-sex couples, New Zealand's civil unions are available to both same-sex and opposite-sex couples and were, therefore, seen by some participants as genuinely "equality driven". Other participants "preferred" civil unions to marriage because it did not have the historical "baggage" that marriage has. Adopting a more differentiated conception of citizenship, a few participants considered the domain of marriage to be exclusively a heterosexual institution and, therefore, as not applicable to them as a same-sex couple. Jody, for example, described herself as quite "traditional" and said that even if they had the choice of marriage she still would have chosen to have a civil union. For Dominic, the word 'marriage' held little relevance for him as a gay man. Geoffrey similarly said that he did not want to be associated with the word marriage: "Even now I wouldn't say that we got married. The word jars somehow". Ross also noted that, "since more than fifty per cent of marriages fail in New Zealand" he could not see why same-sex couples would aspire to have one.

Several participants viewed marriage as essentially a religious institution and, therefore, "preferred" civil unions for the very fact that they were entirely secular. Some of the most hostile opposition that gay men and lesbians have historically 
experienced in New Zealand has come from Christian churches and fundamentalist Christian churches in particular. ${ }^{34}$ Until the Civil Union Bill was being debated, Emile said he had always considered New Zealand a relatively liberal country as it had recognised his relationship with his kiwi partner and allowed him to immigrate into New Zealand on the basis of their de facto relationship. Max had also emigrated to New Zealand to be with his kiwi partner Dominic and like Emile was "shocked" by the level of opposition that erupted during the Civil Union Bill campaign, particularly from the religious sector. Both Max and Emile referred specifically to the high-profile and militant protests of the Destiny Church ${ }^{35}$ and their assertion that same-sex civil unions would devalue or undermine marriage.

Whilst several participants described themselves as having a Christian-based faith and as actively involved in the Church, others described themselves - sometimes vehemently - as non-religious and, in a few cases, as atheists. Garth \& Derek subscribe to Christian values but said they did not, however, affiliate with any church "because of the total hypocrisy of the church in general [...] and [their] being totally unforgiving towards gay and lesbian people [in particular]". For some participants the secular nature of civil unions was, therefore, appealing. Becky \& Bridget, for example, had previously supported the Lindsay Quilter and Margie Pearl case to make marriage available to same-sex couples but said that for them personally a "civil union seemed fine because we don't have a religion. So, there was no need to do that stuff in a church. It just needed to be, we were thinking, something that's recognised by society and that has legal standing” (Becky). Commenting on the distinction between marriage and civil unions, Jill said she considered the civil union legislation to be as binding as the Marriage Act but "without the crap that goes with the religious overtones". For Jill, the most important aspect was "the legal bit of paper". As she explained, "you can have the most religious, grandest ceremony in a church to get married, but if you haven't got your legal bit of paper, it doesn't mean a god damn thing”. Several participants even suggested that civil unions or civil marriage should become the state-recognised

\footnotetext{
${ }^{34}$ I discuss the opposition that gay men and lesbians experienced from Christian institutions in more detail in chapter two.

35 The Destiny Church is a Pentecostal Christian fundamentalist church based in New Zealand.
} 
standard in New Zealand and for those who wanted a religious component to their union they could choose to have a further ceremony in a church or other religious establishment. Many of these participants noted that this was the system adopted by several liberally-oriented European countries.

For some participants (both male and female), their preference for civil unions was motivated by feminist ideals and by a desire to avoid the historically patriarchal connotations associated with marriage whereby women were viewed as "chattels". In his capacity as a priest, Martin had officiated at several weddings. On such occasions, he said he had often been very surprised at the way young people still uncritically wanted to continue with some of the patriarchal marriage traditions, such as the bride being given away by her father. "And I say to people, this isn't about actually being a piece of property. [And they reply] 'Oh, no, no, we don't think like that. It's just that it's a nice thing to do."'. Somewhat reflectively, Martin added, "maybe it's a post-modern thing and you reclaim old traditions and make them your own and make them visible. [...] But for me, there's too much of that stuff associated with marriage and just so many expectations around it".

Yvonne said she would have ultimately gone with whatever legal form the government had come up with but that having something distinct from marriage suited her much better. Unlike her partner, Loana, Yvonne did not view civil unions as a step towards something better. As she expressed it, "I think it is what it is. It's perfectly great and I prefer to do something that is different and separate". As a politically active Mãori woman, Yvonne also commented that she liked the fact that civil unions were "New Zealand grown" and not associated with New Zealand's colonial history and British law.

Couples' views on the civil union legislation were not always congruently aligned. Jenny \& Beth, for example, had in their capacity as musicians both played at several pro-civil union events. In terms of their attitudes towards the civil union legislation, though, Jenny \& Beth started from quite different positions. Jenny was immediately supportive of the legislation and was quite clear that from a social justice perspective that it needed to happen. She said she would have preferred 
that it was marriage and thought the government had played it safe but accepted that it was all about "small steps". Beth, however, was much more ambivalent about civil unions. Although she supported the cause as a musician, she did not feel that civil unions were a "just solution". For Beth, the "just solution, would be marriage for all, an equal solution for all". Although several of Beth \& Jenny's friends had chosen to formalise their relationship in a civil union they also had friends who were adamantly opposed to civil unions.

Yeah. And I kind of felt a little bit torn because some very staunch friends of ours are quite anti-civil union, regard it as a bit of a cop-out. [...] And, you know, there's a part of me that's still politically quite staunch (Beth).

On a more personal level, Beth also acknowledged that there was a dimension of her own homophobia in her reaction to civil unions and her own sense of entitlement. "And part of it is, I guess, the thing of, oh well we've been together for 14 years, what's different now?" (Beth). It was listening to why other people were so passionate about civil unions that finally convinced Beth to embrace them. On a pragmatic level, she also realised, "actually, we could wait around forever, let's grab the moment, lets grab this celebration now".

Participants' views on the civil union legislation highlights a recurring tension between assimilation and difference. Participants who were against the establishment of a separate institution tended to place more importance on the symbolic and cultural aspects of marriage and were typically more assimilationist in their stance. They also subscribed to what Taylor (1994: 38) refers to as a politics of 'equal dignity', whereby rights and entitlements are universally awarded to all citizens. Those participants, by comparison, who voiced a preference for civil unions typically placed more emphasis on formal legal recognition and the rights and responsibilities this recognition conferred. Apart from those participants who found the non-discriminatory nature of the civil union legislation appealing, those who preferred civil unions also tended to adopt a 'politics of difference' whereby society is required to recognise the unique identity of an individual or group based on their distinctiveness from everyone else (Taylor 1994: 38). A 'politics of difference' is aligned with a differentiated conception of 
citizenship, in that it recognises the contextual and pluralistic nature of the democratic public (Leydet 2011).

For many participants the Civil Union Bill campaign provided an opportunity to become an active citizen participating in democratic decisions. Bridget, for example, wrote letters to all the members of Parliament advocating for civil unions.

So we wrote to everybody, and I think my letter had stories - it told our story and about how we considered ourselves to have a marriage - it operates like a marriage, we care for each other just like a marriage - and the disadvantages that we face because [our relationship] wasn't legal. And I related experiences like, Becky going into hospital for an operation, and me not being treated like the next-of-kin. [...] I've got a stack of all the replies including some that go, 'frankly I think that you're disgusting', or something like that [laughing].

Some participants became involved in the Civil Union Bill campaign not because they personally wanted a civil union, but because they were passionate about LGBT people having the right to a legally recognised relationship if they so desired. Hailey, for example, recalled that she had supported the Bill mainly because of the opposition to it. As she explained,

At the time, I didn't really feel that strongly about civil unions. It wasn't really for me. I didn't [...] think, oh gosh, we really need to have the right to get married because that's not my belief structure. It was more [because] of the negative stuff around queer people that I felt I needed to get involved [...]. And then along the way I decided, oh actually this is really important [...]. The negativity around [civil unions] crystallised my own opinions.

\section{Civil union and the socio-political}

Recognition, choice and equality were political factors motivating some participants to have a civil union. For others, their political views were a barrier and strategies of reframing, negotiation and persuasion had to be employed to address these concerns. For these participants, the practical value of a civil union was often in ascendance and the tipping point for shifting them into a positive decision-making mode. A civil union, like a marriage, provides access to a legal 
framework that is both broader and simpler than a set of individual legal documents. It establishes a legal bond that addresses issues related to living a joint economic life and safeguards rights and entitlements of couples as each other's next-of-kin. For Brad \& Marcus, who were initially ambivalent about civil unions, the catalyst for changing their minds came when they found out that their lawyer had lost their wills.

Brad: Yeah, the lawyer moved offices and they lost our wills and they hadn't sent us copies somehow. [...] And so they offered to do them for free again but we were going to have to re-draft everything.

Marcus: At the same time, we heard a story about someone who wasn't allowed to be pall-bearer at their partner's funeral. Suddenly we were wide open.

Gay and lesbian communities have always had some members engaged in longterm relationships and like the rest of the population have suffered their share of losses through the death of a partner. In the absence of social and legal recognition, though, gay and lesbian couples have, unlike their married heterosexual counterparts, often been denied access to a critically ill partner in hospital or to the inheritance rights normally accorded someone classified as next-of-kin. A source of curiosity for me throughout my interviews was indeed the regularity with which participants mentioned stories they had "heard" or recounted experiences that friends had endured. Ross \& Martin, for example, recounted the following:

Ross: I think of those friends where one partner died and his mother moved into the house - the dead one's mother - before the funeral had actually happened. And she said, 'Does this belong to you? Does that belong to him?'

Martin: [And she said,] 'Take your stuff now'. This was to the remaining partner.

Ross: Yeah, and he didn't have anywhere to go. Of course he didn't, he was just coping with this sudden death, and it was just dreadful. And in the end he left the house and said, 'You have the lot of it'. It was very sad and he, well, it's taken him years to recover, still hasn't quite.

During the 1980 s and ' 90 , the legal importance of gaining access to the economic and social benefits associated with marriage became something of a preoccupation for gay and lesbian communities. The HIV/AIDs epidemic and the Sharon Kowalski 
custody case in America were particularly influential. In 1983, Sharon Kowalski was hit by a drunk driver leaving her severely disabled as a result of a head injury. Sharon and her partner of four years, Karen Thompson, had, earlier that year, formalised their relationship in a private commitment ceremony. When Karen informed Sharon's family of the accident and that she and Sharon were lovers in a committed relationship, they reacted harshly and resolutely. Sharon's father acquired legal guardianship of his daughter without even a court hearing, moved her to a nursing home, and denied Karen visitation rights. Sharon continually typed messages saying she wished to live with her partner Karen, but her parents and the court considered her incompetent to decide her own future. What ensued was a lengthy and expensive custodial battle. Karen Thompson led the battle and lesbian communities throughout the country mobilized in her support (D' Emilio 2002: 187). In 1991, Kowalski and Thompson finally won their case and Sharon was allowed to return home.

Meanwhile, the HIV/AIDS epidemic drew attention to the costs, emotional and otherwise, of same-sex intimate relationships having no standing in law. "Partners and close friends could be denied access to someone who was sick or the right to make decisions about life and death" (D'Emilio 2002: 187). The HIV/AIDS epidemic was also, according to Kath Weston, a catalyst for the "movement to incorporate 'chosen kin' into prevailing definitions of family" (1998: 65). The AIDS epidemic highlighted the familial nature of social relationships in the gay community. A positive HIV diagnosis also often forced the issue of 'coming out' to straight relatives. When confronted with rejection or outright abandonment, friends and other peers became the primary caregivers, fulfilling roles typically reserved for family of origin.

Unlike some other countries' comparable legislation, there are very few financial benefits associated with a New Zealand civil union above and beyond those already accorded de facto couples through the Relationship (Statutory References) Act 2005. Being legally defined as the next-of kin of their partner was cited by participants as the most important legal right associated with a civil union. Although de facto couples (same-sex or opposite-sex) are legally accorded the 
status of 'relative', many participants still felt they might one day have to prove their connections in a way that heterosexual couples would not. A civil union, like marriage, was seen as the simplest and surest process for the legal transference of property in that it categorically established partners as next-of-kin. For some participants, formalising their relationship in a civil union was a precautionary step, a way of creating enduring social ties. As Jill articulated it,

With the Civil Union, it was like the legal thing [...]. It's almost like they can't touch us now cos it's legal. They can't take it away because it's legal. And being next-of-kin for somebody, it's the thing that you need most when ... your world's falling apart, you know. If one of us is in intensive care, it's only your next-of-kin that are allowed in. So, if it couldn't be each other that would be, you know, quite tragic.

Legal classification as each other's next-of-kin was a significant motivating factor in Derek \& Garth's decision to have a civil union. They were very clear on what they wanted if either of them ever ended up in a critical medical condition. As a 67 year-old man and an only child, Derek said he did not want such important decisions left to distant relatives who did not know him well. Garth's mother was showing signs of dementia which had also made him think of his own future. By formalising their relationship in a civil union they eliminated the risk that any relatives could make decisions on their behalf if such a situation arose.

Will said he was not originally very interested in a civil union but became more interested once he realised the protection it would provide if one of them predeceased the other. When they first bought their house together, Will recalled that they had gone to "inordinate trouble" to construct wills that would provide protection from "marauding relatives". As partner Geoffrey pointed out, though, "there is one thing you can't put in a will and that's next-of-kin". This aspect of a civil union swayed Will's opinion and was a key motivating factor in their decision to have a civil union.

For some participants, a motivating factor in their decision to have a civil union was that it presented an opportunity to become socially 'visible', thereby 
providing an important means for gaining full recognition as citizens. As Greg explained,

I think that when your relationships have tended to be ignored and invisible - and it's very hard to be visible as a gay man, statistically - I think that it becomes more important to be able to make that choice and to have your relationship officially recognised, which is why I had a civil union. I didn't feel the need to have any official recognition of my sexual relationship.

Visibility was also a motivating factor in Evan \& Bill's decision to have a civil union and for more generally breaking down societal homophobia.

Evan: I feel by having the civil union and being out and telling people, it does good for our visibility as a community.

Bill: It adds a certain amount of prestige I suppose - to the visibility issue [...] There is something that is added, to being out there and visible.

Evan: And [visibility] is one thing to break down homophobia we have found, especially during Homosexual Law Reform. It's the visibility that helps fight the prejudices, because prejudice and phobias come from fear. So by being out there and showing people, 'well hold on, we're just your neighbours', does help [laughs]. And the Civil Union Bill, I think, has also helped with more visibility, and people being able to make statements about who they are.

A civil union also represented, for most participants, a degree of equality. Entering into a civil union was a chance to "stand up and be counted" in the same way that heterosexual couples are; to declare that their relationship is as good as any heterosexual relationship and, therefore, as deserving of the entitlements that other legally partnered people receive. Although Michael would have preferred the option of marriage he said "ultimately" what he wanted was for his partner and himself to be a "publicly declared couple and to be counted in the same way that married [heterosexual] couples are”.

While political principles and the practical value of a civil union were motivating factors in many couples' decision to have a civil union, these factors were, however, premised on the fact that there was an already existing emotional commitment. For some participants, a show of political solidarity was a further 
motivating factor in their decision to have a civil union. Several participants mentioned feeling a sense of obligation to "honour" the efforts of those who had fought for gay liberation and for the legal recognition of same-sex relationships. Some participants also spoke of feeling grateful for having the choice of a civil union, referring to the many others who either had not or still did not have the opportunity to have their relationships legally recognised. As Garth articulated it, "In our own lifetime, you know, the awful things said and done to [gay] people and now here we are able to actually enjoy this".

Max said that his and Dominic's decision to have a civil union was "as much a political response as any". He referred to the determination of the then Prime Minister, Helen Clark, to get the legislation through and a sense of obligation on their part to honour her efforts. Max, along with several other participants, also had a sense that not many gay couples were taking up the opportunity to have a civil union. This perception was often accompanied by a concern that if too few gay couples chose to take up the opportunity then civil unions might be taken away altogether. Gail, for example, ultimately wished to one day have the option of marriage and was concerned that if same-sex couples did not take up the opportunity to have a civil union then "politicos" might also say, "look at them, they are not interested so of course they don't want to get married either". The catch phrase, "use it or lose it", was mentioned on several occasions and was a consideration in several participants' decision to have a civil union. Participants' narrated sense of obligation reveals an attachment to two discrete although highly interconnected "imagined communities": a sexual community and a political or national community (Anderson 2006 [1983]). These narratives also highlight an ethic of active citizenship whereby rights are seen not simply as conferred from above but also as being demarcated from below.

\section{NARRATIVES OF THE Social}

For many participants, the legitimacy conferred through legal recognition translated into a greater sense of entitlement in terms of their rights as citizens and, in particular, as the next-of-kin of their partners. Joss, for example, recalled 
that when her civil union partner, Nicola, was admitted to a hospice she had experienced a feeling of "absolute entitlement".

I actually stayed there and things like that. But I think they might have treated me like that anyway. I don't know. And then actually after Nicola died, and doing the Will and all that kind of thing. She hadn't made a Will [inhales deeply] and she kept saying, 'I'm going to, I'm going to'. And then in that last week in the hospice she wasn't really sound enough to do that. But I knew what she wanted to do. So it helps legally to say that I'm her civil union partner, not that I've just been living with her.

For several participants, the sense of entitlement they felt in being a legally recognised couple had produced a corresponding feeling of confidence to "be more out" about their relationship. Derek \& Garth, for example, recalled that since their civil union it had become "obligatory" for them to introduce each other as "their partner" and to make sure that people understood the nature of their relationship. They said they had, in turn, been encouraged by the relatively unperturbed responses they had received, even when travelling abroad.

We've been away several times around New Zealand. We've been to Australia and we've been to the UK. And on each occasion, we've had a double or a queen size or whatever type room. In other words, we want to make it quite clear that we wanted a double bed. And there's been no raising of an eyebrow, nothing from anybody (Derek).

Arriving in Los Angeles from London with Garth's mother, though, Garth said he had got a little "carried away" and filled out a 'family' immigration form rather than three individual forms. Derek recalled, somewhat humorously, their conversation with the immigration officer,

We said, well you know we're a couple and this is my mother-in-law. This is his [Garth's] mother and we're a family. And this guy was Mexican or something. It threw him totally off the wall - he could not cope at all! And there was this sort of, 'Do New Zealand recognise this?' And I said, 'Yes, that's how he's become a New Zealand resident'. And he was almost totally speechless. And then he said, 'Well next time I suggest you fill out separate ones'. But he was not agro he was just completely thrown, couldn't cope at all [laughing]. 
For some participants, legal recognition translated into a greater sense of security. Becky, for example, said that little had changed in their relationship on a day-today basis since their civil union but that she had experienced a greater sense of "confidence and solidness".

I really do like to have legal protection of our relationship. Nobody can query it or suggest that it doesn't have any standing. Not that people generally do, I suppose, but it's just nice to have that sort of solid backing of the law somehow. Yeah. And, I mean, forms have changed too, so it's less annoying filling out forms. They do actually accommodate our relationship at last [laughing]. We're not outside the mainstream anymore.

For some participants there was a sense of "pride" attached to being a legally recognised couple. Evan \& Bill, for example, recounted the following story.

Evan: I can say with some pride that, yes, you know, we've got a legally recognised relationship. And when we were overseas it was delightful, especially in New York. That first trip, we showed the woman at this little stall - she was selling quite a lot of gay memorabilia - and we showed her our rings, and she hugged us and...

Bill: Said how wonderful it was.

Evan: And she said she was thrilled. And she gave us both a rainbow hat each [laughing]. And then she told her friends around her. I mean, it was just wonderful. Now, if we hadn't of had our civil union, we couldn't have done that.

Yvonne \& Loana, like several other participants in this study, said that little had changed in their relationship in a day-to-day sense but what had changed since their civil union was the way they presented themselves as a couple to "the world". For Yvonne \& Loana, there was a perception of status or prestige attached to being a legally committed couple. Yvonne said that when she and Loana had got together they knew with certainty that their relationship would be "forever". Having a legal institution that acknowledged their commitment was described as very important in that it distinguished their relationship from "just" a de facto relationship. While the practical importance of marriage has declined, Andrew Cherlin (2004) suggests that "its symbolic importance has remained high, and may even have increased”. Marriage, he suggests, 
[...] has evolved from a marker of conformity to a marker of prestige. Marriage is a status one builds up to [...]. It is something to be achieved through one's own efforts rather than something to which one routinely accedes (Cherlin 2004: 855).

Even the wedding, he claims, has become an individual achievement; "an important symbol of the partners' personal achievements and a stage in their selfdevelopment" (Cherlin 2004: 856). While Cherlin is referring specifically to marriage, there are, I suggest, parallels with the attitudes expressed by my own participants. Emile, like Yvonne \& Loana, also perceived a degree of prestige in being in a civil union. As he expressed it, "It's more than signing a bit of paper. [Like marriage] it's being part of a club". Marcus similarly felt that in having a civil union, he and Brad had "kind of jumped up the rank". Referring to de facto heterosexual couples, he added in a half joking manner, "We can actually look down on someone for a change".

An important aspect of the civil union legislation perceived by many participants was the greater awareness it would bring in society more generally. Reflecting on the impact of the civil union legislation, Hailey, for example, commented,

Actually I think it's been a really important step in terms of getting acknowledgment for queer people full stop. The marriage thing is kind of tiny compared to that [acknowledgement] because now people are much more aware. So, [...] if you go to a motel, people don't assume as much that you are just friends and you're going to have two separate beds, those sorts of things.

Some participants found that their civil union had helped them to assimilate with and garner the support of work colleagues. Others noted the positive acknowledgement they had received from more informal acquaintances and how they were now included in the codified set of rituals which society employs to acknowledge and celebrate matrimony. Hailey \& Lara's respective work colleagues, for example, decided to give them a "stag do" in the lead up to their civil union ceremony.

Hailey: Both our work places decided to give us stag dos, but different. Yours was a civilised affair wasn't it? 
Lara: I was very clear that I would have been highly mortified if much of a fuss was made or anything like that and they took that on board.

Hailey: Well, it never occurred to me [...] that anything like that would be happening. Anyway, secretly, one of my staff members was planning this crazy sort of like hens' night sort of ritual. It wasn't that bad because we went to a fairly quiet bar. They did the games - I'd never been to a hens' night - so, little games. And I got made to wear a veil temporarily. It's so not me at all. It was so crazy but it was very sweet, it was very funny. Then we went out for dinner, I think. So it wasn't like a big drunken thing or anything.

Colleen \& Laura recalled the enthusiasm of people's responses when they found out they were having a civil union. Laura bought her suit for their civil union about six months prior. Not wanting Colleen to see it before the day, she had kept the suit in at work where her colleagues reportedly had "pawed over it". She also remembered the positive reception she had received when she went into a shop to buy a top to wear with her suit.

I remember going into Pagani [a women's dress shop] to buy the top which was a little bit feminine for me, a little bit different. And an 18 year old blondie served me and I thought, oh well, I'll make a statement. I said, 'This is for my civil union with my partner Colleen'. And she said, 'Oh, my first sale for a civil union!' And she was just like, 'Oh, that's so sweet, when's the day?' Like, she was lovely.

The hotel where they stayed apparently treated them as they would any other 'honeymooning' couple by having complimentary champagne and chocolates waiting for them in their room. When checking out, the hotel staff also, reportedly, invited Colleen \& Laura to come back and stay on their first 'wedding' anniversary.

Becky \& Bridget recalled with some degree of incredulity the public acknowledgement they had received from relative strangers both before and after their civil union, something they had never before experienced.

Becky: It was like walking a dog or something. And people come up to you and sort of talk to you, 'Oh what a lovely dog' and blah, blah, blah or, if you've got a baby. And so we had this marriage about to happen, and suddenly people were saying nice things to us. 


\section{$[\ldots]$}

Bridget: And then after [the civil union], like people heard from others. Like Becky's brother's neighbours, we met them watching [Becky's niece] play netball or something. And they came up and said, 'Oh, yeah, you got married the other day. Congratulations'. And this was sort of like a neighbour of Becky's brother, you know? We don't know these people, but we were kind of brought into the fold a bit, so that sort of went on for a little while afterwards. It was really nice, yeah.

Marcus recounted with some amusement the mixed reactions he received at work when he announced that he and Brad had formalised their relationship in a civil union the day before.

Like the office secretary, she burst into tears and cried most of the day over how lovely it was. And then there were a couple of Christian staff who just didn't talk to me at all. They made it very clear that they didn't approve. They were so silent and sullen. It was obvious they weren't thrilled about it. And then, at the Christmas party, the director actually did a toast for me. He's a gay man as well so it was half for me and half to stir as well. They all found out. And then I got a bit of flack that we should have told them as they would have done something in advance or had a whip round and brought us a present or something, but that's not me.

Participants' surprise and satisfaction at the mostly positive responses they received are, as Baker and Elizabeth (in press) note, "indicative of a social context where same-sex couples are primed to anticipate opposition to the very idea of legalizing their relationships". The 'normalising' effects of a civil union discussed in the previous chapter were, however, by no means limited to familial relations, but were, I suggest, also applicable at a more general societal level. Once again, the legitimacy conferred through legal recognition intersects with the social intelligibility of 'marriage' to invest same-sex civil unions with meaning. In this way, a civil union renders the gay individual socially recognisable, someone to whom heteronormative society can relate (Green 2010: 414-415). The acknowledgement and support that this newly-acquired status often elicited in turn gave participants a greater sense of incorporation into mainstream society and generated internal feelings of social acceptance. 
Even bureaucratic acknowledgement with a negative financial effect fostered feelings of social incorporation as it represented equality. Prior to civil unions, gay men and lesbians were not counted as having a partner in terms of social welfare benefits. If they were receiving government superannuation, for example, couples received the higher rate of two single persons. Once the legislation came into effect, though, they began to be counted in the same way as married heterosexual couples. While Bill thought that a loss of income may have been a deterrent for some same-sex couples entering a civil union, for him it was a sign of equality and incorporation into the mainstream. Bill recalls that they were contacted by Social Welfare quite soon after their civil union.

We had a letter, probably would have been four weeks [after our civil union], from Social Welfare: 'We understand you've just got married, so you might be eligible for a, you know, some sort of benefit or whatever - some services card.' [...] And the other thing that happened with Social Welfare was that a woman wrote to Social Welfare, saying, 'Make sure these guys get the married rate of pension and not two single pensions'. Somebody actually took the trouble to write and ask them. I mean, that didn't matter. I mean, sure, we lost money in it, but the issue is that we are equal with everybody else - whatever that equality may mean.

\section{Cultural lag and the politics of language}

Among some participants, there was, however, a sense that society had not quite “caught up" with civil unions and that many 'straight' people were unfamiliar with the term or its significance. Hailey, for example, recounted an incident that occurred the day before their civil union when she bumped into a friend who she had not seen for some time.

So I was trying to explain to her that I had to go. It was nice to see her but we are getting civil union tomorrow. [...] And she's like, 'Right...'. She didn't understand what the hell I was talking about. And then a couple of minutes later she's like, 'Oh, like getting married!' Like she thought maybe it was something to do with the union or something. I don't know.

Other participants also felt that sectors of society had not kept pace with the legislative change. Some said that not all forms accommodated civil unions and 
one participant recalled that a telephone survey she had participated in had not included a category for civil unions.

Part of the process of gaining rights as citizens is the right to cease to be seen as 'political' in an agonistic sense. Marcus, however, felt that civil unions were still an inherently political topic and from his own experience thought people felt compelled to comment or voice their opinion either for or against. Max said that, irrespective of the legislation, it was still apparent from his experience "that it takes a long time for people's attitudes to change".

Even now with the Civil Union Bill, I think you know heterosexuals in general speaking don't understand why two men would want to be together and that sort of thing. So, I think that it is still astonishing today the continuance of heterosexuality being the predominant thing and how little education there is for young people around homosexuality and issues around diversity.

Max said that one of the reasons that he had agreed to a civil union was that he wanted Dominic as his life partner to be recognised by the Trustees of his pension scheme. "So if anything happened to me, Dominic would have a dependent's pension". However, while the Trustees were prepared to backdate Dominic's entitlement to the date at which the legislation had been enacted, they would not honour him in the same way that they would if Max had married a woman. “There's a real double standard. So, although they've acknowledged him [Dominic] as a same-sex life partner, they won't honour him equally and that really riles me".

Participants' choice of terminology was often influenced by social context. Because the cultural 'script' of marriage is so dominant and so clearly understood, many participants found it easier to simply use the terms associated with marriage. Lara, for example, said that as a rule she was more likely to use the term 'civil union' when talking with other "queer" people but would use terms like 'marriage' or 'wedding' when talking to "straight" people. Whilst most participants generally employed the term "partner", several also reported that they used the words "husband" or "wife". Hailey said that using marriage terminology had "started as a joke" but had somehow "become real". Other participants also reported defaulting to marriage terminology, often citing the "cumbersome" and unromantic nature of 
civil union language as the reason. As Lara explained, "Civil union seems to me like quite a legislative word, a formal word, rather than a reflection of the actual event". Use of marriage terminology was also often reinforced by others. Frank, for example, said that, "most people who talk to us talk about our wedding. Hardly anyone refers to the word civil union. People talk about our wedding and they talk about us as married".

For some participants, the use of marriage terminology had a political dimension and was a way of seeking inclusion in, or for redefining a social category. ${ }^{36}$ Gail \& Jessie, for example, said they "steadfastly" use the word "lesbian" because in their view, it is "such a difficult word for straight people to hear". Similarly, their use of the word 'wife' was for political reasons but, as Jessie pointed out, it also clarified their relationship.

Jessie: I use wife consciously because this too is difficult for straight people.

Gail: So it makes it very simple to go, fuck everybody, that's what it is. And that's the commitment we made and it's brilliant to embrace it now, aye?

Jessie: And I find people are quite grateful.

Gail: Yeah, cos you make it really clear.

Several participants, however, also reported feelings of grievance over the language of civil unions and the fact that "legally" they did not have available to them the socially intelligible titles associated with marriage. For Brad \& Marcus, this state of affairs was further evidence that society still viewed their relationships as inferior to heterosexual relationships.

Brad: When someone says this is my wife or this is my husband I want to be able to say the same thing about Marcus because in essence it feels that it's the same [sort of] relationship. To have to use a clunky word like 'civil union partner' feels different, it doesn't feel equal.

Marcus: It's like saying, 'my test tube baby'.

\footnotetext{
${ }^{36}$ Gretchen Stiers (1999: 106) also notes in her study that lesbian and gay couples are more often concerned than most heterosexual couples with the political implications of the words they choose.
} 


\section{Socio-historical reflections}

When I asked the celebrant, Eileen, what she thought the civil union legislation represented for same-sex couples, she replied,

[F]or gay and lesbian people, it's something they haven't been able to do before so there's a sense of history in it. As well as it being a personal thing it's also [...] social change, which is significant for them.

For many participants, the historical significance of same-sex civil unions was indeed considerable. In their lifetime, they had gone from being viewed as second class citizens - oppressed, criminalised and 'marked' by their 'otherness' - to having their relationships legally sanctioned and socially celebrated. For Becky (aged 54), the passing of the civil union legislation in her lifetime was profound.

Having grown up when things were quite different - there was a lot of homophobia and I didn't always feel good about myself. I kind of thought, politically I am okay and there are lots of other good people who are like me, but there are a lot of people who hate me because of my sexuality and the lifestyle that I've chosen. And [civil unions] just meant a sort of quantum shift in the way gay and lesbian relationships are viewed in this society - in my lifetime.

Becky believed that the civil union legislation would make New Zealand a more comfortable place for gay people, now and in future generations, to live. Becky also experienced a sense of pride for the part she had played in making same-sex civil unions a reality. "It's nice to have been part of that social change that's moved things forward, at least in this society". Bill articulated a similar sentiment for the part that he and Evan had played.

I think that somehow or other we've done a little something for gay rights. In terms of our personal relationship, I'd say [the civil union has] not made any difference. I guess there is that security thing that, you know, that Evan will be my heir when I fall over sort of thing, you know.

The term 'pride' in the sense of self-esteem holds political and historical significance for the gay community. It emerged during gay liberation and was adopted as the antidote to shame - both the institutionalised shame that society had historically imposed on homosexuals but also the sense of shame that many gay people had themselves internalised. 'Gay Pride', as a motto, was influential in 
bringing gay people out of the 'closet' and in making them less fearful. 'Gay Pride' also in turn made it increasingly difficult for society to oppress them.

Pride was, however, also expressed in the context of being a New Zealand citizen. Derek, for example, recalled the gratitude and pride he felt in being a New Zealander when they were visiting a friend in the "gay capital of the world" - the Castro district in San Francisco.

We had to meet a friend of mine who lives in San Francisco. We were to meet for lunch and, through a bit of carry on, we had to wait. So we went across the road to a bar and sat down and had a glass of wine while we waited. And there was just the bartender and another guy at the other end. They sussed our accents straight away and said, 'Where are you from?' The usual sort of thing. And it was a gay bar and suddenly he was talking about the lack of rights that they have and it's extraordinary. And these guys are in the middle of Castro where literally everybody is gay and so we realised just how privileged we are to live in a society where, other than the odd redneck, we live a perfectly happy and normal life.

In a speech they gave at their civil union ceremony, Jessie \& Gail paid homage to the social change they had witnessed in their years together by referring to the three ceremonies they had held to mark their commitment to each other. "We did this first for ourselves on our own at Peka Peka beach. Ten years later, we did it for our own family and friends, and now we do it before the law" (Jessie).

Viewed within a historical trajectory of homosexual rights, civil unions can, I suggest, be seen as an important institutional bridge of legitimation leading to greater incorporation of gay people into mainstream society and a corresponding 'unmarking' of 'otherness'. In terms of recognition, this trajectory is characterised by three distinct stages. In the first stage, gay men were misrecognised while lesbians were unrecognised and, in varying degrees, both were largely invisible. The second stage coincides with gay liberation and is where gay men and lesbian became highly visible through their activism and their demands for equal recognition. The third stage, which is still on-going, corresponds to their relative incorporation into mainstream society via changes in legislation and social attitudes. Somewhat paradoxically, this latter stage sees a return to relative 
invisibility, largely because gay people have ceased to be seen as 'political' in an agonistic sense. While there are still aspects of New Zealand society that discriminate against non-heterosexuals, such as child adoption and marriage laws, gay men and lesbians are edging closer towards full and inclusive citizenship, whereby being gay becomes irrelevant.

\section{CONCLUDING COMMENTS}

In this chapter I have explored the intersection between private troubles and public issues by situating the civil union specifically within a socio-political trajectory. Many participants' political involvements were tied to issues of human emancipation and personal experiences of discrimination based on identity in a certain social category. In my discussion, I highlighted the role of 'recognition' and its centrality in discourses on human rights and principles of equal citizenship. I argued that gay males have been historically misrecognised by society while lesbians have gone largely unrecognised. Both misrecognition and non-recognition, however, constitute a form of oppression and assign the oppressed a status as a second class citizen. In outlining the social constructedness of civil unions I have, once again, highlighted the powerful role the law plays in defining the symbolic order. While the civil union legislation does much to extend the conventional rights of marriage to gay couples, it still does not permit them to marry. For some participants, the establishment of a separate institution was yet another example of anti-gay discrimination and further evidence that society still viewed their relationships as inferior to heterosexual relationships. Others were more pragmatic in their approach and viewed civil unions as "progress" towards equality. Some participants "preferred" civil unions to marriage because they viewed the legislation as genuinely equality driven. Others "preferred" civil unions because they were entirely secular and/or did not have the historically patriarchal associations that a marriage has.

For those participants who were against civil unions, strategies of reframing had to be employed in order to shift them into a positive decision-making mode. In many cases, the practical value of a civil union was the tipping point. A civil union like a marriage provides access to a legal framework that establishes a legal bond 
and safeguards rights and entitlements of partners as each other's next-of-kin. Being legally defined as each other's next-of-kin was cited as the most important right associated with a civil union in that it created an enduring social tie which subsequently translated into a greater sense of security. Recognition, choice and equality were political factors motivating some participants to have a civil union. Others also felt an obligation to "honour" those people who had fought for gay rights and for the recognition of same-sex couples. Political and practical motivations for having a civil union were, however, premised on the fact that there was an already established emotional commitment.

For most couples, legal recognition translated into a greater sense of entitlement as citizens. Some experienced a sense of "pride" in being in a legally recognised relationship which in a global context also translated into a sense of pride in being a New Zealand citizen. For a few participants there was also a perception of status or prestige associated with being a legally committed couple, one that distinguished them from people in de facto relationships. Most participants experienced greater acknowledgement, assimilation and support from work colleagues and more informal acquaintances as a consequence of their civil union. These changes, I have argued, can be attributed to the 'normalising' effects of a civil union whereby the legitimising effects of law intersect with the social intelligibility of 'marriage' to make the gay individual a more socially recognisable person. Participants, in turn, experienced a greater sense of inclusion in mainstream society. Some participants, however, also noted incidences of 'cultural lag' which sometimes also had a bearing on their choice of terminology. Some defaulted to marriage terminology because of its widespread intelligibility while others employed it for more political reasons, to redefine the boundaries of a social category. I have suggested that civil unions, when viewed within a historical trajectory, can be seen as an important institutional bridge of legitimation leading to greater acceptance and incorporation of gay people as citizens and a corresponding 'demarking' of 'otherness'.

In the chapter that follows, I depart from 'trajectories' to focus specifically on participants' civil union ceremonies in terms of scale, style and the 'ritual' 
experience. However, as will become apparent, many of the themes that have emerged in the preceding 'trajectory' chapters culminate in this one-off occasion. 


\section{7}

\section{Rites of Civil Union}

\section{INTRODUCTION}

In this chapter, I explore the contours of participants' civil union ceremonies. Not only do I seek to describe what participants chose to do for their ceremonies I also pay close attention to the meaning of their choices and actions. Here, the previous four 'trajectory' chapters prove useful in that they form the foundation on which much of my interpretations are based. This chapter, therefore, differs from the previous four chapters in that it is definitively ethnographic and considerably less oriented towards theory.

In New Zealand the rules that couples must follow when entering into a civil union are surprisingly few and practically identical to those associated with getting married. The formal aspect of a civil union can take place almost anywhere as long as it is solemnised in the presence of either a civil union celebrant or a registrar and at least two other witnesses. The parties entering into the union need only make a clear statement that names each of them and acknowledges that they are freely joining in a civil union. The couple, the celebrant or registrar, and the witnesses must then sign two copies of the 'Copy of Particulars' before the celebrant or registrar can formally declare them officially partners in civil union.

Whilst there are few legal rules governing how a marriage should be marked in New Zealand, the dominant practice is to elaborate them in ways that are deemed both personally and socio-culturally significant. In this chapter I explore through participants' narratives how they chose to mark or enact their civil union: the different forms their ceremonies took in terms of scale and style, what social and 
cultural resources they drew upon in constructing their ceremony, and what elements were important for participants to include or consciously exclude. I then examine how participants narrated their 'ritual' experience and how for many it was far more emotional and meaningful than they had anticipated. I argue that civil unions as cultural performances can be defined as reflexive and biographical representations of a couple's particular lifestyle. In constructing their ceremonies, participants, in varying degrees, drew on both queer and heteronormative meaning-constitutive 'traditions' but also felt free to introduce elements of a more innovative nature which largely elaborated significant aspects of identity. I further argue that the gravity of the occasion, the affective nature of ritual, and the sociohistorical significance of same-sex civil unions more generally, combined to make most participants' civil union a highly emotional and meaningful experience.

\section{Conceptual framework}

Turner's notion of 'cultural performance' has efficacy as a framing concept for my participants' civil union events and, in part, accounts for their highly varied nature. Cultural performances are those concerned with representation. They are a form of reading of experience, a story that people tell themselves about themselves (Geertz 1993: 448). Cultural performances are, in this respect, reflexive works involving self-objectification: "consciousness of ourselves as we see ourselves" (Myerhoff 1980: 7). Ritual is a particular genre of cultural performance. Although its formal characteristics are transferable to other genres of performance, ritual can be distinguished "in the area of meaning and effect" (Moore and Myerhoff 1977: 8). As Turner explains, rituals are "transformative performances" involving symbolic manipulation and references to religious beliefs (Turner 1986: 75; Deflem 1991: 6, 22). Even in modern secular societies, where the domain of religion has contracted, becoming a matter of individual choice, rituals are oriented ideologically towards "matters of ultimate concern" (Turner 1977: 36; Turner 1976 cited in Deflem 1991: 16). All civil unions are to some extent symbolic in that they represent a transformation in social status - to that of a legally recognised relationship with associated rights and responsibilities. Some participants' performances, however, were more ideologically orientated than others and more elaborately incorporated symbolic elements of both personal and cultural 
significance so in this respect can be described as more "ritual-like" than others (Alexander 2006: 76).

Constructing a cultural performance involves reflexive processes similar to those involved in the construction of self-narratives: people have to "reflect back upon themselves, upon the relations, actions, symbols, meaning, codes, roles, statuses, social structures, ethical and legal rules, and other sociocultural components which make up their public 'selves"' (Turner 1986: 24). Those aspects perceived as important are then selected and organised to create a more or less meaningful performance both for actors and audience alike. A 'wedding', as cultural performance, can, therefore, be defined as a reflexive and biographical representation, a resource for the display of self and the dyad relationship. Because my participants had already celebrated their civil union they were by all accounts narrating their ceremony retrospectively. This chapter is, in some sense then, based on a double reflexivity: "performative reflexivity" (Turner 1986: 24) in terms of the ceremonies participants constructed and narrative reflexivity in terms of what aspects of their civil union ceremony participants chose to emphasise in their retelling.

Contemporary understandings of self-identity, as mentioned in chapter three, emphasise the idea that each of us has an original or individual way of being human. The achievement of an authentic self, according to Giddens, "comes from integrating life experiences within the narrative of self-development" (1991: 80). The self in this way is also a reflexive project, for which the individual is responsible (Giddens 1991: 75). The notion that each of us has an original way of being human has fostered the idea that each couple's 'wedding' should be an authentic expression of their own unique identity or lifestyle. Lifestyle choices are, in settings of late modernity, increasingly central to the reflexive project of the self, to its making and remaking (Giddens 1991: 81). A lifestyle, in the sense that Giddens uses the term, "can be defined as a more or less integrated set of practices which an individual embraces, not only because such practices fulfil utilitarian needs, but because they give material form to a particular narrative of self-identity" (1991: 81). As Giddens explains, 
Lifestyles are routinised practices, the routines incorporated into habits of dress, eating, modes of acting and favoured milieux for encountering others; but the routines followed are reflexively open to change in the light of the mobile nature of self-identity. Each of the small decisions a person makes every day - what to wear, what to eat, how to conduct himself at work, whom to meet with later in the evening - contributes to such routines. All such choices (as well as larger more consequential ones) are decisions not only about how to act but who to be (1991: 81).

The burgeoning wedding industry is no doubt partly a response to this ideal of individuality; the aim of the industry being to assist couples in crafting their very own, personalised wedding experience, one that reflects their particular lifestyle choice. Lifestyle choices may, however, be affected both by the weight of custom or tradition on the one hand and a relative sense of freedom on the other (Gauntlett 2002).

The freedom to individualise a cultural performance such as a 'wedding' is, to some extent, constrained by a need for familiarity or what Gross (2005: 296) might refer to as 'meaning-constitutive' traditions - semiotic resources out of which people make up their meaningful action including instances of novelty. The absence of familiar 'ritual' components may, according to Catherine Bell, compromise the authenticity of the performance: "A ritual that evokes no connection with any tradition is apt to be found anomalous, inauthentic, or unsatisfying by most people" (1997: 145). Performances, as Turner explains, "are made up of collective representations shared by the actors and audience, who are usually members of the same culture" (Turner 1982: 94). The communicative effectiveness of a performance, indeed, largely depends, as Jeffery Alexander notes, on "an audience knowing already, without thinking about it, the categories within which actors behave" (Alexander 2006: 58). Even performances of resistance, according to Alexander and Mast, "depend on and redeploy dominant, hegemonic codes" (2006: 15). As they explain, "for subaltern performances of resistance to occur, in which the dominant culture is creatively played upon and subverted, subversive performers must to some degree have internalized the hegemonic code" (Alexander and Mast 2006: 14). According to Bell, though, this dance between 'tradition' and 'innovation' is a fundamental dimension of ritual and is especially 
necessary when a rite must be adapted to a new social context (1997 cited in Lash 2012: 163). In this matter, the formal characteristics of ritual also prove useful. As mentioned in chapter five, messages are conveyed in an "authenticating and arresting manner" - as unquestionable - and in doing so have a traditionalizing effect (Moore and Myerhoff 1977: 8, 18). Traditionalization, as Lash (2012: 163) points out, thus assists in converting familiar practices into a new setting by evoking a link with the past.

While heterosexual couples must negotiate between 'innovative' and 'traditional' components in constructing their 'weddings,' same-sex couples also have the added choice between heteronormative and queer meaning-constitutive 'scripts'. Gay men and lesbians, as discussed in chapter three, are dually socialised: first, within the dominant heteronormative meaning-constitutive tradition and second, by virtue of their sexuality and a historic dialectic marked by their exclusion, into a more subversive queer meaning-constitutive tradition that includes norms and practices that depart from and innovate upon dominant heteronormative practices (Green 2010: 428). Because of this dual socialisation, participants in varying degrees arrive at civil unions in the context of discordant meaningconstitutive traditions (Green 2010: 429). Some participants, I have argued, had more weight on the foot in heteronormativity while others had more weight on the foot in homosexuality. A negotiation between heteronormative and queer meaning-constitutive traditions - expressed, more specifically, either as resisting or conforming to heteronormativity - was, I suggest, nowhere more clearly articulated than in participants' narratives of the civil union ceremony. Elements of 'innovation' were, however, also in ascendance. In examining the contours of participants' civil union ceremonies, I pay close attention to this tripartite tension. These three factors were, however, by no means discrete and often fused in creative ways to produce performances that reflected couples' particular lifestyle choices.

\section{NarRatives of Resistance AND CONFORMity}

Although generally celebratory occasions, 'weddings' can, in the planning stages, be stressful and may, as discussed in chapter five, exacerbate new or existing 
tensions between partners. For gay and lesbian couples though, as Smart notes, "the delicate negotiations that occur between partners are not simply about colour schemes and venues, but are also about precisely how 'political' their wedding is going to be and, further, what kind of statement it will make (if any)" (2008: 762). A common concern for many of my participants during the planning stages of their civil union was how to negotiate proximity to, or distance from, a "traditional" heterosexual wedding. Some participants, such as Trisha \& Pam, mentioned in chapter five, wished to emphasise the comparability of their relationship to a heterosexual marriage so consciously employed many of the 'traditional' customs associated with a heterosexual wedding in their own ceremony. Other participants, however, expressed a specific desire to distance themselves from a "traditional" or "straight" wedding.

A desire to distance their ceremony from a heterosexual wedding was analytically distinct on two levels: on a political level and on a level of personal authenticity. Those participants who considered marriage and civil unions to be institutionally discrete were particularly mindful of not replicating a marriage ceremony. For Brad \& Marcus, who considered the establishment of a separate institution as yet another example of gay discrimination, there was a political dimension to their choice of ceremony.

I think part of why we did not copy a traditional marriage ceremony was because on one level it doesn't feel like it is a marriage. And it's like a political thing for me. It's not to pretend that it's the same because it's not equal. They are distinct categories as far as I'm concerned (Brad).

For other participants, their 'distancing desire' was motivated by a 'politics of difference'. The development of the modern notion of identity has, as Taylor (1994: 38) observes, given rise to a politics which requires that society recognise the unique identity of an individual or group based on their distinctiveness from everyone else. In a 'politics of difference', assimilation into a dominant or majority identity is "the cardinal sin and against the ideal of authenticity" (Taylor 1994: 38). A desire to distance themselves from a "straight" wedding is, in this context, evidence of an assertion of a unique identity and a corresponding act of resistance 
against assimilation into mainstream heteronormative society. This stance was, no doubt, also informed both by the collective history of gay men and lesbians as a stigmatised minority and the goals set down by the radical lesbian and gay liberation movements of the 1970 and '8os: to affirm lesbian and gay identity and culture and to celebrate difference.

Typically accompanying these political motivations, however, was an overarching desire to create a ceremony imbued with authenticity and not one that might be perceived as a parody of a heterosexual wedding. Derek \& Garth, for example, were particularly emphatic on this point. They wanted their civil union to be as "un-wedding-like as possible". For them, this meant avoiding formality or anything that might be perceived as "high camp". In their words, "there was no walking down the aisle", "there were no buttonholes", "there were no speeches", "we dressed completely differently" and "we didn't have a cake". Derek said he had been to a commitment ceremony before civil unions were legislated in New Zealand where both males had their mothers give them away and their sisters as "bridesmaids". Derek described this mimicking of a 'straight' wedding as “absolutely embarrassingly hideous" and something they particularly wanted to avoid in their own civil union: "We didn't want histrionics" (Garth). Marcus similarly described a civil union he had attended as a "luke-warm parody" of a heterosexual wedding. "It looked so stressful. I just imagined our families”.

Derek \& Garth, however, also recounted a humorous story of how their two witnesses had turned up early dressed as "bridesmaids".

I was outside meeting [...] this 95 year old and her next door neighbour, who is a lovely lady. And I was sort of helping them out of the car and getting them a glass of champagne when these two arrived in the back of Peter's car dressed as bridesmaids, but send-up, you know. They've got goatee beards and hairy chests. And Simon is a hairdresser and he got these wigs and he had styled them. It was unbelievable. They [had] even gone out and got really, really nice bouquets of roses to carry. I mean Simon's got hairy legs like for Africa and these high heel shoes. I mean, it was a total send-up. Everything was a total send-up. So it wasn't anybody trying to be serious for the whole thing. And we just shrieked, we just cried with laughter. And then they went and got changed for the ceremony. So, I 
mean, there was no hint of trying to do all that sort of nonsense because that was something that we had particularly wanted to avoid, this sort of high camp. You know, we're two guys who happen to love each other and we wanted it to be a celebration of what we feel for each other and to share it with people who are important to us (Derek).

While participants such as Derek \& Garth wished to distance themselves from a heterosexual wedding, they were, in some respects, also distancing themselves from a classically queer 'sensibility': 'Camp'. Camp in the sense that I use the term here refers to an aestheticism based on a degree of artifice in stylization, namely that of "mimicry, effeminisation and transgender carnival" (Padva 2000: 216). Camp has traditionally been associated with homosexual behaviour and an acceptance of [male] gayness as effeminacy. Camp, however, is the antithesis of authenticity. Authentic action, as Alexander (2006: 55) observes, appears to be "sui generis"; without "artifice", "self-consciousness', or "reference to some laboriously thought out plan”. A performance that lacks authenticity will be seen by an audience as "insincere and faked". The actor and their actions will appear out of step and therefore lacking in credibility (Alexander 2006: 55). Whilst all performances involve reflexivity and conscious construction, their ability to appear authentic depends on the actor's abilities to "sew the disparate elements [...] back into a seamless and convincing whole" (Alexander 2006: 55). Effective 're-fusion,' as Alexander calls it, moreover, allows actors and their audiences to experience what Csikszentmihalyi calls 'flow' (1975 cited in Alexander 2006: 56). When actors and/or their audiences experience 'flow' their attention is focussed on the performance "to the exclusion of any other possible interpretive reference" (Alexander 2006: 56). Distancing themselves from a heterosexual wedding was in this respect an attempt on participants' part to eliminate the risk of being seen as parodying heterosexuals, thereby undermining the authenticity and significance of the occasion.

As a relatively new institution, civil unions have not, as yet, developed their own language or body of customs. For those constructing a civil union this meant there were few precedents to draw upon. Having the freedom to create something completely original was for some participants a liberating prospect. For others, 
though, it was, described as rather daunting. In the absence of any viable alternative, many participants found themselves drawn, albeit reluctantly, to the comparable and socially dominant wedding script. Frank \& Bryan, for example, began by thinking that their civil union event would be nothing like a heterosexual wedding but admitted that they eventually found themselves incorporating almost all the elements of one.

We didn't want to be dressed up like grooms in a wedding, we didn't want to have a wedding cake, we didn't want to have rings, we were unsure about vows, and we didn't want photographs. And so essentially we thought we didn't want anything that resembled a wedding. And the reality was, when it finally happened, we had almost everything that looked like a standard wedding. And we went through all the same agony as I guess everyone else has when they plan a wedding: who to invite, who to miss out because you couldn't accommodate everyone, where would you have your venue, what would you wear and lots of those decisions were last minute in the last week or two before the civil union when suddenly it became very real to us. And we did, what people often do, we both went out and brought new outfits independent of each other. We decided that we would have a wedding ring, a ring to symbolise our reunion. We had the most beautiful wedding cake. We had a photographer who took photographs of everything. We had beautiful invitations like people do. So, we had to end up almost having a wedding planner. [...] So all those things sound very traditional and, if you had asked us three months before the civil union, we would have had none of them (Frank).

Given the requirement for 'familiarity' mentioned above, it is not, however, surprising that participants, in varying degrees, relied on an array of weddingrelated references when constructing their ceremonies. Weddings provide the comparable templates for civil unions but also a pre-existing stockpile of symbols whose meanings are already explicit. Giddens also notes that "Fateful moments [highly consequential moments in an individual's life planning] are phases when people might choose to have recourse to more traditional authorities. In this sense, they may seek refuge in pre-established beliefs and in familiar modes of activity" (1991: 142). In her study on same-sex commitment ceremonies in America, Kathleen Hull (2006: 197) also found that couples used the "cultural trappings of marriage" when enacting "their love and their lifetime of commitment to each 
other". Because of its widespread social intelligibility, the extended rituals of marriage become "the logical and interpretable way to signify commitment to an intimate partner in contemporary culture, so even those gays and lesbians who are least invested in marriage as a cultural form sometimes find themselves drawn into marriage's cultural orbit" (Hull 2006: 198; original emphasis). As Lara, for example, expressed it,

[Because] there is no civil union tradition [...] it's quite easy to say, well we can just make up the rules because we are not bound by this kind of wedding culture. But, actually, we are because there [are] still really a lot of expectations around not from our friends or anything but probably from ourselves - around what it needed to be like or who to invite. [...] So there is still that feeling that it's just the same.

Some participants found that the social dominance of the wedding script also created certain expectations among family and friends and a corresponding feeling of pressure to conform. Looked at another way, though, these expectations also indicate that family and friends accepted the comparability of a civil union to a marriage. Emile's parents, for example, wanting to contribute to their son's civil union, bought rings for Emile and his partner to exchange during their ceremony. Rings, however, were not something Emile and his partner had wanted for their civil union, although they eventually agreed to include them in order to keep Emile's family happy. Emile's partner was also adamant about not wanting speeches at their civil union, a stance which Emile in turn had relayed to his parents. When a couple of "strong-minded" friends decided they would make a speech during their ceremony anyway, Emile's family became upset. His father, in particular, said he too would have liked to have prepared and made a speech. Reflecting on the issues and upsets that arose over their civil union, Emile said, "[m]aybe we should have gone with the flow rather than trying to fight desperately against something which was unavoidable”.

Whilst cultural performances are made up of collective representations they are not, however, entirely rigid and often provide opportunities for creativity and personal expression (Turner 1986: 75). People, as David Kertzer points out, "are not just slaves of ritual, or slaves of symbols, they are also molders and creators of 
ritual" (1988: 12). Even rites that adhere to tradition are, as Ronald Grimes (2000) notes, never static. They borrow from the past, mix with the present, and reach toward the future in a process of reinvention (Lash 2012: 170). In constructing their performances, participants typically selected those wedding-related references that resonated but also felt free to 'invent' new ones of their own and to rearrange old symbols and give them a 'new' meaning. Laura \& Colleen, for example, recalled thinking that they did not want their civil union to be, as they put it, like a "straight" wedding ceremony but said they "didn't want them [heterosexuals] to have all the goodies" either.

Colleen: So we wanted some of it but we didn't want it to be a pretend straight ceremony. So it was a matter of taking the good stuff that was there like the rings and the promises and things.

Laura: And the ritual and the public and the church aspects.

Colleen: And putting in what was significant for us.

Laura \& Colleen also tried to give what they saw as the traditional elements of a heterosexual wedding a personal and/or humorous twist. A friend who had attended their civil union, for example, wrote on her blog site:

The cake was gorgeous; mad hatter meets leaning tower, meets an amazing ... I can't describe it properly. It was purple and turquoise and bent and chequered with orange flowers and loops of purple beads. It was carrot cake, chocolate cake, three different cakes and it was frivolous and fun (Laura reading from a sheet).

Colleen described their cake as a "kind of a statement. It was like, ok, if you're going to have a wedding cake you have a wedding cake. We can do that, but it's not your normal wedding cake like [any] you've ever seen before".

By far the most common 'traditional' symbol selected by participants for their civil union were rings. Those couples, who had exchanged rings as part of an earlier commitment, typically re-exchanged them, although a few couples did purchase new rings in honour of the occasion. "Stories" about rings were often narrated at length revealing just how symbolically "prestigious" ${ }^{37}$ they were for couples. Rings,

\footnotetext{
37 The social information conveyed by a symbol such as a wedding ring may, as Goffman (1963: 43-44) suggests, display or establish a person's claim to a desirable status or position that otherwise would not be immediately apparent to another. Goffman calls symbols of this nature "prestige symbols."
} 
they pointed out, symbolised their love and commitment to each other but also signalled to the outside world that they were attached or "spoken for". For some couples, such as Garth \& Derek, having rings that were similar but different was described as significant as it represented both unity as well as their ethos of individuality.

Derek: They [the rings] are exactly the same but slightly different. Mine is a square setting of the diamond and his is a round setting.

Garth: Which actually says a lot about us because we are very similar but also different.

For Marcus, wearing a 'wedding' ring was significant on a number of levels. As he expressed it:

I wanted a ring. I don't know why. I've always wanted a wedding ring. That's one thing that I have held onto. I wanted a traditional plain band. Brad tried to get me into all sorts of shiny stones and all sorts of things. [...] None of the men in my family wear rings. Not wedding rings. They wear other rings. I don't know, but it is important to me to wear a wedding ring on that finger. Brad wears it on his opposite [hand] because it fits better.

Wearing a 'wedding' ring also had a political dimension for Marcus:

Part of me also likes it because I think in my early days of 'coming out' I could pass as straight as a way of kind of hiding ${ }^{38}$. But now it's also a bit of a mind fuck kind of thing that people get thrown by the fact that I wear a ring and that I'm gay. And it's a bit of 'devil may care'. It's like stirring it up a little. It's also, for me, because we didn't have the whole ceremony and suits and honeymoon and all that kind of thing. So this is my thing.

Whilst Marcus welcomed the attention he received from wearing his 'wedding' ring and the opportunity it gave him to make a political statement, other male participants described the attention their rings received as unwelcome and annoying. Michael and Emile both said they had done more "coming out" since

\footnotetext{
${ }^{38}$ In his essay on stigma, Erving Goffman (1963) notes that 'passing' - concealing or withholding information about the stigma so that it is not easily perceived by others - may be used as a strategy to minimise the negative social and psychic consequences of their so-called "discrediting" attributes (Goffman 1963: 73-91; Snow \& Anderson 1987: 1339).
} 
wearing a 'wedding' ring than ever before because people automatically assumed they were married to a woman. As several participants expressed it, the law may have changed in relation to homosexuality but people's attitudes in many instances had not. Heterosexism - bias and discrimination in favour of oppositesex sexuality and relationships - was still the prevailing disposition.

For two couples in this study, rings were not a part of their ceremonial commitment. Barbara \& Marcy said they decided not to exchange rings because Marcy was concerned that hers would end up in the "bowels" of her motorbike engine. They instead chose to buy a lithograph that they considered symbolic of their relationship. "The title of it [the lithograph] is 'My Cup Overflows' and that's how we felt about our relationship and our love. The celebrant talked a bit about the symbolism of that for us [in our ceremony]" (Barbara). Brandon \& Jason also chose not to exchange rings as part of their civil union. As Brandon explained, "I just felt that I didn't need one to say that I was in a civil union". Brandon, however, discovered that they had breached a deeply embedded social expectation. "People asked again and again, 'like, where's your ring? Oh, did you not get a ring? Oh, no!' No, we didn't but we're still in a civil union. It has happened regardless. Actually, [laughs] here's the piece of paper!"

Other established wedding-related references drawn upon by participants in their civil union ceremony included people giving readings, the cutting of a cake, family and friends making speeches, acknowledging 'absent friends', and couples affirming their vows with a kiss. Of the extended rituals of marriage, some couples had, as already mentioned, either a "stag" or "hens" night, and a few couples specifically planned to have a "honeymoon". Several participants reported receiving gifts from their guests but some said they had specifically asked guests not to bother. Many said this decision was based, first, on the fact that as a couple they already had everything they needed and, secondly, that they considered their guests' presence as itself a gift. Some participants did, however, provide guests who felt strongly about making a reciprocal gesture with an alternative opportunity. For Emile and his partner, this was a donation to a charity of their choice and in Jody \& Grace's case it was a donation towards the reception costs. 
Hailey \& Lara came up with a somewhat novel idea and requested that their guests bring along a piece of fabric, which would later be made into a quilt. ${ }^{39}$

Male participants generally dressed either in a suit or in a semi-casual trouser and open-necked shirt ensemble. Most wore non-matching outfits but two male couples wore what can be described as coordinated outfits. Des \& Bill wore black pants and white shirts with different coloured cummerbunds and an orange and white tassel - the colours of the Civil Union Bill campaign. Will \& Geoffrey wore matching black pants and "dressy" white shirts for their civil union. None of my female participants wore white wedding-style dresses or, as Hailey described them, "meringues". The majority did, however, choose to wear either a dress or a skirt for the occasion. Some females described choosing the right outfit as a fraught experience. Hailey, for example, said she could not decide so ended up buying three dresses for the occasion. On the day she wore two of the dresses: one for the ceremony and another for their reception/party.

Jenny's sister acknowledged the comparability of their civil union to a marriage by giving Jenny \& Beth garters to wear as well as the 'traditional' good luck tokens "something old, something new, something borrowed something blue" to carry. Nobody reported being 'given away' or having bridesmaids or groomsmen, although some did refer to their witnesses either as "attendants", a "best man" or as a "matron of honour". Most participants had close friends or family members as their witnesses.

References to a queer meaning-constitutive tradition were typically elaborated through the use of humour, symbolism, and references to the socio-historical significance of same-sex civil unions. The humour employed by participants often reflected a Camp 'sensibility'. While Camp is an aesthetic based on parody and exaggeration it is also a very serious analysis done by people who are willing to

\footnotetext{
${ }^{39}$ Quilts have a strong link to the gay community and, since 1987 , have become a powerful memorial icon for the AIDS pandemic. Each panel on an AIDS memorial quilt commemorates the life of someone who has died from AIDS (The Names Project Foundation n.d.). According to The Names Project Foundation, the Quilt was nominated for a Nobel Peace Prize in 1989 and remains the largest community art project in the world. The Quilt has been the subject of countless books, films, scholarly papers, articles, and theatrical, artistic and musical performances, including 'Common Threads: Stories From The Quilt' which won the Academy Award as the best feature-length documentary film of 1989.”
} 
make fun of themselves to prove a point. In this way, Camp may also be a form of political resistance or oppositional critique expressed through irony. As Padva explains, "Camp, as queer counterculture and counter-praxis, undermines and reconsiders the epistemology intended by the bourgeois to produce and reproduce, present and represent its hegemony. Camp not only subverts and revises the dominant ideology but also creates, produces, and performs counterculture" (2000: 237).

Camp in both senses - parody and subversive irony - was a feature in several participants' civil union invitations. Cheryl \& Nicky's invitation featured a Picasso picture of two naked, fat women. Max \& Dominic's invitation featured an image of a cat in a white wedding dress and was accompanied by the by-line: 'No more nights in the alley'. When people arrived at Heather \& Jill's civil union, they were greeted by a large poster that had an image of Heather \& Jill's heads superimposed onto "meringue" wedding frocks. The poster was intended to strike a humorous note and was a link to their invitations, which were a spin-off of the locally wellknown Tui beer advertising campaign. They read: "See Heather and Jill in matching meringue frocks" which was then followed by the Tui line: "Yeah, right". The multi-vocal nature of symbols, as Turner (1986: 24) notes, means that a symbol may subvert on one level what it simultaneously appears to be 'saying' on another. In this instance, the poster was on the one hand conveying the message that Heather \& Jill were getting married and, on the other hand, it was parodying dominant heterosexual wedding practices i.e. the wearing of a white "meringue" wedding dress. Heather \& Jill also, however, had what they described as their "board of firsts". In contrast to the poster, their "board of firsts" struck a romantic and nostalgic note. It featured pictures from their first holiday together, the first presents they had bought for each other, the first flowers Jill had given Heather, and so on. Touches of Camp humour also featured in some participants' speeches. Evan \& Bill, for example, began their speech by saying in a tone of voice reminiscent of Queen Elizabeth II, "My husband and I". When asked by a media person where they were going for their honeymoon, Evan replied, "Gay Paris of course!" 
Several participants' civil union performances incorporated iconic gay symbols such as the rainbow flag. The rainbow flag has been used as a symbol of lesbian, gay, bisexual and transgender (LGBT) pride since the 1970s; the array of colours in the rainbow representing the diversity of the LGBT community. Will \& Geoffrey, for example, made their "grand entrance" down a "sweeping staircase" accompanied by the iconic drag queen song, "I am what I am", sung by another gay icon, Shirley Bassey. The "huge fireplace", which was the backdrop to their ceremony, was decorated with rainbow flags and flowers. Everyone who attended Evan \& Bill's wedding was given a "blow wave bag" containing a rainbow flag, a balloon, a piece of string and a note which read: "blow up the balloon, tie on string, wave the flag and parade with pride". The stairs leading up to the chamber where Evan \& Bill's ceremony took place was also decorated with an arch of rainbow flags. Several participants' civil union celebrants acknowledged, in their speeches, the socio-historical significance of same-sex civil unions and how, until homosexual law reform, gay men had been classified as criminals.

\section{NARRATIVES OF LifESTYLE REPRESENTATIONS}

Two of the first decisions a couple must make when planning their civil union are where and when to host the occasion. Many participants enacted their civil union ceremony at places and at times that were of personal significance. Several couples chose the anniversary of their meeting or the same date as an earlier commitment ceremony. Having the same date as another anniversary acknowledged the commitment they had made to each other in the absence of any formal recognition of gay and lesbian relationships. In more pragmatic terms, it also helped, as some participants noted, to limit the number of anniversaries to be remembered and celebrated. A motivating factor in some couples' decision to have a civil union was, as mentioned in chapter four, a significant anniversary. Martin \& Ross's civil union coincided with their $25^{\text {th }}$ anniversary, Will \& Geoffrey's with their $40^{\text {th }}$ and Jody \& Grace with their tenth anniversary.

Two participants in this study chose to hold the official part of their civil union in a registry office. Most other participants, however, chose the location for their ceremony on the basis that it was an expression of a particular aspect of their 
lifestyle. Spaces that were meaningful in participants' everyday - non-ritualised world were sometimes selected as the venue for their ceremony. For some this was their home. For others, such as Jody \& Grace, it was a park they "loved" and where they regularly exercised their dogs. Yvonne \& Loana selected a marae as the location for their civil union ceremony because of its cultural resonance. Other participants chose their venue on the basis that it was an expression of their "local" identity. For Cheryl and Nicky, finding the "right" location cemented their decision to have a civil union. As Cheryl described it,

It was just beautiful. It was this undulating piece of land that had a creek running through it. And I remember saying to Nick, 'this would be a really beautiful place to get married. And Nick went, 'absolutely!'

Geographic location was also a consideration in some participants' choices. As mentioned in chapter five, some participants chose the location for their civil union on the basis that it would be more convenient for family members to attend.

\section{The role of celebrants}

Unless a couple is having a registry office civil union, they must also engage the services of an authorised civil union celebrant. ${ }^{40}$ The role of a celebrant in a 'wedding' is vital. Not only are celebrants necessary in an official capacity, they also play an important role in conducting the overall performance. A few participants already had an existing relationship with their civil union celebrant whilst others said they had contacted and selected a celebrant from the official government listing. Their choice of celebrant was often made on the basis that they contributed to the overall lifestyle narrative. Some participants selected their celebrant on the basis of characteristics they found particularly appealing: looks "not like our mums and dads", tone of voice, their sense of humour, or, in Emile's case, because they were able to fulfil a bilingual requirement. Others chose their celebrant because of the degree of comfort and/or affinity they felt after talking to/meeting with them. Some female participants said they specifically wanted a celebrant who was female and, if at all possible, also a lesbian, suggesting a sense

\footnotetext{
${ }^{40}$ Since the 1970s, independent celebrants, justices of the peace, and ministers of religion have been permitted to preside over marriages and civil unions as long as they are registered by the New Zealand state. Many if not most ceremonies now take place outside places of worship.
} 
of solidarity based first on gender and second on sexuality. Male participants, in comparison, did not mention any specific gender or sexual orientation preferences when choosing their celebrant. All but two male couples in this study had a female celebrant.

For some participants, having a celebrant who was also a minister of the church was described as important, even though they were not planning on having a church ceremony. For Jody, having a minister as their celebrant acknowledged her Christian upbringing and her desire to incorporate a "religious" component into their ceremony. Having a minister of the church officiating at their civil union was also important for Loana. Not only did she wish to acknowledge her Samoan Christian upbringing, she also thought that a minister of the church would enhance the perceived authority and legitimacy of their union for her Christian relatives. As she expressed it, "it was huge for dad and my born again [Christian] elder brother and elder sister to see [...] [that] this is not [some] sort of evil thing that [their] sister was doing".

Although many people have chosen to become authorised civil union celebrants, it became apparent from my participants' comments that some celebrants discriminate between same-sex and opposite-sex civil unions and are either unwilling to officiate at gay and lesbian civil unions or are generally uncomfortable with the idea. Max \& Dominic reported that of the six celebrants they had contacted only two said they would be prepared to officiate at a gay civil union. Max described the attitudes they encountered as "quite shocking" and said he had informed "Wellington" (Department of Internal Affairs) of their experience. Several other participants also said they had met with celebrants who they felt were not comfortable with the idea of same-sex civil unions and, in their view, agreed to do them only for the money.

Whilst the primary role of a celebrant is to officiate over the legal proceedings, many participants recalled that their celebrant had played a much more significant role in the planning and staging of their performance. Derek \& Garth, for example, said they "didn't know where to start" when it came to planning their 
ceremony. In their view, their celebrant was responsible for putting "the whole thing together in the end". According to them, she helped them construct a ceremony that they were comfortable with and not one that might be seen as a parody of a heterosexual wedding. They also felt reassured by her competency and her ability to manage any problem that might arise during the ceremony particularly when it came time for them to recite their vows.

A few couples chose to write their entire ceremony themselves but most reported that their celebrant had provided them with different wording options from which they then selected the bits they liked and added personalised phrases and sentiments. Nick reflected that it was not until their celebrant had given them examples of wording to think about, that he realised the gravity of what he was committing to.

That was really quite the turning point for me. Because suddenly seeing these things written down - it was what the relationship was all about. It wasn't just about having a big party after so many marguerites. It was going to be a very serious commitment for the rest of my life. At that stage, I started to feel a wee bit nervous, and wondered if I really wanted to do this. That happened for a wee while there. And I was really thinking it through.

The focal point of a ceremony is when the couple make their statements of commitment to each other or their "vows". Based on his experience as a celebrant, Arthur said he thought the "vows" made by couples in a civil union were much the same as the vows made by couples in a wedding and usually included a declaration of love and a desire for the relationship to be permanent. He did, however, comment that he felt "gay people tended to think through their words more carefully". Gretchen Stiers (1999: 106), as noted in chapter six, similarly suggests that lesbian and gay couples are typically more likely to consider the political implications of the words they choose and attributes this tendency to their historical trajectory as an oppressed minority. Civil unions are still very much a new cultural form and in the absence of any precedence, new webs of symbols and meaning have to be charted, requiring greater levels of reflexivity than might otherwise be required when creating a heterosexual wedding. 
The sentiments conveyed in the wording of the statements which some participants shared with me largely referred to the nature of love and their commitment to share a life together. Some "vows" also alluded to values and aspirations and their joint pledge to foster these in each other and in their relationship. Some couples recited the same vows to each other, whilst others said different things. Dominic \& Max said they had wanted to listen to what they were committing themselves to rather than worrying about getting "the words out right". They had their celebrant recite their vows for them, which they then affirmed by simply saying, "I do". Several participants reported having written poems or stories for their vows, which acknowledged what they valued most in their partner and their relationship. Jody, for example, said she wanted to acknowledge Grace's "willpower to overcome her struggle with alcohol" so had mentioned this in her vows.

\section{Scale, style and symbolism}

Most participants described wanting their civil union to be a personal affair that reflected who they are as a couple and as individuals. For some participants this meant a low key and/or private ceremony while for others it meant a highly public "formal and fabulous" occasion. In her study of same-sex 'weddings' in the United Kingdom, Carol Smart focuses on the decisions taken by couples on the style of their wedding. More specifically, she examines what the final choices meant in terms of how couples negotiated the personal and the political and how they wanted to present themselves to the wider world (Smart 2008: 765). The negotiated choice of ceremony, she argues, is linked to a couple's style of political engagement (Smart 2008: 763). Using the notion of 'personal-political style', Smart elicits four forms or styles of wedding from her research data, which she refers to as 'regular' weddings, 'minimalist' weddings, 'religious' weddings and 'demonstrative' weddings (2008: 765). In distinguishing between these four forms, Smart "seeks to show how the mixture of personal and political can take different shapes while still conveying significant meanings" (2008: 765). 'Minimalist' weddings were private affairs while 'demonstrative' weddings were defined by their full-on public nature. 'Regular' weddings were located variously in-between 
and 'religious' weddings were those where a religious or spiritual component was described as mandatory.

The four forms of 'wedding' identified by Smart have efficacy as an heuristic tool for examining my own participants' styles of 'wedding'. Whilst Smart linked the forms specifically to a couple's particular style of political engagement, I use them to frame the parameters of my participants' civil union ceremonies more generally in terms of a private-public continuum. Rather than using the labels prescribed by Smart I instead defer to the descriptive language employed by my participants. I refer to the four forms of 'wedding' as 'full-on and fabulous' (demonstrative), 'personal and relaxed' (regular), 'private and no-fuss' (minimalist) and 'spiritual' (religious). Where participants' civil union celebrations involved multiple events, I classify their civil union by the form their official ceremony took.

\section{'Personal and relaxed' weddings}

Seventeen couples' ceremonies could be classified as 'personal and relaxed'. These 'weddings' were held in a secular environment, were led by a designated celebrant or registrar, and were followed by a modest reception and/or party. Special people were often called upon during the official part of the ceremony to give nonreligious readings and in Hailey \& Lara's case a friend was asked to be their "ring bearer". Speeches were a feature at most couples' receptions although in some instances these were impromptu or simply delivered "off the cuff". As the largest category, 'personal and relaxed' weddings were the most diverse in terms of location, size and expense (from a few hundred dollars up to \$40,00o including the "honeymoon"). The congregation for these weddings were generally made up of a mixture of family and friends ranging in number from 15 to 80 . In terms of location choice, a distinction can be drawn between those that were 'home-based' and those that were held in a public venue.

Eight couples in this study had 'home-based' civil unions. Half of these were held in the couple's own home while the other half were held at the homes of either friends or parents. In 'home-based' civil unions the private domain is transformed into a public space and the everyday is sacralised for the duration of the ceremony. 
Arthur, a celebrant, said that from his experience there was something very significant about people wanting to have their civil union at home, "because it's the place [where] they have their relationship". He added that, "before there were civil unions there were sometimes gay and lesbian home blessings which had a little bit of the same kind of meaning". 'Home-based' civil unions tended to be fairly relaxed and inclusive in style. A desire for 'informality' is quintessentially 'Kiwi' and reflects an ethic of egalitarianism and a corresponding denial of hierarchy. For many participants it was also important that their guests feel comfortable. Having a relaxed and inclusive style 'wedding' was more likely to facilitate an atmosphere of ease and encourage intermingling between the couple's different social groups.

Derek \& Garth described wanting their civil union to resemble a "dinner party, but on a bigger scale", one that coincidentally "also happened" to include their civil union ceremony. On their front lawn they erected a marquee. They served champagne and finger food as people arrived and at around five pm they had the ceremony. Derek \& Garth said they wanted it to be a bright, colourful day and had asked people to dress accordingly. They themselves wore non-matching, semicasual outfits (long trousers and an open-necked shirt). Wearing non-matching outfits was intentional; a conscious attempt to be as "un-wedding-like as possible" but also conveying the message of personal individuality within their togetherness. Derek \& Garth did, however, draw on a few wedding-related customs. Two friends gave non-religious readings. To avoid creating any sense of formality, though, these were delivered from wherever they happened to be standing.

The more innovative dimensions of my participants' ceremonies were often also the most reflexive and 'ritual-like' actions and were the site where symbols of personal significance, ideology, and aspects of theatre intersected. Derek \& Garth, for example, said they wanted to incorporate into their ceremony something from Garth's UK connections as well as something from their shared lifestyle in New Zealand. They recalled having had a friend who had come from the UK for their civil union pour a bottle of New Zealand Cloudy Bay wine into two Royal Doulton glasses during their ceremony. The glasses had been a gift from two "very special" 
and "lovely ladies" whom Garth had worked with whilst living in the UK. The Cloudy Bay wine was significant in that it was something special they had when celebrating each other's birthdays. Derek \& Garth toasted each other with the glasses of wine, swapped glasses, toasted each other again and then re-gifted the rings they had exchanged early on in their relationship. The pouring and drinking of wine symbolised their coming together in union and affirmed the words of commitment they had pledged to each other during the official part of the ceremony.

Themes unique to New Zealand and nature were evident in the way some participants constructed their ceremonies but also in several participants' ideological elaborations. Lara \& Hailey's tree planting ritual, mentioned in chapter five, is one such example. The tree selected was a New Zealand native - a kōwhai. Its ceremonial planting created a dramatic moment and symbolised a new life and a new beginning. The paper on which guests wrote wishes for the couple then became mulch for the tree, symbolising their commitment to help and support Lara \& Hailey to grow in their relationship as a couple. As Lara \& Hailey had only just purchased their home, the tree planting further symbolised their laying down of roots.

Six couples, who had 'home-based' civil unions, held at least the official part of their civil union outdoors in the garden and, like Derek \& Garth, some had erected marquees from which to serve drinks and food. Brandon \& Jason had planned to stage their ceremony in Brandon's parents' garden but last minute inclement weather meant that it had to be relocated indoors. Of those participants who had 'home-based' civil unions, two couples held their reception/party at a separate venue. For Brandon \& Jason this was a private room in a restaurant for their 22 guests while for Hailey \& Lara it was the nearby memorial hall for their 65 guests. As part of the extended celebrations for their civil union, Barbara \& Marcy hosted a dance party for more than 100 friends on the evening following their more intimate 'home-based' ceremony, which was attended by approximately 30 family members and close friends. Some couples had barbeques for their 'home-based' reception, or in Kate \& Jodie's case a "spit 
roast", while others had mostly finger food. All but two couples organised the catering themselves but typically with some assistance from friends and family.

Nine of the 17 couples, whose civil unions can be classified as 'personal and relaxed', held their ceremony in what might be referred to as a public venue. 'Public venues' included outdoor spaces accessible to the public, commercial venues hired or not, and registry offices. Public venue civil unions were not necessarily any more formal than 'home-based' civil unions but in many instances did involve a greater financial investment due in part to venue hire and/or catering costs. Public venues did not by any means denote any less thought or significance in terms of location choice. Indeed, in many instances the process of choosing a location was even more reflexive than 'home-based' civil unions. Sharon \& Helen, for example, said they wanted a "local" venue but also somewhere that reflected their love of nature. The location they selected combined all these elements and provided an appropriate setting for the relaxed and inclusive celebration they wished to create. As Sharon described it, "you could see the ocean, you could see native bush ... it just had that beautiful feeling about it". They also had what they referred to as a "bring a plate wedding". This helped to reduce their financial outlay but was also in keeping with the relaxed and inclusive atmosphere they wished to create. As an accomplished singer and performer, Sharon was also keen to have music as part of their celebration. After the official part of their ceremony they had a band playing and Sharon sang with a friend. An open microphone also meant that guests, if they felt so inclined, could get up and say something, recite a poem or sing a song. Of all the 'personal and relaxed' weddings, Helen \& Sharon's was the largest in terms of guest numbers. Helen, however, commented that, "although it was 8 o people, it was still private. It was ours and it was about family and it was about ... our little corner of the world".

Nick \& Greg held the formal part of their civil union in Nick's art gallery. Having been an artist himself and then a gallery owner meant that art was a key component of Nick's identity and lifestyle. The art that adorned the walls of the gallery provided an aesthetic and stylish backdrop to their ceremony and without venue-hire costs to pay, importantly helped keep expenses to a minimum. Finger 
food and champagne were served to their guests and, later that evening, the celebrations continued with a "pizza booze up" back at the couple's home. Will \& Geoffrey were offered the use of a friend's lodge for the weekend they celebrated their civil union and $40^{\text {th }}$ anniversary. The venue provided "indoor-outdoor flow", a grand staircase for their entrance, and accommodation facilities for their 45 guests. A champagne breakfast at the lodge the next morning completed the weekend's celebrations before guests and couple alike returned to their everyday lives.

Michael and his partner, who had a registered civil partnership (the equivalent of a civil union) in England, held their ceremony in a "pleasant" local registry office with 30 guests in attendance. The official part of their ceremony was followed by a reception lunch in a restaurant and a party in the evening back at their home. Cathy \& Paige held their civil union in a large garden venue that friends of theirs were renovating specifically for the purpose of holding such functions. Their reception was a sit-down buffet: "the brief to their caterer was a classy Southland barbeque so no bangers and steak" (Paige). Jody \& Grace, as already mentioned, held the official part of their ceremony in a park that they "loved" and where they regularly exercised their dogs. They arranged for the tram that operates in the park to transport them and their 25 guests from the car park to the area they had chosen for their ceremony. A guitarist and saxophonist provided entertainment during the tram ride and helped to put guests at ease. Chairs and umbrellas awaited guests when they arrived at their destination. The reception that followed was held in a local café they had hired.

Deanne \& Chris chose a forest that they loved visiting and walking in as the venue for their civil union ceremony. The forest, birds of prey and butterflies were symbols that ran throughout their ceremony. Deanne \& Chris are both involved in the Wingspan Birds of Prey Trust. They had their bronze falcon feathers incorporated into the corsages they wore and rather than bring gifts had asked guests to instead make a donation to the Trust. Chris had also found a place online from which you can order butterflies for your wedding.

They send them pre-packaged carefully in hibernation so the butterflies are okay. You can either get a box, or you can get individual cards and take the rubber 
band gently off and you open the little card up. [...] And they were still cold, and it was a cool day. It was a grey day. And one of them - I don't know whose it was [...] We couldn't afford for everyone to have one, so we had one per couple. I think we had one together. It was either ours or someone else's, it took off and went and perched on a rock near where the ceremony was [...] and just stayed there for most of the time (Chris).

The opening up and releasing of the butterflies created a dramatic and emotive focal point and for Deanne \& Chris was the stand out moment of their ceremony. Butterflies had special significance for Chris \& Deanne as they are the symbol for transgender. Chris had a few years earlier made the decision to transition to a male identity. Butterflies are representative of the metamorphosis a person must go through when transitioning. The cake which Chris had made for their civil union was styled in the shape of a redwood tree and had butterflies set amongst its branches.

\section{'Private and no fuss' weddings'}

Four couples had 'weddings' that can be described as 'private and no fuss'. For these participants asserting their commitment to outsiders in a public ceremony was not of paramount importance. They instead chose to enact the official part of their civil union in a private, even discrete fashion. Rather than being devoid of any kind of social or political statement, though, Smart suggests that a "rejection of the social display element of weddings may be the most politically radical of all, precisely because it can evade those constraining expectations" (2008: 768). A political act of non-conformity was, as mentioned above, part of Brad \& Marcus's motivation for having a private wedding. Expense, as noted in chapter five, was, however, also a consideration. The official part of their 'wedding' was conducted in the presence of the requisite two witnesses at their celebrant's house. Prior to leaving for their celebrant's house, though, they had what they referred to as their own private "ritual" at home in front of the shrine they had created for "symbolic objects". As they recounted it,

Brad: That morning we spent a long time together talking and hanging out.

Marcus: And we had a nice breakfast, if I remember rightly. 
Brad: And then we had a ritual for ourselves in front of the shrine. And then we put the rings on - to each other. And we said some things to one another; I suppose the equivalent of vows. [...] We just spoke about things and what the rings meant and what we were doing and what that meant and what we meant to each other.

After their private "ritual", Brad and Marcus met with their witnesses, two close male friends, and went to the celebrant's house where the official part of their civil union was conducted. Commenting on the formal part of their ceremony Brad remarked, "It was nice and moving but it wasn't the epicentre of it or the pinnacle of it. Somehow that had happened before." At the conclusion of the formalities, the five of them had a drink together, took some photos, and then Brad \& Marcus went out for dinner with their two witnesses.

Turner (1986: 25-26) suggests that rituals secluded from the gaze of the public tend to be oriented towards personal or inward transformation whereas public performances are oriented more towards social transformation. Reflecting on their choice of ceremony, Brad \& Marcus expressed it thus,

Brad: We thought about it a lot. We kind of thought was it some sort of internalised homophobia or something that we did not have a big ceremony.

Marcus: The, 'oh my god, why are we not doing this?'

Brad: But [...] I'm really glad we did what we did because the spiritually significant part of what I said to Marcus and the ritual in front of our shrine [...] I don't think we would have been able to say or do [that] in front of lots of people. Because then I think there would have been more pressure to conform to some of the social conventions around marriage and commitment ceremonies. [...] So the nice thing of doing things the way we did is that we really got to do what we wanted. We didn't have to worry about anyone else.

Marama \& Deb conducted the official part of their civil union in a registry office. Following the ceremony, which reportedly took less than ten minutes, they went out and had breakfast at a café before returning home to "cut a cake". Their civil union was witnessed by four guests: their mothers, a good friend, and Deb's nephew of whom she is legal guardian. The formal part of Marama \& Deb's civil union was purposely limited in its aesthetic and symbolic capacity. As Deb 
explained, "I'm not into making a fuss. I just wanted to sign on the dotted line". They did however host a party the following weekend for their lesbian community. This was essentially framed as a Matariki ${ }^{41}$ celebration though and, as they described it, was timed to coincide with a big planting they were doing at their property.

Having organised a party at their home to celebrate their "silver" anniversary, Ross \& Martin then decided to further mark the occasion by formalising their relationship in a civil union. Rather than doing this as part of the already planned party, though, they performed their civil union the day before in a "low key" ceremony. The ceremony was held at the home of a friend who, as a registered celebrant, was also able to officiate. Six people including the celebrant were present at their ceremony: their sisters who were there in the capacity as their witnesses, a niece of Martin's who looked after the rings, and two close male friends who also documented the occasion by taking photographs. Martin said he was "absolutely clear" that he did not want a "big do" for their civil union. "I mean, we had this little party the next day which is fine, I mean I loved that, but I didn't want this civil union to be a big thing." Having a "low key", private ceremony meant they could avoid the "hassle" and "drama" associated with organising a venue, making decisions over who to invite and who not to invite, what to wear, and so on. They did, however, announce their civil union the following evening at their $25^{\text {th }}$ anniversary party, the news of which was received with great enthusiasm.

Ross: People said, 'How wonderful!' They were so pleased.

Martin: And I said, 'yeah, it was nice'. Because it didn't feel wonderful to me, it just felt really good.

Ross: But it is affirming to have done it.

\footnotetext{
${ }^{41}$ Matariki is a Māori term and refers to the small cluster of stars also known as Pleiades. Matariki's appearance in the dawn sky during the last months of May or in early June heralds the Māori New Year. According to Paul Meredith (2009), this time signified for Māori "remembrance, fertility and celebration". The coming season's crops were also, according to Meredith (2009), "planted according to the portents read in the Matariki star cluster". Since 2000 Matariki has been undergoing a revival and, according to Te Rangi Huata (2005 cited in Meredith 2009), is gaining in popularity "because it celebrates Māori culture and in doing so brings together all New Zealanders. [...] It's New Zealand's Thanksgiving.”
} 
For Calvin \& Ehsan, a civil union was primarily about securing legal rights and protections. Having attended the commitment ceremony of another couple that was not to their taste, they decided they wanted their civil union to be a discrete affair with a few friends, preferably at home: "We just wanted it to be simple because we just wanted that paper signed" (Ehsan). The official part of their civil union took place in their home in the presence of a few friends - one of who was a registered celebrant so was also able to officiate. They then went out for a "special meal" at a restaurant. "So it was perfect for us because we don't like the limelight too much. We're not show offs and standing in front of a huge room full of people would have been difficult for us" (Calvin).

\section{'Spiritual' weddings}

Four female couples described having a religious or spiritual component to their civil union as extremely important. Three of these couples chose to have the formal part of their ceremony in a church. Rather than a simple capitulation to tradition, though, their choice was a reflection of their ideology and lifestyle. A desire for a spiritual component did not also automatically suggest a conventional type of ceremony either. Trisha \& Pam said straight up that they wanted their civil union ceremony to be in a church. While part of their motive for wanting a church wedding was so their family would see their relationship as comparable to a heterosexual marriage, Trisha is by practice a minister in the Methodist Church. A friend, who is also a Methodist minister and a lesbian, was their celebrant. As part of her sermon, she apparently referred to the political significance of what Trisha \& Pam were doing. Following the church ceremony, they had lunch with their guests in a French restaurant which, reportedly, had also made them a profiterole 'wedding' cake: "So this huge phallic thing came out. It was the talk of the whole civil union was this bloody cake! [laughing]" (Pam).

As practising Catholics, Laura \& Colleen said they would have preferred to have held their ceremony in a Catholic church but as the Catholic Church does not recognise same-sex unions, they instead had their ceremony in a progressive Presbyterian church. A Catholic component was, however, involved. Prior to their ceremony in the Presbyterian Church, they had a "sympathetic" priest conduct a 
special "family" mass in the Catholic Cathedral. Music and art are a dominant feature in Laura and Colleen's lives and was, therefore, also an important component in their civil union. So we played in the foyer - in the Catholic Church beforehand. So then we got to [the Presbyterian Church] and put the banner up [that Colleen had made]. [...] We had a choir; people who had been in our choir over the last twelve years (Laura). Their reception was held in the hall at the back of the Presbyterian Church with sixty guests in attendance.

Jenny \& Beth held their civil union on their $14^{\text {th }}$ anniversary. They wanted their civil union to be somewhere of spiritual significance to them. The venue they chose was a place they had been to as part of the gay Christian group they belonged to and Beth had also been there on retreats while a nun. Attached to the venue was a chapel where the official part of their civil union was held. The reception afterwards was held in the main house. Approximately 65 guests made up of family, friends and work colleagues attended their civil union. Liturgy and candles featured strongly in their ceremony. Beth commented that light had important symbolism for her. Beth had also written a song for their civil union titled "Walk with me" which she and Jenny sang as part of their ceremony. They described their ceremony as "a sacred time of affirmation" for their relationship.

Joss said that she and Nicola had been to quite a few civil unions before they decided to have their own. Nicola had many Christian or ex-Christian friends who, in Joss's opinion, "probably felt more inclined to do something marriage-like". Joss \& Nicola had the official part of their civil union during one of their "house church group" meetings in the home of one of the group members. Their sisters, however, also attended. They fulfilled the role as their witnesses and also delivered readings. Reflecting on the readings they had chosen, Joss commented, "Oh well, Nicola is very traditional in a way. She said, 'We need an Old Testament Reading, and a Gospel and an Epistle". Joss said she had also been keen to use the "Naomi and Ruth passage" from the Bible and incorporated this into her vows. A month or so after their official ceremony, Joss \& Nicola celebrated their civil union with their lesbian friends in what was referred to, somewhat humorously, as a "hens' party". This was followed a few weeks later by a "big do" in a hall near where they lived. A 
300 strong group made up of friends and family attended this celebration. Nicola by this stage was, however, extremely sick. Joss said they invited "everyone". "I thought, gosh, this is her last hurrah. Let her invite whoever she likes. So there was an odd mixture of people really, but lots of them are old friends of Nicola's". Joss \& Nicola repeated their civil union vows and despite being so weak, Nicola managed to make "a little speech". A friend had organised the catering for them. Some guests had also brought food while others performed acts. Two weeks after the "big do" Nicola went into hospice care and, sadly, a few weeks later she passed away.

I was very glad we did it [the civil union] and I think Nicola stayed alive for it looking back - that it kept her going. It was something she wanted to do. Maybe, maybe not ... She just declined so soon after ... I wished we'd done it sooner"(Joss).

\section{'Full-on and fabulous' weddings}

Whilst 'private and no fuss' weddings had both personal and political objections to public display, the opposite could be said for those who chose a 'full-on and fabulous' wedding (Smart 2008: 771). The five couples who chose this style of wedding generally wanted to make their personal commitment as public as possible and, in many cases, this public aspect was also tied to their sexual politics (Smart 2008: 771). The important feature for these couples was "that their wedding could not be overlooked" (Smart 2008: 771). When I asked Yvonne, for example, to recall what she had envisioned for their civil union, she replied,

I wanted a thing that says, yes, we are getting married and we are having a very big party to celebrate that. And we are not having some little ceremony, a quiet thing, to acknowledge our relationship. It's like, no, this is a real wedding. [...] It's like, we are not going to do this little [i.e. on a small scale]. If we are doing this we are doing this big and we are doing this flash and we are putting some serious money into this [...] We wanted people to walk into it and go, 'wow, this is amazing!'.

Most 'full-on and fabulous' weddings also involved a great deal of planning and attention to detail, becoming something of a major production. The formal part of Yvonne \& Loana's civil union, for example, was held on the Te Papa Tongarewa marae. They entered the marae to the sound of a karanga. Passing through the 
large opening doors created a dramatic entrance and, according to Yvonne, represented the symbolic parting of Rangi and Papa in Māori creation stories. A waiata was then performed by their takatāpui kapa haka group and Loana's " $P E$ mates" performed a haka. Ancestors were acknowledged as were all lesbian and gay couples of the past who had not had the opportunity to "marry" or, even to live openly together as a couple. Samoan music of personal significance was then played during the signing of the register. Rather than exchanging rings made of gold or other precious metal, they unwrapped their fingers to reveal rings they had both had tattooed. Their tattooed rings symbolised the significance of their commitment to each other in that it was "written in blood" and, therefore, "forever" but also provided an intersection with their Māori and Samoan cultures where tattooing is customary. Through the conscious manipulation of personally relevant symbols, culture, sexual identity, and whakapapa converged creating a performance that was, reportedly, both evocative and engaging for their audience.

Yvonne \& Loana's reception was held in the grand ballroom of a nearby hotel, which also happened to be one of only a few local venues that could accommodate their 250 guests. They had quizzes and games during their reception with each table competing against the others for points and prizes. A band played and people performed and they themselves danced a foxtrot and an Argentinean tango as well as performing kapa haka and a Samoan siva. Twenty-five different people give speeches - all within the space of an hour - and had people performing impromptu poems and songs. Two television film crews covered their civil union and they were later featured on Māori Television.

Cheryl recalled that they had gone "hugely into debt" over their civil union: "We decided, what the hell! And we wanted to create a memory. It wasn't just another day, it was a big day". Public recognition of their relationship and the significance of the commitment they were making were, as noted in chapter five, extremely important to Cheryl. They had 160 guests made up mostly of Nicky's large family but also work colleagues and friends. "It was a big wedding - so much for a little wedding [laughing]!" (Cheryl). The official part of their ceremony took place in a little dell near to a creek fringed by nikau fronds and toi toi. A karanga called their 
guests down to the dell where Cheryl \& Nicky were waiting. Nicky described seeing all these people coming down towards them as "pretty awesome": "Knowing that they'd all come there to see us and our relationship". Their celebrant was both an actor and a director, which, according to Cheryl, meant she had "a gift" for really appreciating ritual and the timing of an event: "So there was a real sense of ceremony". To finish their ceremony they had someone play the bag-pipes. "So we had the clash of the tangata whenua and the colonist [laughing]" (Cheryl). Their reception was held in two large marquees. Cheryl had done all the catering, which included two spit roast pigs. For their wedding present, Cheryl's three children had offered their services as waiters and waitresses: "They are all trained so did a fabulous job" (Cheryl). Seeing her children take over running the reception was described by Cheryl as one of the standout moments of the day. For Nicky, whose father had subsequently passed away, it was the speech he had made that she recalled most vividly.

Gail \& Jessie had over 80 guests at their civil union. Gail said they had wanted everybody in their lives to witness what they saw as a historically significant event: "So all the people from our jobs and our friends and our families. And it was just very, very big and making a big statement" (Gail). Their 'wedding' was a tasteful occasion held in a large room they had hired in an up-market hotel. They had an open bar, waiters passing around "lots of fancy food platters" and everyone, reportedly, was “dressed to the nines". Jessie \& Gail repeated the vows they had made to each other in their original private commitment ceremony and again at their ten-year anniversary celebration. The significance of same-sex civil unions in the context of gay and lesbian rights was acknowledged by themselves, their celebrant, and another person who spoke during their ceremony. When their celebrant announced that they were now legally "unioned", their guests responded both affirmatively and enthusiastically.

Jessie: Everyone stood up and clapped.

Gail: It was just cheering and yelling.

Jessie: It was incredible!

Gail: It was so fantastic, wasn't it? 
Jessie: It felt like it was a moment when you could feel the world turn, you know? Something had shifted in the world and everyone knew that something had shifted. You know, some people had brought their children along so that they would remember this moment.

For Evan \& Bill, visibility was an important aspect in the style of 'wedding' they created. From their perspective, a very quiet affair with very few witnesses would have been politically pointless because it would have perpetuated the invisibility of gay and lesbian relationships that they had been campaigning to overcome. The Council Chamber, where the official part of their ceremony was held, was filled to capacity with their 200 guests. The local mayor presided over the official proceedings and, in her oration, referred to Evan \& Bill's tireless campaigning for human rights and gay rights in particular. In the parade they had from the Council Chamber to the nearby venue where their reception was held, they had a band playing and a takātapui group performed a waiata composed especially for the occasion. According to Bill, the title of the waiata roughly translated as "the realisation of a dream".

Bryan said the most memorable thing for him from his and Frank's civil union was "having all our friends and family there celebrating our lives". They had 225 guests at their civil union. Frank said they would have had more but the capacity of their venue was a limiting factor. They recalled wanting their civil union to be "local" and "highly reflective and personalised".

We had champagne and canapés outside in the gardens [...] with a little string quartet playing. It was lovely. And then we both wanted something that was reflective of the uniqueness of New Zealand so we had the daughter of a friend and her partner, who are Maori, call us into the building with a karanga and a conch shell. And then the actual ceremony we wrote ourselves with the help of our celebrant [...] And we had a very good friend, a gay friend we have known for many years, as our MC and we had a number of people from the gay and lesbian community who are friends of ours who are entertainers who sang at different parts of the ceremony. It was really neat. And we had our children there and they walked up and brought the rings in the ceremony. It felt really nice. And there were speeches just like there are at weddings. I think, actually, I enjoyed it so 
much I just wish I could have it all over again because I was all so stressed about organising it, you know how you get. It was such a neat party and we danced and we partied till, I don't know, 2.oo in the morning and then we came home here and we ended up swimming at 2.00 in the morning. It was such great fun. And it was very emotional. Lots of people cried. I think actually everybody cried (Frank).

Bryan \& Frank had two big screens at their civil union projecting photographs from their 35 years together. "We wanted to weave in lots of pictures of our friends and family over the last 35 years with us - as part of our lives" [...]. "We told a story that night and it's telling the story that I remember" (Bryan).

\section{NARRATIVES OF THE EXPERIENTIAL}

Most participants experienced their civil union as a highly significant and meaningful occasion. Reflecting upon their civil union event Yvonne, for example, commented,

It was incredible, an absolutely incredible day. I had to take back and apologise to the universe because I've watched things on TV and I've been, in the past, very cynical, you know, with brides saying it was the most important day, most beautiful day of their life. And, having put in the effort to organise it and making it all happen, it just so was. It's such a step up to actually decide to bring all the parts of your life together in a way that only happens if you get married or if you die. And when you get married you have to face it. And there's no other time when that really happens for you.

Grace said that for her their civil union was "like after years and years of slogging to get up some mountain or something. And once we got to the top and it levelled out all our friends and family were [there] waiting for us. And it was such an amazing feeling, wasn't it?" Becky \& Bridget described their civil union as "tearfully joyous":

Bridget: I just had a smile on my face the whole day. It was so joyous. Yeah, that kind of face-aching... Yeah, it was just sort of, yeah, at last!

Becky: Thank God! At last! You know, we really do have legal recognition and acknowledgement of this very fine relationship. So it was a sort of relief and a joy to be able to actually nail it. So it's in the books. 
For most participants their civil union was a highly emotional experience. Some participants recalled feeling extremely nervous on the day, although, only two participants framed this response in terms of having second thoughts. For most, their nerves were about being the centre of attention, publicly declaring very personal feelings and beliefs that had, until this point, been confined largely to the dyad relationship, and the gravity of what they were about to commit to. Lara also recalled that she had been "worried about how [her] family would be on the day with queer stuff". "I didn't want them to be upset". Some female participants were tearful throughout the entire ceremony. For most participants, though, it was when they came to state their "vows" of commitment and to express what the relationship meant to them, that their emotions overwhelmed them. Jason described his and Brandon's ceremony as "very upsetting”. "I mean not upsetting in a bad way [laughs] but it was ... People were bawling their eyes out. It was almost just the significance of it and the fact that it was quite a close group." Brandon added,

People don't go through [this type of occasion] obviously very often. All this sort of attention on you and what you're saying and what you're doing and how you're presenting yourself. But to be honest, when we were going through the ceremony, I actually don't remember the people around me. It was more just the stress of the occasion and the significance of it.

For Michael the memory that stood out most for him from their civil partnership ceremony was their vows of commitment and the moment when their celebrant announced that they were now registered as civil partners. "In that moment, with everyone applauding in the background ... yeah, I can feel the emotion of that coming back as I tap back into that memory”.

Several male participants, who had already been together for many years, or who had justified having a civil union in quite pragmatic terms, expressed amazement at how emotional and meaningful they had found their civil union. Bryan \& Frank, for example, initially decided to have a civil union because of pressure from family and friends but found, "actually, when it happened, it was for us really and it meant much more than we thought it would and we were glad we had made the decision" 
(Bryan). Reflecting on their ceremony and the effect that it had on their relationship, Frank added,

We found it very, very emotional and meaningful and we never expected it to be.

[...] And we were very surprised after 35 years of being together to find that the ceremony was so particularly meaningful. So I think it's changed our lives in another way again.

Brad \& Marcus were, as mentioned above, ambivalent about civil unions because in their view they perpetuated gay discrimination. A major motivating factor in their decision to have a civil union was that it gave them access to a legal framework. Brad in particular was, therefore, surprised at the emotional impact their civil union had on him. "It's had a deep effect on me. That was the surprising thing. I talked about it quite a lot afterwards that emotionally it had an effect that I didn't expect it would" (Brad).

Will, similarly, did a complete "36o degree turn" when it came to their civil union. "Having been very ho-hum [about a civil union], I ended up being very, very much affected by the whole thing" (Will). Reflecting on why they had found their civil union so moving, Will \& Geoffrey commented,

Will: It may be part of our growing up, marriage. It's something you become aware of when you're very young. It's what happens to other people and how it's a big social and important event within a family. And suddenly we were part of that whereas, because of our upbringing, being illegal and all that rhetoric, we've always been outside the mainstream. And I think the civil union suddenly makes you more included in society. And I think it could be something to do with that.

Geoffrey: Hmm, I think you've got a point there.

Will: And you can't get away from the importance of having all your nearest and dearest in the room witnessing something - a ceremony like this - and so I think that added much more weight to it as well.

Geoffrey: And you're saying your vows in front of them. Suddenly it all meshes in and you suddenly realise, this has been worthwhile doing. And it's something we'll always remember. And in a subtle way it's changed our relationship, in a way, hasn't it? I can't put a finger on it, but we both felt a bit different afterwards.

Will: It's something I will treasure forever, a wonderful time. 
The very act of congregating is, as noted in chapter five, an extremely powerful stimulant that may produce what Durkheim refers to as 'collective effervescence'. 'Collective effervescence', like Turner's notion of 'communitas', is usually experienced as a deep or intense emotion, which can also be transformative in nature (Olaveson 2001: 104). Symbols also have a sensory quality and an ability to arouse emotions. The liminal nature of rituals, furthermore, often makes them an acceptable outlet for the expression of emotions that might in ordinary circumstances be deemed inappropriate (Kertzer 1988: 99). The strong emotions associated with rituals of transition are, according to Kertzer, also often a reflection of "the inner conflicts, uncertainties and fears that afflict people in such circumstances" (Kertzer 1988: 100).

While emotions are "subjectively felt and interpreted", they are, as Leavitt explains, also "socially and symbolically produced, expressed, and felt" (1996: 531532). The processes of socialisation and retrospective contemplation are, then, what give feelings their meaning and, to some, extent, are indeed what produces them. Many participants had, as one celebrant noted, "gone through a lot to get to this point where they are”. 'Coming out' for many participants was, as discussed in chapter three, a "traumatic experience" that in a few instances resulted in alienation from family members and exclusion from mainstream society more generally. For several participants, who had lived much of their adult life on the margins of society, there was a surreal element to the occasion. After years of society defining them as criminal and/or unnatural, the state was now legally recognising and sanctioning their relationships. A same-sex civil union ceremony, furthermore, ultimately embodies the sexuality of the couple, making it something to celebrate and share rather than something to hide. As noted in chapter three, a civil union in this way moves beyond simply treating same-sex couples with equal dignity but respects them as a same-sex couple. For many participants, such as Will mentioned above, their civil union represented incorporation into an important meaning-constitutive practice as well as incorporation into mainstream society more generally. A civil union in this respect optimises the notion of a rite of passage in a dual sense: not only does it 
mark a transition in social status to a legally recognised relationship, it also signals greater recognition and incorporation for gay people more generally as citizens.

\section{CONCLUding COMMENTS}

How to negotiate proximity to and distance from a 'traditional' heterosexual wedding was a common concern for many participants in the planning stages of their civil union. Some wished to draw a parallel between what they were doing and a heterosexual marriage so consciously drew on 'traditional' wedding-related customs. Others, however, wished to distance themselves from a "traditional" or "straight" wedding. This distancing desire was, as I have shown, informed both by a 'politics of difference' as well as a desire to create a ceremony imbued with authenticity and not one that might be interpreted as a parody of a heterosexual wedding. A need for familiarity, however, typically meant that participants selected those wedding-related references that resonated but also felt free to 'invent' new ones of their own or to rearrange old symbols and give them a 'new' meaning. The use of wedding-related customs can on one level be seen as a capitulation to heteronormativity, but on another level can be interpreted as political in that it challenges the perceived heteronormativity of 'marriage', thereby forcing a redefinition. A queer 'sensibility' was evidenced through touches of humour, the use of iconic gay symbols and through references to the sociohistoric significance of same-sex civil unions.

In tracing the shape of participants' ceremonies, I have sought to show how queer and heteronormative meaning-constitutive 'traditions' fused with more innovative elaborations to produce authentic performances reflective of the couple's particular lifestyle. The more innovative dimensions of my participants' ceremonies were, as I have discussed, often the most reflexive and 'ritual-like' actions and were the site where symbols of personal significance, ideology, and aspects of theatre intersected. Participants who had 'full-on and fabulous' weddings were often motivated by issues of recognition and visibility. An important feature in these weddings is that they could not be overlooked (Smart 2008: 771). Those participants who had 'personal and relaxed' weddings were concerned with creating a personal, relaxed and inclusive occasion. Those who 
had 'spiritual' weddings did so primarily because they were a reflection of their ideology and lifestyle. For participants who chose 'private and no fuss' weddings, asserting their commitment to outsiders in a public ceremony was not of paramount importance. Many of these participants entered a civil union primarily for pragmatic reasons and their ceremonies tended to be oriented more towards personal rather than social transformation. A rejection of public display may, however, as Smart (2008) notes, be the most politically radical choice in that it evades socially constraining expectations.

Most participants experienced their civil union ceremony as highly significant and emotional. For some male participants, in particular, this response was both unexpected and surprising. The emotions experienced by participants during their ceremony can, as I have argued, be attributed to the gravity of the occasion, but were also shaped by an historic dialectic based on exclusion. The affective characteristics of ritual, moreover, have the ability to arouse often intense and deeply transformative emotions and the liminal nature of ritual makes the expression of emotion more generally acceptable. 


\section{8}

\section{Reflecting on Social Change}

\section{INTRODUCTION}

In this thesis I have explored civil unions through the narratives of New Zealandbased same-sex couples who chose to formalise their relationship. The use of life narrative both as a research strategy and a method has provided me as a researcher with access to my participants' own voices and understandings of experience. While my research sought to uncover 'native' meanings it also sought to discover how these meanings relate to broader socio-historical processes. Rather than treating the civil union as an isolated event, I have, furthermore, recognised the processual nature of cultural performances by situating them as a point along four longer trajectories. In doing so I have sought a more contextual understanding of these events and how they fit within participants' overall biographical narratives.

In chapter two, I used Victor Turner's notion of a 'social drama' to frame the broader socio-historical trajectory that forms the backdrop to my participants' civil union experiences. In tracing the background to the 'social drama' - gay liberation - I showed how religion, patriarchy, law, psychiatry and the mass media each played a role in the condemnation of homosexuality in New Zealand. I argued that the success of homosexual law reform largely depended on a number of important antecedents: the liberalisation of attitudes towards sex, second-wave feminism's success in challenging presumed natural gender differences, the context of change generated by the social reform movements of the late 1960s, and the formation and growth of homophile groups accompanied by a strong sense of community. The Stonewall Inn riots were the catalyst that mobilised the 
gay liberation movement and the 'social drama' that subsequently unfolded. In a post homosexual law reform era, the decline in regulative traditions around marriage and family forms, combined with the emergence of more openly committed same-sex couples wanting the same rights and responsibilities as heterosexual couples, provided a further context of pressure for the civil union legislation. The progression in homosexual rights can be situated more generally within the dual processes of detraditionalisation and denaturalisation. These processes have, in turn, also produced a significant destabilisation in the heterosexual/homosexual binary which previously characterised the sexual order (Giddens 1991; Roseneil and Budgeon 2004).

Chapter three situated the civil union within trajectories of the self. Using the three phases of a rite of passage as a metaphor, I explored the process of identity formation as a gay man or lesbian and the meaning of the civil union specifically within this context. Gender, life-stage identification, and socio-historical context each worked to shape participants' particular experience of 'coming out'. For many participants, 'marriage' represented an important meaning-constitutive practice and was a powerful motivating factor in their desire to have a civil union. A civil union provided an opportunity to fulfil aspirations established through early socialisation and created a sense of order and meaning for future life plans. Other participants experienced a greater sense of incorporation into mainstream society as a result of their civil union and a positive recoding of the once negative gay life script. Rather than a passive act of assimilation on the part of the gay individual, incorporation instead signals that the boundaries of wider society have shifted to accommodate gay and lesbian relationships. In celebrating and affirming same-sex love, the civil union ceremony moves beyond simply assigning legal equality to same-sex relationships to respecting them as a same-sex couple.

Chapter four focused on the dyad relationship and the meaning of the civil union specifically within the context of partner interactions. I explored how participants met and got together, how their relationship developed over time and what aspects they considered important for ensuring relationship durability. Through my analysis, I engaged with theories of 'late' modernity. Many of the attributes 
characteristic of what Giddens (1992) refers to as the 'pure relationship' - equality, reciprocity, commitment and a friendship ethic - were implicit in participants' relational narratives. However, against Giddens, I have argued that the meaningconstitutive 'scripts' of romantic love and the image of couple-hood inscribed in marriage were also important in structuring many participants' relationships (Gross 2005). Rather than a unidirectional trajectory towards modernity, participants in varying degrees drew on both 'traditional' and 'modern' ways of relating and, indeed, on 'queer' and 'heteronormative' scripts. At the level of partner interactions, love and commitment - past and future - were the most commonly narrated motivations for couples to want a civil union. A growing commitment to the dyad relationship was also often reported as consequence of the civil union. Premised on life-long partnerships, the civil union had a strengthening effect on some couples' relationships. For other couples, the reality of their commitment was enhanced through its public witnessing. As a 'key experience' the civil union also creates an important 'memory' in the couples' 'shared history' and further entwines the partners' 'life-plan calendars'.

Chapter five and six recognised the social embeddedness of couples' relationships. Chapter five explored the significance of the civil union within the context of close social relationships, namely those with family and friends. Some participants placed more importance on interactions with family of origin, while others, who had experienced detachment or exclusion from their family either because of their sexuality or a more general history of familial dysfunction, placed more importance on friendships or 'chosen' family. For most participants, having family and friends at their civil union was described as extremely important. Some simply wished to celebrate their relationship and commitment with those people most meaningful to them. Others used their civil union more consciously and purposefully as a vehicle for gaining recognition, acceptance and support. Guests' attendance was, in turn, highly valued by couples and many went to extraordinary lengths to include family and friends and to style a ceremony that would bring everyone together. For many participants their civil union represented a decompartmentalisation between their 'queer' world and their 'straight' world and in this way signalled another level of incorporation in the ongoing process of 
'coming out'. Often the most profound outcome of a couple's civil union was the transformations that occurred in their relationships with 'given' family. In accounting for these transformations, I argued that the civil union operates as a 'normalizing rite of passage' that catalyses support and recognition from family members otherwise opposed to or nominally tolerant of homosexuality (Green 2010). The legitimacy conferred through legal recognition intersects with the social intelligibility of marriage to invest same-sex civil unions with meaning (Hull 2006) and, in many instances initiated or accelerated processes of familial acceptance and incorporation. The effective and affective qualities of ritual, furthermore, worked to intensify the connection between ritual participants and the symbolic objects of communication and, in doing so, had the ability to transform the attitudes and behaviour of those present (Alexander 2006; Deflem 1991).

In chapter six, I continued the theme of social embeddedness by exploring the significance of same-sex civil unions within a macro socio-political context. Participants' political involvements typically revealed the centrality of human emancipatory ideals (Giddens 1991) and the importance of 'recognition' (Taylor 1994) both as a means of gaining equal rights as citizens but also in challenging societal homophobia. In exploring participants' views towards the civil union legislation, I highlighted a recurring tension between assimilation and difference and how a politics of 'equal dignity' correlates with an assimilationist stance while a 'politics of difference' is the basis for asserting difference (Taylor 1994). Recognition, choice and equality were political factors motivating some participants to have a civil union. For others, the practical value of a civil union was in ascendance in that it provided access to a legal framework that establishes a legal bond and safeguards the rights and entitlements of a couple as each other's next-of-kin. Political and practical motivations were, however, premised on the fact that there was an already existing emotional commitment. For participants, the legitimacy conferred through legal recognition often translated at a social level into a greater sense of entitlement as citizens and as next-of-kin to their partners. Participants in turn often noted the positive acknowledgements they had received from work colleagues and more informal acquaintances and how 
they had been included in the codified set of rituals which society employs to acknowledge matrimony. The legitimacy conferred through legal recognition once again intersects with the social intelligibility of marriage to invest same-sex civil unions with meaning. In this way, a civil union renders the gay individual socially recognisable and someone to whom heteronormative society can relate (Green 2010). Civil unions when viewed within an historical trajectory can be seen as an important institutional bridge of legitimation leading to greater acceptance and incorporation of gay people as citizens.

In chapter seven, I explored the contours of participants' civil union ceremonies. A tension between assimilation and difference was once again evident as participants in the planning stages sought to negotiate proximity to and distance from a 'traditional' heterosexual wedding. Some participants wished to emphasise the comparability of their ceremony to a heterosexual wedding while others wished to distance themselves. This distancing desire was informed by a 'politics of difference' (Taylor 1994) but also by a desire to create a ceremony imbued with authenticity and not one that might be interpreted as a heterosexual parody. A need for familiarity, however, meant that most participants selected those wedding-related references that resonated but also felt free to 'invent' new ones of their own. Using four forms (Smart 2008), I traced the shape of participants 'weddings' in terms of scale, style and symbolic content. I argued that civil unions as cultural performances can be defined as reflexive, biographical representations of a couple's particular 'lifestyle' choice. In constructing their ceremonies, couples drew on both queer and heteronormative meaning-constitutive practices but also introduced elements of a more innovative nature, largely as a means for elaborating significant aspects of identity. The gravity of the occasion, the liminal and affective nature of ritual, and the socio-historical significance of same-sex civil unions more generally, combined to make the civil union experience much more meaningful and emotional than many participants had anticipated. The ceremony ultimately embodies the sexuality of the couple, making it something to celebrate and share rather than something to hide, and in this way moves beyond simply treating same-sex couples with equal dignity to respecting them as same-sex couples. A civil union in this respect optimises the notion of rite of passage in a 
dual sense: not only does it mark a transition in social status to a legally recognised relationship, it also signals greater recognition and incorporation of gay people as citizens.

Throughout this thesis, I have demonstrated how civil unions facilitate incorporation for same-sex couples on a number of levels: incorporation in terms of inclusion in an important meaning-constitutive practice; familial incorporation; and incorporation into mainstream society more generally. The incorporating effect of civil unions owes much to the symbolic capacities of law, the meaning inscribed in the socially dominant cultural model of marriage, and the characteristics of ritual. While incorporation is still far from complete, the progress that gay men and lesbians have made in the last few decades has been dramatic. As mentioned, at the outset of this thesis, in less than 20 years, New Zealand society shifted from defining homosexuals as criminal and 'unnatural' to a position where the state legally sanctions their relationships. Incorporation in this context therefore also signals a corresponding shift in the boundaries of wider society in terms of what is deemed socially and culturally acceptable.

\section{SHIFTING BOUNDARIES AND Social REVITALization}

Institutions in a modern era are, according to Giddens (1991: 1), marked by their dynamism, the extent to which they undercut tradition, and their global impact. 'Marriage' in many ways epitomises Giddens' notion of a modern institution. While marriage has never been a static institution, it is fair to say that, in conditions of late modernity, changes have been both dramatic and rapid. While the opening up of 'marriage' to same-sex couples may be, as Badgett (2009: 213) notes, "just the latest step toward renewing marriage's relevance for the $21^{\text {st }}$ century", its effect has been profound in that it has fundamentally challenged the previously assumed heteronormative basis of marriage. The context of pressure for Western nation states to formally recognise same-sex relationships is a global one. Changes at the local level, however, also have a bearing on the global context. The more countries that legislate for same-sex marriage, the greater the pressure is placed on those which do not. Same-sex 'marriage' can also be situated within the broader processes of detraditionalisation and denaturalisation, which, in turn, 
have produced a destabilisation in the homosexual/heterosexual binary that has previously characterised the sexual order (Giddens 1991; Roseneil and Budgeon 2004). The decline in regulative traditions that has contributed to this destabilisation has given us as 'moderns' more choice in terms of the 'tool kit' of options from which we make up our identities. While as modern individuals we assert our unique and authentic identities, we have, I suggest, become less distinctive at least in terms of discrete categories. The boundaries between categories such as gender, sexuality, and intimate relationships have become increasingly blurred or fluid and categorical definitions such as family have expanded to accommodate greater diversity.

Giddens claims that the moral fixity of 'tradition' "loses its rationale the more thoroughly reflexivity, coupled to expert systems, penetrates to the core of everyday life" (1991: 206). However, people still choose from both 'traditional' and 'modern' scripts as a way of encapsulating and representing their chosen 'lifestyles'. People may also reconstruct 'tradition' as a way of coping with the increasingly anomic conditions of modern social life. Here, ritual also has a role to play. Rites of passage, as Giddens explains, "place those concerned in touch with wider cosmic forces, relating individual life to more encompassing existential issues" (1991: 204). Through ritual, as well as religious belief, individual actors are connected to "moral frameworks and to elemental questions about human existence" (Giddens 1991: 204). While rituals may seek to reaffirm and strengthen existing moral ideals, they may also be "a phenomenon during which new ideas and morality can emerge as well as ideal conceptions of society" (Olaveson 2001: 101).

Durkheim and Turner both believed that "society must be periodically renewed or revitalized" through certain classes of ritual and that "this renewal was fundamental and necessary to a healthy, functioning society" (Olaveson 2001: 111, original emphasis). Both also believed that their respective notions of 'collective effervescence' and 'communitas' were central to this revitalizing process in that they provide a necessary counterbalance to the alienating nature of social structure. All societies, according to Turner (1969), are dialectical processes of 
alternating experiences of structure and communitas. This alternation, he suggests, is necessary for the generation of new social ideas as well as the regeneration of society (Turner 1985: 159; Olaveson 2001: 109). Liminality and communitas together comprise what Turner refers to as 'anti-structure', which contains "the germ of future social developments, of societal change" (Turner 1979: 16). For Turner, liminal phenomena are the locus of innovation, which then becomes legitimized in the social structure. The experience of communitas that occurs in liminal phenomena is also, according to Turner, a necessity for the proper functioning of society. As Olaveson explains,

Without it, structure can begin to stagnate or die, or become too partisan and individualistic. It must be periodically imbued with the anti-structural values of communitas, and made to serve the common good (2001: 111).

A healthy dialectic between collective effervescence/communitas and social structure is for Durkheim and Turner essential for the existence of society. Indeed, the dialectic constitutes society itself (Olaveson 2001: 111).

This thesis contributes to a rich new vein of empirical explorations into the practices, meanings and effects of same-sex relationship recognition. Grounded specifically with a New Zealand context, the research provides a unique sociocultural perspective. Like other similar studies (Lewin 1998; Stiers 1999; Hull 2006; Green 2010), my research draws attention to a recurring tension between assimilation and difference, resistance and conformity, and to the ways in which people in 'late' modern society simultaneously draw upon both 'traditional' and 'modern' scripts in creating their identities, lifestyles, and ways of relating. My particular emphasis on the nature of ritual distinguishes my research. By paying close attention to the affective and effective characteristics of ritual I have highlighted the role that ritual plays in 'normalizing' same-sex relationships and in shifting the boundaries of wider society. Same-sex civil union ceremonies can be seen both as creative and re-creative in that they reinforce the ideals associated with marriage while also challenging the presumed heteronormativity of marriage. In this way they provide an important lens through which to examine the normative values of society but also the origins of social revitalization. In recognising the processual nature of ritual I have, furthermore, shown how 
particular actions speak to larger issues of both personal and socio-political significance. By doing so, I have achieved an altogether deeper articulation of meaning of this new and complex phenomena. This study reaffirms the importance of ritual to the anthropological enterprise. In an era marked by its institutional dynamism, the 'reading' of ritual may, indeed, be more vital than ever as a means for keeping pace with the shifting constitution of human societies. 


\section{Appendix 1}

\section{Participant Interview Guide}

\section{Background/Demographic Information}

- Can we start by each of you telling me a bit about your own personal and family histories

- Prompts: Where did you grow up, siblings, parents. Inquire about parents' marriage.

- What is the highest level of education you have attained?

- Can you tell me a little bit about what you do for work and what you like about it?

- Do you mind telling me your age?

- Do you own or rent your home?

- Do you have any children?

- Prompts: How many, what age, how did that all work etc.

- What, if any, ethnicity do you identify with?

- Do you identify with or practice any religion?

- How would you describe your political orientation?

- Is there anything you feel particularly passionate about?

- How do you define or refer to your sexual identity?

- Can you tell me when and how you came to identify as gay/lesbian and a little about your 'coming out' and where you see yourself now?

- Impact on identity/sense of self?

- How has 'coming out 'affected your relationship with family/friends?

\section{History of Relationship}

- Can you tell me a bit about your relationship, how it began, a bit about its evolution and its duration

- Were there different stages in your relationship's development with different levels of commitment? 
- On a day-to-day basis, how do you divide up household chores?

- How do you manage your finances?

- How would you describe yourselves and your lifestyle?

\section{Motivations and meaning}

- Thinking back, can you describe the events leading up to your decision to have a civil union?

- What motivated/prompted your decision?

- Why was it important for you to have a civil union?

- What did it represent or mean for you - then and now?

- Did you tell friends and family? How did they take the news?

- When the Civil Union Bill was being debated, do you remember having any particularly strong views about it? How did or do you feel about the distinction between marriage and civil unions?

- If same-sex couples in NZ had the choice between marriage and civil unions, which option do you think you would have taken?

- Why is that?

- What do you think are the main differences between marriage and civil union?

- Before we move on to your civil union itself, did you have any pre-civil union ceremony celebrations?

\section{The Civil Union "Story"}

- Can you please describe your civil union ceremony - where you had it and when, who was invited, what you wore, how the event unfolded etc. (Use photo album if couple are willing.)

- Prompts:

- Location/venue - any significance?

- What did you wear? Why?

- Celebrant - how and why did you choose that person?

- Did you have any readings as part of your ceremony? What were they and who gave them? 
- Did you exchange rings? Was that important for you? What did they represent?

- Who did you choose to have as your witnesses?

- Were there any other attendants?

- Guest list - how many did you have there? How did you decide on who you should invite?

- Flowers/music/photographer

- Reception

- Did guests bring presents?

- Did you take a holiday after your civil union?

- Words/vows - what message did you want to convey?

- What would you say were your main priorities when planning and organising your civil union ceremony? The must haves.

- Were there any types of ceremony that you particularly did not want?

- Prompts: Church, registry office, themed, destination, why/why not?

- What do you think the ceremony ultimately represented for you?

- Did you seek help, inspiration, and ideas for your ceremony from any particular sources?

- Prompts: Magazines, Exhibitions, Internet, Shops, Other

- If you had won a couple of million dollars on the lottery do you think you would have had a different type of ceremony?

- Can you tell me roughly how long you took to plan your civil union ceremony?

- Was one of you more responsible for planning/organising the ceremony than the other?

- Can you recall how much your civil union cost in total?

- Do you mind telling me who paid for your ceremony?

- Did you encounter any problems in the lead up to your civil union?

- Did you encounter any resistance to your decision?

- What about the day itself, do you recall how you felt? Is there any particular moment that stands out?

- Were there any problems, unforseen circumstances or pleasant surprises on the day?

- Did the day live up to, exceed, or fall short of your expectations? 
- Overall, what do you think your civil union said about you?

- In hindsight, is there anything you might have done differently either at the preparation stage or on the day itself?

\section{Relationship Post Civil Union}

- Do you feel that your relationship has changed in any way since you had your civil union?

- How do you and others refer to your civil union?

- Do you feel that your civil union has changed your relationship with family or friends in anyway? 


\section{Bibliography}

Adams, Matthew

2003 The Reflexive Self and Culture: A Critique. British Journal of Sociology 54(2): 221-238.

Albury, Erika Lynn

1996 The Creation of Image: Symbolic Consumption in the New Zealand

Wedding Industry, M.A. thesis, Geography, University of Auckland.

Alderson, Kevin, and Kathleen Lahey

2004 Same-Sex Marriage: The Personal and the Political. Toronto:

Insomniac Press.

Alexander, Jeffery

1996 Critical Reflections on 'Reflexive Modernization'. Theory, Culture $\mathcal{E}$ Society 13(4): 133-138.

2006 Cultural Pragmatics: Social Performance Between Ritual and

Strategy. In Social Performance: Symbolic Action, Cultural Pragmatics, and

Ritual. J. Alexander, B. Giesen, and J. Mast, eds. Pp. 29-9o. Cambridge, UK;

New York: Cambridge University Press.

Alexander, Jeffery, and Jason Mast

2006 Introduction: Symbolic Action in Theory and Practice: The Cultural Pragmatics of Symbolic Action. In Social Performance: Symbolic Action, Cultural Pragmatics, and Ritual. J. Alexander, B. Giesen, and J. Mast, eds. Pp. 1-28. Cambridge, UK; New York: Cambridge University Press.

Allan, James

1996 Growing Up Gay: New Zealand Men Tell Their Stories. Birkenhead, Auckland, N.Z.: Godwit.

Altman, Dennis

1993 [1971] Homosexual: Oppression and Liberation. New York: New York University Press. 
Anderson, Benedict

2006 [1983] Imagined Communities: Reflections on the Origin and Spread of Nationalism. London; New York: Verso.

Andersson, Gunnar, Turid Noack, Ane Seierstad, and HaraldWeedon-Fekjaer 2006 The Demographics of Same-Sex Marriages in Norway and Sweden. Demography 43(1): 79-98.

Andrews, Molly, Corinne Squire, and Maria Tamboukou 2008 Doing Narrative Research. Los Angeles; London: Sage.

Andyszewski, Tricia

2008 Same-Sex Marriage: Moral Wrong or Civil Right? Minneapolis:

Twenty-First Century books.

Appiah, K. Anthony

1994 Identity, Authenticity, Survival: Multicultural Societies and Social Reproduction. In Multiculturalism: Examining the Politics of Recognition. A. Gutmann, ed. Pp. 149-164. Princeton, N.J.: Princeton University Press.

Aspin, Clive

2005 The Place of Takatāpui Identity within Māori Society:

Reinterpreting Māori sexuality within a Contemporary Context. In Competing Diversities: Traditional Sexualities and Modern Western Sexual Identity Constructions Conference. Mexico City: Accessed November 10, 2008 from http://www.tpt.org.nz/downloads/takatapuiidentity.doc.

Austin, Graeme 2006 Essay: Family Law and Civil Union Partnerships - Status, Contract and Access to Symbols. Victoria University of Wellington Law Review 37: 183-198.

Badgett, M. V. Lee

2009 When Gay People Get Married: What Happens When Societies Legalize Same-Sex Marriage. New York: New York University Press. 
Baker, Maureen, and Vivienne Elizabeth

In press Second-Class Marriage? Civil Union in New Zealand. Journal of Comparative Family Studies.

Bascand, Geoff

2010 Marriages, Civil Unions, and Divorces: Year Ended December 2009. In Hot Off The Press. Statistics New Zealand.

http://www.stats.govt.nz/ /media/Statistics/Browse\%2ofor\%2ostats/Marri agesCivilUnionsandDivorces/HOTPYeDecog/MarriagesCivilUnionsandDiv orcesYeDecogHOTP.pdf

2012 Marriages, Civil Unions, and Divorces: Year Ended December 2011.

In Hot Off The Press. Statistics New Zealand.

http://www.stats.govt.nz/browse_for_stats/people_and_communities/mar riages-civil-unions-and-

divorces/MarriagesCivilUnionsandDivorces_HOTPYeDec11.aspx

Bauman, Richard

1986 Story, Performance, and Event: Contextual Studies of Oral Narrative. Cambridge, New York: Cambridge University Press.

Bauman, Zygmunt

2000 Liquid Modernity. Cambridge; Malden, Mass.: Polity Press;

Blackwell.

Beattie, John

1966 Ritual and Social Change. Man 1: 60-74.

1970 On Understanding Ritual. In Rationality. B. Wilson, ed. Pp. 240-268. Oxford: Blackwell.

Beautiful Monsters

2004 Enough is Enough.

http://stonesoup.co.nz/ecoqueer/archives/o03699.html, accessed

September 28, 2009 . 
Beck, Ulrich

1992 Risk Society: Towards a New Modernity. M. Ritter, transl. London;

Newbury Park, Calif.: Sage.

Beck, Ulrich, and Elisabeth Beck-Gernsheim

1995 The Normal Chaos of Love. M. Ritter and J. Wiebel, transl.

Cambridge, UK: Polity Press.

Beck, Ulrich, Anthony Giddens, and Scott Lash

1994 Reflexive Modernization: Politics, Tradition and Aesthetics in the Modern Social Order. Cambridge: Polity Press.

Beehre, Mark

2010 Men Alone, Men Together. Wellington, N.Z.: Steele Roberts.

Bell, Catherine

1992 Ritual Theory, Ritual Practice. New York; Oxford: Oxford University Press.

1997 Ritual: Perspectives and Dimensions. New York: Oxford University Press.

Benedict, Ruth

1939 Sex in Primitive Society. American Journal of Orthopsychiatry 9(3): $570-573$

1959 Patterns of Culture. Boston: Houghton Mifflin.

Benson-Pope, David

2004 Civil Union Bill (First Reading). P. 13927, Vol. 618: New Zealand Parliamentary Debates.

2004 New Laws Remove Discrimination: Minister. New Zealand

Government, Press Release, June 21, 2004.

http://www.beehive.govt.nz/release/new-laws-remove-discriminationminister 
Blackwood, Evelyn, ed.

1986 The Many Faces of Homosexuality: Anthropological Approaches to Homosexual Behaviour. New York; London: Harrington Park Press.

Blankenhorn, David 2007 The Future of Marriage. New York: Encounter Books.

Blasius, Mark

1994 Gay and Lesbian Politics: Sexuality and the Emergence of a New Ethic. Philadelphia: Temple University Press.

Blumenfeld, Warren, and Diane Raymond 1993 Looking at Gay and Lesbian Life. Boston: Beacon Press.

Boden, Sharon

2003 Consumerism, Romance, and the Wedding Experience. Hounsmill, Basingstoke, Hampshire; New York: Palgrave Macmillan.

Bönisch-Brednich, Brigitte 2002 Keeping a Low Profile: An Oral History of German Immigration to New Zealand. Wellington N.Z.: Victoria University Press.

Bonthuys, Elsje 2008 Possibilities Foreclosed: The Civil Union Act and Lesbian and Gay Identity in Southern Africa. Sexualities 11(6): 726-739.

Boele-Woelki, Katharina, and Angelika Fuchs 2003 Legal Recognition of Same-Sex Couples in Europe. Antwerp; New York: Intersentia.

Boswell, John 1980 Christianity, Social Tolerance, and Homosexuality: Gay People in Western Europe from the Beginning of the Christian Era to the Fourteenth Century. Chicago: University of Chicago Press.

1995 The Marriage of Likeness: Same-Sex Unions in Pre-Modern Europe. London: Harper Collins. 
Bourdieu, Pierre

1984 Distinction: A Social Critique of the Judgement of Taste. R. Nice, transl. London: Routledge \& Kegan Paul.

1987 Force of Law: Toward a Sociology of the Juridical Field. Hastings Law Journal 38(5): 814-853.

Brewer, John

2005 The Public and Private in C.Wright Mills's Life and Work. Sociology 39(4): 661-677.

Brickell, Chris

2008 Mates and Lovers: A History of Gay New Zealand. Auckland, N.Z.: Godwit.

2009 Sexuality, Morality and Society. In The New Oxford History of New Zealand. G. Byrnes, ed. South Melbourne, Victoria: Oxford University Press Australia and New Zealand.

Broad, Kendal

2011 Coming Out for Parents, Families and Friends of Lesbians and Gays: From Support Group Grieving to Love Advocacy. Sexualities 14(4): 399-415.

Bruner, Jerome

1987 Life as Narrative. Social Research 54(1): 11-32.

1990 Acts of Meaning. Cambridge, Mass: Harvard University Press.

Bryman, Alan

2004 Social Research Methods. Oxford; New York: Oxford University Press.

Bulcroft, Richard, Kris Bulcroft, Karen Bradley and Carl Simpson 2000 The Management and Production of Risk in Romantic Relationships: A Postmodern Paradox. Journal of Family History 25(1): 6392. 
Byrne, Bridget

2003 Reciting the Self: Narrative Representations of the Self in

Qualitative Interviews. Feminist Theory 4(1): 29-49.

Callero, Peter

2003 The Sociology of the Self. Annual Review of Sociology 29: 115-133.

Caringan, Carl, dir.

2006 Why Thee Wed? Robina, QLD: Heathcliff Distribution. National Film Board of Canada.

Castells, Manuel

1997 The Power of Identity. Cambridge, Mass: Blackwell.

Cerulo, Karen

1997 Identity Construction: New Issues, New Directions. Annual Review of Sociology 23: 385-409.

Chamberlain, Mary, and Paul Thompson

1998 Narrative and Genre. London; New York: Routledge.

Chauncey, George

2004 Why Marriage? The History Shaping Today's Debates Over Gay Equality. Cambridge, Mass: Basic Books.

Cherlin, Andrew

2004 The Deinstitutionalization of American Marriage. Journal of Marriage and Family 66(4): 848-861.

Christiano, Tom

2008 Democracy. In The Stanford Encyclopedia of Philosophy. E.N. Zalta, ed. http://plato.stanford.edu/archives/fall20o8/entries/democracy/.

Clark, Edward

2006 The Construction of Homosexuality in New Zealand Judicial Writing. Victoria University of Wellington Law Review 37: 199-221. 
Clarke, Victoria, and Sara-Jane Finlay

2004 'For Better or For Worse?' Lesbian and Gay Marriage. Feminism E Psychology 14(1): 17-23.

Cohler, Bertram, and Phillip Hammack

2006 Making a Gay Identity: Life Story and the Construction of a

Coherent Self. In Identity and Story: Creating Self in Narrative. D.P.

McAdams, R. Josselson, and A. Lieblich, eds. Pp. 151-172. Washington DC:

American Psychological Association.

Coleman, Jenny

2001 Unsettled Women: Deviant Genders in Late Nineteenth and Early Twentieth-Century New Zealand. Journal of Lesbian Studies 5(1-2): 13-26.

Coney, Sandra

1995 I Do: 125 Years of Weddings in New Zealand. Auckland, N.Z.: Hodder Moa Beckett.

Connell, Raewyn

2005 Masculinities. Crows Nest, N.S.W.: Allen \& Unwin.

Coontz, Stephanie

2005 Marriage, a History: From Obedience to Intimacy or How Love Conquered Marriage. New York: Viking.

Deery, Francesca Campbell

2005 Sexuality and the State: Evaluating the Relationship Between the New Zealand State and Social Norms Concerning Sexuality, from 1977-2005. M.A. thesis, Political Studies, The University of Auckland.

Deflem, Mathieu

1991 Ritual, Anti-Structure, and Religion: A Discussion of Victor Turner's Processual Symbolic Analysis. Journal for the Scientific Study of Religion 30(1): 1-25. 
D'Emilio, John

2002 The World Turned: Essays on Gay History, Politics and Culture.

Durham and London: Duke University Press.

Denzin, Norman

1994 The Art and Politics of Interpretation. In Handbook of Qualitative Research. N. Denzin and Y. Lincoln, eds. Pp. 500-515. Thousand Oaks, Calif.: Sage.

Denzin, Norman, and Yvonna Lincoln 2003 Introduction: The Discipline and Practice of Qualitative Research. In Strategies of Qualitative Research. N. Denzin and Y. Lincoln, eds. Pp. 145. Thousand Oaks, Calif.: Sage.

Dolgin, Janet

1997 Defining the Family: Law, Technology, and Reproduction in an Uneasy Age. New York: New York University Press.

Duberman, Martin

1993 Stonewall. New York: Dutton.

Dumesnil, Cheryl, ed.

2005 Hitched! Wedding Stories from San Francisco City Hall. New York: Thunder's Mouth Press.

Dupuis, Martin

2002 Same-Sex Marriage, Legal Mobilization, and the Politics of Rights. New York: Peter Lang.

Dupuis, Martin, Mark Strasser, Traci West, and William Thompson, eds. 2007 Defending Same-Sex Marriage. Westport, Conn.: Praeger Publishers.

Durkheim, Emile, and Karen E. Fields 1995 The Elementary Forms of Religious Life. New York: Free Press.

Durkheim, Emile, and Marcel Mauss

1963 Primitive Classification. R. Neddham, transl. Chicago: University of Chicago Press. 
Eskridge, William

1993 A History of Same-Sex Marriage. Virginia Law Review 79(7): 14191513.

1996 The Case for Same-Sex Marriage: From Sexual Liberty to Civilized Commitment. New York: Free Press.

2002 Equality Practice: Civil Unions and the Future of Gay Rights. New York: Routledge.

Evans-Pritchard, E. E.

1940 The Nuer. New York: Oxford University Press.

1951 Kinship and Marriage among the Nuer. Oxford: Oxford University Press.

1970 Sexual Inversion among the Azande. American Anthropologist 72(6): 1428-1434.

1976 Witchcraft, Oracles, and Magic among the Azande. Oxford: Clarendon Press.

Flemming, Robin 1997 The Common Purse: Income Sharing in New Zealand Families. Auckland: Auckland University Press with Bridget Williams Books.

Floyd, Frank, and Roger Bakeman 2006 Coming-Out Across the Life Course: Implications of Age and Historical Context. Archive of Sexual Behavior 35(3): 287-296.

Foucault, Michel

1994 What is Enlightenment? In The Essential Foucault. P. Rabinow and N. Rose, eds. Pp. 43-57. New York: The New Press. 
Frank, David John, and Elizabeth Mceneaney

1999 The Individualization of Society and the Liberalisation of State Policies on Same-Sex Sexual Relations, 1984-1995. Social Forces 77(3): 911943.

Freemantle, Jasmine, and Alison Laurie 2005 Shaping Sex? A Feminist Discussion of Contemporary Sex Education Booklets Distributed to Young People in Aotearoa/New Zealand High Schools as Part of Sex Education Programmes. Wellington, N.Z.: School of Education Studies, Victoria University of Wellington.

Gauntlett, David 2002 Media, Gender, and Identity: An Introduction. London; New York: Routledge.

Gaus, Gerald, and Shane Courtland 2011 Liberalism. In The Stanford Encyclopedia of Philosophy. E.N. Zalta, ed. http://plato.stanford.edu/archives/sprzo11/entries/liberalism/.

Gearing, Nigel

1997 Emerging Tribe: Gay Culture in New Zealand in the 1990s. Auckland: Penguin Books.

Geertz, Clifford 1993 [1973] The Interpretation of Cultures: Selected Essays. London: Fontana.

Gell, Alfred

2011 On Love. Anthropology of This Century (2):

http://aotcpress.com/articles/love/: AOTC Press.

Gennep, Arnold Van

1960 The Rites of Passage. M. Vizedom and G. Caffee, transl. London: Routledge and Kegan Paul. 
George, Robert, and Jean Bethke Elshtain, eds.

2006 The Meaning of Marriage. Dallas, Texas: Spence Publishing Company.

Giddens, Anthony

1991 Modernity and Self-Identity. Cambridge: Polity Press.

1992 The Transformation of Intimacy: Sexuality, Love and Eroticism in Modern Societies. Stanford, Calif.: Stanford University Press.

Glamuzina, Julie, and Alison Laurie

1995 Parker \& Hulme: A Lesbian View. Ithaca, New York: Firebrand Books.

Glamuzina, Julie, and Jenny Rankine

1993 Out Front: Lesbian Political Activity in Aotearoa, 1962 to 1985.

Hamilton, N.Z.: Lesbian Press.

Goffman, Erving

1963 Stigma: Notes on the Management of Spoiled Identity. Englewood Cliffs, N.J.: Prentice-Hall.

1971 The Presentation of Self in Everyday Life. Harmondsworth: Penguin.

Gough, Kathleen

1959 The Nayars and the Definition of Marriage. The Journal of the Royal Anthropological Institute of Great Britain and Ireland 89(1):23-34.

Green, Anna

2004 'Unpacking' the Stories. In Remembering: Writing Oral History. A. Green and M. Hutchings, eds. Pp. 9-24. Auckland: Auckland University Press.

Green, Adam Isaiah

2010 Queer Unions: Same-Sex Spouses Marrying Tradition and Innovation. Canadian Journal of Sociology 35(3): 399-436. 
Grimes, Ronald

2000 Deeply into the bone: re-inventing rites of passage. Berkeley, Calif.:

University of California Press.

Gross, Neil

2005 The Detraditionalization of Intimacy Reconsidered. Sociological Theory 23(3): 286-311.

Guy, Laurie

2002 Worlds in Collision: The Gay Debate in New Zealand, 1960-1986.

Wellington, N.Z.: Victoria University Press.

Harding, Rosie

2008 Recognizing (and Resisting) Regulation: Attitudes to the Introduction of Civil Partnership. Sexualities 11(6): 740-760.

Hayden, Corinne

1995 Gender, Genetics, and Generation: Reformulating Biology in Lesbian Kinship. Cultural Anthropology 10(1): 41-63.

Herdt, Gilbert, and Andrew Boxer

1992 Introduction: Culture, History, and Life Course of Gay Men. In Gay Culture in America: Essays from the Field. G. Herdt, ed. Boston: Beacon Press.

Herdt, Gilbert

1987 The Sambia: Ritual and Gender in New Guinea. New York: Holt, Rinehart and Winston.

1989 Introduction: Gay and Lesbian Youth, Emergent Identities, and Cultural Scenes at Home and Abroad. In Gay and Lesbian Youth. G.H. Herdt, ed. Pp. 1-42. New York: Haworth Press.

Herek, Gregory

1990 The Context of Anti-Gay Violence: Notes on Cultural and

Psychological Heterosexism. Journal of Interpersonal Violence 5(3): 316-333. 
1991 Myths about Sexual Orientation: A Lawyer's Guide to Social Science Research. Law \& Sexuality: A Review of Lesbian and Gay Legal Issues (1): $133-172$.

2006 Legal Recognition of Same-Sex Relationships in the United States. American Psychologist 61(6): 607-621.

Heyes, Cressida

2012 Identity Politics. In The Stanford Encyclopedia of Philosophy. E.N.

Zalta, ed. http://plato.stanford.edu/archives/spr2o12/entries/identitypolitics/.

Hindmarsh, Catherine 2005 Narratives and Passages: An Ethnographic Study of Recent American Immigrants in the Nelson and Tasman Regions. M.A. thesis, Anthropology, Victoria University of Wellington.

Hirsch, Jennifer, and Holly Wardlow 2006 Modern Loves: The Anthropology of Romantic Courtship \& Companionate Marriage. Ann Arbor: University of Michigan Press.

Hodges, Herbert

1974 The Philosophy of Wilhelm Dilthey. Westport, Conneticut: Greenwood Press.

Holden, Barry 1993 Understanding Liberal Democracy. New York: Harvester Wheatsheaf.

Hornblower, Simon, and Antony Spawforth 1996 The Oxford Classical Dictionary. Oxford; New York: Oxford University Press.

Horrocks, Eleanor 1973 Wedding Rituals in Auckland. M.A. thesis, Anthropology, University of Auckland. 
Hull, Kathleen

2006 Same-Sex Marriage: The Cultural Politics of Love and Law.

Cambridge, UK; New York: Cambridge University Press.

Hunter, Nan

1991 Marriage, Law, and Gender: A Feminist Inquiry. Law E Sexuality: A Review of Lesbian \& Gay Legal Issues (1): 9-30.

Husbands, Lucy

2006 Laboured Romance: Wedding Tourism in Aotearoa New Zealand.

M.A. thesis, Sociology, University of Auckland.

Huston, Ted

2000 The Social Ecology of Marriage and Other Intimate Unions. Journal of Marriage and Family 62(2): 298-320.

Hutchings, Jessica, and Clive Aspin, eds.

2007 Sexuality and the Stories of Indigenous People. Wellington, N.Z.:

Huia.

Jamieson, Lynn

1999 Intimacy Transformed? A Critical Look at the 'Pure Relationship'. Sociology 33(3): 477-494.

Johnston, Cristina

2008 The PACS and (Post-) Queer Citizenship in Contemporary

Republican France. Sexualities 11(6): 688-705.

Josephson, Jyl

2005 Citizenship, Same-Sex Marriage, and Feminist Critiques of Marriage. Perspectives on Politics 3(2): 269-284.

Jowett, Adam, and Elizabeth Peel

2010 “Seismic Cultural Change?” British Media Representations of SameSex 'Marriage'. Women's Studies International Forum 33(3): 206-214. 
Kandaswamy, Priya

2008 State Austerity and the Racial Politics of Same-Sex Marriage in the US. Sexualities 11(6): 706-725.

Kertzer, David

1988 Ritual, Politics, and Power. New Haven: Yale University Press.

Khan, Faris

2011 Powerful Cultural Productions: Identity Politics in Diasporic SameSex South Asian Weddings. Sexualities 14(4): 377-398.

Kiernan, Kathleen

2004 Redrawing the Boundaries of Marriage. Journal of Marriage and Family 66(4): 980-987.

King, Michael

1988 After the War: New Zealand Since 1945. Auckland, N.Z.: Hodder and Stoughton in association with Wilson and Horton.

Kinsey, Alfred, Clyde Martin, and Wardell Baxter Pomeroy

1949 Sexual Behavior in the Human Male. Philadelphia: Saunders.

Kinsey, Alfred, and Institute for Sex Research, Indiana University.

1953 Sexual Behavior in the Human Female. Philadelphia: Saunders.

Kirkman, Allison

2001 Ethics and the Politics of Research: Where Gender and Sexuality

Still Matter. In Research Ethics in Aotearoa New Zealand. C. Davidson and M. Tolich, eds. Pp. 53-63. Auckland: Pearson.

Kurdek, Lawrence

2004 Are Gay and Lesbian Cohabiting Couples Really Different From Heterosexual Married Couples? Journal of Marriage and Family 66(4): 880900.

2005 What Do We Know About Gay and Lesbian Couples? Current Directions in Psychological Science 14(5): 251-254. 
2006 Differences Between Partners From Heterosexual, Gay, and Lesbian Cohabiting Couples. Journal of Marriage and Family 68(2): 509-528.

La Fontaine, Jean, ed.

1972 The Interpretation of Ritual: Essays in Honour of A. I. Richards. London: Tavistock.

1986 Initiation. Manchester, UK: Manchester University Press.

Laird, Joan

2000 Gender in Lesbian Relationships: Cultural, Feminist, and Constructionist Reflections. Journal of Marital and Family Therapy 26(4): $455-467$.

Landes, Ruth

1937 Ojibwa Society. New York: Columbia University Press.

1940 A Cult Matriarchate and Male Homosexuality. Journal of Abnormal and Social Psychology 35: 386-397.

Lannutti, Pamela 2005 For Better or For Worse: Exploring the Meanings of Same-Sex Marriage within the Lesbian, Gay, Bisexual and Transgendered Community. Journal of Social and Personal Relations 22(1): 5-18.

Lash, Shari Rochelle 2012 Jewish Same-Sex Weddings in Canada: Rites of Resistance or Rituals of Conformity? In Negotiating Rites. U. Hüsken and F. Neubert, eds. Pp. 161-175. New York: Oxford University Press.

Laurie, Alison 1986 Identifying Lesbian Texts. Essay (BA Hons), Victoria University of Wellington.

2001 Lesbian Studies in Aotearoa/New Zealand. New York: Harrington Park Press. 
2003 Lady-Husbands and Kamp Ladies: Pre-1970 Lesbian Life in Aotearoa/New Zealand. Ph.D. thesis, Women's Studies, Victoria University of Wellington.

2004 The Aotearoa/New Zealand Homosexual Law Reform Campaign. In Queer in Aotearoa New Zealand. L. Alice and L. Star, eds. Pp. 13-31. Palmerston North, NZ: Dunmore Press.

Laurie, Alison, and Linda Evans, eds.

2005 Outlines: Lesbian E Gay Histories of Aotearoa. Wellington, N.Z.: Lesbian \& Gay Archives of New Zealand.

2009 Twenty Years On: Histories of Homosexual Law Reform in New Zealand. Wellington, N.Z.: Lesbian \& Gay Archives of New Zealand.

Laurie, Alison, and School of Education Studies, Victoria University of Wellington. 2004 Report on the Written Submissions to the Justice and Electoral Select Committee on the Civil Union Bill and Relationships (Statutory References) Bill. Wellington, N.Z.: School of Education Studies, Victoria University of Wellington.

Law Commission 1999 Study Paper Four: Recognising Same-Sex Relationships. Wellington: New Zealand Law Commission.

Leach, Edmund 1955 Polyandry, Inheritance and the Definition of Marriage. Man 55(199): 182-186.

Leavitt, John 1996 Meaning and Feeling in the Anthropology of Emotions. American Ethnologist 23(3): 514-539.

Leonard, Diana 1982 Sex and Generation: A Study of Courtship and Weddings. London: Tavistock. 
Lewin, Ellen

1998 Recognizing Ourselves: Ceremonies of Lesbian and Gay Commitment. New York: Columbia University Press.

2001 Weddings without Marriage: Making Sense of Lesbian and Gay Commitment Rituals. In Queer Families, Queer Politics: Challenging Culture and the State. M. Bernstein and R. Reimann, eds. Pp. 44-52. New York: Columbia University Press.

2008 Location, Location, Location: Same-Sex Marriage as a Moving Target. Sexualities 11(6): 777-781.

Lewin, Ellen, and William Leap

2002 Out in Theory: The Emergence of Lesbian and Gay Anthropology. Urbana: University of Illinois Press.

Leydet, Dominique 2011 Citizenship. In The Stanford Encyclopedia of Philosophy. E.N. Zalta, ed. http://plato.stanford.edu/archives/fall2o11/entries/citizenship/.

Lindholm, Charles 2001 Love and Culture. In Culture and Identity: The History, Theory, and Practice of Psychological Anthropology. Pp. 333-365. Boston, Mass.: McGraw Hill.

Logan, Bruce 2000 Same Sex Marriage? In Affirm, Vol. 13. Tauranga, N.Z.: Affirm Publications.

Mair, Lucy 1971 Marriage. Harmondsworth: Penguin.

Makkreel, Rudolf 1975 Dilthey, Philosopher of the Human Studies. Princeton, N.J.: Princeton University Press. 
Malinowski, Bronislaw

1927 Sex and Repression in Savage Society. New York: Meridian.

1962 Sex, Culture, and Myth. New York: Harcourt, Brace \& World.

Markowe, Laura

1996 Redefining the Self: Coming Out as Lesbian. Cambridge, Mass: Polity Press.

Mason, Jennifer, Beccy Shipman, and Carol Smart 2006 Gay and Lesbian 'Marriage': An Exploration of the Meanings and Significance of Legitimating Same-Sex Relationships. Manchester: Morgan Centre for the Study of Relationships and Personal Life, The University of Manchester.

Maynes, Mary Jo, Jennifer Pierce, and Barbara Laslett 2008 Telling Stories: The Use of Personal Narratives in the Social Sciences and History. Ithaca: Cornell University Press.

McAdams, Dan

1988 Biography, Narrative and Lives: An Introduction. Journal of Personality 56(1): 1-18.

McAdams, Dan, Ruthellen Josselson, and Amia Lieblich, eds. 2006 Identity and Story: Creating Self in Narrative. Washington, DC: American Psychological Association.

McWhorter, Ladelle 2004 Rites of Passing: Foucault, Power, and Same-Sex Commitment Ceremonies. In Thinking Through Rituals: Philosophical Perspectives. K. Schilbrack, ed. Pp. 72-98. New York: Routledge.

Mead, Margaret

1949 Male and Female: A Study of the Sexes in a Changing World. New York: Morrow. 
Meezan, William, and Jonathan Rauch

2005 Gay Marriage, Same-Sex Parenting, and America's Children. The Future of Children 15(2): 97-115.

Meredith, Paul

2009 Matariki - Māori New year. In Te Ara - the Encyclopedia of New Zealand. http://www.TeAra.govt.nz/en/matariki-maori-new-year/.

Mines, Katie

2002 Why Knot? An Exploration of Weddings for Women in

Contemporary New Zealand. M.A. thesis, Anthropology, University of Otago.

Moore, Sally, and Barbara Myerhoff

1977 Secular Ritual. Assen: Van Gorcum.

Myerhoff, Barbara

1980 Number Our Days. New York: Simon and Schuster.

1992 Remembered Lives: The Work of Ritual, Storytelling, and Growing

Older. Ann Arbor: University of Michigan Press.

Myers, David, and Letha Scanzoni

2005 What God Has Joined Together? The Christian Case for Gay Marriage. San Francisco: Harper.

Nadi, Peter

1992 That's What Friends Are For: Friends as Family in the Gay and Lesbian Community. In Modern Homosexualities: Fragments of Lesbian and Gay Experience. K. Plummer, ed. Pp. 108-120. London; New York: Routledge.

Naffine, Ngaire

2006 The Sexual Citizen. Victoria University of Wellington Law Review 37: $175^{-181 .}$

Needham, Rodney, ed.

1971 Rethinking Kinship and Marriage. London; New York: Tavistock. 
New Zealand Legislation

2005 Relationships (Statutory References) Act. Ministry of Justice, ed.

http://www.legislation.govt.nz/act/public/2005/0003/latest/whole.html:

Parliament Counsel Office.

Nicol, Nancy, and Miriam Smith

2008 Legal Struggles and Political Resistance: Same-Sex Marriage in

Canada and the USA. Sexualities 11(6): 667-687.

Olaveson, Tim

2001 Collective Effervescence and Communitas: Processual Models of Ritual and Society in Emile Durkheim and Victor Turner. Dialectical Anthropology 26(2): 89-124.

Ortner, Sherry

1973 On Key Symbols. American Anthropologist 75(5): 1338-1346.

Ortner, Sherry, and Harriet Whitehead

1981 Sexual Meanings, the Cultural Construction of Gender and Sexuality.

Cambridge; New York: Cambridge University Press.

Padva, Gilad

2000 Priscilla Fights Back: The Politicization of Camp Subculture. Journal of Communication Inquiry 24(2): 216-243.

Parkin, Robert, and Linda Stone

2004 Kinship and Family: An Anthropological Reader. Malden, Mass:

Blackwell Publishing.

Paulus, Andreas

2000 Law and Politics in the Age of Globalization. European Journal of International Law 11(2): 465-472.

Peel, Elizabeth, and Rosie Harding 2008 Editorial Introduction: Recognizing and Celebrating Same-Sex Relationships: Beyond the Normative Debate. Sexualities 11(6): 659-666. 
Phillips, Jock

1996 A Man's Country? The Image of the Pakeha Male: A History.

Auckland, N.Z.: Penguin Books.

Phy-Olsen, Allene

2006 Same-Sex Marriage: Historical Guides to Controversial Issues in America. Westport, Conn.: Greenwood Press.

Pichardo, José Ignacio

2011 We are Family (or not): Social and Legal Recognition of Same-Sex

Relationships and Lesbian and Gay Families in Spain. Sexualities 14(5): 544561.

Plummer, Kenneth

1981 Going Gay: Identities and Lifestyles in the Male Gay World. In The Theory and Practice of Homosexuality. J. Hart and D. Richardson, eds. Pp. 93-110. London: Routledge \& Kegan Paul.

2001 The Square of Intimate Citizenship: Some Preliminary Proposals.

Citizenship Studies 5(3): 237-253.

Polikoff, Nancy

2008 Beyond (Straight and Gay) Marriage: Valuing All Families Under the Law. Boston; Beacon Press.

Polkinghorne, Donald

1991 Narrative and Self Concept. Journal of Narrative and Life History 1(2\&3): 135-153.

Porche, Michelle, and Diane Purvin

2008 "Never in Our Lifetime": Legal Marriage for Same-Sex Couples in Long-Term Relationships. Family Relations 57(2): 144.

Post, Robert

N.d. Theorizing Disagreement: Reconceiving the Relationship Between Law and Politics. In Public Law E Legal Theory Research Paper Series. Yale Law School. http://papers.ssrn.com/abstract\#1434103 
Pusch, Heide

2003 Civil Union - Partnership of Equals: State Registration of Adult Partnerships and its Impact on Women in Aotearoa New Zealand: An Analysis of Marriage and Civil Unions (Based on the Proposed Concept of Civil Unions in the Civil Union Bill) From a Feminist Perspective. Essay (BA), Victoria University of Wellington.

Ramp, William

1998 Effervescence, Differentiation and Representation in The Elementary Forms. In On Durkheim's Elementary Forms of Religious Life. N.J. Allen, W.S.F. Pickering, and W. Watts Miller, eds. London; New York: Routledge.

Rickman, Hans Peter

1988 Dilthey Today: A Critical Appraisal of the Contemporary Relevance of His Work. New York: Greenwood Press.

Riessman, Catherine 2003 Analysis of Personal Narratives. In Insider Interviewing: New Lenses, New Concerns. J. Holstein and J. Gubrium, eds. Pp. 331-346. Thousand Oaks, California: Sage Publications.

2008 Narrative Methods for the Human Sciences. Los Angeles: Sage.

Rimmerman, Craig, and Clyde Wilcox

2007 The Politics of Same-Sex Marriage. Chicago: University of Chicago Press.

Rippingale, Grace Kowhai

2005 Civil Unions in New Zealand. Essay, Law School, Wellington:

Victoria University of Wellington.

Rolfe, Alison, and Elizabeth Peel 2011 "It's a Double-Edged Thing": The Paradox of Civil Partnerships and Why Some Couples are Choosing Not to Have One. Feminism \& Psychology 21(3): 317-335. 
Rosaldo, Renato

1989 Culture and Truth: The Remaking of Social Analysis. Boston: Beacon Press.

Rose, Nikolas

1998 Inventing Our Selves: Psychology, Power, and Personhood.

Cambridge, UK; New York: Cambridge University Press.

Roseneil, Sasha, and Shelley Budgeon

2004 Cultures of Intimacy and Care Beyond 'The Family': Personal Life and Social Change in the Early 21st Century. Current Sociology 52(2): 135159.

Rountree, Kathryn

1996 Writing by Degrees: A Practical Guide to Writing Theses and Research Papers. Auckland, N.Z.: Longman.

Rust, Paula

1993 "Coming Out" in the Age of Social Constructionism: Sexual Identity Formation among Lesbian and Bisexual Women. Gender and Society 7(1): $50-77$

Salzman, Philip Carl

2002 On Reflexivity. American Anthropologist 104(3): 805-813.

Schecter, Ellen, Allison Tracy, Konjit Page, and Gloria Luong 2008 Shall We Marry? Legal Marriage as a Commitment Event in SameSex Relationships. Journal of Homosexuality 54(4): 400-422.

Schneider, David

1997 The Power of Culture: Notes on Some Aspects of Gay and Lesbian Kinship in America Today. Cultural Anthropology 12(2): 270-274.

1980 American Kinship: A Cultural Account. Chicago: University of Chicago Press. 
1984 A Critique of the Study of Kinship. Ann Arbor: University of Michigan Press.

Scoop

2004 Civil Union Bill Rubbished by Marilyn Waring.

http://www.scoop.co.nz/stories/POo411/Soo212.htm, accessed February 28, 2009.

Seidman, Steven

2001 From Identity to Queer Politics: Shifts in Normative

Heterosexuality and the Meaning of Citizenship. Citizenship Studies 5(3): 321-328.

Seidman, Steven, Nancy Fischer, and Chet Meeks

2011 Introducing the New Sexuality Studies. Abingdon, Oxon; New York: Routledge.

Seuffert, Nan

2006 Sexual Citizenship and the Civil Union Act 2004. Victoria University of Wellington Law Review 37: 281-306.

Shiffrin, Deborah

1996 Narrative as Self-Portrait: Sociolinguistic Construction of Identity. Language in Society 25(2): 167-203.

Shipman, Beccy, and Carol Smart 2007 'It's Made a Huge Difference': Recognition, Rights and the Personal Significance of Civil Partnership. Sociological Research Online 12(1). http://www.socresonline.org.uk/12/1/shipman.html.

Shrader, Ben 2010 Parades and Protest Marches - Royalty, Sport, Commerce. In Te Ara - the Encyclopedia of New Zealand. http://www.TeAra.govt.nz/en/paradesand-protest-marches/3: 
Siedenbiedel, Mirjam.

2004 Civil Unions in New Zealand. Essay, Law School, Victoria University of Wellington.

Silva, Elizabeth Bortolaia, and Carol Smart

1999 The 'New' Family? London; Thousand Oaks, Calif.: Sage.

Simon, William, and John H. Gagnon

1967 Homosexuality: The Formulation of a Sociological Perspective.

Journal of Health and Social Behavior 8(3): 177-185.

Smart, Carol

2007 Same Sex Couples and Marriage: Negotiating Relational Landscapes with Families and Friends. The Sociological Review 55(4): 671-686.

2008 'Can I Be Bridesmaid?' Combining the Personal and Political in Same-Sex Weddings. Sexualities 11(6): 761-776.

Smart, Carol, and Beccy Shipman

2004 Visions in Monochrome: Families, Marriage and the

Individualization Thesis. The British Journal of Sociology 55(4): 491-509.

Snow, David, and Leon Anderson

1987 Identity Work among the Homeless: The Verbal Construction and Avowal of Personal Identities. The American Journal of Sociology 92(6): 1336-1371.

Snyder, Claire 2006 Gay Marriage and Democracy: Equality For All. Lanham: Rowan \& Littlefield Publishers. 
Statistics New Zealand

2011 Marriage, Civil Unions, and Divorces: Year Ended December 2011 Tables.

http://www.stats.govt.nz/browse_for_stats/people_and_communities/mar riages-civil-unions-and-

divorces/MarriagesCivilUnionsandDivorces_HOTPYeDec11/mcud-dec11all-tables.xls.

Stewart, Terry

1993 Invisible Families: A Resource for Family and Friends of Lesbian or Gay Daughters and Sons. Dunedin, N.Z.: New Women's Press.

Stiers, Gretchen

1999 From This Day Forward: Commitment, Marriage, and Family in Lesbian and Gay Relationships. New York: St. Martin's Press.

Stone, Linda

2001 New Directions in Anthropological Kinship. Lanham: Rowan \& Littlefield Publishers.

Strathern, Marilyn

1992 After Nature: English Kinship in the Late Twentieth Century.

Cambridge; New York: Cambridge University Press.

1993 Review of Families We Choose: Lesbians, Gays, Kinship by Kath Weston. In Man, N.S. 28(1): 195-196.

2005 Kinship, Law and the Unexpected: Relatives are Always a Surprise. New York: Cambridge University Press.

Strauss, Anslem, and Juliet Corbin 2008 Basics of Qualitative Research ze: Techniques and Procedures for Developing Grounded Theory. Newbury Park, Calif.: Sage.

Stychin, Carl

2001 Sexual Citizenship in the European Union. Citizenship Studies 5(3): 285-301. 
Sullivan, Andrew, ed.

1997 Same-Sex Marriage: Pro and Con, A Reader. New York: Vintage Books.

Swidler, Ann

1986 Culture in Action: Symbols and Strategies. American Sociological Review 51(2): 273-286.

Taylor, Charles

1994 The Politics of Recognition. In Multiculturalism: Examining the Politics of Recognition. A. Gutmann, ed. Pp. 25-73. Princeton, N.J.:

Princeton University Press.

Taylor, Gordon Rattray

1973 Sex in History. New York: Harper \& Row.

Taylor, Lindsay

1977 Aspects of the Ideology of the Gay Liberation Movement in New Zealand. Australian \& New Zealand Journal of Sociology 13(2): 126-132.

Television New Zealand

2004a Civil Union Bill Raises Tension.

http://www.tvnz.co.nz/view/news_national_story_skin/443454?format=ht

ml, accessed September 28, 2009.

2004b Is Destiny Destined to Rule?

http://www.tvnz.co.nz/view/news_national_story_skin/451171, accessed

September 28, 2009.

Te Taura Whiri Te Reo Māori (Māori Language Commission)

N.d. Matariki: Te Whetu O te Tau.

http://www.tetaurawhiri.govt.nz/maori/downloads/matariki/MatarikiBoo

klet.pdf. 
The Department of Internal Affairs

2009 Civil Union: A Guide for Couples Preparing to Enter into a Civil Union in New Zealand.

http://www.dia.govt.nz/Pubforms.nsf/URL/CivilUnionbrochurecolour.pdf/ \$file/CivilUnionbrochurecolour.pdf

The NAMES Project Foundation 1987-2011 The AIDS Memorial Quilt.

http://www.aidsquilt.org/about/the-aids-memorial-quilt: The NAMES Project Foundation, accessed March 18, 2011.

Thomson, Alistair

1994 Anzac Memories: Living with the Legend. Melbourne: Oxford University Press.

Troiden, Richard 1989 The Formation of Homosexual Identities. In Gay and Lesbian Youth. G.H. Herdt, ed. Pp. 43-74. The Research on Homosexuality Series. New York: Haworth Press.

Trundle, Catherine 2009 The Reflexive Gift: The Charitable Practices of English-Speaking Migrants in Florence, Italy. Ph.D. thesis, Social Anthropology, University of Cambridge.

Turner, Victor

1957 Schism and Continuity in an African Society: A Study of Ndembu Village Life. Manchester: published on behalf of the Institute for African Studies, University of Zambia, by Manchester University Press.

1967 The Forest of Symbols: Aspects of Ndembu Ritual. Ithaca, New York: Cornell University Press.

1969 The Ritual Process: Structure and Anti-Structure. Chicago: Aldine Publishing Company. 
1974 Dramas, Fields, and Metaphors: Symbolic Action in Human Society. Ithaca, New York: Cornell University Press.

1979 Process, Performance and Pilgrimage. New Delhi: Concept Publishing.

1982 From Ritual to Theatre: The Human Seriousness of Play. New York: Performing Arts Journal Publications.

1985 Experience and Performance: Towards a New Processual Anthropology. In On the Edge of the Bush: Anthropology as Experience. E. Turner, ed. Tuscon, Arizona: The University of Arizona Press.

1986 The Anthropology of Performance. New York: PAJ Publications.

Vanita, Ruth

2004 "Wedding of Two Souls": Same-Sex Marriage and Hindu Traditions. Journal of Feminist Studies in Religion 20(2): 119-135.

2005 Love's Rite: Same-Sex Marriage in India and the West. New York: Palgrave Macmillan.

Warde, Alan

1994 Consumption, Identity-Formation and Uncertainty. Sociology 28(4):877-898.

Wardle, Lynn, Mark Strasser, William Duncan, and David Coolidgeeds. 2003 Marriage and Same-Sex Unions: A Debate. Westport, Conneticut: Praeger Publishers.

Watkins, Gareth 2006 Homosexual Law Reform in New Zealand. In New Zealand History Online. http://www.nzhistory.net.nz/culture/homosexual-lawreform/homosexual-law-reform, (Minister for Culture and Heritage). 
Weeks, Jeffrey

1977 Coming Out: Homosexual Politics in Britain from the Nineteenth Century to the Present. London; New York: Quartet Books.

1993 Introduction. In Homosexual: Oppression and Liberation. D. Altman. New York: New York University Press.

2008 Regulation, Resistance, Recognition. Sexualities 11(6): 787-792.

Weeks, Jeffrey, Brian Heaphy, and Catherine Donovan

1999 Everyday Experiments: Narratives of Non-Heterosexual

Relationships. In The 'New' Family? E. Silva and C. Smart, eds. London:

Sage.

2001 Same Sex Intimacies: Families of Choice and Other Life Experiments. London; New York: Routledge.

Westermarck, Edward

1906 The Origin and Development of the Moral Ideas. London: Macmillan.

1921 The History of Human Marriage. London: Macmillan.

Weston, Kath

1991 Families We Choose: Lesbians, Gay, Kinship. New York: Columbia University Press.

1993 Do Clothes Make the Woman? Gender, Performance, Theory, and Lesbian Eroticism. Genders (17): 1-21.

1993 Lesbian/Gay Studies in the House of Anthropology. Annual Review of Anthropology 22: 339-367.

1996 Render Me, Gender Me: Lesbians Talk Sex, Class, Color, Nation, Studmuffins. New York: Columbia University Press.

1998 Long Slow Burn: Sexuality and Social Science. New York: Routledge. 
Wilson, Monica

1954 Nyakyusa Ritual and Symbolism. American Anthropologist N.S. 56(2): 228-241.

Worth, Heather

2003 Gay Men, Sex and HIV in New Zealand. Palmerston North, N.Z.:

Dunmore Press.

Withy, Vanessa

2005 The Fight For True Equality: Civil Unions Versus Same-Sex Marriage: Assessing the Significance of Civil Unions on the Right to Freedom of Discrimination on the Basis of Sexual Orientation. Essay, Law School, Victoria University of Wellington

Yip, Andrew

1997 Gay Male Christian Couples: Life Stories. Westport, Conn.: Praeger. 